\title{
Surgical management of chronic inguinal pain syndromes
}

Citation for published version (APA):

Loos, M. (2011). Surgical management of chronic inguinal pain syndromes. [Doctoral Thesis, Maastricht University]. Maastricht University. https://doi.org/10.26481/dis.20110929ml

Document status and date:

Published: 01/01/2011

DOI:

10.26481/dis.20110929ml

Document Version:

Publisher's PDF, also known as Version of record

\section{Please check the document version of this publication:}

- A submitted manuscript is the version of the article upon submission and before peer-review. There can be important differences between the submitted version and the official published version of record.

People interested in the research are advised to contact the author for the final version of the publication, or visit the DOI to the publisher's website.

- The final author version and the galley proof are versions of the publication after peer review.

- The final published version features the final layout of the paper including the volume, issue and page numbers.

Link to publication

\footnotetext{
General rights rights.

- You may freely distribute the URL identifying the publication in the public portal. please follow below link for the End User Agreement:

www.umlib.nl/taverne-license

Take down policy

If you believe that this document breaches copyright please contact us at:

repository@maastrichtuniversity.nl

providing details and we will investigate your claim.
}

Copyright and moral rights for the publications made accessible in the public portal are retained by the authors and/or other copyright owners and it is a condition of accessing publications that users recognise and abide by the legal requirements associated with these

- Users may download and print one copy of any publication from the public portal for the purpose of private study or research.

- You may not further distribute the material or use it for any profit-making activity or commercial gain

If the publication is distributed under the terms of Article $25 \mathrm{fa}$ of the Dutch Copyright Act, indicated by the "Taverne" license above, 


\section{Surgical management of chronic inguinal pain syndromes}




\section{COLOFON}

๑) M. Loos, Eindhoven, The Netherlands, 2011.

All rights reserved. No part of this book may be repoduced or transmitted in any form by any means, without prior written permission of the author.

\section{Design cover}

Dolf Heebing

\section{Lay out}

Dolf Heebing

\section{Printing}

Enk druck \& media gmbh

\section{ISBN/EAN}

978-94-6190-103-3

\section{Surgical management of chronic inguinal pain syndromes}

Een wetenschappelijke proeve op het gebied van de Medische Wetenschappen

Proefschrift

ter verkrijging van de graad van doctor aan de Universiteit Maastricht op gezag van rector magnificus prof. mr. G.P.M.F. Mols, volgens besluit van het College van Decanen

in het openbaar te verdedigen op donderdag 29 september 2011 om uur 16:00 uur 


\section{Promotor}

Prof. dr. E. Heineman, UMC Groningen

\section{Copromotores}

dr. R.M.H. Roumen, MMC Eindhoven/Veldhoven

dr. M.R.M. Scheltinga, MMC Eindhoven/Veldhoven

Manuscriptscommissie

Prof. dr. M. van Kleef (voorzitter)

Prof. dr. R.P. Bleichrodt (UMC St Radboud)

Prof. dr. R. van der Hulst

Prof. dr. M. Miserez (UZ Leuven)

Prof. dr. J.G. Nijhuis

\section{TABLE OF CONTENTS}

Chapter 1 Introduction, aim and outline of the thesis

Chapter 2 Chronic sequelae of common elective groin hernia repair. Hernia 2007; 11: 169-173

Chapter 3 The Pfannenstiel approach as a source of chronic pain.

Obstet Gynecol 2008; 111: 839-846

Chapter 4 Evaluating postherniorrhaphy groin pain:Visual Analogue or Verbal Rating Scale? Hernia 2007; 11: 169-173

Chapter 5 Classifying postherniorrhaphy pain syndromes following elective groin hernia repair. World J surg 2007; 31: 1760-1767

Chapter 6 Tailored neurectomy for treatment of postherniorrhaphy inguinal neuralgia. Surgery 2010; 147: 275-81

Chapter 7 Randomized controlled trial of neurectomy versus injection with lidocain, corticosteroids and hyaluronic acid on postherniorrhaphy inguinal neuralgia:

Rationale and study design. Hernia 2010; 14: 593-597

Chapter 8 Surgical management of inguinal neuralgia after a low transverse Pfannenstiel incision. Ann Surg 2008; 248:880-885

Chapter 9 Occupational disability due to chronic postherniorrhaphy neuralgia: a plea for tailored neurectomy. Submitted

Chapter 10 Summarizing discussion, conclusions and future perspectives

Chapter $11 \quad$ Nederlandse samenvatting

Chapter 12 List of publications

Chapter 13 Dankwoord

Dutch Hernia Society

Chapter 14 Currriculum Vitae 


\section{CHAPTER 1}

Introduction, aims and outline 


\section{INTRODUCTION}

Implantation of mesh is considered the 'gold standard' for the treatment of inguinal hernia repair as the risk of recurrence is half compared to traditional non-mesh techniques'. Ever since recurrence rates declined, attention has gradually shifted towards studying the onset of chronic pain following inguinal mesh repair as an early study reported a staggering $63 \%$ incidence rate of chronic postoperative pain ${ }^{2}$. From the midnineties on somewhat lower (0-53\%) incidence rates of chronic pain were published ${ }^{3-5}$. However, the need for additional research on etiology and treatment of these chronic pain syndromes following inguinal mesh repair became increasingly evident.

Non-mesh inguinal procedures including Pfannenstiel incisions that are frequently used as an aid in laparoscopic or gynaecological surgery are also noted to coincide with pain symptoms that appeared similar as observed following mesh inguinal hernia repair ${ }^{6,7}$. Interestingly, efforts that systematically studied incidence rate and risk factors for chronic pain syndromes after a Pfannenstiel incision have not been performed.

Chronic pain after mesh implantation for inguinal hernia repair or after a Pfannenstiel approach is likely related to the interference with nerve structures located in the lower abdominal and inguinal area. A thorough knowledge on the complex anatomy of these regions aids in understanding the characteristics of these chronic inguinal pain syndromes.

\section{Anatomy}

Different myofascial layers compose the lower abdominal and the inguinal canal. The sensory innervation of these areas is provided by four inguinal nerves, the iliohypogastric, ilioinguinal, genitofemoral and lateral femoral cutaneous nerve. The latter is rarely affected due to its lateral position and is not discussed. In contrast, the other three nerves may be injured following surgical manipulation associated with inguinal hernia repair or Pfannenstiel incisions.

The iliohypogastric nerve is the most cranial of the three. It arises from T12 / L1 vertebrae, runs ventrally from the lumbar quadrate muscle and gradually pierces various layers of the abdominal wall. Its function is to supply the suprapubic region with sensation. The ilioinguinal nerve originates from the same vertebral level and travels a similar course a few centimetres caudal to the iliohypogastric nerve. Sensation to the base of the pubic area and inner thigh is provided by this nerve. Endings of both these nerves can be found subcutaneously or subfascially at the lateral margin of the rectus border.

The genitofemoral nerve originates from L1/ $L 2$ and pierces the iliopsoas muscle where it runs caudally on its ventral surface. It usually demonstrates a division into a genital and femoral branch some centimetres proximal to the inguinal ligament. The genital branch subsequently runs underneath the spermatic cord or round ligament innervating the scrotum or labia majora. In men, the genital branch also forms the afferent 
pathway for the cremasteric reflex. The femoral branch innervates the skin of the anterior upper leg region. It should be stressed that anatomical variations in the inguinal course of all three inguinal nerves are exceedingly common ${ }^{8}$.

Pain characteristics after inguinal hernia repair or Pfannenstiel incisions

The pathogenesis of chronic pain after inguinal hernia repair in general has been scarcely investigated. An early 1942 study reported on 'genitofemoral causalgia' following a hernia operation'. In 1988 Lichtenstein published a review on causes and prevention of postherniorrhaphy neuralgia following mesh repair emphasizing the necessity of nerve identification and preservation ${ }^{10}$. However, it took nearly twenty years before a classification for postherniorrhaphy groin pain syndromes was proposed" ${ }^{11}$ It was suggested

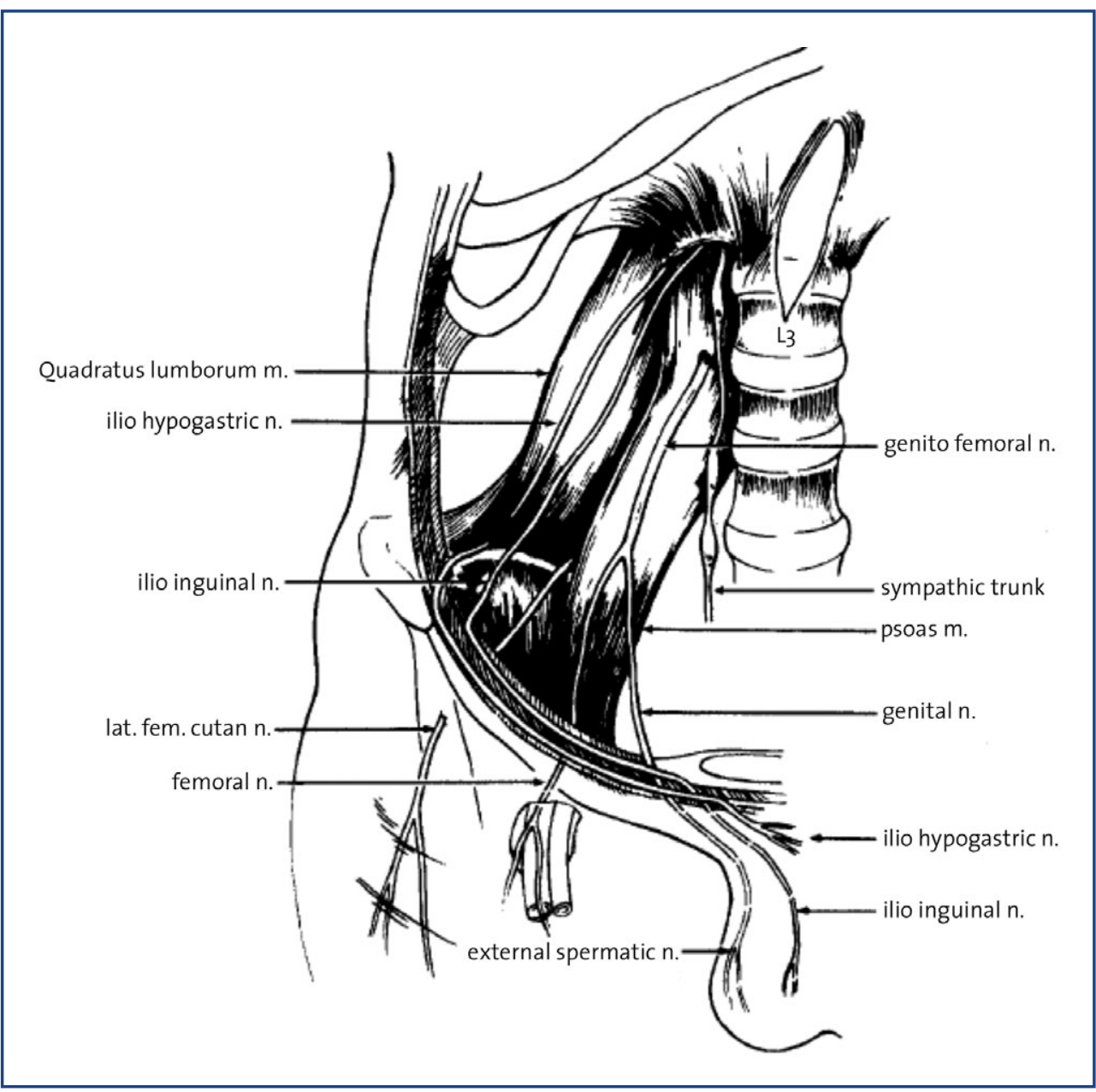

Figure 1 Neuro-anatomy of the male inguinal region. that pain syndromes should be classified as 'neuropathic' and 'non-neuropathic'

Neuropathic pain is thought to be caused by neuroma formation due to damaged nerve tissue or entrapment following compressive sutures or mesh material. Development of fibrosis over time may also lead to compression of neural structures. Neuropathic pain is characterized as sharp or stabbing and is situated in or around the inguinal scar. Neuropathic pain frequently radiates into its associated skin area. Physical examination often reveals neurophysiological abnormalities including hypoesthesia, hyperesthesia or allodynia. On the other hand, non-neuropathic ('nociceptive') pain is due to damaged surrounding structures such as periostal layers or musculotendinous tissues. Mechanica pressure due to gradual mesh displacement or contraction is also implicated as a source of nociceptive pain". Nociceptive pain is often described as aching or pulling in the

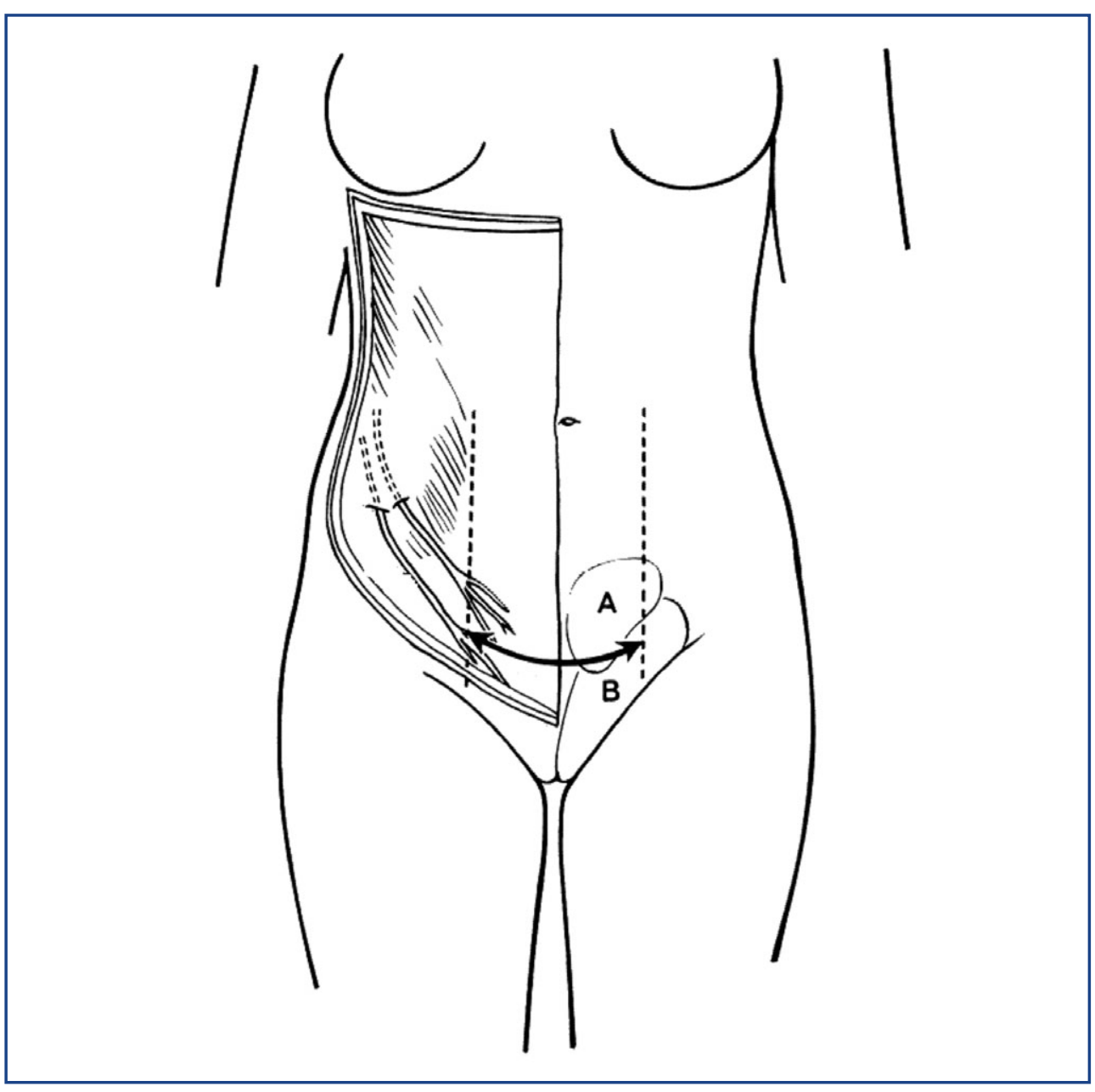

Figure 2 The Pfannenstiel incision in relation to the iliohypogastric (A) and ilioinguinal (B) nerve?. 
presence of a normal cutaneous sensation. Patients usually report an increase in local pain if pressure is applied to the mesh by the palpating fingers of the investigator. A combined pain syndrome entailing neuropathic and nociceptive elements is not uncommon.

An early study on nerve entrapment after a Pfannenstiel incision was published in the late $1980{ }^{\prime} \mathrm{s}^{12}$. The pathogenesis of 'post-Pfannenstiel pain' is thought similar compared to postherniorrhaphy pain. A (too) lateral dissection beyond the border of the abdominal rectus muscle may lead to nerve damage causing neuroma formation of the ilioinguinal or iliohypogastric nerve ${ }^{7}$. Moreover, constricting sutures or development of postoperative fibrosis can also induce nerve entrapment with an identical neuropathic pain syndrome. The genitofemoral nerve is often beyond the operated area and is usually not affected after Pfannenstiel incisions.

\section{Management of pain syndromes after inguinal or Pfannenstiel incisions}

Studies on diagnosing chronic postherniorrhaphy inguinal pain syndromes are few ${ }^{11}$ In 2004 Amid published his findings on computed tomography as a tool in diagnosing displaced and rolled-up prosthetic material (so-called 'meshoma') ${ }^{13}$. He concluded that this radiologic modality can be useful in unravelling chronic pain after inguinal hernia repair. A few years later, the role of Magnetic Resonance Imaging in diagnosing specific pathogenic mechanisms in chronic postherniorrhaphy inguinal pain was analyzed. The authors concluded that the inter-observer agreement is low and that MRI-assessed pathology is not necessarily related to persistent postherniotomy pain ${ }^{14}$

Evidence concerning adequate treatment options for chronic inguinal pain syndromes is also limited. Non-surgical treatment options including peripheral nerve blocks, analgesics (e.g. antidepressants or anticonvulsants), Transcutaneous Electric Nerve Stimulation (TENS), and Pulsed Radio Frequency (PRF) for chronic postherniorrhaphy inguinal pain have been used for a limited number of patients ${ }^{15-20}$. Most reported cases were successful suggesting publication bias. Moreover, surgery including inguinal neurectomy for neuropathic pain is incidentally reported ${ }^{10,11,21-25}$. Consensus on an optimal treatment strategy has not been reached ${ }^{26}$.

Studies on chronic pain after a Pfannenstiel incision are rare. Very few studies on effective treatment regimes for chronic pain after a Pfannenstiel incision have been published ${ }^{27}$.

\section{GENERAL AIM OF THIS THESIS}

To study management of chronic pain syndromes after inguinal hernia repair and Pfannenstiel incisions in a general patient population

\section{SPECIFIC AIMS}

1. To quantify the overall prevalence of chronic pain and functional impairment after inguinal hernia repair and Pfannenstiel incisions.

2. To assess which pain measurement tool, Visual Analogue Scale (VAS) or a Verbal Rating Scale (VRS), performs best in postherniorrhaphy pain patients.

3. To classify chronic inguinal pain after inguinal hernia repair and Pfannenstiel incisions. 4. To assess the long-term results of inguinal neurectomy for pain syndromes after inguinal hernia repair and Pfannenstiel incisions.

5. To describe the socio-economic consequences of chronic neuropathic postherniorrhaphy pain and the influence of surgical treatment strategies on occupational disability in a cohort of pain patients.

\section{OUTLINE}

Chronic pain as a complication after routine inguinal hernia repair is increasingly recognized as a major problem. However, incidence in an average post-hernia repair population in the Netherlands is hardly known. The prevalence of long-term chronic pain, numbness and functional impairment after open and laparoscopic inguinal hernia repair was studied using a novel questionnaire. Results of this investigation are reported in chapter 2

A Pfannenstiel incision may initiate similar postoperative pain syndromes compared to an inguinal hernia repair. In chapter 3 , prevalence, risk factors and etiology of 'post-Pfannenstiel pain syndromes' in a large patient cohort are investigated.

Several tools for pain measurement including a Visual Analogue Scale (VAS) and a Verbal Rating Scale (VRS) are currently used in various patient populations with chronic pain. Objective of the study in chapter 4 was to determine which of these two pain measurement scales performs optimal in chronic pain patients following inguinal hernia repair.

Chronic postherniorrhaphy pain is diverse in origin. The study described in chapter 5 
aims at classifying postherniorrhaphy pain syndromes following elective inguinal hernia repair.

Patients with postherniorrhaphy inguinal neuralgia usually do not respond to conservative treatment regimens. However, a surgical neurectomy may offer long-term pain relief. The authors assessed the long-term results of a selective (tailored') neurectomy in patients with postherniorrhaphy groin neuralgia in chapter 6 .

In chapter 7 rationale and outline of a randomized controlled trial investigating neurectomy versus injection with lidocain, corticosteroids and hyaluronic acid in individuals with postherniorrhaphy inguinal neuralgia are presented.

Chapter 8 focuses on the results of surgical management of inguinal neuralgia after a Pfannenstiel incision.

Severe chronic inguinal neuralgia often results in occupational disability. The aim of chapter 9 is to assess the effects of tailored neurectomy on pain-induced occupational disability.

Results of all studies are summarized and discussed in chapter 10. Future perspectives are provided at the end of this chapter.

\section{REFERENCES}

1. EU Hernia Trialists Collaboration. Repair of groin hernia with synthetic mesh: meta-analysis of randomized controlled trials. Ann Surg 2002; 235: 322-332

2 Cunningham J, Temple WJ, Mitchell P, Nixon JA, Preshaw RM, Hagen NA. Cooperative hernia study: pain in the postrepair patient. Ann Surg 1996; 224:598-602

3 Bay-Nielsen M, Perkins FM, Kehlet H. Pain and functional impairment 1 year after inguina herniorrhaphy: a nationwide questionnaire study. Ann Surg 2001; 233: 1-7

4 Franneby U, Sandblom G, Nordin P, Nyrén O, Gunnarsson U. Risk factors for long-term pain after hernia surgery. Ann Surg 2006; 244: 212-219

5 Nienhuijs SW, Boelens OB, Strobbe LJ. Pain after anterior mesh hernia repair. J Am Coll Surg 2005; 200: $885-889$

6 Kisielinski K, Conze J, Murken AH, Lenzen NN, Klinge U, Schumpelick V. The Pfannenstiel or so called "bikini cut": still effective more than 100 years after first description. Hernia 2004; 8: 177-181

7 Luijendijk RW, Jeekel J, Storm RK, Schutte PJ, Hop WC, Drogendijk AC, Huikeshoven FJ. The low transverse Pfannenstiel incision and the prevalence of incisional hernia and nerve entrapment. Ann Surg 1997; 225: 365-369
8 Al-dabbagh AK. Anatomical variations of the inguinal nerves and risks of injury in 110 hernia repairs. Surg Radiol Anat 2002; 24:102-107

9 Magee RK. Genitofemoral causalgia. Can Med Assoc J 1942; 46:326

10 Lichtenstein IL, Shulman AG, Amid PK, Montllor MM. Cause and prevention of postherniorrhaphy neuralgia: a proposed protocol for treatment. Am I Surg 1988; 155: 786-790

11 Amid PK. Causes, prevention, and surgical treatment of postherniorrhaphy neuropathic inguinodynia: triple neurectomy with proximal end implantation. Hernia 2004; 8: 343-349

12 Sippo WC, Burghardt A, Gomez AC. Nerve entrapment after Pfannenstiel incision. Am J Obstet Gynecol 1987; 157: 420-421

13 Amid PK. Radiologic images of meshoma: a new phenomenon causing chronic pain after prosthetic repair of abdominal wall hernias. Arch Surg 2004; 139: 1297-1298

14 Aasvang EK, Jensen KE, Fiirgaard B, Kehlet H. MRI and pathology in persistent postherniotomy pain. J Am Coll Surg 2009; 208: 1023-1028

15 Cohen SP, Foster A. Pulsed radiofrequency as a treatment for groin pain and orchialgia. Urology 2003; 61: 645

16 Hameroff SR, Carlson GL, Brown BR. Ilioinguinal pain syndrome. Pain 1981; 10:253-257

17 Maaliki H, Naja Z, Zeidan A. Repeated ilioinguinal block using a catheter technique for pain relief in inguinal neuralgia. Pain Pract 2008; 8:144-146

18 Rauchwerger JJ, Giordano J, Rozen D, Kent JL, Greenspan J, Closson CW. On the therapeutic viability of peripheral nerve stimulation for ilioinguinal neuralgia: putative mechanisms and possible utility. Pain Pract 2008; 8: 138-143

19 Rho RH, Lamer TJ, Fulmer JT. Treatment of genitofemoral neuralgia after laparoscopic inguinal herniorrhaphy with fluoroscopically guided tack injection. Pain Med 2001; 2: 230-233

20 Rozen D, Parvez U. Pulsed radiofrequency of lumbar nerve roots for treatment of chronic inguinal herniorraphy pain. Pain Physician 2006; 9: 153-156

21 Hahn L. Clinical findings and results of operative treatment in ilioinguinal nerve entrapment syndrome. Br J Obstet Gynaecol 1989; 96: 1080-1083

22 Heise CP, Starling JR. Mesh inguinodynia: a new clinical syndrome after inguinal herniorrhaphy? J Am Coll Surg 1998; 187: 514-518

23 Kim DH, Murovic JA, Tiel RL, Kline DG. Surgical management of 33 ilioinguinal and iliohypogastric neuralgias at Louisiana State University Health Sciences Center. Neurosurgery 2005 56:1013-1020

24 Madura JA, Madura JA 2nd, Copper CM, Worth RM. Inguinal neurectomy for inguinal nerve entrapment: an experience with 100 patients. Am J Surg 2005; 189: 283-287

25 Starling JR, Harms BA. Diagnosis and treatment of genitofemoral and ilioinguinal neuralgia. World J Surg 1989; 13: 586-591

26 Aasvang E, Kehlet H. Surgical management of chronic pain after inguinal hernia repair. Br J Surg 2005; 92: 795-801

27 Ducic I, Moxley M, Al-Attar A. Algorithm for treatment of postoperative incisional groin pain after cesarean delivery or hysterectomy. Obstet Gynecol 2006; 108:27-31 


\section{CHAPTER 2}

Chronic sequelae of common elective groin hernia repair

Loos MJA, Roumen RMH, Scheltinga MRM

Hernia 2007; 11: 169-173 
ABSTRACT

\section{Background}

The aim of this study was to assess long-term chronic pain, numbness and functional

impairment after open and laparoscopic groin hernia repair in a teaching hospital.

Methods

We performed a cross-sectional study in which all adult patients with a groin hernia repair between January 2000 and August 2005 received a questionnaire by mail. It contained questions concerning frequency and intensity of pain, presence of bulge, numbness, and functional impairment.

Results

One thousand seven hundred and sixty-six questionnaires were returned (81.6\%) and after a median follow-up period of nearly 3 years $40.2 \%$ of patients reported some degree of pain. Thirty-three patients (1.9\%) experienced severe pain. Almost one-fourth reported numbness which correlated significantly with pain $(P<0.001)$. Other variables identified as risk factors for the development of pain were young age $(P<0.001)$ and recurrent hernia repair $(P=0.003)$. One-fifth of the patients felt functionally impaired in their work or leisure activities.

\section{Conclusion}

Chronic pain and functional impairment are very common long-term complications after groin herniorrhaphy in a Dutch teaching hospital. 


\section{INTRODUCTION}

Worldwide groin hernia repair is one of the most common operations performed in general surgery, with any complication affecting a high number of patients. Since the introduction of the 'tension-free mesh technique' by Lichtenstein in 1970, recurrence rates have diminished to an acceptable level. Low recurrence rates have shifted attention towards chronic pain and functional impairments. With a reported incidence varying from 14 to $54 \%$, several studies have shown chronic pain to be a common seque after groin hernia repair ${ }^{1-11}$. As a result about $11 \%$ of the patients is claimed to be functionally impaired in their work or leisure activities'. Causative mechanisms are thought to be neuropathic (entrapment or injury of ilioinguinal, iliohypogastric or genitofemoral nerves) or somatic (tissue damage, scar formation) $)^{14}$. In the present study we evaluate the results and complaints of a large group of patients after elective groin hernia repair performed mainly by residents in two teaching hospitals.

\section{PATIENTS AND METHODS}

This is a population based postal questionnaire study of consecutive adult patients ( $\geq 18$ years) who underwent groin hernia repair between January 2000 and August 2005 in two teaching hospitals (the Máxima Medical Center in Eindhoven (MMC-E) and Veldhoven (MMC-V), The Netherlands, serving a total population of approximately 350.000 inhabitants). Patient records were checked to exclude patients who were deceased or unable to return the questionnaire because of mental incapacities. If patients had moved and no current address was available, they were excluded as well. The different surgical techniques that were used were both open (Lichtenstein, Shouldice) and laparoscopic repair (Total Extra Peritoneal = TEP, Trans Abdominal Pre Peritoneal = TAPP) for primary or recurrent and uni- or bilateral groin hernias.

To assure that the 'The International Association for the Study of Pain definition' of chronic pain (pain persisting beyond the normal tissue healing time of 3 months) was applicable to all reported pain complaints, the shortest follow-up period comprised three months ${ }^{12}$. The questionnaire was based on information from various previous studies ${ }^{1-11}$ (See appendix). Between November 2005 and February 2006 all patients of the Máxima Medical Center were sent a questionnaire with a pre-stamped envelope with questions regarding frequency and intensity of pain, suspicion of recurrence, presence of numbness and degree of functional impairment in work or leisure activities. Pain intensity was measured with a Visual Analogue scale (VAS). This is a $10 \mathrm{~cm}$ scale with on the one end 'no pain' and on the other 'unbearable pain'. In order to evaluate different severities it was subdivided according to a previously validated classification: $0=$ no pain, $<3=$ mild pain, 3-7 = moderate pain, $>7=$ severe pain ${ }^{13}$. In the present study, chronic pain was defined as any VAS $>0$. After two months all non-responders were reminded by telephone or by post.

Statistical analysis was carried out using Statistical Package for the Social Sciences (SPSS) for Windows version 12.0.1. The level of significance was set at a p-value of 0.05. Pearson $\mathrm{X}$ 2-test was used to determine statistical significance between different variables and the presence of pain.

\section{RESULTS}

A total of 2339 elective groin hernia repairs was performed on adult patients between January 2000 and August 2005 in the Máxima Medical Center in Eindhoven $(n=973)$ and in Veldhoven $(n=1368)$. Since the operation 82 patients were deceased and 75 patients had moved. Another 18 patients were excluded because of mental incapacitation, leaving 2164 patients. The questionnaire was returned by 1766 patients (MMC-E $\mathrm{n}=702, \mathrm{MMC}-\mathrm{V} \mathrm{n}=1064$ ) resulting in a response rate of $81.6 \%$ (Figure 1 ).

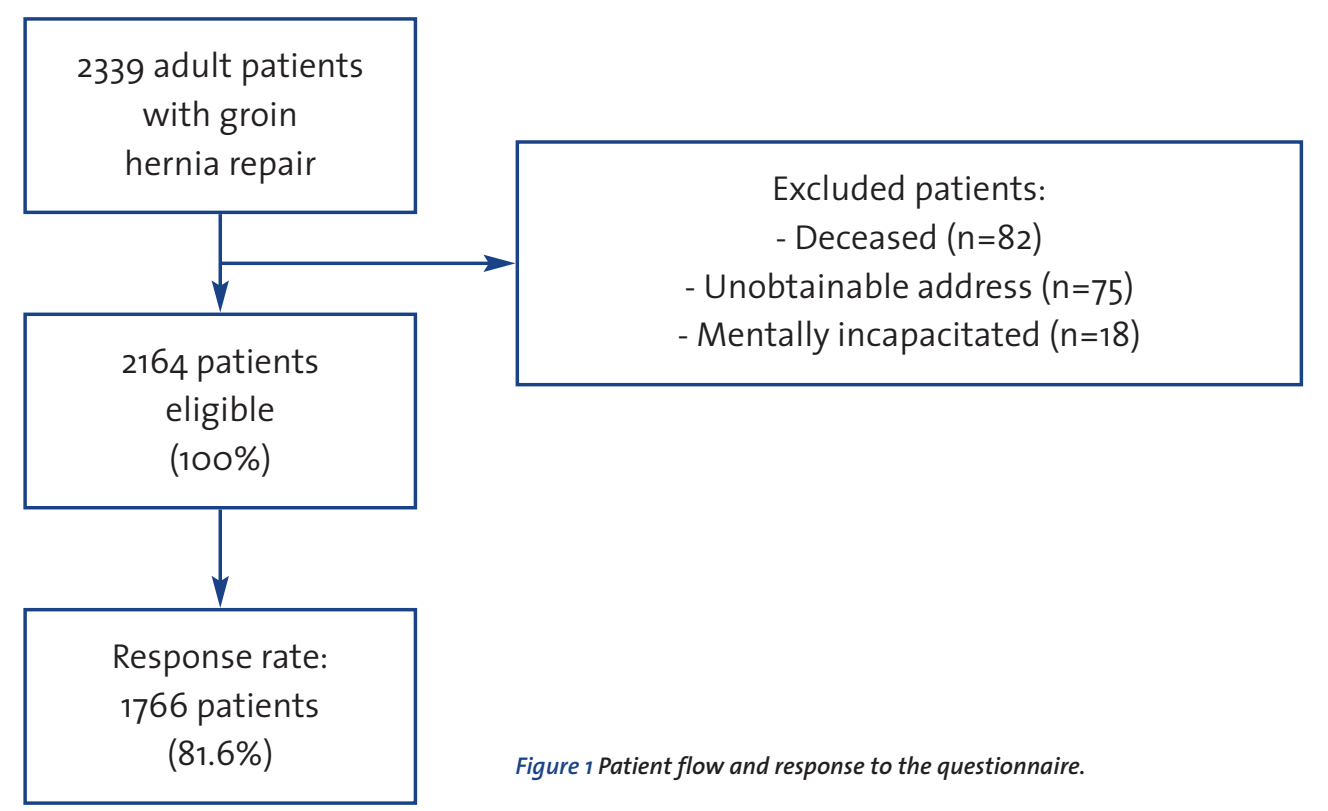


The study population consisted mainly of males (95\%) with a median age of 60 years. In the MMC-V $90.5 \%$ of all repairs was performed using an open anterior technique (Lichtenstein $89.0 \%$, Shouldice 1.5\%), as opposed to the MMC-E, where almost half of the surgery was done laparoscopically (47.5\%, mainly TAPP). Demographic and operative characteristics are listed in table 1.

After a median follow-up period of 2 years and 11 months, pain was reported by 40.2 percent of the patients $(810 / 1766)$. Severe pain was reported by 33 patients $(1.9 \%)$. Pain frequency and intensity are graphically shown in figure 2 and 3 respectively.

As a result of persisting pain $21 \%$ of the patients was confronted with some degree of limitations in daily functioning (severe functional impairment $=1.2 \%$ ). Severity of functional impairment is detailed in table 2.

A bulge was noticed by $13.2 \%$ of the patients and $25.8 \%$ (MMC-E 16.6\%, MMC-V $29.9 \%$ ) experienced numbness in the groin area. Laparoscopic procedures were associated with statistically fewer numbness than the anterior approach ( $p<0.001)$. Surgical technique (open or laparoscopic treatment) was not significantly related to reported pain intensity $(p=0.15)$. However, age $(<65$ yrs, $p<0.001)$, presence of numbness $(p<0.001)$ and recurrent hernia repair $(p=0.003)$ did appear as significant determinants for chronic pain (table 3).

$\begin{array}{ll} & \%(\mathrm{n}) \\ \text { Age - yrs } & \\ 18-65 & 61.0(1078) \\ \quad>65 & 39.0(688) \\ \text { Sex ratio male/female } & 94.8 / 5.2(1674 / 92) \\ \text { Hernia type } & \\ \quad \text { Primary } & 89.0(1571) \\ \quad \text { Recurrence } & 11.0(195) \\ \text { Surgical technique } & 75.4(1331) \\ \text { Open } & 67.5(1192) \\ \quad \text { Lichtenstein } & 7.9(139) \\ \text { Shouldice } & 24.6(435) \\ \text { Laparoscopic } & \\ \text { (TEP/TAPP) } & 35[3-72]^{*} \\ \text { Median follow up - months } & \end{array}$

Table 1 Demographic and operative characteristics of 1766 patients who completed the questionnaire.

TEP $=$ Total Extra Peritoneal, TAPP $=$ Trans Abdominal Pre Peritoneal,${ }^{*}=[$ range $]$.

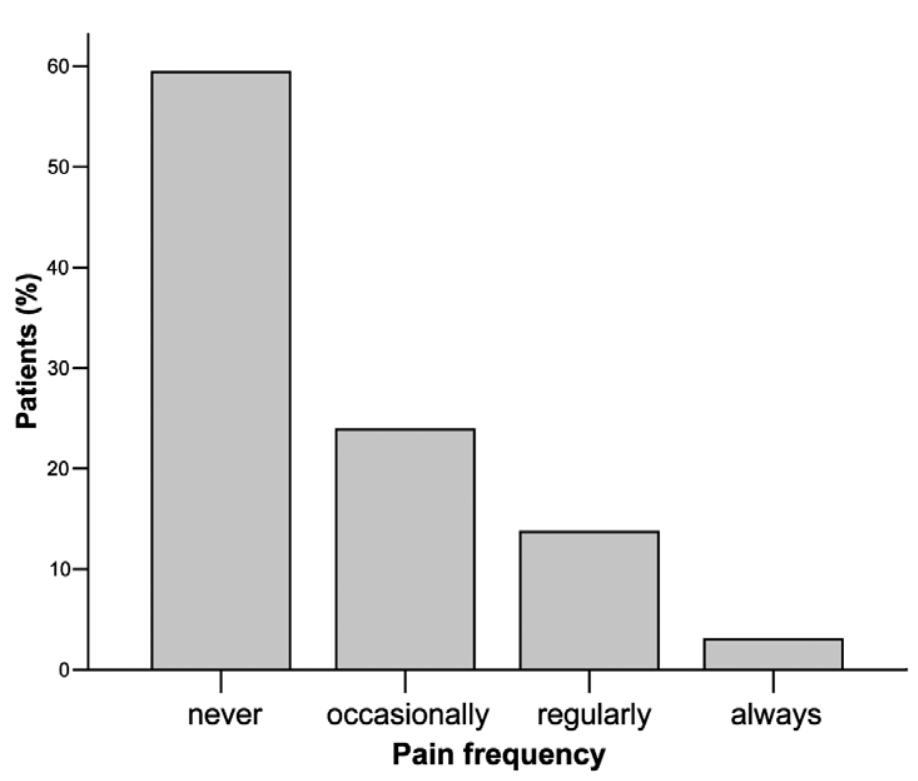

Figure 2 Postoperative pain frequency after routine inguinal hernia repair.

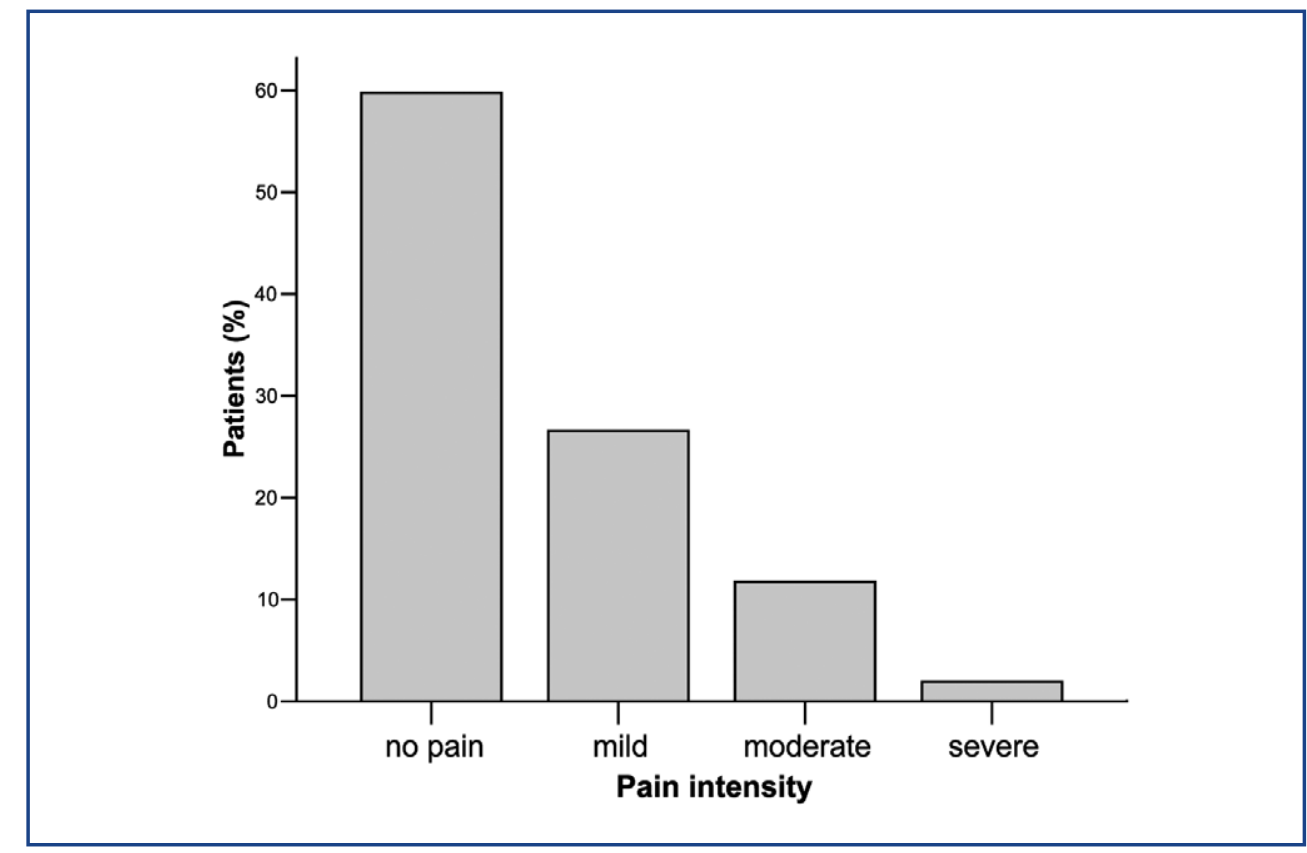

Figure 3 Postoperative pain intensity after routine inguinal hernia repair. 


$\begin{array}{ll} & \%(\mathrm{n}) \\ \text { No impairment } & 79.1(1348) \\ \text { Mild } & 13.3(226) \\ \text { Moderate } & 6.5(110) \\ \text { Severe } & 1.2(21)\end{array}$

Table 2 Functional impairment after hernia repair ( $\left(n=1705\right.$ patients $\left.{ }^{*}\right)$. ${ }^{*}$ issing data in 61 patients.

$\begin{array}{llll} & \text { Pain*\%(n) } & \text { No pain \% }(\mathrm{n}) & \text { p-value* } \\ \text { Age } & & & \\ 18-65 & 49.0(528) & 51.0(550) & <0.001 \\ 65+ & 26.9(185) & 73.1(503) & \\ \text { Numbness } & & \\ \quad \text { Present } & 72.8(310) & 27.2(116) & <0.001 \\ \quad \text { Absent } & 29.7(385) & 70.3(914) & \\ \text { Surgical technique } & & & \\ \quad \text { Open } & 41.7(555) & 58.3(776) & 0.15^{* * *} \\ \text { Laparoscopic } & 36.3(158) & 63.7(277) & \\ \text { Recurrent groin hernia repair } & & \\ \quad \text { Present } & 50.8(99) & 49.2(96) & 0.003 \\ \quad \text { Absent } & 39.0(612) & 61.0(959) & \\ & & \end{array}$

Table 3 Risk factors for chronic postoperative pain.

"pain intensity (any severity), "*Pearson X2-test, ***Surgical technique did not significantly relate to the development of chronic pain.

\section{DISCUSSION}

Taking the large sample size $(n=2164)$ and the good response rate $(81.6 \%)$ into consideration, these results seem a valid representation of the current prevalence of chronic pain following groin hernia repair. Especially since all applied surgical techniques for both unilateral and bilateral, primary and recurrent hernias were included, a complete picture of the current pain problem can be obtained. Drawbacks in this study are its retrospective design and the lack of a validated questionnaire. By using items from previous validated questionnaires, we tried to minimize such methodical bias.

In the past decade numerous studies have pointed out long-term groin pain complaints as a very common complication of hernia repair. A previous one year follow-up Dutch questionnaire study revealed that $43.3 \%$ of the patients (138/319) still experienced some degree of groin pain, of which $14.5 \%$ was reported to be severe 7 . The present study shows equal results based on a large group of post-repair cases. Some degree of pain persisted in as much as $40 \%$ of the patients after a median postoperative period of three years. Although the majority of reported pain intensity was mild, one in every eight groin hernia repairs was followed by moderate or severe pain complaints. These results confirm the significance of chronic pain as a complication of groin hernia surgery in Dutch hospitals.

Residual pain is frequently accompanied by limitations in general functioning. In a published series of 1166 hernia repairs one year after surgery, $11 \%$ of the patients was negatively influenced by their groin pain in work performance or leisure activities'. Bozuk et al reported that $2.2 \%$ of the patients was unable to return to work ${ }^{14}$. In the present series $21 \%$ of the respondents was functionally impaired. An alarming $1.2 \%$ of the patients felt severely impaired, resulting in filing for workers' compensation in most cases. Unfortunately, we did not assess quality of life. By using the Short-Form 36 (SF-36) Poobalan and colleagues concluded that quality of life was significantly affected in chronic pain patients on three of eight dimensions: social functioning, mental health and pain?3.

A number of studies revealed that hernia type, size of defect, experience of surgeon, length of incision, and choice of anaesthesia do not correlate with chronic pain. At first the introduction of laparoscopy in inguinal hernia surgery seemed promising with respect to the prevention of residual pain. However, long-term pain complaints are similar, despite a reduction in the early postoperative period a one day faster resumption of daily activities ${ }^{8-11}$. Our study confirms these results and we conclude that laparoscopic surgery should not be considered as a chronic pain preventing measure.

Various variables have been recognized as independent risk factors for the onset of long-term pain after inguinal hernia repair: age, numbness, high pain levels before and directly after the operation, surgery for a recurrence and postoperative complications ${ }^{7-11}$. Firstly, our results show a correlation between younger age ( $<65 \mathrm{yrs})$ and pain. This is probably due to an age-related change in pain-experience and daily exertional level 7 . Secondly, with one fourth of the patients reporting numbness, local cutaneous neurosensory disturbances appear to be common after inguinal herniorrhaphy, in particular after the open technique. Compared to patients with normal sensory functions, twice as many patients with numbness experienced some degree of pain. Most likely sensory abnormalities and pain both are due to damage or entrapment of the ilioinguinal, iliohypogastric and genitofemoral nerves symptoms ${ }^{15}$. Thirdly, as demonstrated in previous literature recurrent inguinal hernia repair was identified as a significant risk factor for the development of chronic pain as well ${ }^{2-3}$.

Hernia surgery research hitherto focused on preventing recurrences. However, the prevention of chronic pain should be dealt with in a different way. Amid emphasized the importance of a thorough knowledge of groin anatomy to avoid injury or entrapment of the nerves, a meticulous dissection, and cautious nerve handling ${ }^{15}$. Based on a basic concept of 'no nerves no pain', two randomized controlled trials were conducted to 
evaluate if preservation or elective division of the inguinal nerves during hernia repair would influence chronic pain ${ }^{16-17}$. These trials reported inconclusive results. A consecutive double-blind randomized controlled trial with one hundred subjects studying a prophylactic neurectomy of the ilioinguinal nerve during Lichtenstein hernia repair demonstrated a decreased incidence of exertional chronic pain ${ }^{18}$. The procedure was neither associated with more neurophysiological abnormalities nor with deterioration in quality of life. Therefore the authors proposed prophylactic ilioinguinal neurectomy as a routine surgical step during open mesh hernia repair. From an empirical point of view a neurectomy is advisable when the ilioinguinal nerve is at high risk of entrapment due to the placement of the mesh. However, larger clinical trials with a longer follow up period are required.

A standard polypropylene mesh is associated with a strong foreign body reaction resulting in the desired abdominal wall strength, but in itself may also act as a probable cause of pain ${ }^{19}$. Based on this hypothesis Bringman et al. assessed the impact of a lightweight or standard mesh on chronic pain with a three-year follow up ${ }^{20}$. The use of lightweight mesh (LW) produced less chronic pain, although the reported difference was small and only significant during palpation in the groin (standard $=3,3 \% \mathrm{vs}$. LW $=$ $0,8 \%)$. There was no difference in recurrence rate. However, considering increased costs of lightweight mesh, these results were not convincing in altering daily surgical practice. The issue of chronic postherniorrhaphy pain has created the dilemma if surgery should always be the preferential treatment in patients with absent or mild symptoms. In a published series of 323 operated patients, those who graded their pre-operative pain as moderate or severe benefited the most of their hernia repair, which is in contrast to those patients who had no pain at rest before operation 4 . These latter patients had significant pain scores at 1 year. Overall five percent of the total study group graded their present pain as slightly or much worse compared to their preoperative situation. The question thus rises whether asymptomatic patients should be treated surgically at all. A possible answer to this question is given by Fitzgibbons et al. ${ }^{21}$. Their randomized controlled trial showed 'watchful waiting' to be an acceptable option for men with minimally symptomatic inguinal hernias. Because of the low incidence of incarceration [1.8/1000 patient-years], delaying surgical repair was considered to be a safe option. In conclusion, the present study shows that pain and long-term functional impairment affect a large number of patients after groin herniorrhaphy in a Dutch teaching hospital. Fortunately, much attention is presently drawn to preventive issues of groin pain Surgeons, however, should set up protocols for recognizing and treating these serious events. Additional research on the etiology and treatment of postherniorrhaphy pain is recommended.

\section{APPENDIX OUESTIONNAIRE}

1 How often did you experience pain in the groin area during the previous month? Never, Occasionally, Regularly, Always

2 Please draw an $\mathrm{x}$ to indicate the average pain intensity in the operated groin area during the past month.

VAS: No pain

Unbearable pain

3 Did you ever notice a bulge in the operated groin area during the past month? Yes, No

4 Did you notice a numb feeling in the groin, pubic area or the upper leg during the past month?

Yes, No

5 Are you functionally impaired in daily activities by your complaints?

No, Occasionally, Regularly, Always

6 What was the average functional impairment during the past month? None, Mild, Moderate, Severe

\section{REFERENCES}

1 Bay-Nielsen M, Perkins FM, Kehlet H. Pain and functional impairment 1 year after inguinal herniorraphy: a nationwide questionnaire study. Ann Surg 2001; 233: 1-7

2 Callesen T, Bech K, Kehlet H. Prospective study of chronic pain after groin hernia repair. Br J Surg 1999; 86: 1528-1531

3 Poobalan AS, Bruce J, King PM, Chambers WA, Krukowski ZH, Smith WC. Chronic pain and quality of life following open inguinal hernia repair. Br I Surg 2001; 88: 1122-1126

4 Page B, Paterson D, Young D, O'Dwyer PJ. Pain from primary inguinal hernia and the effect of repair on pain. BrJ Surg 2002; 89:1315-1318

5 Cunningham J, Temple WJ, Mitchell P, Nixon JA, Preshaw RM, Hagen NA. Cooperative hernia study: pain in the postrepair patient. Ann Surg 1996; 224:598-602

6 Courtney CA, Duffy K, Serpell MG, O'Dwyer PJ. Outcome of patients with severe chronic pain following repair of groin hernia. Br J Surg 2002; 89: 1310-1314

7 Nienhuijs SW, Boelens O, Strobbe LJA. Pain after anterior hernia repair. J Am Coll Surg 2005; 200: 885-889

8 Liem MSL, Graaf van der Y, Steensel van C, Boelhouwer RU, Clevers GJ, Meijer WS, Stassen LP, Vente JP, Weidema WF, Schrijvers AJ, van Vroonhoven TJ. Comparison of conventional anterior surgery and laparoscopic surgery for inguinal hernia repair. N Engl I Med 1997; 336: 1541-1547

9 Neumayer L, Giobbie-Hurder A, Jonasson O, Fitzgibbons R Jr, Dunlop D, Gibbs J, Reda D, Henderson W, Veterans Affairs Cooperative Studies Program 456 Investigators. Open mesh versus laparoscopic mesh repair of inguinal hernia. N Engl J Med 2004; 350: 1819-1827 
10 Grant AM, Scott NW, O'Dwyer PJ, MRC Laparoscopic Groin Hernia Trial Group. Five year followup of a randomised trial to assess pain and numbness after laparoscopic or open repair of groin hernia. Br J Surg 2004; 91: 1570-1574

11 Fränneby U, Sandblom G, Nordin P, Nyren O, Gunnarson U. Risk factors for long-term pain after hernia surgery. Ann Surg 2006; 244: 212-219

12 Classification of chronic pain, Descriptions of chronic pain syndromes and definitions of pain terms. Prepared by the International Association for the Study of Pain, Subcommittee on Taxonomy. Pain 1986; 3 (Suppl): S1-226

13 Kelly A-M. The minimum clinically significant difference in visual analogue scale pain score does not differ with severity of pain. Emerg Med J 2001; 18: 205-207

14 Bozuk M, Schuster R, Stewart D, Hicks K, Greaney G, Waxman K. Disability and chronic pain after open mesh and laparoscopic inguinal hernia repair. Am Surg 2003; 69: 839-841

15 Amid PK. Causes, prevention, and surgical treatment of postherniorrhaphy neuropathic inguinodynia: Triple neurectomy with proximal end implantation. Hernia 2004; 8:343-349

16 Ravichandran D, Kalambe BG, Pain JA. Pilot randomised controlled study of preservation or division of ilioinguinal nerve in open mesh repair of inguinal hernia. Br J Surg 2000; 87: 1166-1167

17 Picchio M, Palimento D, Attanasio U. Randomized controlled trial of preservation or elective division of ilioinguinal nerve in open inguinal hernia repair with polypropylene mesh. Arch Surg 2004; 139: 755-758

18 Miu WL, Ng CS, Fung TM, Cheung FK, Wong CM, Ma TH, Bn MY, Ng EK. Prophylactic ilioinguinal neurectomy in open inguinal hernia repair. A double-blind randomized controlled trial. Ann Surg 2006; 244: 27-33

19 Klinge U, Klosterhalfen B, Muller M, Schumpelick V. Foreign body reaction to meshes used for the repair of abdominal wall hernias. Eur J Surg 1999; 165: 665-673

20 Bringman S, Wollert S, Österberg J, Smedberg S, Granlund H, Heikkinen TJ. Three-year results of a randomised clinical trial of lightweight or standard polypropylene mesh in Lichtenstein repair of primary inguinal hernia. Br J Surg 2006; 93: 1056-1059

21 Fitzgibbons RJ Jr, Giobbie-Hurder A, Gibbs JO, Dunlop DD, Reda DJ, McCarthy M Jr, Neumayer LA Barkun JS, Hoehn JL, Murphy JT, Sarosi GA Jr, Syme WC, Thompson JS Wang J, Jonasson O. Watch ful waiting vs. repair of inguinal hernia in minimally symptomatic men, a randomized controlled trial. JAMA 2006; 295:285-292 


\section{CHAPTER 3}

The Pfannenstiel approach as a source of chronic pain

Loos MJA, Scheltinga MRM, Mulders LGM, Roumen RMH

Obstet Gynecol 2008; 111: 839-846 
ABSTRACT

\section{Background}

To estimate prevalence, risk factors, and etiology of post-Pfannenstiel pain syndromes.

\section{Methods}

All women ( $\mathrm{n}=866)$ with a Pfannenstiel incision for cesarean delivery or abdominal hysterectomy performed between January 2003 and December 2004 received a ques tionnaire evaluating pain located in the Pfannenstiel region. A multivariate logistic regression analysis was done to determine predictors for chronic pain development. Patients with moderate or severe pain were interviewed and underwent a physical examination.

\section{Results}

The response rate was $80 \%$ ( 690 of 866 patients). Subsequent to a follow-up after 2 years, one third (223 of 690) experienced chronic pain at the incision site. Moderate or severe pain was reported by $7 \%$, and in $8.9 \%$ of respondents, pain impaired daily activities. Numbness, recurrent Pfannenstiel surgery, and emergency cesarean delivery were significant predictors of chronic pain. Nerve entrapment was present in over half the examined patients with moderate-to-severe pain (17 of 32).

\section{Conclusion}

Chronic pain occurs commonly after a Pfannenstiel incision. Nerve entrapment was found to be a frequent cause of moderate-to-severe pain. 


\section{INTRODUCTION}

The Pfannenstiel incision is praised for its low incidence of incisional hernias (0-2\%) and aesthetically pleasing appearance ever since its introduction in 1900'. A Pfannenstie approach (also termed 'bikini-cut') is frequently used for safe access in pelvic surgery including cesarean deliveries (CD) and gynaecologic interventions. Furthermore, it is also used for an appendectomy, prostatectomy and inguinal hernioplasty ${ }^{2,3}$. Recently, minimally invasive laparoscopic gastrointestinal and urological procedures have utilized Pfannenstiels and its modifications for removal of several organs including colon and kidney ${ }^{4,5}$.

Despite the described advantages, some authors have reported chronic pain associated with entrapment of lower abdominal wall nerves such as the iliohypogastric or the ilioinguinal nerves ${ }^{6-13}$. Although chronic nerve-related postoperative pain is extensively studied in various surgical fields such as axillary surgery, thoracotomy, amputations and inguinal hernia repair ${ }^{14-17}$, data on chronic pain after a Pfannenstiel incision are scarce and knowledge is limited.

The aim of the present study is to estimate prevalence, risk factors and etiology of chronic pain after a Pfannenstiel incision with special attention to nerve entrapment in a large cohort of patients.

\section{PATIENTS AND METHODS}

The study was performed as a combined effort by the surgical and gynaecological departments of the Máxima Medical Center, a teaching hospital in Veldhoven, a city in the south-eastern part of the Netherlands serving a population of approximately 175,000 . All adult women ( $\geq 18$ years) who underwent a primary or secondary CD or an abdominal hysterectomy $(\mathrm{AH})$ using a Pfannenstiel incision between January $1^{\text {st }} 2003$ and December $31^{\text {st }} 2004$ were eligible for this study. Patients were not included if abdominal access was gained via a midline laparotomy, vaginal or laparoscopic assisted techniques. Patients with recurrent Pfannenstiel incisions in 2005 or 2006 were also excluded because a minimal follow-up period of at least one year was deemed important for the aim of the study. In case of previous abdominal surgery 'other than a Pfannenstiel incision' patients were excluded as well, unless a laparoscopic technique was used (e.g. laparoscopic appendectomy). Surgical and gynaecological clinical and outpatient charts were studied and data were collected including age, date of operation, elective versus emergency CD and previous laparoscopic surgery.

In our teaching hospital, a Pfannenstiel incision is generally performed by consultant gynaecologists or senior residents supervised by a consultant according to the following protocol. A 12 to $15 \mathrm{~cm}$ transverse incision is made approximately 2 to $3 \mathrm{~cm}$ cranial to the symphysis pubis, and subcutaneous fat and rectus sheath is diathermally incised. If necessary, the incision is extended laterally by cutting the fibrous sheath containing the aponeuroses of the external, internal oblique and transverse abdominal muscles. The anterior fascia and linea alba are separated from underlying rectus and pyramidalis muscles over the entire distance between symphysis and umbilicus. Abdominal rectus muscles are then separated in the midline followed by division of the preperitoneal fat tissue and the opening of the peritoneum. No retractors are used. Once the abdominal procedure is completed, 2.0 Vycril absorbable running sutures are used to approximate facial and muscle layers. The skin is closed intradermally.

\section{Questionnaire}

All patients meeting study criteria were sent a questionnaire with a pre-stamped envelope by mail in February 2006. All questions concerned a one-month period prior to reception of the questionnaire. A portion of items in the present questionnaire was extracted from three other published questionnaires used in postoperative pain studies (Appendix) ${ }^{17,19,20}$. Patients were asked to report the average frequency and intensity of pain situated close to or in their Pfannenstiel incision using a previously validated 4-point verbal rating scale $\left(\mathrm{VRS}, 1=\right.$ absent, $2=$ mild, $3=$ moderate, $4=$ severe ${ }^{21}$. If patients experienced pain they were offered ten separate pain descriptors that are thought to reflect either a neuropathic or a non-neuropathic origin'19. Women were also instructed to mark the exact location of pain in a schematic drawing (Figure 1). Patients were instructed to measure scar length (in cm's) and asked to report pain-related doctor's consultations, use of pain medication, aggravation of scar pain during a menstrual period, observed bulging of the scar, number of 'Pfannenstiel surgeries', presence of numbness and functional impairment. Patients who did not respond to the first questionnaire were sent a reminder by mail.

In the present study, pain is defined as chronic using 'the International Association for the Study of Pain's definition' (pain persisting beyond the normal tissue healing time, assumed to be three months) ${ }^{22}$. This definition includes the entire spectrum of pain intensities (mild, moderate and severe).

\section{Outpatient assessment}

Only patients with moderate or severe pain complaints as determined by the VRS scale were invited for follow-up at the outpatient department. A standardized evaluation of pain etiology was performed by a team consisting of a resident $(M L)$ and two general surgeons skilled in diagnosing abdominal wall and groin pain pathology (MS or RR) ${ }^{23}$. Pain history was taken with special attention to neuropathic pain, which is traditionally characterized as an activity-induced 'sharp' pain, located at one or both lateral edges of the incision. These painful sensations frequently irradiate towards a labium and/or 


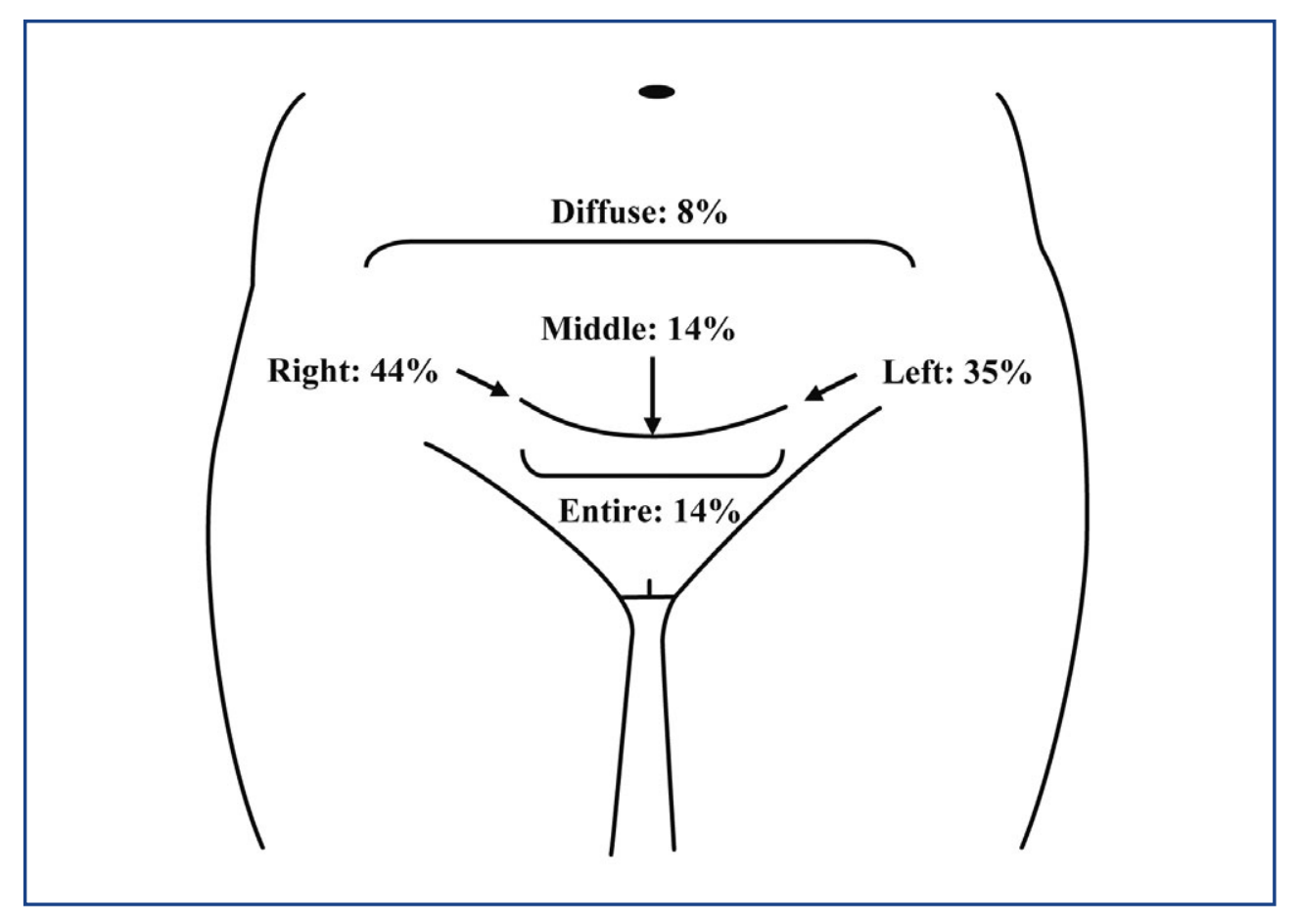

figure 1 Schematic drawing in questionnaire that women used for pain localisation with corresponding results. ( $n=205$, missing data in 18 patients). Pain distribution showed in percentages: at the right end of the scar, left end, entire scar, middle of the scar and diffusely in the lower abdomen. 30 patients reported pain at both lateral ends of the scar. Mean incision length, $\mathrm{cm}(\mathrm{SD}=$ standard deviation $)=13.5(3.4)$.

upper inner thigh. Stretching, upper body torsion or flexion of the hip joint can induce pain by means of traction or compression of an entrapped nerve.

The physical examination includes attention to signs of neurophysiologic disorders such as hypoesthesia, hyperesthesia or allodynia and pain elicitation by direct pressure on a distinct 'trigger point' located along the lateral edge of the abdominal rectus margin. If the pain is considered neuropathic, a fan-shaped deposition of an anaesthetic (10 cc of $1 \%$ Lidocain) is placed around this trigger point and should provide immediate pain relief. In contrast, nociceptive or inflammatory causes may be supposed if these neuropathic signs are absent. Patients were also evaluated by the gynaecologist (LM) if a gynaecological abnormality was suspected as a cause for their pain.

\section{Statistical analysis}

Continuous data were expressed as median with range and were compared using a Mann-Whitney $U$ test. Categorical data are presented as percent frequencies and differences between proportions were compared using a Chi-square test. A univariate logistic regression analysis was performed to test the influence of possible risk factors on chronic pain. Presence of chronic pain was the dependent variable whereas age, follow-up duration, priority of CD, number of Pfannenstiel incisions, numbness, and sca length were used as independent variables. The multivariate model was constructed by backward stepwise selection with entry testing based on significance of score statistics. CD priority was assessed in a multivariate analysis with CD patients only. The limit of statistical significance was set at $\mathrm{p}=0.05$ (two-sided). Analysis was performed using the Statistical Package for the Social Sciences (SPSS), Windows version 12.0.1

\section{RESULTS}

Questionnaire

A total of 872 CD's and 95 AH's using a Pfannenstiel approach was performed during the two year time period. A patient flow chart is depicted in Figure 2 . There were 866 postPfannenstiel patients who were eligible for this study that received a questionnaire. Eventually, 690 patients returned the questionnaire (response rate $690 / 866,80 \%$ ). Demographic and clinical details of both responders as well as non-responders are listed in table 1. Except for priority of CD, these two groups were comparable. A CD was performed in more than $90 \%$ of the women, and an average CD patient was approximately 15 years younger compared to an abdominal hysterectomy patient (35 vs. 50 yrs, $p<0.05$ ). About $25 \%$ of the individuals had received previous surgery using the Pfannenstiel incision

Approximately one third of all patients (223/690,33\%) experienced chronic pain at the incision site during the month prior to assessment (median follow up: 26 months). Pain frequency and intensity are graphically shown in Figure 3 and 4 , respectively. One out of every 12 patients $(61 / 690,8.2 \%)$ experienced pain on regular or continuous basis whereas moderate or severe pain was reported by 61 patients (7.0\%). A total of $8.9 \%$ of the women was impaired in daily activities because of pain intensity (table 2). Both neuropathic (e.g. 'stabbing', 'prickling') and non-neuropathic (e.g. 'nagging', 'pulling') descriptors were chosen in similar quantities ( 27.7 vs. $30.0 \%$, respectively). More than $90 \%$ of the population $(189 / 205,92 \%)$ experienced their pain at the level of the incision, and in $70 \%(132 / 189)$ the pain was located at lateral end(s) of the incisional scar (figure 1).

Table 2 shows medical consumption as reflected by number of pain-related consultations ( $8 \%$ of patients, mostly visiting a general practioner) and intake of pain medication (3\%). The onset of a menstrual cycle exacerbated scar pain in $8.1 \%$ of the women. Mean incision length (SD) was $13.5(3.4) \mathrm{cm}$.

Using multivariate logistic regression analysis, more than two Pfannenstiel incisions $(\mathrm{OR}, 2.92 ; 95 \% \mathrm{Cl}, 1.44-5.93)$ and presence of numbness (OR, 3.01; $95 \% \mathrm{Cl}, 2.05-4.40$ ) 
significantly and independently predicted chronic pain, whereas age, follow-up and scar length did not (table 3). In subgroup multivariate analysis, emergency CD remained a significant factor $(\mathrm{OR}, 1.56 ; 95 \% \mathrm{Cl}, 1.01-2.40)$

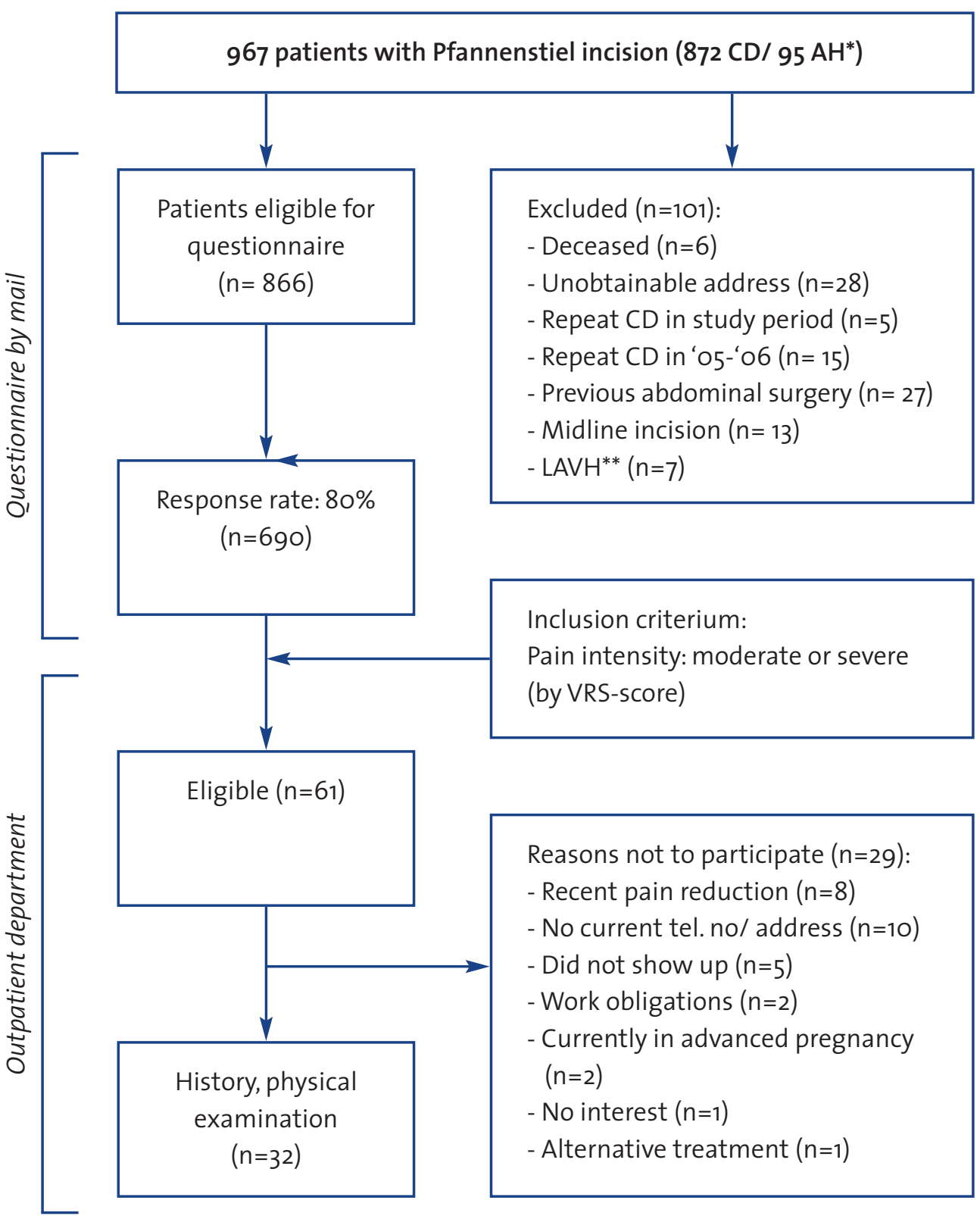

Figure 2 Flow chart of in-/ excluded patients following a Pfannenstiel incision.

${ }^{*} C D=$ Cesarean Delivery, $A H=$ Abdominal Hysterectomy, ${ }^{* *} L A V H=$ Laparoscopic Assisted Vaginal Hysterectomy.

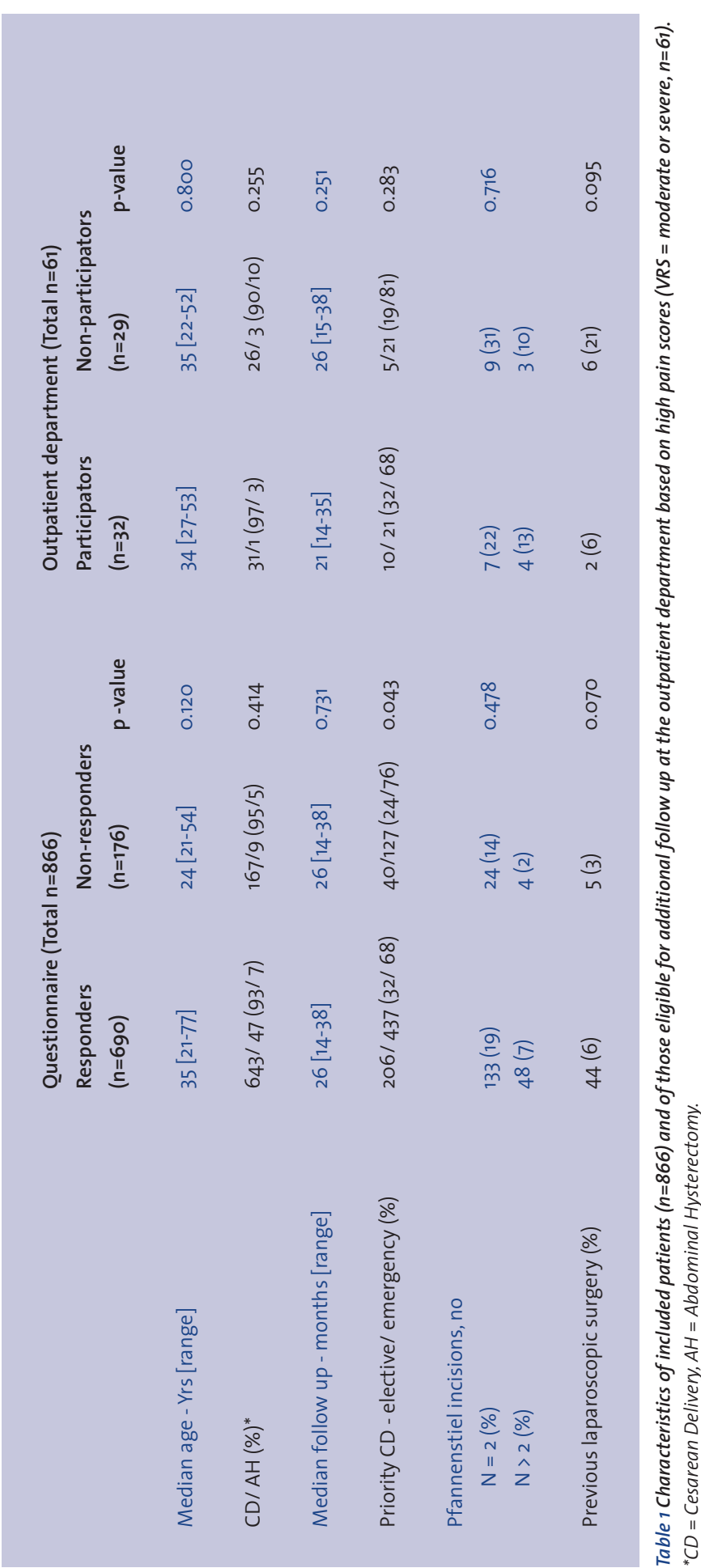

The Pfannenstiel approach as a source of chronic pain 


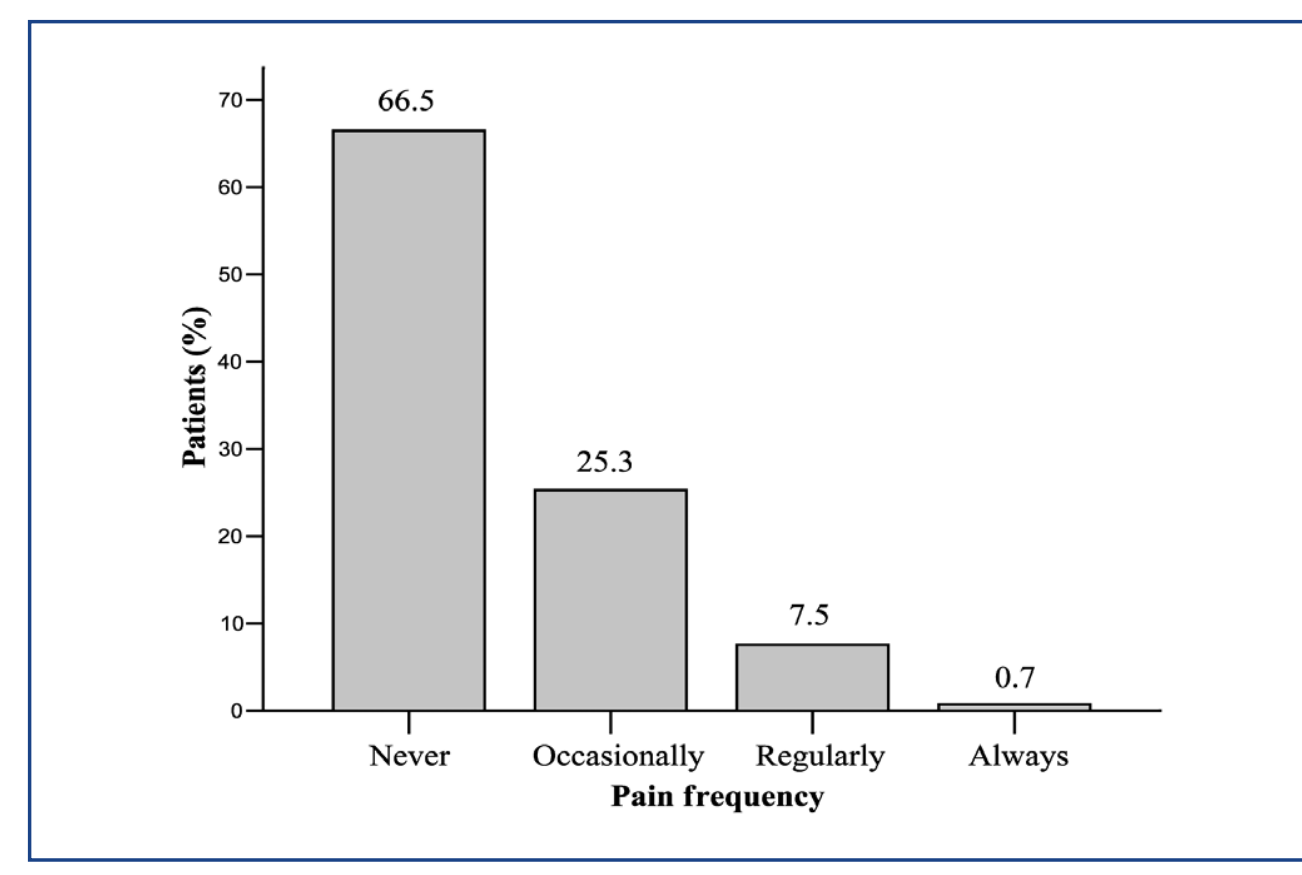

Figure 3 Pain frequency in patients following a Pfannenstiel incision ( $n=689$, one patient missing).

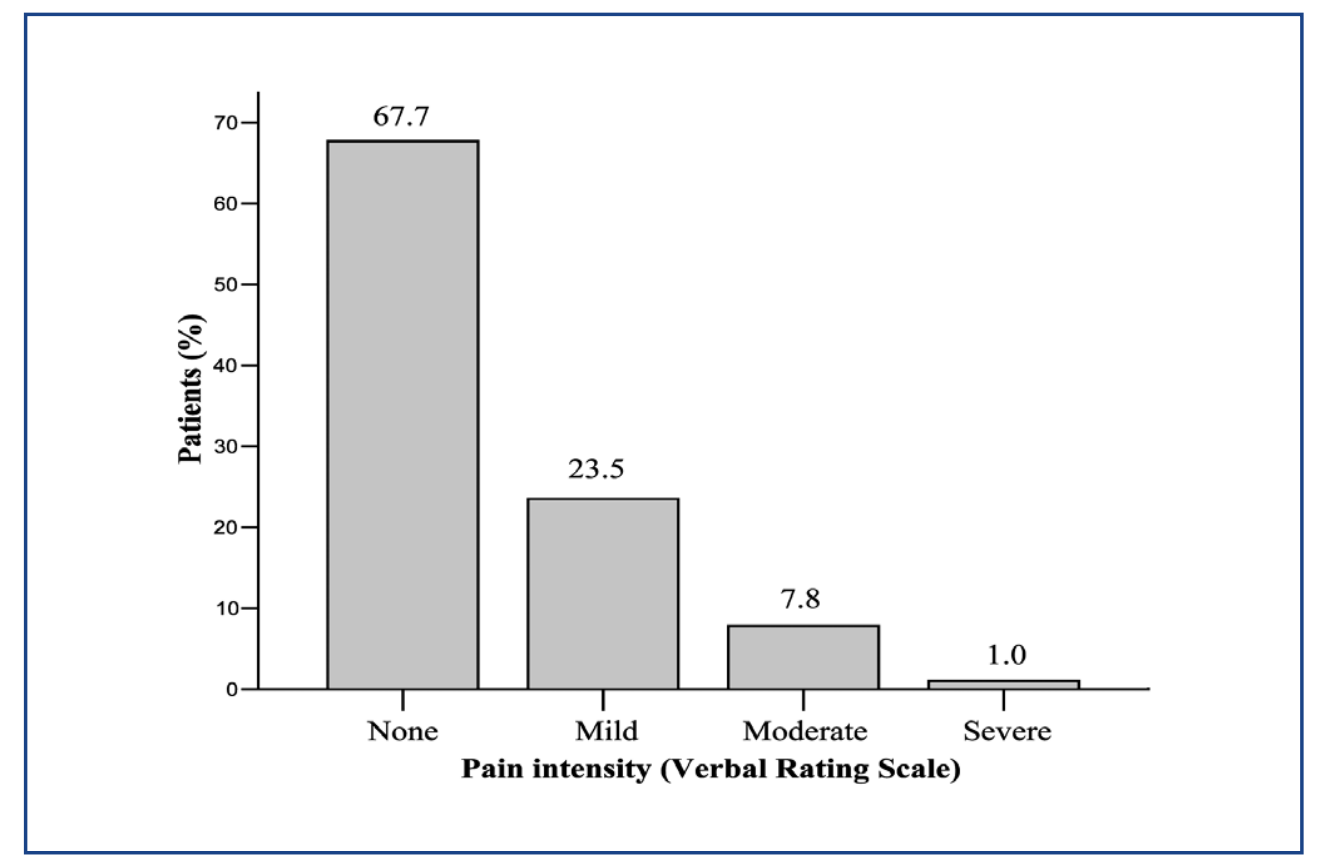

Figure 4 Pain intensity in patients following a Pfannenstiel incision $(n=690)$.

$\begin{array}{ll} & \mathrm{n}(\%) \\ \begin{array}{ll}\text { Previous visits to a physician because of persisting pain* } \\ \quad \text { General Practioner }\end{array} & 32(4.6) \\ \quad \text { Gynaecologist } & 15(2.2) \\ \quad \text { General surgeon } & 5(0.7) \\ \quad \text { Other (Speciality consulted physician unknown) } & 3(0.4) \\ \text { Frequency of pain medication intake* } & \\ \quad \text { Yes, occasionally } & 16(2.3) \\ \quad \text { Yes, regularly } & 5(0.7) \\ \text { Cyclic pain* } & 56(8.1) \\ \text { Bulge noticed* } & 130(18.8) \\ \text { Numbness* } & 199(28.8) \\ \text { Functional impairment } & \\ \quad \text { None } & 628(91.0) \\ \text { Mild } & 45(6.5) \\ \text { Moderate } & 16(2.3) \\ \text { Severe } & 1(0.1)\end{array}$

Table 2 Chronic pain characteristics reported by patients that responded to the questionnaire $(n=690)$. Pain located at the Pfannenstiel incision

\begin{tabular}{|c|c|c|c|c|c|c|}
\hline & \multicolumn{3}{|c|}{ Univariate model } & \multicolumn{3}{|c|}{ Multivariate model } \\
\hline & OR & $(95 \% \mathrm{Cl})$ & $\mathrm{p}$ & OR & $(95 \% \mathrm{Cl})$ & $p$ \\
\hline Age & 1.0 & $(1.0-1.0)$ & 0.079 & - & & \\
\hline Follow up duration & 0.99 & (0.99-1.0) & 0.036 & - & & \\
\hline Emergency CD* & 1.53 & $(1.07-2.20)$ & 0.021 & 1.56 & $(1.01-2.40)$ & $0.020^{*}$ \\
\hline \multicolumn{7}{|c|}{ No of Pfannenstiel incisions } \\
\hline$N=2$ & 1.60 & $(1.07-2.39)$ & 0.020 & 1.27 & $(0.82-1.97)$ & 0.291 \\
\hline$N>2$ & 2.95 & $(1.62-5.37)$ & 0.000 & 2.92 & $(1.44-5.93)$ & 0.003 \\
\hline Numbness & 3.19 & $(2.25-4.51)$ & 0.000 & 3.01 & $(2.05-4.40)$ & 0.000 \\
\hline Scar length & 1.06 & $(1.01-1.11)$ & 0.029 & - & & \\
\hline
\end{tabular}

Table 3 Logistic regression analysis of risk factors predicting chronic pain development following a Pfannenstiel incision ( $n=690)$. "Emergency CD in multivariate analysis among CD patients. 


\section{Outpatient assessment}

All patients with moderate or severe pain $(n=61)$ as determined by the VRS-scoring system were eligible for follow up. As 29 patients did not participate in this assessment for reasons as stated in figure 2, a population of 32 patients was evaluated using an extensive interview and a physical examination. The demographic and clinical details of these patients are shown in table 1. This subgroup forms a representative portion of the entire population. Findings of pain history and physical examination are listed in table 4 .

$\begin{array}{ll} & n(\%) \\ \text { Plan History } & \\ \text { Character } & 23(72) \\ \quad \text { Neuropathic } & 9(28) \\ \quad \text { Non-neuropathic } & \\ \text { Frequency } & 2(6) \\ \quad \text { Occasionally } & 12(38) \\ \quad \text { Regularly } & 20(58) \\ \text { Always } & \\ \text { Course } & 22(68) \\ \quad \text { Constant } & 4(13) \\ \text { Intermittent } & 2(6) \\ \quad \text { Progressive } & 4(13) \\ \text { Decreasing } & 23(72) \\ \text { Other chronic pain syndromes* } & \\ \text { Physical examination } & \\ \text { Bulge } & 1(3) \\ \text { Neurophysiology } & \\ \text { Normal } & 14(44) \\ \text { Hypoesthesia } & 14(44) \\ \text { Hyperesthesia } & 3(9) \\ \text { Allodynia } & 1(3) \\ \text { Trigger point } & 17(53) \\ \text { Nerve block (lidocain 1\%) } & 9(28) \\ \text { Significant pain reduction (10 minutes) } & \\ \text { Persisting total pain reduction (12 months) } & 6(18) \\ & 2(6) \\ & \end{array}$

Table 4 Pain history and physical examination in patients who visited the outpatient department based on high pain scores (VRS $=$ moderate or severe ${ }^{*}, n=32$.

VRS = Verbal Rating Scale, ${ }^{* *}$ Chronic pain syndromes = chronic headache, low back pain, complex regional pain syndrome irritable bowel syndrome, ${ }^{* * *}$ Pain reduction following nerve block after 10 minutes and after 12 months.
Neuropathic pain caused by an entrapment of the iliohypogastric or ilioinguinal nerve was present in 17 patients (17/32,53\%). Nine patients opted for a diagnostic nerve block that led to a significant pain reduction in six of them. The initial pain reduction persisted for at least 12 months in two of these 6 patients. The remaining eight patients refused injection.

A variety of non-neuropathic causes was diagnosed including non-specific diffuse scar pain. Bulges indicating incisional hernias were not found, although one patient presented with bulging of the entire lower abdominal wall due to muscle atrophy. Two patients complained of a 'pulling' pain confined to the midline which was classified as musculotendinous in origin. Keloid formation and fat necrosis produced local scar pain in two other patients. Three additional patients were diagnosed by the gynaecologist with endometriosis, secondary vaginism and primary dysmenorrhoea, respectively. A diagnostic classification of post-Pfannenstiel syndromes is proposed in table 5 .

$\begin{array}{ll} & \mathrm{n}(\%) \\ \text { 1. Neuropathic } & 17(53.1) \\ 2 \text { Non-neuropathic } & \\ \text { Non-gynaecological } & 7(21.9) \\ \text { - Diffuse scar pain } & 2(6.3) \\ \text { - Musculotendinous } & 1(3.1) \\ \text { - Abdominal wall atrophy with bulging } & 1(3.1) \\ \text { - Keloid } & 1(3.1) \\ \text { - Fat necrosis } & \\ & \\ \text { Gynaecological } & 1(3.1) \\ \text { - Endometriosis } & 1(3.1) \\ \text { - Secondary vaginism } & 1(3.1) \\ \text { - Dysmenorrhoea } & \end{array}$

Table 5 Diagnostic classification of patients with chronic pain following a Pfannenstiel incision $(n=32)$.

\section{DISCUSSION}

The current study showed that chronic pain after a Pfannenstiel incision is common. These results are thought valid and representative as $80 \%$ of a large sample size responded to the questionnaire. Even if all non-responders were pain-free, the pain prevalence would still be $26 \%$. As far as we know, the well known international 'Term Breech Trial' is the only study that prospectively assessed pain after both cesarean 
deliveries $(C D)$ and vaginal births $(V B)^{24}$. Based on an intention to treat analysis, they concluded that the total reported pain was similar in both groups (planned CD 21\% vs. planned VB 22.2\%). However, when those patients who actually had a CD $(n=611)$ were compared to those who underwent a VB $(n=306)$, it appeared that CD patients more often complained of abdominal pain (outside $4.7 \%$ / deep $6.2 \%$ / total $10.9 \%$ ) than those after VB (outside 1.6\% / deep 3.9\% / total 5.5\%). In our opinion, this significant difference (by Fisher's exact test) is most probably associated with the surgical abdomina intervention itself and partially scar-related. Another study using questionnaires among a group of patients with 'Pfannenstiels' (93\% of 221 CD patients), identified a $12.3 \%$ lower abdominal pain prevalence after one year, but grade was not reported ${ }^{25}$. Similarly, chronic pain was mentioned by $23 \%$ of patients 5 years after a Pfannenstiel incision, but also not graded $(n=243)^{18}$. Results of these and our study indicate that post-Pfannenstiel pain is common, even after an extended time period. Most women are thought to accept this chronic pain, although one out of twelve patients consulted a physician and received symptomatic medical treatment.

Why do some patients develop severe postoperative pain following a Pfannenstie incision whereas others do not? Previous research identified length of incision as an exclusive factor for pain development ${ }^{18}$. The innervating nerves of the suprapubic area and lower abdominal portions are easily damaged or trapped when the incision is extended beyond lateral edges of the rectus sheath ('danger area'). Moreover, sutures or scar tissue trapping nervous tissue as well as neuroma formation may also result in neuropathic pain. Although the present study could not confirm scar length as a risk factor for pain, $70 \%$ of all women experienced pain in lateral portions of the scar indicating the lateral borders of importance in Pfannenstiel pain mechanism. Other significant chronic pain predictors include regional numbness and recurrent surgery, denominators that were also found important in a recent study evaluating pain after inguinal hernia repair ${ }^{17}$. Increased risk of nerve entrapment after recurrent surgery is likely due to the development of larger areas of fibrosis. An additional risk for pain was an emergency CD compared to an elective operation. One may hypothesize that suboptimal conditions and a stressed surgical technique may enhance iatrogenic traumatisation of nerves and other tissues. The identification of risk factors for postoperative Pfannenstiel pain may be used in optimizing the surgical technique as well as the process of informed consent prior to a surgical procedure.

One may question the value of a questionnaire as a means of detecting the origin of pain, as visceral pain is often difficult to distinguish from parietal pain ${ }^{26}$. Assessment of nerve involvement and other abdominal wall pathology requires physical examination with additional testing performed by specialists trained in recognizing patterns of pain. In the present study a little over half of all patients (32/61) reporting moderate to severe pain were interviewed and underwent a physical examination. Interestingly, more than half of this population (17/32) was diagnosed with entrapment of iliohypogastric or ilioinguinal nerves. With the limited number of examined patients, this percentage $(2.5 \%, 17 / 690)$ approximating a previously reported incidence of $2.3 \%$ is probably an underestimation ${ }^{18}$. Interestingly, two patients with nerve entrapment who received a single lidocain block experienced ongoing pain relief. This phenomenon, also described in postherniorrhaphy groin pain patients, may possibly be explained by the hypothesis of resetting pain stimulation thresholds ${ }^{23}$. Nerve block failure (as in three patients with neuropathic pain symptoms) may indicate that the central nervous system is inflicted as well, eliminating the possibility of pain reduction by blocking peripheral nerves. However, anaesthetic blocks in suspected nerve entrapment syndromes are important as diagnostic and possibly therapeutic measures.

The present inventarisation has identified a variety of diagnoses including several nonneuropathic syndromes following a Pfannenstiel incision. Although not encountered in the present study, cutaneous endometriomas in Pfannenstiel incisions have been previously described ${ }^{27,28}$. Furthermore, lower abdominal pain following abdomina surgery may also be of visceral origin, such as intra-abdominal adhesions associated with frequent complaints of altered bowel habits 29

Although long-term pain after a Pfannenstiel incision has been identified in some earlier studies, the present study demonstrates the large prevalence of Pfannenstiel pain with contributing risk factors ${ }^{30}$. Doctor's delay and unnecessary psychosomatisation of pain complaints, events that frequently occurred in this patient population, may be avoided if awareness of these pain syndromes is increased.

In conclusion, chronic pain following a Pfannenstiel incision is common. Nerve entrapment was found to be a frequent cause of moderate to severe pain.

\section{APPENDIX}

\section{Questionnaire}

1 How often did you experience pain at the lower transverse abdominal scar during the previous month?

Never/ occasionally/ regularly/ always

2 How intense was the pain at the lower transverse abdominal scar during the previous month? None/ mild/ moderate/ severe

3 Please choose one or more of the following characteristics best describing your pain at the lower transverse abdominal scar during the previous month. Burning, stabbing, sharp, electric, prickling, gnawing, pounding, pinching, nagging, pulling

4 Please mark with an $x$ the exact location of your pain during the previous month using the following schematic drawing (figure 1).

5 Please measure the length of the lower transverse abdominal scar. Length scar $=\ldots . . . . . \mathrm{cm}$ 
6 Did you ever visit a physician because of pain complaints at the lower transverse abdominal scar since the operation?

No/ yes, please specify: (name/ speciality physician)

7 Did you take any pain medication because of pain complaints at the lower transverse abdominal scar during the previous month?

No/ yes, occasionally/ yes, regularly

8 Was there any aggravation of pain at the lower transverse abdominal scar during menstruation during the previous month?

No/ yes

9 Have you ever noticed a bulge at the lower transverse abdominal scar? No/yes

10 How many times were you operated on using the lower transverse abdominal incision? Once/ twice/ more than twice

11 Did you notice any numbness of the skin at the lower transverse abdominal scar during the previous month?

No/ yes

12 Were you functionally impaired in your daily activities caused by pain at the lower abdominal scar during the previous month?

Never/ occasionally/regularly/always

13 What was the average functional impairment intensity caused by pain at the lower abdominal scar during the previous month?

None/ mild/ moderate/ severe

\section{REFERENCES}

1 Kisielinski K, Conze J, Murken AH, Lenzen NN, Klinge U, Schumpelick V. The Pfannenstiel or so called "bikini cut": Still effective more than 100 years after first description. Hernia 2004; 8: 177-18

2 Manoharan M, Vyas S, Araki M, Nieder AM, Soloway MS. Concurrent radical retropubic prostatectomy and Lichtenstein inguinal hernia repair through a single modified Pfannenstiel incision: a 3-year experience. BJU Int 2006; 98:341-344

3 Saetta JP, Abel KP. The use of the Pfannenstiel incision in the female with presumed appendicitis. BrJ Clin Pract 1990; 44: 145-147

4 Tisdale BE, Kapoor A, Hussain A, Piercey K, Whelan JP. Intact specimen extraction in laparoscopic nephrectomy procedures: Pfannenstiel versus expanded port site incisions. Urology 2007; 69: 241-244

5 Kessler H, Hohenberger W. Laparoscopic total colectomy for slow-transit constipation. Dis Colon Rectum 2005; 48: 860-861

6 Whiteside JL, Barber MD. Ilioinguinal/iliohypogastric neurectomy for management of intractable right lower quadrant pain after cesarean section: a case report.J Reprod Med 2005; 50: 857-859
7 Melville K, Schultz EA, Dougherty JM. Ilioinguinal-iliohypogastric nerve entrapment. Ann Emerg Med 1990; 19: 925-929

8 Tosun K, Schäfer G, Leonhartsberger N, Herwig R, Pinggera G-M, Bartsch G, Rehder P. Treatmen of severe bilateral nerve pain after Pfannenstiel incision. Urology 2006; 67: 623.e5-6

9 Hahn L. Clinical findings and results of operative treatment in ilioinguinal nerve entrapment syndrome. Br J Obstet Gynaecol 1989; 96:1080-1083

10 Huikeshoven FJ, Dukel L. De bikini-snede, mooi maar niet altijd zonder pijnlijke gevolgen. Ned Tijdschr Geneesk 1998; 142: 1481-483

11 Sippo WC, Burghardt A, Gomez AC. Nerve entrapment after Pfannenstiel incision. Am J Obstet Gynecol 1987; 157: 420-421

12 Sippo WC, Gomez AC. Nerve-entrapment syndromes from lower abdominal surgery. J Fam Pract 1987; 25:585-587

13 Piura B. Nerve entrapment after Pfannenstiel incision (comment and reply). Am J Obstet Gynecol 1989; 161: 499-500

14 Kooijman CM, Dijkstra PU, Geertzen JHB, Elzinga A, van der Schans CP. Phantom pain and phantom sensations in upper limb amputees: an epidemiological study. Pain 2000; 87:33-41

15 Perttunen K, Tasmuth T, Kalso E. Chronic pain after thoracic surgery: a follow-up study. Acta Anaesthesiol Scand 1999; 43:563-567

16 Wallace MS, Wallace AM, Lee J, Dobke MK. Pain after breast surgery: a survey of 282 women. Pain 1996; 66: 195-205

17 Loos MJA, Roumen RMH, Scheltinga MRM. Chronic sequelae of common elective groin hernia repair. Hernia 2007; 11: 169-173

18 Luijendijk RW, Jeekel J, Storm RK, Schutte PJ, Hop WC, Drogendijk AC, Huikeshoven FJ. The low transverse Pfannenstiel incision and the prevalence of incisional hernia and nerve entrapment. Ann Surg 1997; 225: 365-369

19 Bay-Nielsen M, Perkins FM, Kehlet H. Pain and functional impairment 1 year after inguinal herniorraphy: a nationwide questionnaire study. Ann Surg 2001; 233: 1-7

20 Callesen T, Bech K, Kehlet H. Prospective study of chronic pain after groin hernia repair. Br J Surg 1999; 86: 1528-1531

21 Loos MJA, Houterman S, Scheltinga MRM, Roumen RMH. Evaluating postherniorrhaphy groin pain: Visual Analogue or Verbal Rating Scale? Hernia 2007; 11: 169-173

22 Classification of chronic pain. Descriptions of chronic pain syndromes and definitions of pain terms. Prepared by the International Association for the Study of Pain, Subcommittee on Taxonomy. Pain 1986; 3 (Suppl):S1-S226

23 Loos MJA, Roumen RMH, Scheltinga MRM. Classifying postherniorrhaphy pain syndromes following elective inguinal hernia repair. World I Surg 2007; 31: 1760-1765 
24 Hannah ME, Whyte H, Hannah WJ, Hewson S, Amankwah K, Cheng M, Gafni A, Guselle P, Helewa $M$, Hodnett ED, Hutton E, Kung R, McKay D, Ross S, Saigal S, Willan A: Term Breach Trial Collaborative Group. Maternal outcomes at 2 years after planned cesarean section versus planned vaginal birth for breech presentation at term: the international randomized term breach trial. Am J Obstet Gynecol 2004; 191: 917-927

25 Nikolajsen L, Sørensen HC, Jensen TS, Kehlet H. Chronic pain following Caesarean section. Acta Anaesthesiologica Scandinavica 2004; 48: 111-116

26 Mandelkow $H$, Loeweneck $H$. The iliohypogastric and ilioinguinal nerves. Distribution in the abdominal wall, danger areas in surgical incisions in the inguinal and pubic regions and reflected visceral pain in their dermatomes. Surg Radiol Anat 1988; 10: 145-149

27 Daye SS, Barone JE, Lincer RM, Blabey RC, Smego DR. Pfannenstiel syndrome. Am Surg 1993; 59:459-460

28 Blanco R.G, Parithivell V.S, Shah A.K, Abdominal wall endometriomas. Am Jour Surg 2003; 185:596-598

29 Monk BJ, Berman ML, Montz, FJ. Adhesions after extensive gynecologic surgery: clinical significance, etiology, and prevention. Am J Obstet Gynecol 1994; 170: 1396-1403

30 Ducic I, Moxley M, Al-Attar A. Algorithm for treatment of postoperative incisional groin pain after cesarean delivery or hysterectomy. Obstet Gynecol 2006; 108: 27-31 


\section{CHAPTER 4}

Evaluating postherniorrhaphy groin pain: Visual Analogue or Verbal Rating Scale?

Loos MJA, Houterman S, Scheltinga MRM, Roumen RMH

Hernia 2007; 11: 169-173 


\section{Background}

Several tools for pain measurement including a Visual Analogue Scale (VAS) and a Verbal Rating Scale (VRS) are currently used in patients with chronic pain. The aim of the present study was to determine which of these two pain tests performs optimally in patients following groin hernia repair.

\section{Methods}

A questionnaire identified pain level in a cohort of patients that had previously undergone corrective groin hernia surgery. Current pain intensity was graded on a four-point VRS scale (no pain, mild, moderate or severe pain) and on a 100-mm VAS scale ( $0=$ no pain, 100 = unbearable). "Scale failure" (one or both tests not completed correctly) was determined, and cut-off points for the VAS test were calculated by creating the optimum kappa coefficient between both tools.

Results

The response rate was $78.2 \%$ (706/903). Scale failure occurred more often in VAS than in VRS (VAS: $12.5 \%, 88 / 706$ vs. VRS: $2.8 \%, 20 / 706$; P < 0.001). Advanced age was a risk factor for scale failure $(\mathrm{P}<0.001)$. The four categories of VRS corresponded to mean VAS scores of 1, 20,42, and $78 \mathrm{~mm}$, respectively. VAS categories associated with the highest kappa coefficient $(\mathrm{k}=0.78)$ were as follows: $0-8=$ no pain, $9-32=$ mild, $33-71=$ moderate $>71=$ severe pain. VAS scores grouped per VRS category showed considerable overlap. Age and sex did not significantly influence cut-off points.

\section{Conclusions}

Because of lower scale failure rates and overlapping VAS scores per VRS category, the VRS should be favored over the VAS in future postherniorrhaphy pain assessment. If VAS is preferred, the presented cut-off points should be utilized. 


\section{INTRODUCTION}

The introduction of mesh techniques in groin hernia surgery has reduced recurrence rates but has rekindled interest in postherniorrhaphy pain syndromes. Several tools for assessment of pain severity are currently utilized. The McGill Pain Questionnaire ${ }^{1}$ and the Wisconsin Brief Pain Questionnaire ${ }^{2}$ are multidimensional pain questionnaires assessing sensory, affective and evaluative aspects of pain. In contrast, the Visual Analogue Scale (VAS), Verbal Rating Scale (VRS) and Numerical Rating Scale (NRS) are simple unidimensional tests which only rate sensory components of pain and omit affective and psychosocial pain aspects. Researchers often rely on unidimensional systems ${ }^{3}$ as multidimensional questionnaires are generally considered too long and too complicated.

The widely used VAS represents a $100 \mathrm{~mm}$ horizontal line with on the one end written 'no pain' (score o) and on the other end 'unbearable pain' (score 100). Individuals are instructed to put a mark along this line at a position that is currently reflecting their intensity of pain. A VAS test may allow for rapid completion and harbours a high sensitivity. However, its conceptual complexity may result in a high non-compliance rate or scale failure, particularly in elderly patients with cognitive and psychomotor impairments 4 . In contrast, a VRS exists in several versions ranging from a simple 4-point (no pain, mild, moderate or severe pain) to a more complex 15-point list. A VRS excels in simplicity but may lack sensitivity due to its ordinal character ${ }^{4}$.

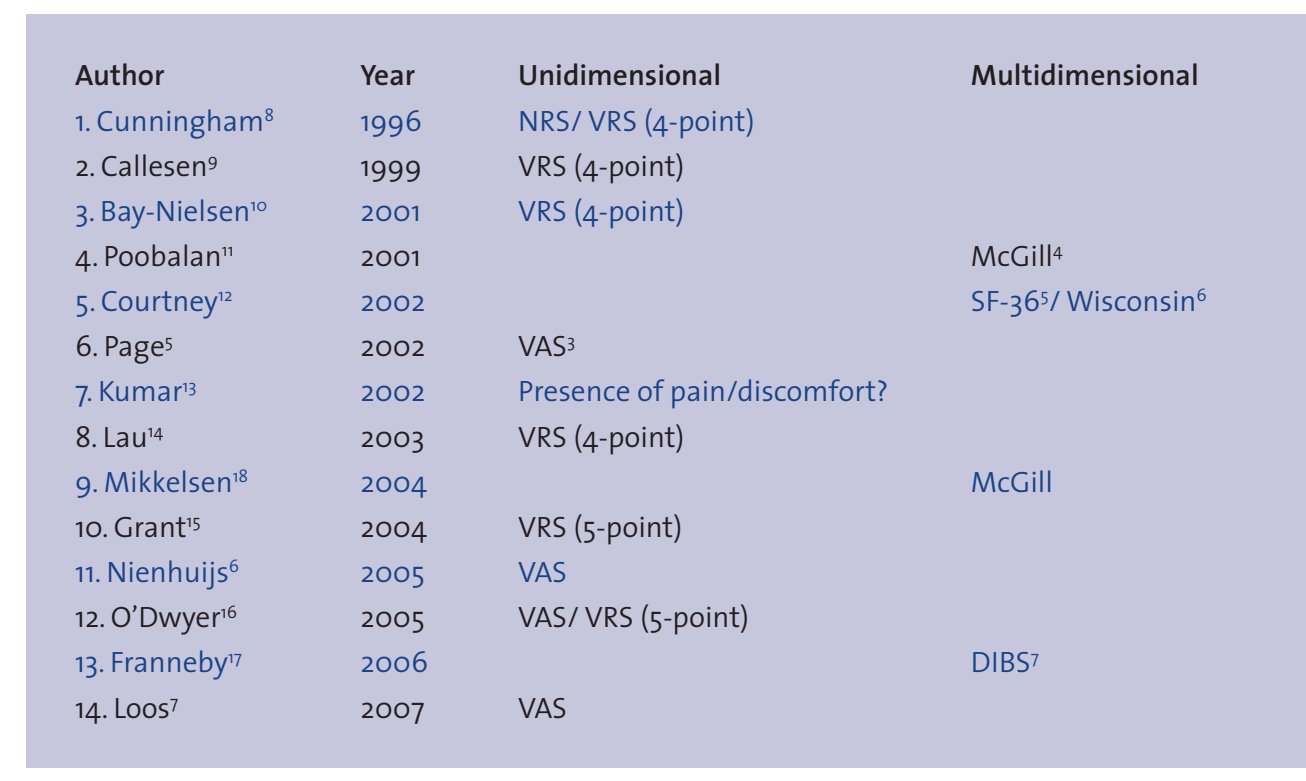

Table 1 Pain measurement tools used in postherniorrhaphy groin pain literature.

NRS = Numerical Rating Scale, VRS = Verbal Rating Scale, VAS = Visual Analogue Scale, McGill = McGill Pain questionnaire, $S F-36=$ Short-Form 36 , Wisconsin $=$ Wisconsin Brief Pain questionnaire, DIBS $=$ Duration-Intensity - Behavior-Scale.
The ideal pain assessment tool should be determined by type of pain and the setting in which it is measured. Unidimensional scales have routinely been employed in the evaluation of postherniorrhaphy groin pain syndromes. Which pain rating scale serves best under these circumstances is unknown since a gold standard is lacking. A random list of groin pain studies and employed pain assessment tools is depicted in Table $1^{5-8}$. Some investigators used VAS tests to investigate groin pain intensity 5,6 . To convert VAS into VRS scores, cut-off points are mandatory. These investigators introduced VAS cutoff points on arbitrary grounds ( $\mathrm{mm}=$ no pain, $<10 \mathrm{~mm}=$ mild, $10-50 \mathrm{~mm}=$ moderate, and $>50 \mathrm{~mm}=$ severe pain $)^{5}$ while other general pain researchers suggested different cut-off points ${ }^{19-22}$

Aim of this study was to evaluate two frequently used pain rating scales (VAS and 4-point VRS) for scale failure, and to determine which test performs better in patients following groin hernia repair.

\section{PATIENT AND METHODS}

The present study was based on pain data obtained from a questionnaire among postherniorrhaphy cases 7 . Patients with a groin hernia repair between January 2000 and August 2005 in the Máxima Medical Center received a postal questionnaire in February 2006. The Máxima Medical Center is a teaching hospital serving a total population of approximately 175,000 inhabitants. Each individual was asked to grade their present groin pain intensity on a 4-point VRS (no pain, mild, moderate or severe pain) followed by a VAS (0-100 $\mathrm{mm}$ ). Brief written instructions regarding the VAS were provided whereas VRS instructions were deemed unnecessary. Results were analyzed for scale failure, which was defined as a situation in which the patient did not complete the pain rating scale, or if the response could not be coded to a unique score.

Statistical analysis was carried out using the Statistical Package for the Social Sciences (SPSS), Windows version 12.0.1. An 'outlier' in Figure 1 was defined as a position between 1.5 and 3 box lengths from the upper or lower interquartile range. Similarly, an 'extreme case' was defined as a position more than 3 box lengths removed from the upper or lower interquartile range. Mean and median VAS scores per VRS category with standard deviation and range were calculated. Frequency distribution of paired VAS-VRS data using different cut-off points for VAS classification was evaluated by means of square contingency tables. Optimal VAS cut-off points were identified in such a way that the VAS-classification concurred optimally with VRS-answers creating the optimal kappa coefficient. Using these optimal cut-off points, a subgroup analysis for sex and age was carried out to detect any difference in kappa. Kappa coefficients were compared after application of Page's cut-off points ${ }^{5}$ ( $0 \mathrm{~mm}=$ no pain, $<10 \mathrm{~mm}=$ mild, $10-50 \mathrm{~mm}=$ moderate, and $>50 \mathrm{~mm}=$ severe pain) on the current data set. 


\section{RESULTS}

A total of 903 eligible adult patients received an elective groin hernia repair in the study period. The questionnaire was returned by 706 individuals (response rate 78.2\%) Ninety-three percent of the patients was male and the mean age was $60 \pm 14 \mathrm{yr}$. A total of $7.6 \%$ was octogenarian ( $\geq 80 \mathrm{yr}$ ).

Scale failure rates are listed in Table 2. Failures were predominantly present in VAS tests compared to VRS [VAS: $12.5 \%$ (88/706) vs. VRS: $2.8 \%$ (20/706), p<0.001]. Five patients failed to complete both tests. Sex did not affect scale failure. In contrast, age appeared to be a significant factor for scale failure as patients who failed to complete a test $(n=103)$ were on an average 7 years older compared to the remainder of the group (67 vs. 60 yrs, $p<0.001)$.

Table 3 shows VRS categories plotted against corresponding VAS scores. Each VRS category displays a wide range of VAS values. Moreover, a considerable overlap between

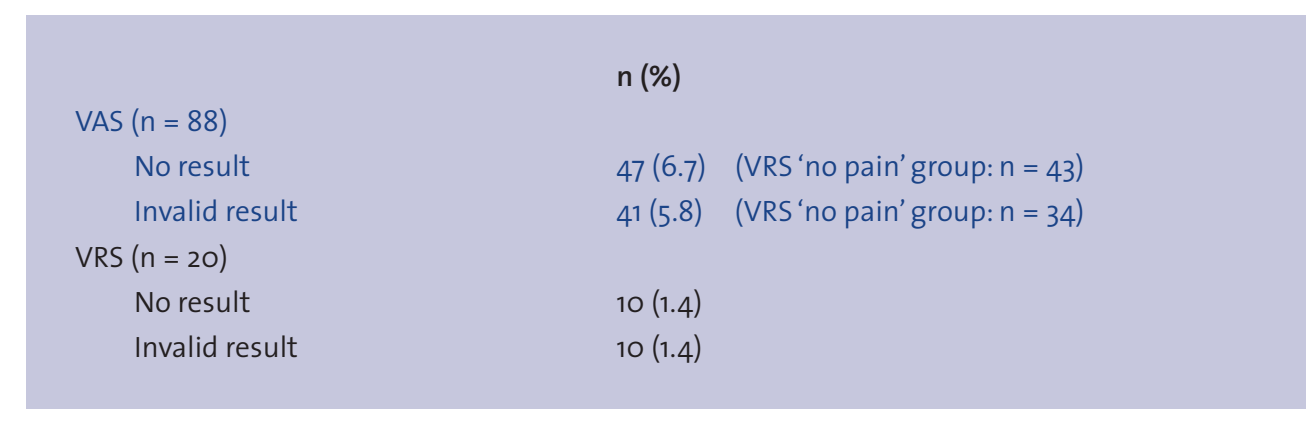

Table 2 Scale failures in VAS and VRS completion in patients with groin hernia repair.

VAS = Visual Analogue Scale, VRS = Verbal Rating Scale, 5 patients failed to complete both scales.

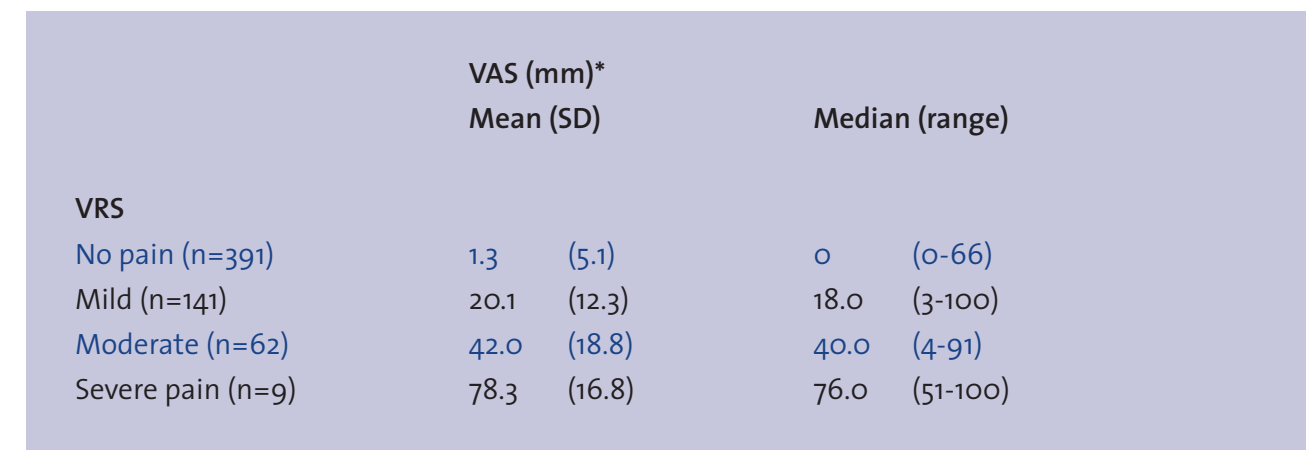

Table 3 Descriptive statistics of VAS and VRS in patients with groin hernia repair.

"VAS = Visual Analogue Scale $(m m)$, VRS = Verbal Rating Scale, SD = standard deviation. categories is observed. The median categorized VAS scores are also depicted in figure 1 showing outliers $\left({ }^{\circ}, n=3\right)$ and extreme cases $\left({ }^{*}, n=18\right)$. Noticeably, all extreme cases except for one were present in the 'no pain' group.

Paired VRS and VAS data are listed in square contingency tables after application of various cut-off points. Table 4 a depicts a VAS subdivision (o- $8=$ no pain, 9-32 = mild, 33-71 = moderate, $>71=$ severe pain), resulting in the highest kappa coefficient $(=0.78)$. With these optimal cut-off points there was no significant difference for the variables sex or age. In contrast, applying cut-off points as proposed by Page et al. ${ }^{5}$ to the present data set $(0 \mathrm{~mm}=$ no pain, $<10 \mathrm{~mm}=$ mild, $10-50 \mathrm{~mm}=$ moderate, and $>50 \mathrm{~mm}=$ severe pain) led to a kappa coefficient of only 0.43 (Table $4 \mathrm{~b}$ ).

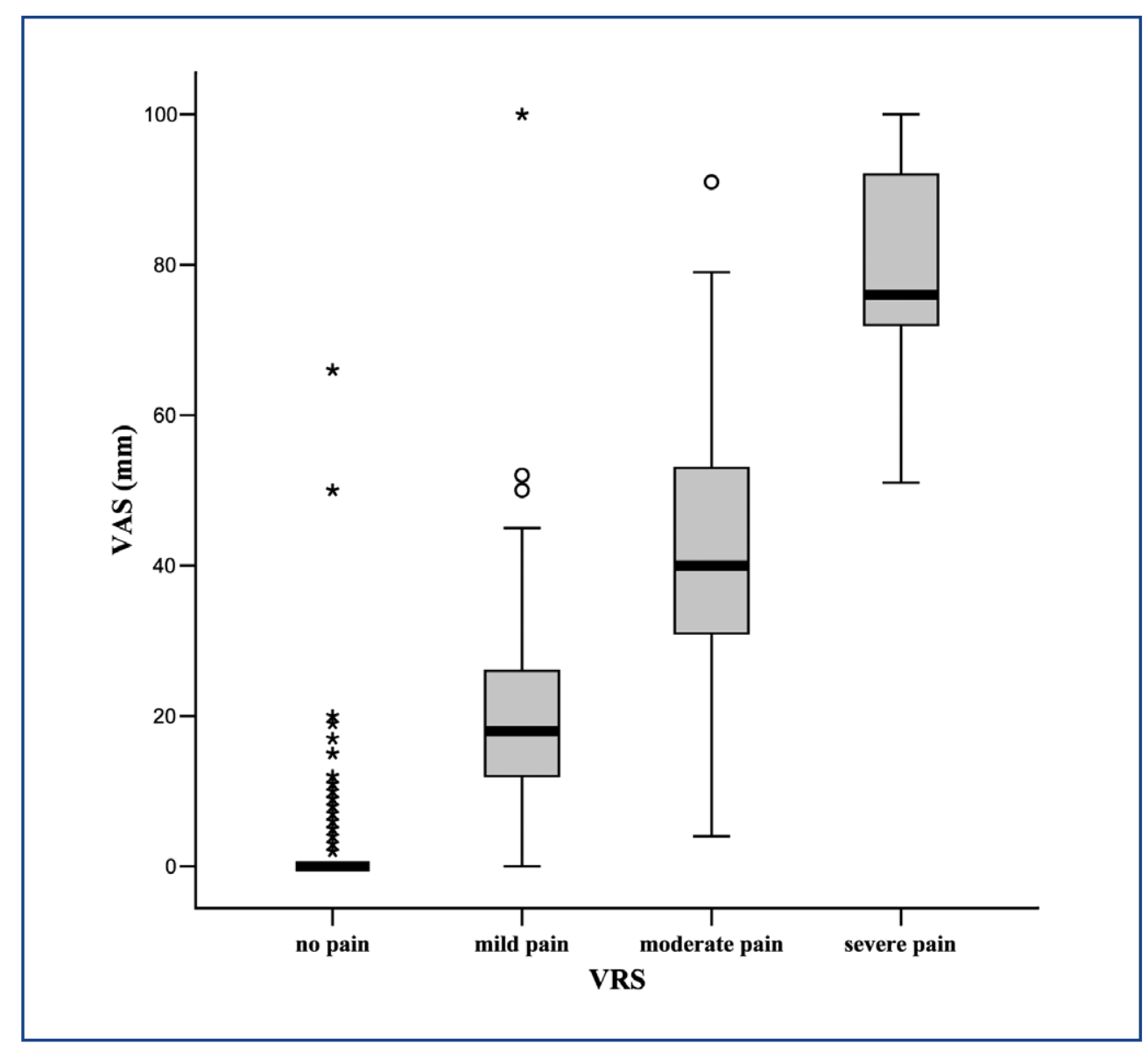

Figure 1 VAS scores ranged per VRS category in patients with groin hernia repair $(n=603)$. Dutlier $=$ between 1.5 and 3 box lengths from the upper or lower interquartile range. "Extreme case $=>3$ box lengths from the upper or lower interquartile range. 


\begin{tabular}{|c|c|c|c|c|c|}
\hline \multicolumn{6}{|l|}{ VAS* } \\
\hline Values & no pain & mild & moderate & severe & Kappa' \\
\hline Cut-off points $(\mathrm{mm})$ & $\begin{array}{l}0-8 \\
(n=388)\end{array}$ & $\begin{array}{l}9-32 \\
(n=143)\end{array}$ & $\begin{array}{l}33-71 \\
(n=61)\end{array}$ & $\begin{array}{l}>71 \\
(n=11)\end{array}$ & \\
\hline \multicolumn{6}{|l|}{ VRS* } \\
\hline No pain $(n=391)$ & 372 & 17 & 2 & o & 0.78 \\
\hline Mild $(n=141)$ & 13 & 113 & 14 & 1 & \\
\hline Moderate $(n=62)$ & 3 & 13 & 43 & 3 & \\
\hline Severe $(n=9)$ & o & o & 2 & 7 & \\
\hline
\end{tabular}

Table 4a Optimal VAS cut-off points in patients with groin hernia repair who completed the questionnaire $(n=603)$.

*VAS = Visual Analogue Scale (mm), VRS = Verbal Rating Scale, 'Kappa coefficient.

\begin{tabular}{|c|c|c|c|c|c|}
\hline \multicolumn{6}{|l|}{$\mathrm{VAS}^{*}$} \\
\hline Values & no pain & mild & moderate & severe & Карра' \\
\hline Cut-off points (mm) & $\begin{array}{l}\circ \\
(n=341)\end{array}$ & $\begin{array}{l}1-9 \\
(n=51)\end{array}$ & $\begin{array}{l}10-50 \\
(n=179)\end{array}$ & $\begin{array}{l}>50 \\
(n=32)\end{array}$ & \\
\hline \multicolumn{6}{|l|}{ VRS* } \\
\hline No pain $(n=391)$ & 341 & 34 & 15 & 1 & 0.43 \\
\hline Mild $(n=141)$ & 0 & 14 & 125 & 2 & \\
\hline Moderate $(n=62)$ & o & 3 & 39 & 20 & \\
\hline Severe $(n=9)$ & o & o & o & 9 & \\
\hline
\end{tabular}

Table 46 VAS cut-off points as used in groin pain literature [5] $(n=603)$.

"VAS = Visual Analogue Scale (mm), VRS = Verbal Rating Scale, 'Kappa coefficient.

\section{DISCUSSION}

Several tools for pain measurement including a Visual Analogue Scale (VAS) and a Verbal Rating Scale (VRS) are currently used in patients with chronic pain. Ideally a tool is simple, sensitive and reproducible. In the present study determining intensity of postherniorrhaphy pain, both tests have been examined for simplicity by assessing their failure rate. The VAS failure rate appeared to be significantly higher compared to the VRS. This may have been affected by the order in which the scales were presented, since the highest VAS non-compliance rate was in the VRS 'no pain' group. However, comparable scale failure rates ranging from 10.0 to $14.1 \%$ (VAS) and 0.0 to $0.5 \%$ (VRS) have been reported in the literature 3.4 . Our study identified advanced age as a risk factor for
VAS scale failure. In a previous pain study evaluating various pain rating scales, mental and motor impairment were also identified as relative risk factors associated with scale failure ${ }^{4}$. The lowest scale failure in postherniorrhaphy groin pain patients can thus be attained using a VRS.

Apart from a mandatory simplicity, any pain test must also possess a high sensitivity. VAS tests are inherently associated with a higher sensitivity when compared to a VRS However, in cross-sectional pain assessment studies this advantage also poses analytical difficulties. Application of cut-off points is mandatory in order to convert VAS into VRS scores. VAS cut-off points were introduced at an arbitrary level in one postherniorrhaphy groin pain study5. After application of both VAS and VRS tests on a comparable cohort of postherniorrhaphy groin pain patients, the present study revealed totally different cut-off points with higher kappa values. Moreover, our results agreed with other pain studies assessing patients with a stroke, laparotomy or knee surgery (o $\mathrm{mm}$ = no pain, $<30 \mathrm{~mm}=$ mild, $30-70 \mathrm{~mm}=$ moderate and $>70 \mathrm{~mm}=$ severe pain $)^{19-22}$. Thus, with employment of the present cut-off points, the best possible interpretation of VAS scores can be obtained.

Which factors determine level of VAS cut-off points? The present study did not reveal any age or sex-related VAS scale variation in concert with others ${ }^{20,22}$. However, cut-off points are known to be influenced by pain experience and etiology. A study among 80 patients recovering from spinal cord injury demonstrated that chronic pain of neuropathic etiology is associated with higher cut-off points compared to nociceptive pain ${ }^{22}$. Patients with postherniorrhaphy pain frequently suffer from neuropathic pain concurring with the need for upgrading cut-off points ${ }^{23}$.

There are considerable inter-individual differences in the way patients grade their pain intensity on a VAS. Wide ranges with outliers and extreme cases in the 'no pain, mild and moderate pain' categories resulted in a considerable overlap. For example, three cases with each different VRS scores (mild, moderate and severe) marked their VAS at $52 \mathrm{~mm}$. For these individuals identical VAS scores represented entirely different pain intensities. In accordance with a previous study this suggests that VAS scores are not interchangeable with VRS results ${ }^{22}$. To simplify the matter, Collins et al. tried to investigate what moderate pain is in millimetres on the VAS. 1080 cases (with both VAS and 4-point VRS scores) were taken from eleven randomized controlled trails investigating the analgesic effects of various drugs on postoperative pain ${ }^{20}$. They suggested grading an estimate of $>30 \mathrm{~mm}$ on a VAS as moderate or severe pain since $85 \%$ of all patients who reported moderate pain and $98 \%$ of those who reported severe pain on a 4-point VRS would be included. However, this statement also implies acceptance of over- and underestimation of pain intensity as well, which is certainly not desirable in clinical practice. Therefore, VAS data should not be labelled with VRS categories for individual pain assessment.

Reproducibility is another quality a test should exhibit. Unfortunately, the present study 
did not contain sequential ratings making a test-retest reliability analysis impossible. Previous studies showed that rapid repeated VAS assessments frequently result in different ratings as opposed to the more consistent VRS 21,22. In follow up pain intensity measurements the VRS is also preferable over the VAS

In conclusion, a higher scale failure was present using the Visual Analogue Scale compared to the Verbal Rating Scale in a large cohort of patients following corrective groin hernia surgery. The VAS can be categorized in VRS scores using more optimized cut-off points ( $<10 \mathrm{~mm}=$ no pain, $10-30 \mathrm{~mm}=$ mild pain, $31-70 \mathrm{~mm}=$ moderate pain and $>70 \mathrm{~mm}=$ severe pain) compared to those used in previous groin pain research. VAS scores are not interchangeable with VRS scores due to considerable overlap. The VRS should therefore be favoured over the VAS in future postherniorrhaphy pain assessment.

\section{REFERENCES}

1 Melzack R. The McGill Pain Questionnaire: major properties and scoring methods. Pain 1975; 1: $277-299$

2 Daut RL, Cleeland CS, Flanery RC. Development of the Wisconsin Brief Pain questionnaire to assess pain in cancer and other diseases. Pain 1983; 17: 197-210

3 Briggs M, Closs JS, Phil M. A descriptive study of the use of visual analogue scales and verbal rating scales for the assessment of postoperative pain in orthopaedic patients. J Pain Sympt Man 1999; 18: 438-446

4 Herr KA, Spratt K, Mobily PR, Richardson G. Pain intensity assessment in older adults. Use of experimental pain to compare psychometric properties and usability of selected pain scales with younger adults. Clin J Pain 2004; 20: 207-219

5 Page B, Paterson D, Young D, O'D wyer PJ. Pain from primary inguinal hernia and the effect of repair on pain. Br J Surg 2002; 89: 1315-1318

6 Nienhuijs SW, Boelens O, Strobbe LJA. Pain after anterior hernia repair. J Am Coll Surg 2005, 200: $885-889$

7 Loos MJA, Roumen RMH, Scheltinga MRM. Chronic sequelae of common elective groin hernia repair. Hernia 2007; 11: 169-173

8 Cunningham J, Temple WJ, Mitchell P, Nixon JA, Preshaw RM, Hagen NA. Cooperative hernia study: pain in the postrepair patient. Ann Surg 1996; 224:598-602

9 Callesen T, Bech K, Kehlet H. Prospective study of chronic pain after groin hernia repair. Br J Surg 1999; 86: 1528-1531

10 Bay-Nielsen M, Perkins FM, Kehlet H. Pain and functional impairment 1 year after inguinal herniorraphy: a nationwide questionnaire study. Ann Surg 2001; 233:1-7

11 Poobalan AS, Bruce J, King PM, Chambers WA, Krukowski ZH, Smith WC. Chronic pain and quality of life following open inguinal hernia repair. Br J Surg 2001; 88: 1122-1126
12 Courtney CA, Duffy K, Serpell MG, O'Dwyer PJ. Outcome of patients with severe chronic pain following repair of groin hernia. Br J Surg 2002; 89: 1310-1314

13 Kumar S, Wilson RG, Nixon SJ, Macintyre IM. Chronic pain after laparoscopic and open mesh repair of groin hernia. Br J Surg 2002; 89: 1476-9

14 Lau H, Patil NG, Yuen WK, Lee F. Prevalence and severity of chronic groin pain after endoscopic totally extraperitoneal inguinal hernioplasty: Surg Endosc 2003; 17: 1620-3

15 Grant AM, Scott NW, O'Dwyer PJ, on behalf of the MRC Laparoscopic Groin Hernia Trial Group. Five year follow-up of a randomized trial to asses pain and numbness after laparoscopic or open repair of groin hernia. Br I Surg 2004; 91: 1570-1574

16 O'Dwyer PJ, Kingsnorth AN, Molloy RG, Small PK, Lammers B, Horeyseck G. Randomized clinical trial assessing impact of a lightweight or heavyweight mesh on chronic pain after inguinal hernia repair. Br J Surg 2005; 92: 166-70.

17 Franneby U, Sandblom G, Nordin P, Nyren O, Gunnarsson U. Riskfactors for long-term pain after hernia surgery. Ann Surg 2006; 244: 212-9

18 Mikkelsen T, Werner MU, Lassen B, Kehlet H. Pain and sensory dysfunction 6 to 12 months after inguinal herniotomy. Anesth Analg 2004; 99: 146-151

19 Jönsson A-C, Lindgren I, Hallström B, Norrving B, Lindgren A. Prevalence and intensity of pain after stroke: a population based study focusing on patients' perspectives. J Neurolog. Neurosurg. Psychiatry 2006; 77: 590-595

20 Collins SL, Moore RA, McQuay HJ. The visual analogue pain intensity scale: what is moderate pain in millimetres? Pain 1997; 72: 95-97

21 Jensen MP, Chen C, Brugger AM. Interpretation of Visual Analog Scale Ratings and change scores: a reanalysis of two clinical trial of postoperative pain. J Pain 2003; 4: 407-414

22 Lund I, Lundeberg T, Sandberg L, Norrbrink Budh, Kowalski J, Svensson E. Lack of interchangeability between visual analogue and verbal rating pain scales: a cross sectional description of pain etiology groups. BMC Medical Research Methodology 2005; 5:31

23 Loos MJA, Roumen RMH, Scheltinga MRM. Classifying postherniorrhaphy pain syndromes following elective inguinal hernia repair. World I Surg 2007; 31: 1760-5 


\section{CHAPTER 5}

Classifying postherniorrhaphy pain syndromes following elective groin hernia repair.

Loos MJA, Roumen RMH, Scheltinga MRM

World J Surg 2007; 31: 1760-1765 
ABSTRACT

\section{Background}

Chronic postherniorrhaphy pain is diverse in origin. The aim of our study was to classify postherniorrhaphy pain syndromes following elective inguinal hernia repair.

Methods

All patients with an elective inguinal hernia repair performed between January 2000 and August 2005 received a questionnaire evaluating chronic inguinal pain (Visual Analogue Scale, VAS 0-10). Patients with moderate to severe pain complaints (VAS score z3) were invited for an interview and an outpatient department physical examination.

Results

A total of 2,164 cases underwent an elective hernia repair and received the questionnaire; 1,766 individuals responded (response rate: $81.6 \%$ ). Moderate to severe pain was present in 211 patients (11.9\%). Follow-up was performed in 148 patients. Three separate groups of diagnoses were identified. Group I: neuropathic pain $(n=72)$ indicating inguinal nerve damage; group II: non-neuropathic pain $(n=40)$ due to an array of diagnoses including periostitis $(n=18)$ and recurrent hernia $(n=13)$; and group III: a tender spermatic cord and/or a tight feeling in the lower abdomen $(n=43)$.

\section{Conclusions}

Chronic pain following elective hernia repair is common and diverse in etiology but may allow for a classification contributing to the development of tailored treatment regimens. 


\section{INTRODUCTION}

Chronic pain following elective inguinal hernia repair is common. Approximately 14 to 54 per cent of patients still experience some degree of inguinal pain several years after 'successful' surgery ${ }^{1-6}$. Moreover, up to 21 per cent of patients is functionally impaired in work or leisure activities ${ }^{1,2}$. One per cent of individuals suffering from pain after open repair is eventually referred to a specialized pain clinic, as is 0.4 per cent after laparoscopic hernia repair?

Efforts have been made to clarify the etiology of these postoperative pain syndromes using pain descriptors in questionnaires ${ }^{2,3}$. Neuropathic symptomatology was more often present compared to non-neuropathic descriptors suggesting a significant nerverelated contribution to pain. However, this approach only allows for a limited insight in underlying etiology. A complete physical examination possibly supported by additional testing may provide answers in the quest for a correct diagnosis and tailored treatment regimens.

Aims of the present study were to classify postherniorrhaphy pain syndromes following elective inguinal hernia repair

\section{DEFINITIONS}

Some authors have attempted to classify inguinal pain after hernia repai ${ }^{8,12}$. In the present study it was decided to make a distinction between neuropathic and non-neuropathic (nociceptive) causes of pain as suggested by Amid ${ }^{12}$.

Neuropathic pain is characterized as an activity-induced sharp pain, located in proximity to the inguinal scar. The pain frequently radiates towards scrotum, labium and/or upper inner thigh. Upper body stretching or twisting and/or hip joint flexing may cause pain due to nerve traction or compression. Physical examination often reveals signs of a disturbed neurophysiologic equilibrium including hypoesthesia, hyperesthesia or allodynia. A distinct trigger point situated in or close to the scar may cause pain following stimulation, e.g. after palpation. A local anaesthetic nerve block can possibly act as a diagnostic and (temporary) therapeutic agent. The complex of symptomatology is thought to be caused by an entrapment of ilioinguinal, iliohypogastric or genital branches of the genitofemoral nerves. Suture material, staples or tacks, perineura fibrosis or prosthetic material are all implicated as well as accidental iatrogenic nerve damage possibly causing a neuroma.

In non-neuropathic causes of inguinal pain after hernia repair, other conditions are responsible for symptomatology including residual/ recurrent hernias, hip pathology, periostitis pubis, etc. All nerves are usually intact. These definitions are applicable in the following text.

\section{PATIENTS AND METHODS}

The study was conducted in the Máxima Medical Center, a teaching hospital serving approximately 350,000 inhabitants in the Eindhoven and Veldhoven region, The Netherlands. Patients were eligible for study if they reported moderate or severe pain (Visual Analogue Scale, VAS $\geq 3$, range $O=$ no pain, $10=$ unbearable pain) as identified by a recent questionnaire study (figure 1$)^{1}$.

Eligible patients were contacted and invited at the Surgical Outpatient Department for a standardised interview and physical examination. Current pain intensity was then again tested using a VAS-score. Patients received a local injection of $10 \mathrm{cc}$ lidocainhydrochlorid $1 \%$ (Lidocain ${ }^{\circledR}$ ) if the combination of patient's history and physical examination (trigger point) suggested pain of neuropathic origin. If a non-neuropathic origin of pain was suspected, the diagnostic approach depended on the suggested diagnosis. For instance, if a periostitis was diagnosed, patients received a local injection containing $5 \mathrm{cc}$ lidocain and $40 \mathrm{mg}$ methylprednisolonacetaat $40 \mathrm{mg} / \mathrm{ml}$ (depo-medro ${ }^{\otimes}=$ corti $^{-}$ costeroid) at the site of maximal pain intensity. Additional imaging techniques including ultrasound, CT-scans, or Magnetic Resonance Imaging were performed if deemed necessary. Following a 10 minute equilibrium period after injection, this regimen's efficacy was evaluated using a VAS score.

\section{RESULTS}

\section{Demographic and pain characteristics}

Figure 1 describes patient inclusion. A total of 211 patients (11.9 per cent) was eligible for study as dictated by a VAS-score $\geq 3$. Sixty-three patients did not visit the outpatient department for reasons stated in figure 1, leaving 148 patients (8.4 per cent) for analysis. The mean age of participants was forty years, with the majority being male ( 87.2 per cent, table 1). Most hernia operations were done by open techniques ( 76.4 per cent, mainly Lichtenstein) whereas almost one quarter of patients (23.6 per cent) was treated using a laparoscopic method (TEP 12.8 per cent, TAPP 10.8 per cent).

Pain history of the study population is listed in Table 2. Almost 90 per cent reported groin pain prior to corrective surgery. However, the present postoperative pain level was judged comparable or worse by half of the patients. Nearly always the pain had started directly after surgery, and its severity was considered by 28 patients ( 18.9 per cent) to be progressive. More than half of the individuals was constantly suffering from pain. Othe chronic pain syndromes (chronic headache, low back pain etc) were observed in 31.8 per cent of patients. 
Overall 26 male patients (20.1 per cent) reported a bothersome or even invalidating sensation during or after ejaculation, which was frequently described as 'burning' or 'stabbing'. One patient mentioned a worrisome feeling of mechanical obstruction during ejaculation. Most of these patients (16/26) had neuropathic pain complaints as well.

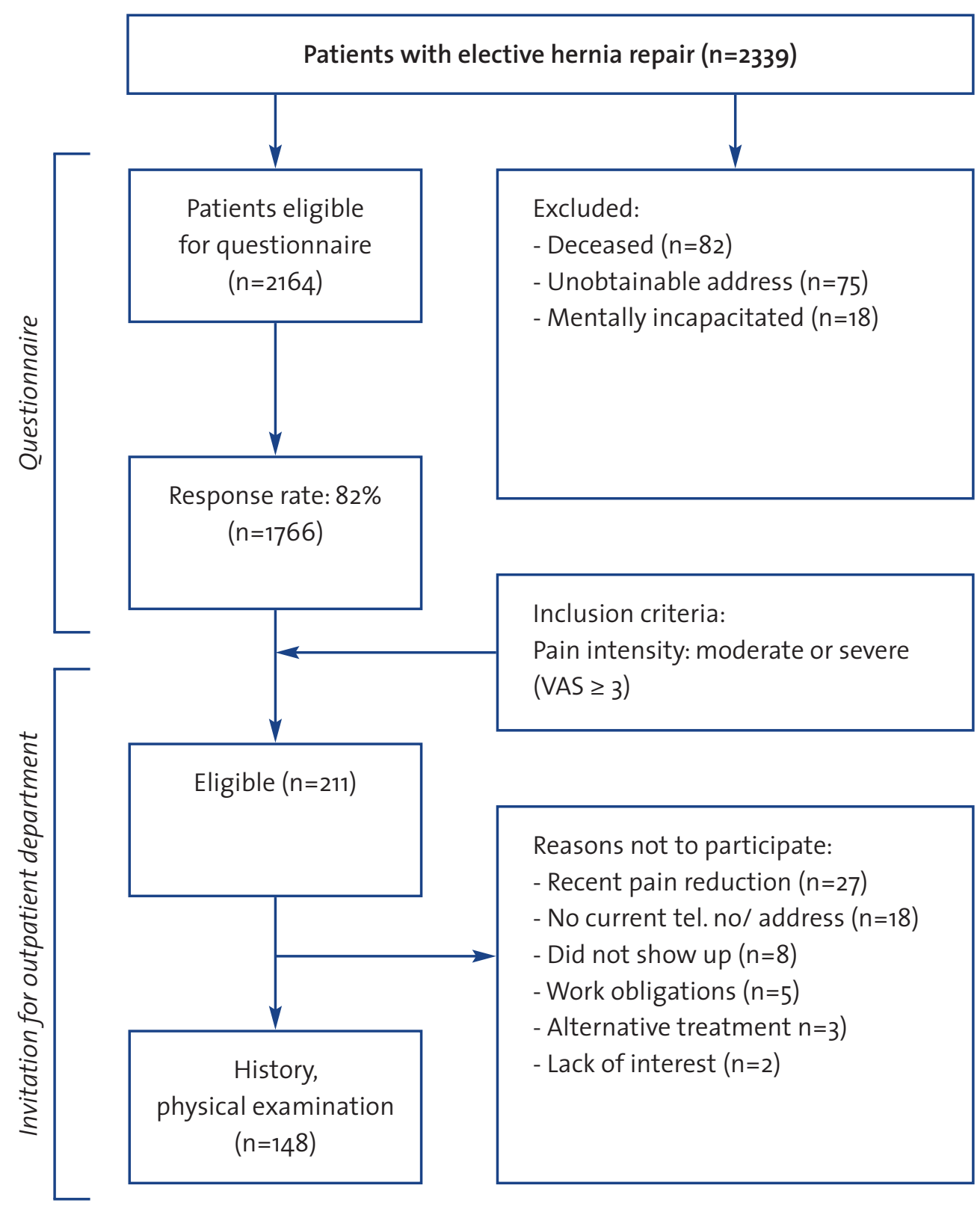

Figure 1 Flow chart of identified pain patients following an elective inguinal hernia repair.
Eighteen men complained of increasing inguinal pain during an erection. Testicular pain was mentioned by 17 patients. Not all patients with testicular pain had ejaculatory complaints, or a painful erection. A direct postoperative onset of impotence was mentioned by three patients.

\section{Physical examination}

Findings on physical examination are listed in table 3 . Inspection revealed bulges in 8.8 per cent of patients. Palpation unveiled a distinct trigger point in or around the scar in the majority of patients (46.6 per cent). Moreover, the pubic tubercle was painful in 12.2 per cent of patients. Neurophysiologic abnormalities were frequently observed. Hypoesthesia was diagnosed in 95 patients, whereas hyperesthesia was present in eleven cases. No patient showed signs of allodynia.

\section{Proposed classification}

\section{Group I: Neuropathic pain}

A classification including different causes of pain is provided in table 4. Pain was judged neuropathic in nearly half of the patients ( $n=72,46.5$ per cent). They all complained of an activity-induced sharp pain combined with a trigger point and signs of a neurophysiologic disequilibrium. Eleven patients showed hyperesthesia. All patients were offered a peripheral nerve block with $10 \mathrm{cc}$ lidocain, and 51 patients agreed with this nerve block. The remainder of the group did not value their pain serious enough $(n=14)$, had previously received a successful nerve block $(n=2)$, showed contra-indications (e.g. bleeding disorders, $n=2)$, or were scared of needles $(n=3)$. Eighty percent of all patients receiving a local block $(n=41)$ reported pain relief (VAS-scores $>50$ per cent lower). Pain relief was

$\begin{array}{ll} & \mathrm{n}(\%) \\ \text { Mean age - } \mathrm{Yr} \text { [range] } & 40[22-69] \\ \text { Sex ratio male/female } & 129 / 19(87.2 / 12.8) \\ \text { Surgical technique } & \\ \quad \text { Lichtenstein } & 103(69.6) \\ \text { Shouldice } & 10(6.8) \\ \text { TEP* } & 19(12.8) \\ \text { TAPP } & 16(10.8) \\ \text { Surgery for recurrent hernia } & 38(25.7) \\ \text { Bilateral hernia repair } & 32(21.6) \\ \text { Median follow up - Months [range] } & 46[3-300]\end{array}$

Table 1 Demographic and operative characteristics of patients with chronic postherniorrhaphy pain who visited the outpatient department $(n=148)$. Values between parentheses are percentages, unless otherwise specified. the outpatient department $(n=148)$. Values between parentheses are
${ }^{*} T E P=$ Total Extra Peritoneal, TAPP $=$ Trans Abdominal Pre Peritoneal. 
not attained in the remaining ten patients. In one patient meralgia paresthetica was present.

\section{Group II: Non-neuropathic pain}

Non-neuropathic causes of pain were detected in forty individuals. In 18 patients a periostitis pubis was diagnosed. On examination their pain was clearly situated on the pubic tubercle, possibly as a result of an incorrectly positioned deep suture. Eight patients with a suspected periostitis received an injection with lidocain and corticos-

$\begin{array}{ll} & \mathrm{n}(\%) \\ \text { Inguinal pain prior to surgery } & 132(89.2) \\ \text { Postoperative inguinal pain comparable or worse } & 74(50.0) \\ \text { Current VAS-score - Median (25-75\%) } & 4.0(2.5-5.5)^{*} \\ \text { Time of onset after surgery - Median [range] } & 0[0-60] \\ \text { Duration of pain - Median [range] } & 31[3-300] \\ \text { Frequency } & \\ \quad \text { Occasionally } & 18(12.2) \\ \text { Regularly } & 52(35.1) \\ \text { Always } & 77(52.0) \\ \text { Course of pain } & 85(57.4) \\ \quad \text { Intermittent } & 13(8.8) \\ \text { Progressive } & 28(18.9) \\ \text { Decreasing } & 21(14.2) \\ \text { Location } & \\ \text { Groin/ pubic region } & 134(90.5) \\ \text { Scrotum/labium } & 24(16.2) \\ \text { Medial thigh } & 25(16.9) \\ \text { Lower abdomen } & 13(8.8) \\ \text { Pain triggers } & \\ \text { Erection } & 17(13.2) \\ \text { Ejaculation } & 25(19.4) \\ \text { Chronic pain syndromes** } & 47(31.8) \\ \text { Working status } & \\ \text { Working } & 73(49.3) \\ \text { Disabled (workers' compensation) } & 40(27.0) \\ \text { Retired } & 27(18.2) \\ \text { None } & 7(4.7) \\ & \end{array}$

Table 2 Pain characteristics of postherniorrhaphy patients $(n=148)$.

Values between parentheses are percentages, unless otherwise specified. *VAS-score as measured at outpatient department. "Chronic pain syndromes = chronic headache, back pain, rheumatoid arthritis, fibromyalgia, irritable bowel syndrome. teroids in tissue overlying the painful periosteum for diagnostic purposes. All eight participants reported pain reduction of more than 50 per cent on their VAS-score. An injection was refused by ten patients, because of reasons described previously.

Thirteen recurrences and one femoral hernia were diagnosed, some with the help of an ultrasound or CT-scan. Seven patients had a contralateral inguinal hernia as well. In an eighteen-year-old soccer player bilateral adductor tendinitis was diagnosed. One 45 year-old woman with painful and limited hip endorotation suffered from an iliopectineal bursitis. She regained persistent full pain-free motion of the hip after an intrabursal injection with lidocain and corticosteroids. Patients with 'non-surgical' problems including hip osteoarthritis, referred lumbosacral pain and urological problems were referred to respective specialists $(n=6)$ who confirmed these diagnoses at a later stage.

Group III: Pain possibly related to spermatic cord

Forty-three patients (27.7 per cent) could not be identified on the basis of an existing classification. These patients predominately described their pain as 'aching' in the absence of a specific trigger point. The spermatic cord was often diffusely tender in those patients who had undergone an anterior approach. Similarly, in selected cases the inserted mesh during laparoscopic surgery produced a tight aching feeling in the lower abdomen, especially during exercise. In most cases no neurophysiologic abnormalities were present.

Combining pain history, physical examination and additional tests 155 diagnoses could be made in 148 patients. In 7 patients a second cause for their pain was present periostitis $(n=5)$, hernia recurrence $(n=1)$ and ipsilateral adductor tendinitis $(n=1)$.

$\begin{array}{ll} & \mathrm{n}(\%) \\ \text { Bulge } & 13(8.8) \\ \text { Pain pressing pubic tubercle } & 18(12.2) \\ \text { Trigger point } & 69(46.6) \\ \text { Neurophysiological } & \\ \quad \text { Normal } & 42(28.4) \\ \quad \text { Hypoesthesia } & 95(64.2) \\ \text { Hyperesthesia } & 11(7.4) \\ \text { Nerve block (Lidocain) } & 51(34.5) \\ \text { Significant pain reduction* } & 41 \\ \text { Periostal injection (Lidocain/ corticosteroids) } & 8(5.4) \\ \quad \text { Significant pain reduction** } & 8 \\ \end{array}$

Table 3 Physical Examination and additional injections in patients with postherniorrhaphy pain $(n=148)$.

Values between parentheses are percentages, unless otherwise specified. *Significant pain reduction defined as $>50 \%$ VAS reduction after 10 min. ${ }^{* *}$ One patient with iliopectineal bursitis received an intrabursal injection with lidocain/ corticosteroids. 


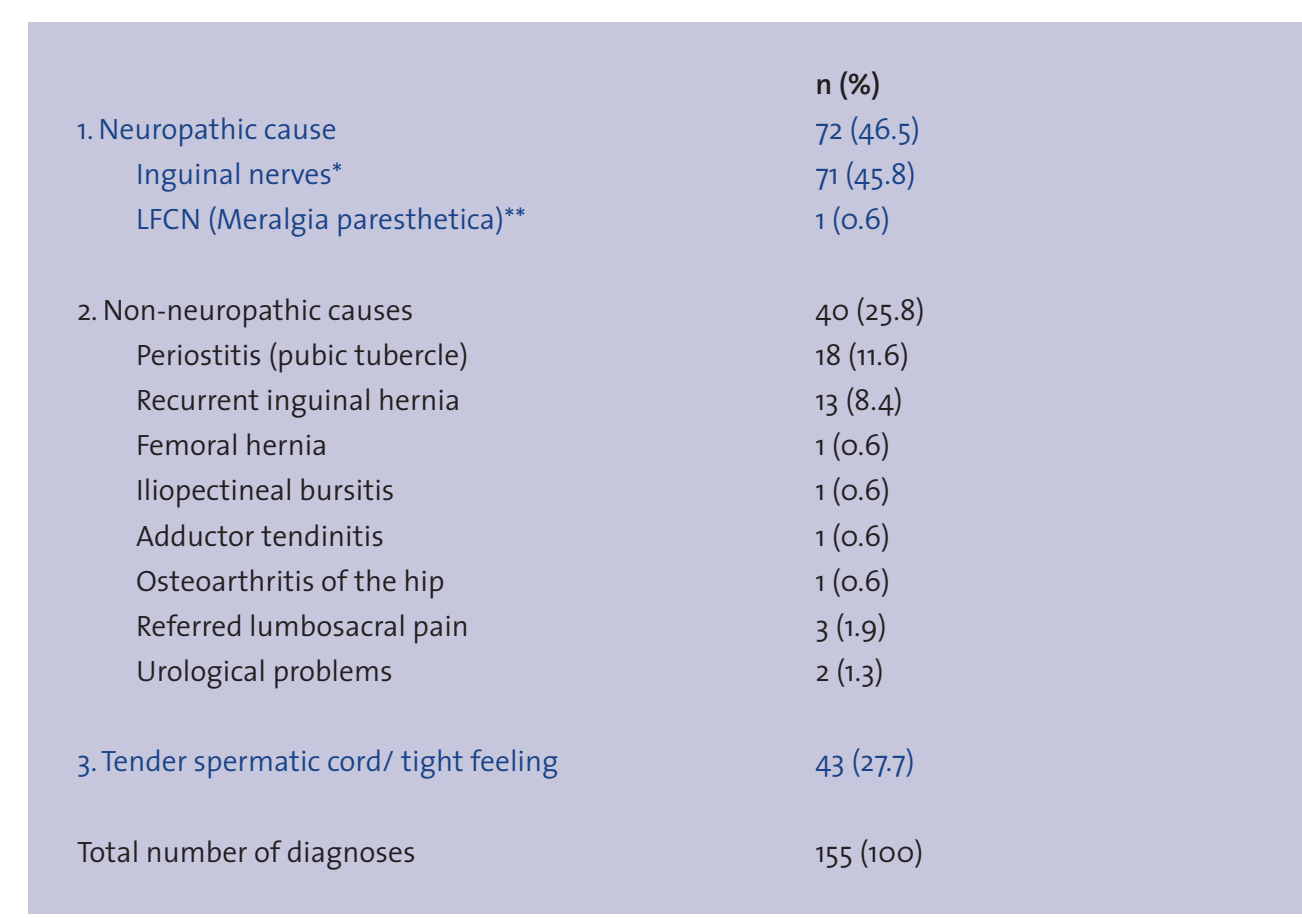

Table 4 Classification of chronic inguinal pain in patients following elective inguinal hernia repair $(n=148)$. Values between parentheses are percentages, unless otherwise specified, 7 patients were diagnosed with two conditions, Values between parentheses are percentages, unless otherwise specified, 7 patients were

\section{DISCUSSION}

The issue of unravelling the dilemma of long-term moderate to severe postherniorrhaphy pain is not new ${ }^{16}$. However, to our knowledge this is the first study in which a large cohort of patients was examined at the outpatient department to clarify the underlying mechanisms that are responsible for pain following hernia repair. A similar but smaller study was conducted by Cunningham et al. in $1996^{8}$. A subset of 10 patients referred to a pain clinic with persisting pain was investigated two years after inguinal repair. He proposed three distinct pain syndromes; somatic $(n=9)$, neuropathic $(n=1)$ and visceral $(n=1)$. The first one was judged as a ligamentous pain syndrome caused by suture insertion in the iliopubic tract and periosteum. The second syndrome was neuralgic and caused by inguinal sensory nerve damage whereas a third complex was associated with ejaculation pain. They concluded that severe pain syndromes following hernia repair are most commonly somatic in origin. Similar groups of patients were identified in the present study. Pain of neuropathic origin was suspected in nearly half of the patients and confirmed by nerve block in 28 per cent of all patients. If one extrapolates these results to the initial patient population encompassing 1,766 individuals, one could cautiously assume that approximately 4 per cent of all corrected inguinal hernias are associated with nerve entrapment or damage. Previous authors have estimated a similar prevalence varying between 3 and $5 \%$. Chronic nerve irritation should be considered as an important cause of moderate or severe chronic pain after inguinal hernioplasty.

Another well known source of postherniorrhaphy pain is periostitis of the pubic tuber$\mathrm{cle}^{10}$. A too deeply positioned suture aimed at medially fixing the mesh may cause inflammation and chronic irritation. In the present examined cohort one in every eight patients experienced pain while exerting digital pressure on the pubic tubercle. This pain syndrome can be avoided by careful placement of suture material ideally sparing the bone's periostal layers. An injection with a local anaesthetic and corticosteroids in painful periosteum could be tried first as this was effective in a substantial number of our patients. Surgical suture removal must be considered if pain persists.

When a patient presents with residual pain following hernia repair, a recurrent hernia is often the only diagnosis that surgeons consider and rule out. Although relatively infrequent in the present study, thirteen patients were encountered with such a recur rence. This number approximates the $1 \%$ of the initial 1766 patients used in our previous questionnaire study. The real recurrence rate is probably higher due to the fact that asymptomatic and mild symptomatic recurrences remain undetected.

A variety of additional musculoskeletal problems was observed in the remainder of the patients with recurrent pain including iliopectineal bursitis, adductor tendinitis, and referred low back pain. These pain syndromes are very likely the secondary result of postural and functional changes in the presence of persisting inguinal pain. However, a third group of 43 individuals demonstrated a clearly distinct history and physical examination. They presented with a tender spermatic cord (after open mesh repair) or a tight aching feeling of the lower abdomen (after laparoscopic procedures). Compression by scar tissue or prosthetic material may possibly explain this type of groin pain ${ }^{12}$ Compromised musculotendinous structures might play a roll as well. It remains unclear if venous congestion contributes to pain in this group of patients. Overall pain intensity is less pronounced compared to the neuropathic pain group although most patients experience some limitations in daily activities. Except for pain medication no optimal treatment is currently available for them. We suggest to name this type of pain 'funiculodynia' as this syndrome is mainly characterized by pain in structures surrounding the spermatic cord.

Prevalence, etiology and treatment of genital complications following hernia repair including erectile and ejaculatory pain are largely unknown. In a recently published Danish questionnaire study three per cent of younger male patients with inguinal hernia repair exhibited pain during sexual activity and subsequent sexual dysfunction ${ }^{13}$. In the present study dysejaculation was reported by one in every five male patients. Several pathophysiologic mechanisms have been suggested, for instance intraoperative nerve 
damage, dysfunction of periurethral structures involved in ejaculation, or encasement of the spermatic cord caused by mesh or scar tissue. This is supported by anecdotal reports on patients with dysejaculation in which dissection of twisted fibrotic spermatic cords combined with an ilioinguinal neurectomy provided total pain relief'4. Due to its high incidence and the scarce literature, more research on etiology and treatment of dysejaculatory complaints after inguinal hernioplasty is recommended.

Over thirty per cent of all postherniorrhaphy pain patients reported to suffer from other chronic pain syndromes as well. A correlation between the onset of postherniorrhaphy pain and other pain syndromes has been previously described in hernia literature and may be due to genetic and psychosocial factors ${ }^{13}$. Patients with a tendency to develop chronic pain are more susceptible to develop additional pain syndromes as well.

Classifying postherniorrhaphy pain syndromes may allow for tailored treatment regimens. The first step in a protocol for treatment of postherniorrhaphy neuralgia described by Lichtenstein nearly two decades ago consisted of primary diagnosis and treatment by injection ${ }^{16}$. Surprisingly, in the present study a single diagnostic nerve block with Lidocain led to a long-term (>1 month) pain reduction in twenty-five percent of our patients, confirming the therapeutic potential of such injections. Although recognized, the phenomenon of permanent or long-term cure following injection of short acting anaesthetics is not well understood'15. If (repeated) injection therapy fails, the second step might be an operative transsection ${ }^{16}$. Later on it was suggested by Amid that transsection should include all three groin nerves ('triple neurectomy') ${ }^{2}$. Because of central and peripheral communication and possible involvement of all three nerves, a maximal length of ilioinguinal, iliohypogastric and genitofemoral in both directions should be transsected and removed.

Reports on the effect of mesh on nerves and chronic pain are scarce. According to a recent animal study, inserted mesh may lead to an inflammatory and fibroblastic response resulting in adhesions and mechanical entrapment of adjacent nerve fibres and structures such as the spermatic cord ${ }^{17}$. Whether these mesh-related nerve changes are responsible for any pain sensation is unknown. One study comparing mesh with suturing techniques using the body's own tissue showed similar incidence rates of chronic pain". Nevertheless, removal of mesh in combination with a neurectomy appeared to be successful in $60 \%$ of patients with chronic inguinodynia ${ }^{18}$. Apart of its inflammatory potential, implanted mesh may also exert mechanical pressure on neighbouring structures or may fold or wrinkle ('meshoma') causing chronic pain'19. A (partial) removal of mesh in combination with a (triple) neurectomy may be considered the preferred treatment in patients with severe neuropathic pain in the presence of a meshoma. In concert with a recent review on surgical management of chronic pain after groin hernia repair there is an obvious need for more prospective research ${ }^{20}$.

The results of the present study demonstrate that the differential diagnosis of moderate or severe postherniorrhaphy pain is diverse but allow for a classification with resultant treatment options. Proper research concerning different types of therapy for chronic pain after groin hernia repair is recommended. A randomized controlled tria comparing peripheral injections with neurectomy has recently been initiated by our group of investigators.

\section{REFERENCES}

1 Loos MJA, Roumen RMH, Scheltinga MRM. Chronic sequelae of common elective groin hernia repair. Hernia 2007; 11: 167-169

2 Bay-Nielsen M, Perkins FM, Kehlet H. Pain and functional impairment 1 year after inguinal herniorrhaphy: a nationwide questionnaire study. Ann Surg 2001; 233: 1-7

3 Nienhuijs SW, Boelens O, Strobbe LJA. Pain after anterior hernia repair. J Am Coll Surg 2005; 200: 885-889

4 Callesen T, Bech K, Kehlet H. Prospective study of chronic pain after groin hernia repair. Br J Surg 1999; 86: 1528-1531

5 Poobalan AS, Bruce J, King PM, Chambers WA, Krukowski ZH, Smith WC. Chronic pain and quality of life following open inguinal hernia repair. Br I Surg 2001; 88: 1122-1126

6 Page B, Paterson D, Young D, O'Dwyer PJ. Pain from primary inguinal hernia and the effect of repair on pain. BrJ Surg 2002; 89:1315-1318

7 Hindmarsh AC, Cheong E, Lewis MP, Rhodes M. Attendance at a pain clinic with severe chronic pain after open and laparoscopic inguinal hernia repairs. Br J Surg 2003; 90: 1152-1154

8 Cunningham J, Temple WJ, Mitchell P, Nixon JA, Preshaw RM, Hagen NA. Cooperative hernia study: pain in the postrepair patient. Ann Surg 1996; 224: 598-602

9 Starling JR, Harms BA. Diagnosis and treatment of genitofemoral and ilioinguinal neuralgia. World J Surg 1989; 13: 586-591

10 Shulman AG. Changes in technique of primary inguinal hernioplasty since 1984. In: the Lichtenstein hernia repairs, how to do them right! 1st ed. United States of America: Wagner design, ISBN 0-9653526-0-9, 1996; 49

11 Vrijland WW, van den Tol MP, Luijendijk RW, Hop WC, Busschbach JJ, de Lange DC, van Geldere $D$, Rottier $A B$, Vegt $P A$, IJzermans JN, Jeekel I. Randomized clinical trial of non-mesh versus mesh repair of primary inguinal hernia. Br J Surg 2002; 89: 293-297

12 Amid PK. Causes, prevention, and surgical treatment of postherniorrhaphy neuropathic inguinodynia: Triple neurectomy with proximal end implantation. Hernia 2004; 8: 343-349

13 Aasvang E, Møhl B, Bay-Nielsen M, Kehlet $H$. Pain related sexual dysfunction after inguina herniorrhaphy. Pain 2006; 122: 258-263

14 Butler JD, Hershman MJ, Leach A. Painful ejaculation after inguinal hernia repair. $J$ Soc Med 1998; 91:432-433

15 Hahn L. Clinical findings and results of operative treatment in ilioinguinal nerve entrapment syndrome. Br J Obstet Gyn 1989; 96:1080-1083 
16 Lichtenstein IL, Schulman AG, Amid PK. Cause and prevention of postherniorrhaphy neuralgia: A proposed protocol for treatment. Am I Surg 1988; 155: 786-790

17 Demirer S, Kepenekci I, Evirgen O, Birsen O, Tuzuner A, Karahuseyinoglu S, Ozban M, Kuterdem E. The effect of polypropylene mesh on ilioinguinal nerve in open mesh repair of groin hernia. J Surg Res 2005; 131: 175-181

18 Heise CP, Starling JR. Mesh Inguinodynia: a new clinical syndrome after inguinal herniorrhaphy? J Am Coll Surg 1998; 187: 514-518

19 Amid P. Radiologic images of meshoma. Arch Surg 2004; 139: 1297-1298

20 Aasvang E, Kehlet H. Surgical management of chronic pain after inguinal hernia repair. Br J Surg 2005; 92: $795-801$ 


\section{CHAPTER 6}

Tailored neurectomy for treatment of postherniorrhaphy inguinal neuralgia

Loos MJA, Scheltinga MRM, Roumen RMH

Surgery 2010;147:275-81 


\section{Background}

Groin hernia repair occasionally leads to severe chronic pain associated with entrapped or damaged nerves. Conservative treatment is often unsuccessful. Selective neurectomy may be effective but long-term results are scarce. The authors assessed the long-term efficacy of surgical neurectomy for chronic postherniorrhaphy groin neuralgia.

\section{Methods}

A registry of patients with postherniorrhaphy groin pain treated by neurectomy was analyzed. Patients received a questionnaire evaluating the current pain intensity, overall treatment results, and effects on sexual intercourse-related pain. The risk factors for failure and presence of a learning curve were investigated.

\section{Results}

Fifty-four patients underwent a neurectomy over a 5-year time period, 49 of whom responded to the questionnaire (response rate $91 \%$ ). After a median follow-up period of 1.5 years, $52 \%$ claimed to be pain free or almost pain free (good to excellent), $24 \%$ reported some relief but still felt pain at a regular basis (moderate), and $24 \%$ did not benefit (poor or worse). Sexual intercourse-related pain responded favorably to neurectomy in two thirds of patients. There seemed to be a steep learning curve, and poor treatment results depended on previously received pain regimens $(P=.021)$.

\section{Conclusion}

A selective operative neurectomy for postherniorrhaphy groin neuralgia provides good long-term pain relief in most patients. Hernia surgeons should feel responsible for this iatrogenic complication and should consider incorporating selective neurectomy in their surgical armamentarium. 


\section{INTRODUCTION}

Worldwide, many patients are affected by chronic pain after 'routine' inguinal hernia repair'. Determining the specifics of this chronic pain may be challenging. Recently, a classification identifying three, separate, pain syndromes was proposed by our group of investigators ${ }^{2}$. First, pain of neuropathic origin (also termed neuralgia) is demonstrated in about half of the patients. They present with a sharp pain that irradiates to the scrotum, upper leg, or back. Symptoms usually appear immediately after the hernia repair but a delayed presentation may also occur. Physical examination reveals neurophysiologic abnormalities, including hyper-/ hypoesthesia or allodynia with a trigger point usually situated in proximity to the incision. Diagnostic nerve blocks with a short-acting anaesthetic agent confirm the diagnosis ${ }^{2}$. At operative exploration, inguinal nerves (iliohypogastric, ilioinguinal or genital branch of the genitofemoral nerve) may be found 'entrapped' by suture material or encased in fibrosis. A traumatic neuroma may be identified on histologic examination ${ }^{2}$.

Second, about $25 \%$ of the population may harbor non-neuropathic pain syndromes including pubic periostitis, mechanical irritation due to wadded mesh ('meshoma') ${ }^{3}$ recurrent inguinal hernias, or musculoskeletal overcompensation. Suture material penetrating periostal layers of the pubic tubercle may result in a chronic inflammatory state 3 . Third, the remaining quarter of the affected patients presents with diffuse pain situated in proximity of the spermatic cord without signs of nerve entrapment ('funiculodynia'). This latter syndrome may be related to venous congestion or mesh-related inflammation of the spermatic cord.

A combination of neuropathic and non-neuropathic pain syndromes is not uncommon. A number of conservative treatment modalities has been proposed for postoperative inguinal neuralgia, including nerve blocks 4 , medication, Transcutaneous Electric Neuro Stimulation (TENS), or capsaicin crème ${ }^{5}$. Data on the efficacy of these modalities, however, are scarce. Patients with refractory pain may undergo operative exploration of the groin. Long-term pain relief in small studies is found between 60 to $100 \%$ after neurectomy ${ }^{3,6-12}$. The aim of the present study was to assess whether a selective operative neurectomy provides satisfactory results for postherniorrhaphy inguinal neuralgia.

\section{ANATOMY AND PATHOPHYSIOLOGY}

Knowledge on inguinal neuroanatomy is crucial. There are four inguinal nerves, the iliohypogastric, ilioinguinal, genitofemoral, and lateral femoral cutaneous nerve. As the latter is only at risk during laparoscopic hernia repair, it will not further be discussed. The following neuroanatomy will apply in most patients, but anatomic variations are exceedingly common ${ }^{3,13}$
The iliohypogastic nerve arises from $\mathrm{T} 12 / \mathrm{L} 1$ and runs ventrally from the quadratus lumborum muscle and gradually pierces the various layers of the abdominal wall. It may be injured accidentally during dissection or may become encased in fibrotic tissue or suture material after mesh fixation. The ilioinguinal nerve originates from the same vertebral level and travels a similar course a few centimetres caudal from the lliohypogastric nerve. It is damaged easily during opening of the inguinal canal or dissection of the spermatic cord, or it may be entrapped by closing of the external oblique aponeurosis or encased by fibrotic tissue after mesh implantation later on. The genitofemoral nerve originates from $\mathrm{L} 1 / \mathrm{L} 2$ and pierces the iliopsoas muscle where it lies on its ventral surface. The genitofemoral nerve demonstrates a clear division into a genital and femoral branch some several centimetres proximal to the inguinal ligament. The genital branch runs posterior to the spermatic cord and is at risk during spermatic cord dissection, or may be caught by constriction at the internal ring or by perineural fibrosis. Moreover, the main trunk with its branches can also be harmed by a laparoscopically placed preperitoneal mesh. Its inguinal segment can be injured if fixating devices penetrate through the transversal fascia and entrap the nerve.

\section{PATIENT AND METHODS}

A database search was performed identifying all consecutive patients treated by the senior authors (M.S. and R.R.) who underwent a neurectomy for postherniorrhaphy inguinal neuralgia in the Máxima Medical Center (MMC, Veldhoven, The Netherlands) between January 2003 and June 2008. Our hospital is a 865-bed hospital in the Southeastern part accommodating some 350.000 individuals. The yearly number of primary inguinal hernia repairs is about 500 . Most patients with postherniorrhaphy inguinal neuralgia were treated according to a previously published algorithm ${ }^{14}$. Inclusion criteria were unilateral inguinal hernia repair and $>3$ months of pain associated with the operative procedure. Patients treated for non-neuropathic pain syndromes exclusively (pubic periostitis, meshoma) were excluded. All medical and surgical records were obtained to determine the duration of pain symptoms, type of inguinal hernia repair and previous pain treatments (e.g. nerve blocks, neurectomies, pain medication). Findings on physical examination including neurophysiologic abnormalities and trigger points were assessed. Special attention was paid to the palliative effect of nerve blocks and imaging modalities (CT/MRI). Finally, diagnosis as well as number of operative interventions, postoperative complications, and histopathologic findings were tabulated.

\section{Operative technique}

All patients were offered operation using spinal or general anaesthesia in a day-care setting. They received 5.000 IU of low molecular heparin (Fragmin ${ }^{\circledR}$, Pfizer bv, Capelle 


\begin{tabular}{|c|c|c|}
\hline \multicolumn{2}{|c|}{ Question } & Possible answers \\
\hline 1 & $\begin{array}{l}\text { Could you estimate the average pain intensity } \\
\text { before your operative inguinal pain treatment? }\end{array}$ & $\begin{array}{l}\text { No pain, Mild pain, Moderate pain, } \\
\text { Severe pain, Very severe pain }\end{array}$ \\
\hline 2 & $\begin{array}{l}\text { Could you estimate the average pain intensity } \\
\text { directly after your operative inguinal pain } \\
\text { treatment? }\end{array}$ & $\begin{array}{l}\text { No pain, Mild pain, Moderate pain, } \\
\text { Severe pain, Very severe pain }\end{array}$ \\
\hline 3 & $\begin{array}{l}\text { Could you estimate the average pain intensity } \\
\text { in the treated groin during the past two weeks? }\end{array}$ & $\begin{array}{l}\text { No pain, Mild pain, Moderate pain, } \\
\text { Severe pain, Very severe pain }\end{array}$ \\
\hline 4 & $\begin{array}{l}\text { Imagine that your preoperative pain intensity } \\
\text { is set at } 100 \% \text {. What is the percentage of pain } \\
\text { you experienced during the past two weeks? }\end{array}$ & $\ldots \ldots \ldots \ldots \%$ \\
\hline 5 & $\begin{array}{l}\text { Did you experience any of the following } \\
\text { 'complications'? }\end{array}$ & $\begin{array}{l}\text { Wound infection, Postoperative } \\
\text { haemorrhage, Skin numbness } \\
\text { Skin hypersensitivity, Bulge, } \\
\text { Onset of other pain symptoms }\end{array}$ \\
\hline 6 & How is the sensitivity of your skin? & $\begin{array}{l}\text { Normal, No sensitivity, Numb, } \\
\text { Hypersensitive, Painful at light touch }\end{array}$ \\
\hline 7 & How do you judge your treatment result? & $\begin{array}{l}\text { Excellent - I am pain free } \\
\text { Good - I am almost pain free } \\
\text { Moderate - Although there is some } \\
\text { pain reduction, I am still frequently } \\
\text { bothered by pain complaints } \\
\text { Poor - The operation had no effect } \\
\text { and the pain is virtually the same } \\
\text { Worse - The operation has worsened my pain }\end{array}$ \\
\hline 8 & $\begin{array}{l}\text { If you had the choice, would you then opt to } \\
\text { receive the operative treatment again? }\end{array}$ & Yes, No \\
\hline 9 & $\begin{array}{l}\text { Did you experience any inguinal pain } \\
\text { preoperatively during one or more } \\
\text { of the following situations? }\end{array}$ & $\begin{array}{l}\text { During sex, During orgasm, Following an } \\
\text { orgasm, Not appropriate, } \\
\text { No I did not experience sex-induced pain }\end{array}$ \\
\hline & $\begin{array}{l}\text { If you experienced sex-induced pain, did the } \\
\text { operation relieve these pain complaints? }\end{array}$ & $\begin{array}{l}\text { Yes, I am now totally pain free } \\
\text { Yes, there was some improvement } \\
\text { No, these pain symptoms are unchanged }\end{array}$ \\
\hline
\end{tabular}

Table 1 Questionnaire aan de IJssel, the Netherlands) subcutaneously two hours prior to the procedure. By extending the inguinal incision several centimetres laterally, access was gained to a non-operated area. The iliohypogastric and/or ilioinguinal nerves penetrating the internal oblique muscles were identified. Any prosthetic material was dissected free of these nerves for additional exposure. The genital branch of the genitofemoral nerve was usually found just posterior to the spermatic cord. Nerves were excised if fibrotic encasement or neuroma formation was observed. After peripheral division, proximal nerve ends were cauterized, occasionally ligated under traction, and allowed to retract into the internal oblique muscle to prevent fibrotic encasement. If nerves were thought 'entrapped' by preperitoneal mesh, the preperitoneal space was opened by dividing the internal oblique and transversus abdominis layers. When a displaced bulk of mesh material was found, parts of the bunched up mesh were removed. The sequence of technical steps was not standardized, because perioperative findings guided decisions concerning nerve resection and mesh removal ('tailored approach').

\section{Questionnaire and statistical analysis}

A slightly modified questionnaire based on a recently published review was sent to all patients in October 2008 (table 1) 13. Non-responders received two reminders, one by mail and one by phone. Preoperative and current pain intensity as measured by a 5-point Verbal Rating Scale (and percentages), perceived treatment results, and effect on sexual intercourse-related complaints were scored. To identify possible factors predicting poor treatment results, a multivariate logistic regression analysis was performed. Treatment results served as the dependent factor (excellent/good/moderate vs. poor/ worse), whereas presence of recurrent inguinal hernia surgery, type of initial hernia repair (open non-mesh repair, open or laparoscopic mesh repair), previous pain treatment and presence of nerve tissue at histopathologic examination acted as covariate categorical factors. In order to detect a possible learning curve for the procedure, treatment results were analyzed per treatment year. Results were considered significant for $p$-values $\leq 0.05$

\section{RESULTS}

Between January 2003 and June 2008, 68 patients underwent operative treatment for postherniorrhaphy inguinal pain. Fourteen patients were excluded for reasons listed in fig 1, leaving 54 patients for analysis ( 56 groins, bilateral neurectomy in 2 patients).

Combined pain syndromes were present in 6 patients (e.g. nerve entrapment and pubic periostitis or pain from a meshoma). There were 43 males and 11 females with a median age of 50 years (range: 18-88 years). As most patients ( $n=41,75 \%)$ were referred from 


\begin{tabular}{|c|c|}
\hline \multicolumn{2}{|c|}{$\begin{array}{l}\text { Patients with chronic postherniorrhaphy groin pain } \\
\text { who received operative treatment }(n=68)\end{array}$} \\
\hline$\downarrow$ & $\downarrow$ \\
\hline $\begin{array}{l}\text { Patients eligible for study } \\
\text { (questionnaire) }(n=54)\end{array}$ & \multirow{3}{*}{$\begin{array}{l}\text { Excluded }(n=14) \text { : } \\
\text { - Follow-up period too short }(n=6) \\
\text { - Nociceptive pain treated by } \\
\text { mesh/suture removal }(n=8)\end{array}$} \\
\hline$\downarrow$ & \\
\hline $\begin{array}{l}\text { Response rate to questionnaire } \\
\qquad 91 \%(\mathrm{n}=49)\end{array}$ & \\
\hline \multicolumn{2}{|l|}{ Figure 1 Patient flow chart and response rate to the questionnaire. } \\
\hline & $n(\%)$ \\
\hline \multicolumn{2}{|l|}{ Previous groin hernia repair* } \\
\hline Open mesh & $36(67)$ \\
\hline Non-mesh & $24(44)$ \\
\hline Laparoscopic & $10(19)$ \\
\hline \multicolumn{2}{|l|}{ Previous pain therapy } \\
\hline Groin exploration (without neurectomy) & $12(22)$ \\
\hline Nerve blocks & $11(20)$ \\
\hline Neurectomy & $5(9)$ \\
\hline Neuropathic pain medication & $5(9)$ \\
\hline TENS $^{* *}$ & $1(2)$ \\
\hline Rhizotomy & $1(2)$ \\
\hline Orchidectomy & $1(2)$ \\
\hline \multicolumn{2}{|l|}{ Sensory abnormalities ${ }^{* * *}$} \\
\hline Hypoesthesia & $23(43)$ \\
\hline Hyperesthesia & $14(26)$ \\
\hline Normal sensation & $8(15)$ \\
\hline Allodynia & $4(7)$ \\
\hline Anaesthesia & $1(2)$ \\
\hline Trigger point ${ }^{* * * *}$ & $56(100)$ \\
\hline
\end{tabular}

Table 2 Characteristics of postherniorrhaphy pain patients and clinical details $(n=54)$. "Including recurrent hernia repairs, ** Transcutaneous Electric Neuro Stimulation,

${ }_{* * *}^{* *}$ missing data in 6 patients, **** in 2 patients bilateral trigger points. other hospitals, there was a relatively long median period of 2.5 years (range: 3 months25 years) before patients were evaluated in our clinic. The initial type of hernia repair was predominantly an onlay mesh-based repair, while recurrent repairs were performed in 11 patients (20\%). Nearly half of the patients had received some form of previous treatment for groin pain (table 2). Physical examination revealed abnormalities in sensation including hypoesthesia, hyperesthesia, or allodynia, and trigger points in most patients (table 2).

Diagnostic nerve blocks were often used $(n=49,88 \%)$ and gave a positive effect in 34 patients (76\%). Additional imaging modalities, such as Computed Tomography, and Magnetic Resonance Imaging excluded other diagnoses in 12 patients.

\section{Perioperative details}

Sixty-eight operative procedures were performed in the 5-year study period (table 3). Exploration usually involved examining multiple nerves. The ilioinguinal nerve was resected in over $80 \%$ of patients followed by the genital branch of the genitofemoral nerve. To assure an adequate exposure, these procedures were often supplemented by (partial) mesh removal. Five patients underwent a triple neurectomy. Repeated interventions due to persistent pain $(n=10)$ or recurrent pain symptoms $(n=2)$ were required in 12 patients. Postoperative complications were rare. Histology revealed a range of abnormalities, such as neuromas and perineural fibrosis. In 8 patients, no histopathologic examination of removed tissue was done.

\section{Early follow-up and questionnaire}

At early follow-up (<3 months) in the outpatient department, 32 groins (57\%) were completely pain-free, whereas pain relief was partial in 10 groins (18\%). The intensity of the inguinal pain was unchanged in 14 groins (25\%).

The questionnaire was returned by 49 patients ( 50 groins, response rate $91 \%$ ). Almost all respondents reported severe pain prior to neurectomy. After a median of 2.5 years, perceived treatment results were good or excellent in $52 \%$, moderate in $24 \%$, and poor or worse in $24 \%$ (table 4 ). Knowing their postoperative outcome, three quarters of all respondents would undergo the operative procedure again. Re-intervention $(n=12)$ resulted in good to excellent results in another 5 patients. Surgical records of those who did not respond to the questionnaire $(9 \%, n=5)$ were checked for early treatment results (pain-free $n=3$, similar pain $n=2$ ), indicating an absence of selection bias in the responder group. Figure 2 depicts the number of successful neurectomies per year and suggests that there is a learning curve. In most patients the intensity of early postoperative pain and the intensity of pain at follow-up visits were similar, suggesting no significant pain relapse.

Previous pain treatment was an important determinant of a poor treatment result (OR $5.14,95 \% \mathrm{Cl} 1.19-22.22, p=0.021)$. In contrast, previous repair of a recurrent inguinal 


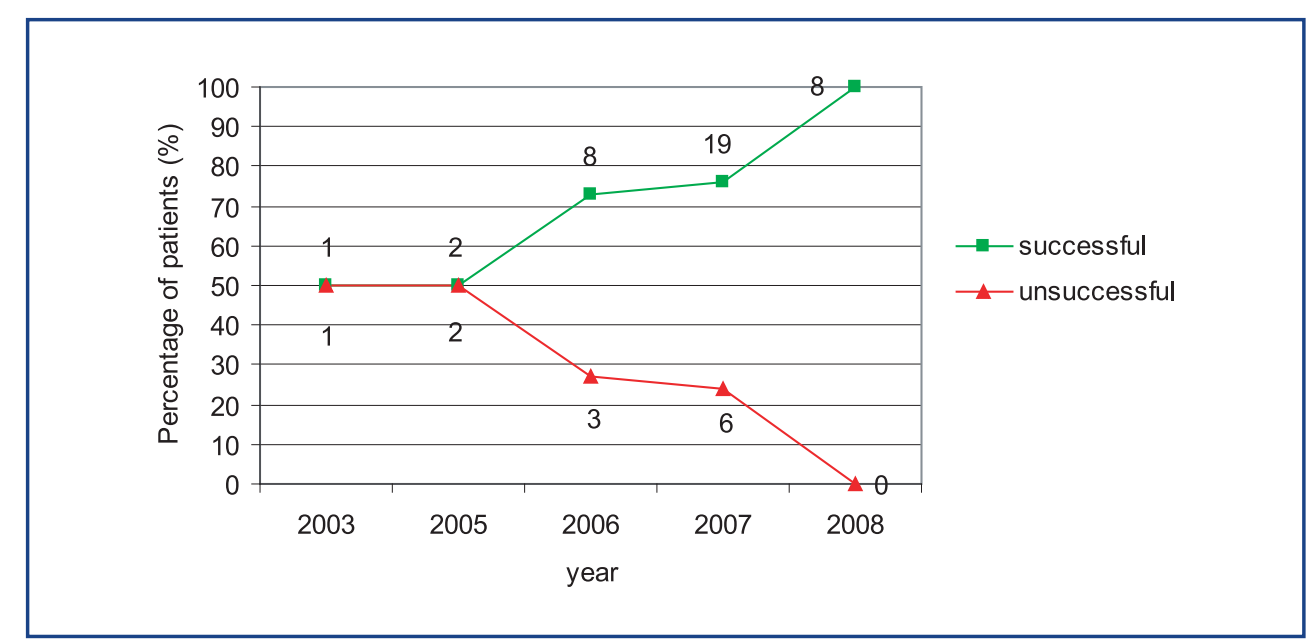

Figure 2 Treatment results per year indicating a learning curve.

Successful = moderate, good or excellent results, unsuccessful = poor or worse results,

numbers at lines indicate number of patients/ year/ treatment result (successful or unsuccessful).

$\begin{array}{ll}\text { Operative procedure } & n(\%) \\ \quad \begin{array}{l}\text { Neurectomy of the*: } \\ \quad \text { Ilioinguinal nerve }\end{array} & 44(81) \\ \quad \text { Genital branch } & 25(46) \\ \quad \text { Iliohypogastric nerve } & 9(17) \\ \text { (Partial) mesh removal } & 19(35) \\ & \\ \text { Postoperative complications } & 1 \\ \text { Surgical site infection } & 1 \\ \text { Hematoma } & 1 \\ \text { Persisting haemorrhage requiring re-intervention } & 1 \\ \text { Ischemic orchitis requiring orchidectomy } & \\ \text { Histopathology } & \\ \text { Normal nerve tissue } & 25(46) \\ \text { Neuroma } & 12(22) \\ \text { Tissue without nerve fibres } & 7(13) \\ \text { Perineural fibrosis } & 2 \\ \text { Nerve tissue with reactive changes } & 1 \\ \text { Mesh or suture material } & 1\end{array}$

Table 3 Perioperative details of postherniorrhaphy pain patients $(n=54)$.

"In 5 five patients a triple neurectomy was performed. hernia, the type of initial hernia repair (open non-mesh repair, open or laparoscopic mesh repair), or presence of nerve tissue at histopathologic examination did not show a significant association with treatment outcome. Pain during sexual intercourse and/or orgasm prior to operative treatment was found in $40 \%$ of all patients (20/50), and this percentage decreased to $14 \%$ after operative treatment (7/50). Although pain complaints were not specific to males or females, orgasm-related pain (i.e. pain on ejaculation) was mostly reported by male patients.

\section{DISCUSSION}

This study on postherniorrhaphy neuropathic groin pain demonstrates that operative neurectomy provides good to excellent pain reduction in about half of the patients, whereas an additional $25 \%$ of patients experience a partial but important decrease in inguinal pain. The first report of mesh removal plus neurectomy (in the case of visible nerve involvement) ${ }^{8}$ for so-called 'mesh inguinodynia' was reported about 10 years ago, and showed comparable outcomes as did another prospective study ${ }^{15}$. The latter report emphasized the importance of detailed, neurophysiologic work-up, because patients with central nervous system sensitization should be excluded from neurectomy. Apart from pain, nearly all of our patients experienced sensory abnormalities as well. Considering these characteristics, a operative neurectomy seems to provide acceptable success rates in terms of sufficient pain decrease in inguinal pain in most patients.

Which factors influence operative success? Correct patient selection is crucial. Evaluating our failures leads us to suggest that the success depends on the type of previous pain treatments and thus relies on the complexity of the pain problem. In our opinion, operative treatment of a simple nerve entrapment after an onlay mesh repair performed several months previously will likely have a better chance of success compared to

$\begin{array}{ll} & \mathrm{n}(\%) \\ \text { - Excellent - I am pain free } & 10(20) \\ \text { - Good - I am almost pain free } & 16(32) \\ \text { - Moderate - Although there is some pain reduction, } & 12(24) \\ \text { I am still frequently bothered by pain complaints } & \\ \text { - Poor - The operation had no effect and the pain is } & 4(8) \\ \text { virtually the same } & 8(16) \\ \text { - Worse - The operation has worsened my pain } & \end{array}$

Table 4 Long-term surgical treatment results based on questionnaire response $(n=50)^{*}$.

* In 1 patient responding to the questionnaire both groins were treated. 
operative exploration for a patient with numerous prior conservative and operative treatments. Moreover, some patients with a complex array of complaints of inguinal pain may be suffering from central nervous system sensitisation, and may therefore be refractory to any intervention directed at peripheral nerves ${ }^{16}$. These patients should receive pain medication or other modalities such as TENS. An effective peripheral nerve block is helpful in excluding such central pain syndromes and allows for a better selection of patients eligible for successful, selective, operative neurectomy².

Apart from adequate patient selection, a proper operative technique is of importance for success. According to several studies, neuropathic pain syndromes are treated ideally with removal of the affected nerve(s) rather than only freeing of the nerve (neurolysis), because the latter technique often results in re-entrapment ${ }^{6,10,17}$. Moreover, some experts advocate removal of all three nerves at once ('triple neurectomy') ${ }^{17}$, because they claim that any remaining nerve branches may still transfer pain stimuli. In contrast, we believe that a selective 'tailored' removal of only the affected nerve is sufficient and may prevent unnecessary neuroma formation in otherwise unaffected neurectomized nerves. The nerves presumed to be affected are often related to the initial hernia repair approach. In the case of an earlier laparoscopic procedure, the genital branch may be entrapped, and anatomy precludes an effective treatment by the anterior approach Instead, the genital branch must be identified using a retroperitoneal route. Nonetheless, the following procedural aspect should be respected. The affected nerve should be resected as proximal and as distal as possible, leaving the proximal end retracted into unscarred tissue. Whether the proximal nerve stump should be ligated or only cauterized remains unclear.

The present study shows an improved success rate in our experience over time sugges ting a learning curve. This type of inguinal operative exploration takes place in scarred tissues, and proper identification of nerve tissue may be difficult and requires experience. Variability in inguinal neuroanatomy acts as a further complicating factor. For feedback purposes, the nerve specimen should, therefore, be sent for confirmative histopathologic examination. Another possible explanation for improved results in our more recent neurectomies might be the recurrence of pain in the early operated patients; however, similar or even less pain compared to the early postoperative period was reported by an equal percentage of patients (50-88\%) per treatment year. Therefore, it is unlikely that time to follow-up acted as a confounder for treatment results and augmented success rates over time are probably due to a learning curve effect. In our opinion, a surgeon may be able to achieve comparable results after a learning curve of about ten inguinal neurectomies.

Pain during sexual activities occurred in nearly half of the patients and in both men and women. Neurectomy often relieved this sexual intercourse-related pain. Except for a few case studies, there are no similar reports on long-term operative treatment results for this troublesome problem ${ }^{18,19}$. We recently demonstrated a similar response in women with Pfannenstiel-related neuralgia complaining of intercourse/orgasmrelated pain ${ }^{14}$. Because $3 \%$ of the younger patients with inguinal pain after inguinal herniorrhaphy are affected by ejaculatory pain complaints ${ }^{20}$, these findings may be of great importance.

In conclusion, neurectomy for postherniorrhaphy inguinal neuralgia provides substantial long-term pain relief in the majority of patients. Surgeons who frequently perform inguinal hernia repair should incorporate selective neurectomy in their surgical repertoire. The present study illustrates that effective pain relief may be obtained after a reasonably steep learning curve. Future studies should focus on identifying subgroups that benefit most from tailored operative neurectomies.

\section{REFERENCES}

1 Loos MJ, Roumen RM, Scheltinga MR. Chronic sequelae of common elective groin hernia repair. Hernia 2007; 11: 169-173

2 Loos MJ, Roumen RM, Scheltinga MR. Classifying post-herniorrhaphy pain syndromes following elective inguinal hernia repair. World J Surg 2007; 31: 1760-1765

3 Amid PK. A 1-stage surgical treatment for postherniorrhaphy neuropathic pain: triple neurectomy and proximal end implantation without mobilization of the cord. Arch Surg 2002; 137:100-104

4 Amir R, ArgoffCE, Bennett GJ, Cummins TR, Durieux ME, Gerner P, Gold MS, Porreca F, Strichartz GR. The role of sodium channels in chronic inflammatory and neuropathic pain.J Pain 2006;7(5 Suppl 3)S1-29

5 Ferzli GS, Edwards E, Al-Khoury G, Hardin R. Postherniorrhaphy groin pain and how to avoid it. Surg Clin North Am. 2008; 88: 203-202

6 Ducic I, West J, Maxted W. Management of chronic postoperative groin pain. Ann Plast Surg 2008; 60: $294-298$

7 Hahn L. Clinical findings and results of operative treatment in ilioinguinal nerve entrapment syndrome. Br J Obstet Gynaecol 1989; 96: 1080-1083

8 Heise CP, Starling JR. Mesh inguinodynia: a new clinical syndrome after inguinal herniorrhaphy? J Am Coll Surg 1998; 187: 514-518

$9 \mathrm{Kim}$ DH, Murovic JA, Tiel RL, Kline DG. Surgical management of 33 ilioinguinal and iliohypogastric neuralgias at Louisiana State University Health Sciences Center. Neurosurgery 2005; 56: 1013-1020

10 Lee CH, Dellon AL. Surgical management of groin pain of neural origin. J Am Coll Surg 2000; 191 137-142

11 Madura JA, Madura JA 2nd, Copper CM, Worth RM. Inguinal neurectomy for inguinal nerve entrapment: an experience with 100 patients. Am J Surg 2005; 189:283-287

12 Starling JR, Harms BA. Diagnosis and treatment of genitofemoral and ilioinguinal neuralgia. World J Surg 1989; 13: 586-59

13 Wijsmuller AR, Lange JF, Kleinrensink GJ, van Geldere D, Simons MP, Huygen FJ, Jeekel J, Lange JF. Nerve-identifying inguinal hernia repair: a surgical anatomical study. World J Surg 2007; 31:414-420 
14 Loos MJ, Scheltinga MR, Roumen RM. Surgical management of inguinal neuralgia after a low transverse pfannenstiel incision. Ann Surg 2008; 248: 880-885

15 Aasvang $E$, Kehlet $H$. The effect of mesh removal and selective neurectomy on persistent postherniotomy pain. Ann Surg 2009; 249:327-334

16 Kehlet H, Jensen TS, Woolf CJ. Persistent postsurgical pain: risk factors and prevention. Lancet 2006; 367: 1618-1625

17 Amid PK. Causes, prevention, and surgical treatment of postherniorrhaphy neuropathic inguinodynia: triple neurectomy with proximal end implantation. Hernia 2004; 8: 343-349

18 Aasvang EK, Kehlet H. Postherniotomy dysejaculation: successful treatment with mesh removal and nerve transection. Hernia 2008; 12: 645-647

19 Butler JD, Hershman MJ, Leach A. Painful ejaculation after inguinal hernia repair.J R Soc Med 1998; 91: $432-433$

20 Aasvang EK, Mohl B, Bay-Nielsen M, Kehlet H. Pain related sexual dysfunction after inguinal herniorrhaphy. Pain 2006; 122: 258-263 


\section{CHAPTER 7}

Randomized controlled trial of neurectomy versus injection with lidocain, corticosteroids and hyaluronic acid for postherniorrhaphy inguinal neuralgia: rationale and study design

Loos MJA, Verhagen T, Scheltinga MRM, Roumen RAAH

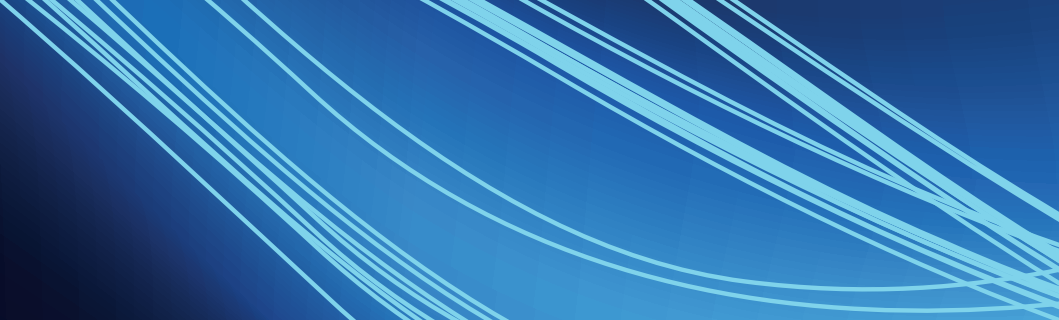

Loos $M U A$, Verhagen T, Scheteinga

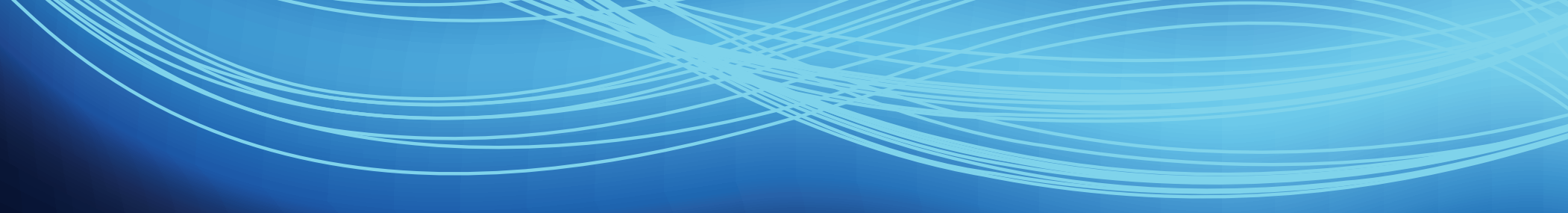




\section{Background}

Chronic inguinal neuralgia is considered to be an important complication after hernia repair. As a high-level evidence-based treatment regime is currently lacking, these patients usually receive a random combination of pain medication, local nerve blocks or an occasional surgical neurectomy. A controlled trial ('GroinPainTrial') was constructed to identify the optimal treatment modality in this population. The aim and rationale of the trial are presented in this paper.

\section{Patients and methods}

Adult patients with chronic post-herniorrhaphy inguinal pain (>3 months) caused by inguinal nerve entrapment having a temporary pain reduction after a lidocain nerve block are eligible for randomisation. They received either repetitive nerve blocks with lidocain, corticosteroids and hyaluronic acid, or a 'tailored' surgical neurectomy.

Results

Patient enrollment started in February 2006 and is expected to end in June 2011. The initial results will be available at the end of 2011.

\section{Conclusions}

This trial is the first randomised controlled effort comparing two invasive treatment modalities for peripheral inguinal nerve entrapment. As awareness and knowledge on chronic neuropathic pain after inguinal herniorrhaphy in the near future is expected to increase, the findings of this trial will aid in optimising care in this patient population. 


\section{INTRODUCTION}

Hernia recurrence rates have plummeted ever since the introduction of mesh. Research interest has, therefore, shifted towards studying the characteristics of chronic pain following routine implantation of mesh'. Approximately $11 \%$ of all operated hernia patients are troubled by chronic inguinal pain ${ }^{2-4}$. About half suffers from neuropathic pain caused by entrapment or damage to one (or more) of the inguinal nerves (ilioinguinal, iliohypogastric or/ and genital branch of the genitofemoral nerve). The other half experience nociceptive pain including periostitis, recurrent hernia, folded mesh ('meshoma'), fibrotic tissue or funiculodynia'.

Published studies on treatment regimes for postherniorrhaphy inguinal pain syndromes are scarce. Examples of non-operative treatment options include nerve blocks with local anaesthetics and corticosteroids ${ }^{6}$, transcutaneous electric nerve stimulation (TENS), or pulsed radio frequency (PRF)7. Neuropathic pain caused by nerve entrapment can also be treated by an open nerve removal (neurectomy), as this technique effectively decreased pain in $60-80 \%$ of the patients ${ }^{8-13}$. Peripheral nerve blocks likely aid in discriminating between pain types. However, it is important to realize that to our knowledge no validation studies on sensitivity and specificity of nerve blocks in discriminating neuropathic from nociceptive pain have been conducted.

In order to evaluate which therapeutic regime serves best for neuropathic postherniorrhaphy pain syndromes, a randomized controlled trial was constructed comparing two frequently used treatment modalities, nerve blocks and neurectomy of the inguinal nerves. Characteristics of this randomized controlled trial will be discussed in the present article.

\section{METHODS}

\section{Study design}

The GroinPain Trial is a randomized, non-blinded, monocenter study. The protocol was approved by the Regional Ethics Committee of the Máxima Medical Center, Veldhoven, The Netherlands (no. 0543). The objective is to evaluate long-term pain reduction in patients with chronic postherniorrhaphy groin neuralgia following two different treatment modalities. Clinical results of nerve blocks with lidocain, corticosteroids and hyaluronic acid are compared with a operative neurectomy of the ilioinguinal, iliohypogastric or/and genital branch of the genitofemoral nerve(s). Patient enrolment started in February 2006. The study protocol has been registered at www.clinicaltrial.gov (ClinicalTrials.gov identifier: NCTo0306839).

\section{Study population}

All adult patients (18 years or older) with chronic neuropathic pain after routine inguinal hernia repair (open or laparoscopic) are considered for inclusion. A pain-free interval (hours to days/weeks) after a diagnostic nerve block using 10 cc 1\% lidocain injected into the trigger point is a prerequisite for inclusion. Patients with less than $50 \%$ pain reduction do not qualify for study. A nerve block administered at the outpatient department is part of our standard diagnostic pathway. In some patients, a diagnostic nerve blocks results in a persistent pain reduction. These patients are excluded from further participation but are registered and monitored over time. To assure that the international definition for the study of chronic pain (pain persisting beyond the normal healing period of 3 months) was applicable to all patients, the minimal follow-up period of three months was chosen. Patients were excluded if an adequate follow-up was impossible, omitting all patients with severely compromised physical or mental health. Patients with a recurrent inguinal hernia, harbouring signs of local inflammation or having an American Society of Anaesthesiologists classification 3 or more are also excluded.

\section{Randomization}

After a thorough explanation regarding rationale and important characteristics of the trial, verbal and written informed consent is obtained the outpatient department. Patients are subsequently randomized to repetitive nerve blocks using lidocain, corticosteroids and hyaluronic acid (group A) or a neurectomy (group B, figure 1). Blocks of eight-randomization principle without prestratification are applied by computer.

\section{Interventions}

Nerve blocks (Group A, figure 2): This group receives an injection with 2 cc 1\% Lidocain, 40 mg corticosteroids (Depomedrol ${ }^{\circledR}$ ), and 75 IE hyaluronic acid (Hyason ${ }^{\circledR}$ ) at the surgical outpatient department. These blocks are placed in the pain trigger point. In case of additional genital branch neuralgia, a separate nerve block placed at the internal inguinal ring is often mandatory. If pain reduction is temporary, injections are repeated at two week intervals. A maximal number of three blocks is used over a six week period. All injections are administered by the principal investigators (M.L. or T.V.)

Neurectomy (Group B): Patients are offered surgery using spinal or general anaesthesia in a day-care setting. All operations are performed by the senior authors M.S. and R.R., both experienced in performing this procedure. Patients receive $2.500 \mathrm{IU}$ of low molecular heparin (Fragmin ${ }^{\oplus}$ ) subcutaneously two hours prior to the procedure. By extending the inguinal incision some centimetres laterally, access is gained to an unaffected area in most cases. The iliohypogastric and/or ilioinguinal nerves penetrating internal oblique muscles are identified and followed as proximal as possible. The prosthetic material is usually opened and dissected for additional exposure. If indicated, the genital branch 
of the genitofemoral nerve is identified just underneath the spermatic cord. The genital branch can also be affected at the level of the internal ring, making an anterior approach difficult or less effective. Therefore an additional retroperitoneal approach can be chosen in case of a suspected genital branch neuropathy. Occasionally the genital branch is absent or is not found due to previous procedures. Nerves are excised if fibrotic encasement or possible neuroma formation is observed. After peripheral division including the intramuscular segment, proximal nerve ends are cauterized, occasionally ligated under traction and allowed to retract into the internal oblique muscle to prevent

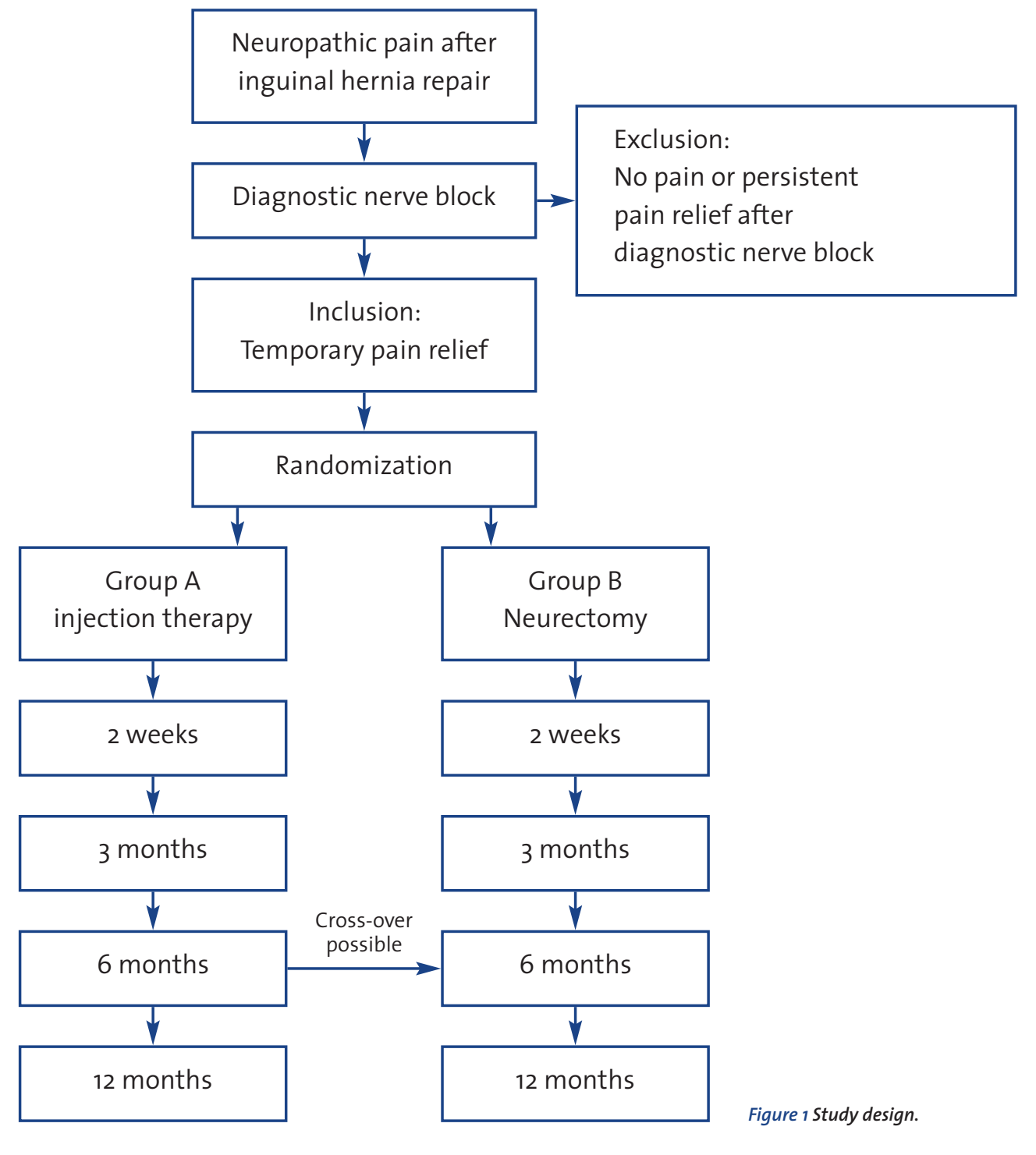

a relapse of fibrotic encasement. If nerves are thought 'entrapped' by preperitoneal mesh placement, the preperitoneal space is opened by dividing the internal oblique and transversus abdominis layers. In case of displaced bulky mesh material, parts of mesh are removed. In case of mesh removal, it is always accompanied by a neurectomy. The sequence of surgical steps is dictated by the perioperative findings. A decision concerning nerve resection and (partial) mesh removal is thus guided by the individual situation, the 'tailored approach', which has been published recently by our group of investigators ${ }^{11}$. All resected specimens are histopathologically examined.

\section{Collection of data and clinical follow-up}

A total of five assessments are planned for each patient by the principal investigators. Baseline details and a standard questionnaire assessment are collected at inclusion (visit 1). In case of randomization for nerve blocks, patients return two weeks after the first nerve block to the outpatient department for clinical examination and a second questionnaire assessment (visit 2). If pain reduction after nerve bocks is only temporary, a cross-over to the neurectomy group is offered 6 months post-inclusion (Fig. 1).

If randomized to neurectomy, the surgeon tabulates all operative details including all surgical steps in a standard report. Two weeks after the operation, patients are assessed

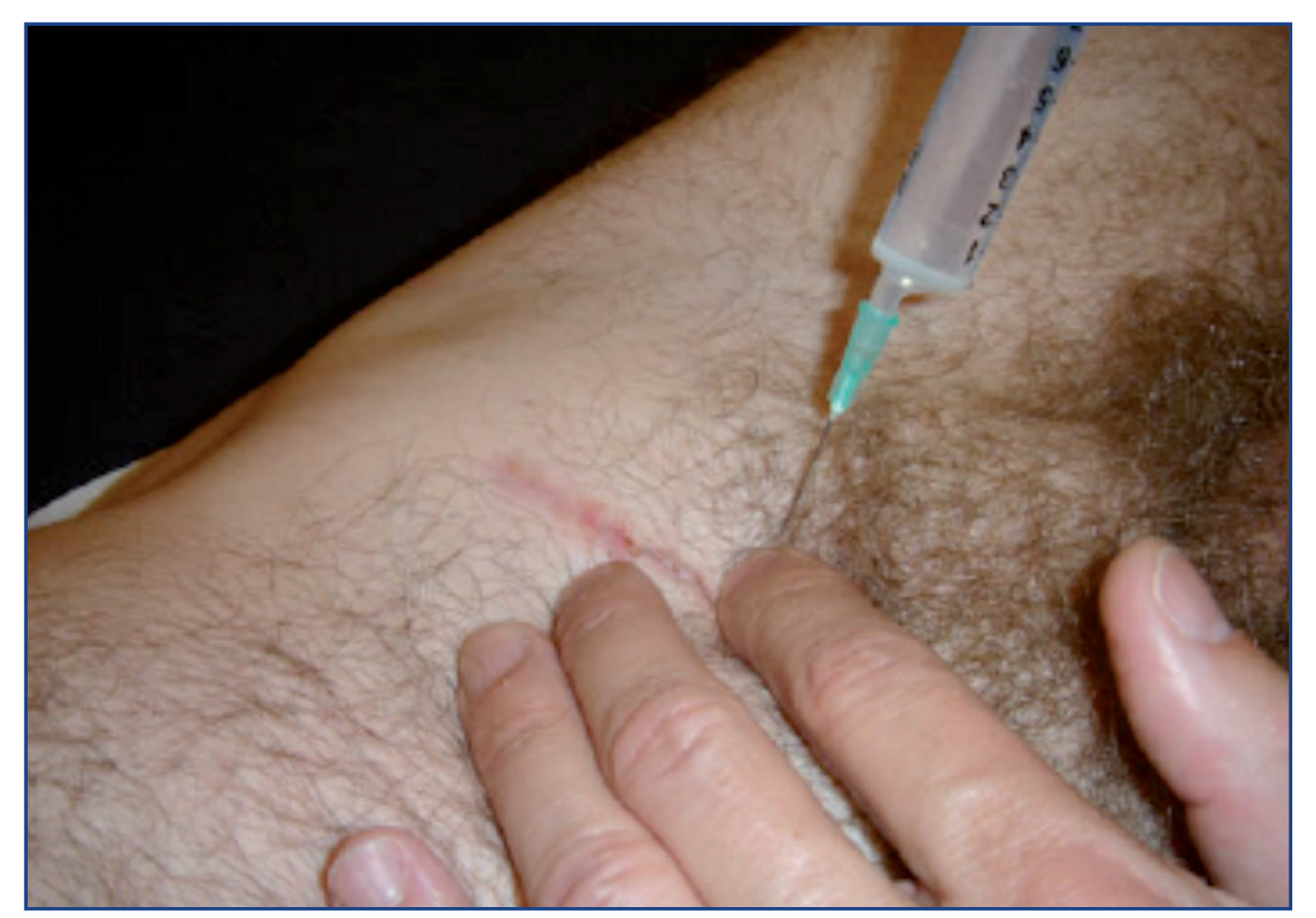

Figure 2 Diagnostic nerve block in a left groin. 
at the outpatient department as well (visit 2). Cross-over from the neurectomy to the nerve block group does not seem beneficial and is not included in the protocol.

All patients receive a questionnaire by mail 3 and 6 months postoperatively. One year post-intervention, all participants are invited for final questionnaire assessment and physical examination at the surgical outpatient department (visit 3). Each patient will complete a Surgical Pain Scales ${ }^{14}$, McGill Pain Questionnaire - Dutch Language Version'5, SF-36 version II quality of life questionnaire at each follow-up moment ${ }^{16}$. At the outpatient department visits (baseline, after 2 weeks, 12 months) the LANNS Pain scale, the Leeds Assessment of neuropathic pain and symptoms and signs, is completed 7 . Complications and change in employment status is noted at each post-intervention evaluation moment.

\section{Study endpoints}

The primary endpoint is number of successfully treated patients with respect to pain reduction. Successful pain reduction is defined as a $>50 \%$ pain reduction during resting conditions measured with the Surgical Pain Scales after 6 months. In case of necessity to cross-over from the nerve block group to the neurectomy group or if additional treatment like chronic pain medication remains necessary, this is considered a treatment failure.

Secondary endpoints are quality of life (SF-36 version II), alterations in inguinal neurophysiological status (LANNS pain scale), complications (self-constructed questionnaire), and change in employment status (self-constructed questionnaire).

\section{Sample size}

A successful intervention is defined as a $50 \%$ reduction (Visual Analogue Scale) in rest pain (Surgical Pain Scales) after 6 months of follow-up. After a thorough study of the available literature, success rates of a nerve block appeared unknown. After a consultation of several of our anaesthesiologists specialized in the treatment of chronic pain, the success rate of a nerve block is set at $25 \%$. Based on retrospective cohort studies, the success percentage following a surgical neurectomy approximates $75 \%$. Using a type error of 0.05 and type II error of 0.10 , a sample size is calculated of 54 patients (2 groups of 27 patients).

\section{Statistical analysis}

Intention-to-treat analysis will be applied on the primary endpoint pain reduction. Since we expect a significant cross-over from the nerve block group towards the neurectomy group, an 'as treated analysis' will be made as well. Endpoints will be analyzed per group and at each evaluation time. Chi/square test is used for comparison of categorical variables. Quantitative variables will compared by Mann-Whitney $U$ test. Results will be considered significant if $P \leq 0.05$.

\section{DISCUSSION}

In recent years, a number of studies has stressed the importance of chronic pain as an important complication after inguinal hernia repair ${ }^{1-4}$. However, to date only a few studies on treatment options such as operative neurectomy or therapeutic nerve blocks have been published. There is a definite need for more evidence-based treatment regimes in these populations. The present trial will be the first randomized study comparing two frequently used treatment modalities for chronic neuralgia after inguinal hernia repair.

Populations with postherniorrhaphy pain syndromes are notoriously heterogeneous. Therefore, only patients with presumed peripheral inguinal nerve entrapment are included. In contrast, individuals with non-neuropathic pain ('nociceptive') including periostitis or folded or migrated fibrotic mesh material are not eligible as their pain is probably unresponsive to an exclusive neurectomy ${ }^{8}$. Patients that will probably also not respond to a tailored neurectomy are the 'long-term neuropathic pain sufferers', as they may have developed sensitization of the central nervous system. Permanent sensitisation on cerebral level is thought to render peripheral interventions such as a neurectomy insufficient ${ }^{18}$. Although these patients typically report symptomatology associated with neuropathic pain, peripheral nerve blocks will probably not induce pain reduction. There fore, a substantial temporary pain reduction after inguinal nerve block with lidocain serves as an important prerequisite for inclusion in the present trial.

There is little evidence on the beneficial effects of an injection of a cocktail of agents for the treatment of chronic inguinal neuropathic pain. The choice for a combination of lidocain, corticosteroids and hyaluronic acid was made after consultation of several anaesthesiologist-pain specialists ${ }^{19}$. One study suggested that corticosteroids act by suppression of ectopic neural discharges from the injured nerve endings ${ }^{6}$. Moreover, hyaluronic acid may soften scar tissue and may aid in local infiltration of the anaesthe tic and corticosteroids ${ }^{20}$. It was hypothesized that the combination of these two substances acted synergistically and facilitated and potentiated the analgesic effects of lidocain.

Although the sequence of steps in the surgical neurectomy is standardized as much as possible, experience with past cases indicated that each patient requires individualization. Therefore, pre- and perioperative findings guided us on the handling of the affected nerves, 'the tailored approach'12. In contrast, a single specialist center advocates a standard 'triple neurectomy' for this pain syndrome, removing all three inguinal nerves during one procedure, achieving success rates up to $85 \%$. However, slightly lower success rates for this difficult chronic pain issue are probably more realistic, which we have demonstrated in a recently published retrospective review on the 'tailored approach'. The latter patient cohort exhibited a more heterogeneous pain pattern (e.g. also non-neuropathic) and had often received surgical interventions in other clinics as well. 
The patients in the GroinPain trial will be more homegeneous, hopefully resulting in higher success rates. Moreover, a potential disadvantage of a classic triple procedure is neuroma formation in previously unaffected nerves with a possible onset of deafferentation pain.

This study also evaluates secondary endpoints such as quality of life and impact on occupational disability. Any improvement in quality of life will further underscore the need for standardized treatment protocols. We are currently under the impression that an operative neurectomy may serve as the backbone of such treatment regimes. However, the present randomized study may find that nerve blocks may also serve as an important tool in the treatment of this growing patient population.

\section{REFERENCES}

1 Cunningham J, Temple WJ, Mitchell P, Preshaw RM, Hagen NA. Cooperative hernia study. Pain in the postrepair patient. Ann Surg 1996; 224:598-602

2 Bay-Nielsen M, Perkins FM, Kehlet $H$. Pain and functional impairment 1 year after inguinal herniorrhaphy: a nationwide questionnaire study. Ann Surg 2001; 233: 1-7

3 Loos MJ, Roumen RM, Scheltinga MR. Chronic sequelae of common elective groin hernia repair. Hernia 2007; 11: 169-1734.

4 Nienhuijs SW, Boelens OB, Strobbe LJ. Pain after anterior mesh hernia repair.J Am Coll Surg 2005; 200: 885-889

5 Loos MJ, Roumen RM, Scheltinga MR. Classifying post-herniorrhaphy pain syndromes following elective inguinal hernia repair. World J Surg 2007; 31: 1760-1765

6 Johansson A, Bennett GJ. Effect of local methylprednisolone on pain in a nerve injury model. A pilot study. Reg Anesth 1997; 22: 59-65

7 Cohen SP, Foster A. Pulsed radiofrequency as a treatment for groin pain and orchialgia. Urology 2003; 61: 645

8 Aasvang EK, Kehlet $H$. The effect of mesh removal and selective neurectomy on persistent postherniotomy pain. Ann Surg 2009; 249:327-334

9 Amid PK. Causes, prevention, and surgical treatment of postherniorrhaphy neuropathic inguinodynia: triple neurectomy with proximal end implantation. Hernia 2004

10 Ducic I, West J, Maxted W. Management of chronic postoperative groin pain. Ann Plast Surg 2008; 60: 294-298; 8:343-349

11 Giger U, Wente MN, Buchler MW, Krahenbuhl S, Lerut J, KrahenbuhI L. Endoscopic retroperitoneal neurectomy for chronic pain after groin surgery. Br J Surg 2009; 96:1076-1081

12 Loos MJ, Scheltinga MR, Roumen RM. Tailored neurectomy for treatment of postherniorrhaphy inguinal neuralgia. Surgery 2010; 147: 275-281

13 Vuilleumier H, Hubner M, Demartines N. Neuropathy after herniorrhaphy: indication for surgical treatment and outcome. World J Surg 2009;33: 841-845
14 McCarthy M, Jr., Chang CH, Pickard AS, Giobbie-Hurder A, Price DD, Jonasson O, Gibbs J, Fitzgibbons $R$, Neumayer L. Visual analog scales for assessing surgical pain. J Am Coll Surg 2005; 201: 245-252

15 Van der Kloot WA, Oostendorp RA, van der MJ, van den HJ. [The Dutch version of the McGill pain questionnaire: a reliable pain questionnaire]. Ned Tijdschr Geneeskd 1995; 139: 669-673

16 Ware JE, Jr., Gandek B. Overview of the SF-36 Health Survey and the International Quality of Life Assessment (IOOLA) Project. J Clin Epidemiol 1998; 51: 903-912

17 Bennett M. The LANSS Pain Scale: the Leeds assessment of neuropathic symptoms and signs. Pain 2001; 92: 147-157

18 Kehlet H, Jensen TS, WoolfCJ. Persistent postsurgical pain: risk factors and prevention. Lancet 2006 , 367: 1618-1625

19 Hameroff $S R$, Crago BR, Blitt CD, Womble J, Kanel J. Comparison of bupivacaine, etidocaine, and saline for trigger-point therapy. Anesth Analg 1981; 60: 752-755

20 Curatolo M, Bogduk N. Pharmacologic pain treatment of musculoskeletal disorders: current perspectives and future prospects. Clin J Pain 2001; 17:25-32 


\section{CHAPTER 8}

Surgical management of inguinal neuralgia after a low transverse Pfannenstiel incision

Loos MJA, Scheltinga MRM, Roumen RMH

Ann Surg 2008; 248: 880-885 


\section{Background}

The low transverse Pfannenstiel incision has been associated with chronic lower abdominal pain because of nerve entrapment (2\%-4\%). Treatment options include peripheral nerve blocks or a neurectomy of neighboring nerves. Knowledge on adequate (surgical) management is scarce. The authors assessed the long-term pain relief after local nerve blocks or neurectomy in patients suffering from chronic pain because of Pfannenstielinduced nerve entrapment.

\section{Methods}

Patients treated for iliohypogastric and/or ilioinguinal neuralgia after a Pfannenstiel incision received a questionnaire assessing current pain intensity (by 5 -point verbal rating scale), complications, and overall satisfaction.

\section{Results}

Twenty-seven women with Pfannenstiel-related neuralgia were identified between 2000 and 2007. A single diagnostic nerve block provided long-term pain relief in 5 patients. Satisfaction in women undergoing neurectomy $(n=22)$ was good to excellent in $73 \%$, moderate in $14 \%$, and poor in $13 \%$ (median follow-up, 2 years). Complications were rare. Successful treatment improved intercourse-related pain in most patients. Co-morbidities (endometriosis, lumbosacral radicular syndrome) and earlier pain treatment were identified as risk factors for surgical failure.

\section{Conclusions}

Peripheral nerve blocking provides long-term pain reduction in some individuals. An iliohypogastric or ilioinguinal nerve neurectomy is a safe and effective procedure in most remaining patients. 


\section{INTRODUCTION}

Worldwide millions of low transverse Pfannenstiel incisions are performed each year in obstetric and gynaecological practice. Ever since its introduction this approach has been a successful access path for lower abdominal surgery with an exceptionally low incisional hernia rate (o-2\%) and an aesthetically pleasing appearance ('bikini cut') $)^{1,2}$. Moreover Pfannenstiel incisions are frequently used in laparoscopic procedures for removal of resected specimens 3.4 .

The Pfannenstiel technique harbours one serious drawback being 'nerve entrapment'². According to recent reports chronic pain is more commonly observed than previously thought $(12.3 \%-33 \%)^{2,5-8}$. One study with a two year follow up reported that $8 \%$ of patients with a Pfannenstiel incision graded their pain as moderate or severe leading

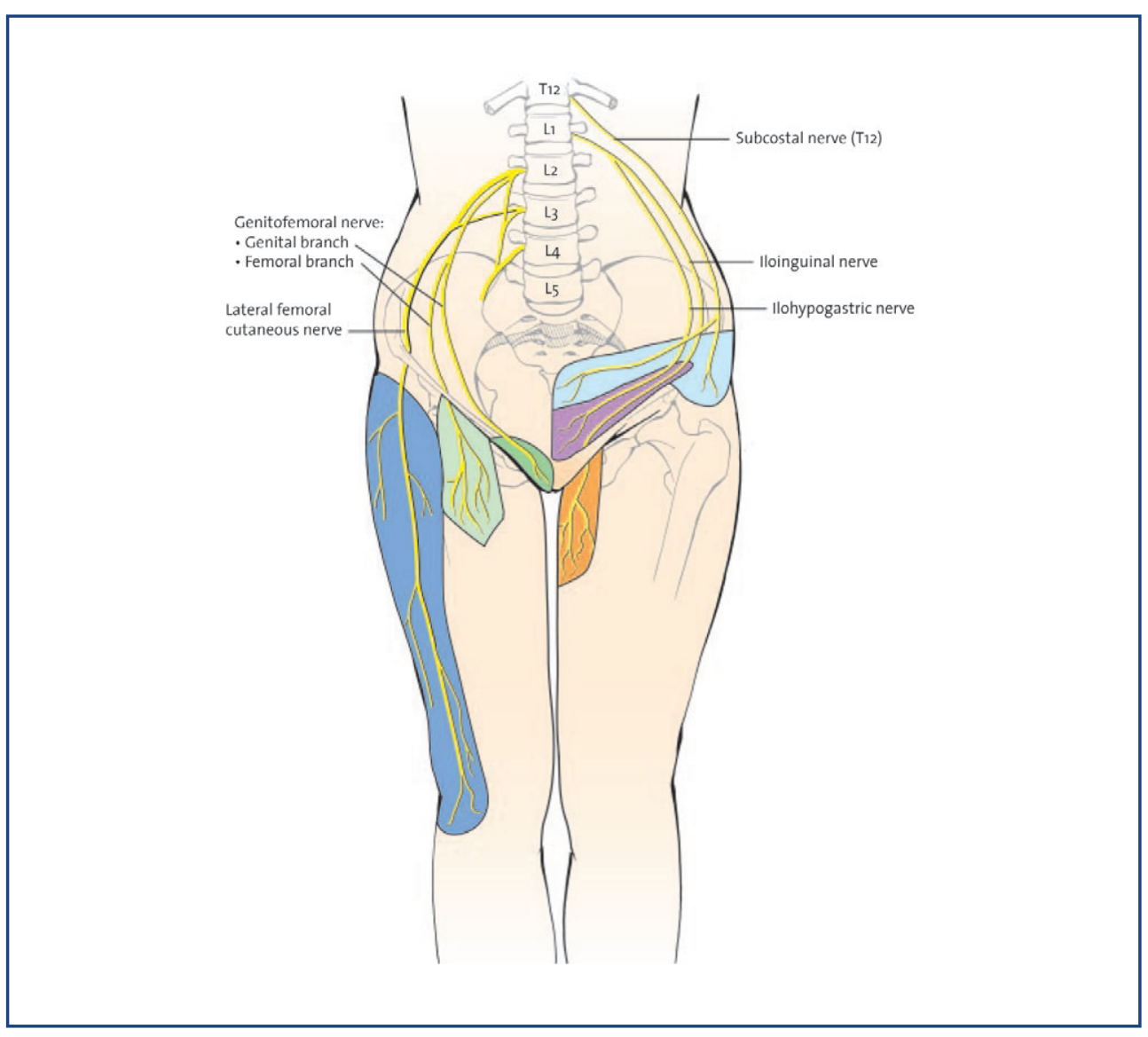

Figure 1 Cutaneous innervation of lower abdomen ${ }^{21}$

This figure has appeared in the article by Ducic et al. Algorithm for treatment of postoperative incisional groin pain after cesarean delivery or hysterectomy. Obstet Gynecol 2006; 108: 27-31. to limitations in daily functioning. As laparoscopy with concomitant Pfannenstiel incision is gaining popularity in general surgery, the incidence of nerve entrapments will probably rise as well.

Treatment consists of nerve blocks or neurectomy. Aim of the present study was to assess long-term pain relief following these treatment modalities in patients suffering from chronic pain due to Pfannenstiel-induced nerve entrapment.

\section{Anatomy and pathophysiology ${ }^{5}$}

The cutaneous innervation of the lower abdomen is mainly supplied by two nerves, the iliohypogastric and the ilioinguinal nerves (figure 1). Originating from 12th thoracic and 1st lumbar roots, they run on the anterior aspect of the lumbar quadrate muscle and penetrate the transverse and internal oblique muscles. Endings of these nerves can be found subcutaneously or subfascially at the lateral margin of the abdominal rectus muscles. If dissection during a Pfannenstiel incision is executed too laterally, these nerves may be harmed potentially creating a neuroma ${ }^{2}$. Moreover, nerves may be trau matized due to perioperative retraction or following constricting sutures. Development of fibrotic tissues later on can also initiate nerve entrapment. Considerable anatomic variability and overlapping cutaneous innervation areas complicate localisation and identification of affected nerves and render clinical discrimination of iliohypogastric and ilioinguinal nerves exceedingly difficultg,10. In women the genitofemoral nerve accompanies the round ligament and is nearly always unaffected during Pfannenstie surgery. A neurectomy of the genital branch is therefore unnecessary. However concurrent ipsilateral inguinal hernioplasty mandates a triple neurectomy according to Amid.

\section{Clinical presentation and diagnostic work-up}

Pain may be reported immediately postoperatively or may develop over time. Neuropathic pain initiated by entrapped or damaged nerve tissue is characterized by lancinating, sharp or stabbing pain sensations at the incisional corners irradiating to pubic area and/or upper leg. Hyperextension or twisting upper body movements can induce pain by means of nerve traction or compression. Menstruation may increase pain sensations due to hormone-induced neurotransmitters. However, cutaneous endometriosis should also be considered".

At physical examination neurophysiological disorders such as hypoesthesia, hyperesthesia or allodynia are often present. Remarkably, patients may not be aware of these neurological abnormalities. Pressuring the incisional edge(s) at the abdominal rectus margin may reveal a distinct trigger point. If active abdominal muscle contraction intensifies pain (positive Carnett's sign), the pain is probably located in the abdominal wall. If nerve entrapment is likely, the diagnostic work-up should include a nerve block using a short-acting anaesthetic (e.g. lidocain) placed into the trigger point. Such injections ideally provide immediate pain relief and contribute to the diagnosis 5 . 




Figure 2 Diagnostic and therapeutic algorithm for neuropathic post-Pfannenstiel pain.

\section{PATIENT AND METHODS}

A retrospective database search was performed extracting all consecutive patients of the Máxima Medical Center (Veldhoven, The Netherlands), who were treated for neuralgia of the iliohypogastric and/ or ilioinguinal nerve following a Pfannenstiel incision since 2000. All medical charts were reviewed for pain history, physical examination, additional tests, co-morbidities (defined as endometriosis and lumbosacral radicular syndrome) and previously received pain treatments. Patients were excluded if other known causes of pain such as cutaneous endometriosis were suspected.

\section{Treatment algorithm ${ }^{12}$}

All patients were evaluated according to a standard algorithm (figure 2). If pain of neuropathic origin was suspected, patients received a nerve block using a local anaesthetic into the trigger point. A substantial but temporary pain reduction led to a repeat nerve block also using corticosteroids. If these nerve blocks did not result in long-term pain reduction, patients were offered a neurectomy of the affected nerve (ilioinguinal and/or iliohypogastric). This procedure was performed in day-care setting under spinal or general anaesthesia by general surgeons specialized in groin and abdominal wall pain pathology (RR and MS). Prior to operation, the responsible nerve was localized by marking the skin overlying the trigger point. A portion of the scar was incised and lateralized if deemed necessary. The overlying subcutaneous tissue and external oblique fascia were dissected and the nerve was identified and removed up to the anterior superior iliac spine (figure 3). For haemostatic purposes nerve endings were cauterised. In an attempt to prevent to recurrent fibrotic encasement the proximal nerve end was buried in healthy muscular tissue. Nearly all removed specimens underwent pathological examination (figure 4)

\section{Questionnaire}

Between September 2007 and November 2007 all treated patients received a questionnaire that was composed of parts of previously published pain studies ${ }^{13-15}$. The following items were assessed: pain reduction (expressed in a 5-point Verbal Rating Scale and percentages), complaints associated with sexual activities, perceived complications, overall satisfaction ${ }^{14}$, and current need for pain medication.

\section{RESULTS}

From January 2000 to September 2007 twenty-seven women presenting at the surgical outpatient department were diagnosed with neuralgia following a Pfannenstiel incision. During the standard workup 5 patients attained long-lasting pain relief with a single 
'diagnostic' nerve block. A one-stage neurectomy was performed in the remaining 22 cases. Two patients underwent a second surgical exploration as the first operation (neurolysis and resection of possible neuroma, which was not sent for histopathological examination) did not have the desired effect.

Median age was 43 years (range: 22-67 years) and the initial surgery was a cesarean delivery $(n=19)$, abdominal hysterectomy $(n=6)$, or other $(n=2)$. Women were suffering from pain for a median period of two years (range: 4 months-32 years). Sensory abnormalities including hypesthesia $(41 \%)$, hyperesthesia $(26 \%)$, or allodynia $(4 \%)$ were usually present. In all women a trigger point was present. Two patients also harboured a paresthetic meralgia. Additional imaging including CT-scan was performed in $37 \%$ of patients but did not contribute to the diagnosis apart from excluding other diagnoses.

Figure 5 shows pain intensity before neurectomy (70\% suffering from severe pain or very severe pain, and after neurectomy ( $80 \% \mathrm{no} /$ mild pain, median follow up two years). The median pain reduction was $90 \%$. Complications were rare: wound infection $(n=1)$, bulge $(n=3)$, and onset of pain elsewhere $(n=6)$. Treatment satisfaction in patients undergoing neurectomy $(n=22)$ was good or excellent in $73 \%$ of women, moderate in $14 \%$, and poor or worse in $13 \%$ (table 1). Due to mild recurrent pain elsewhere in the groin/ lower abdomen, three women graded their initial excellent postoperative results as 'good' during questionnaire enrolment.

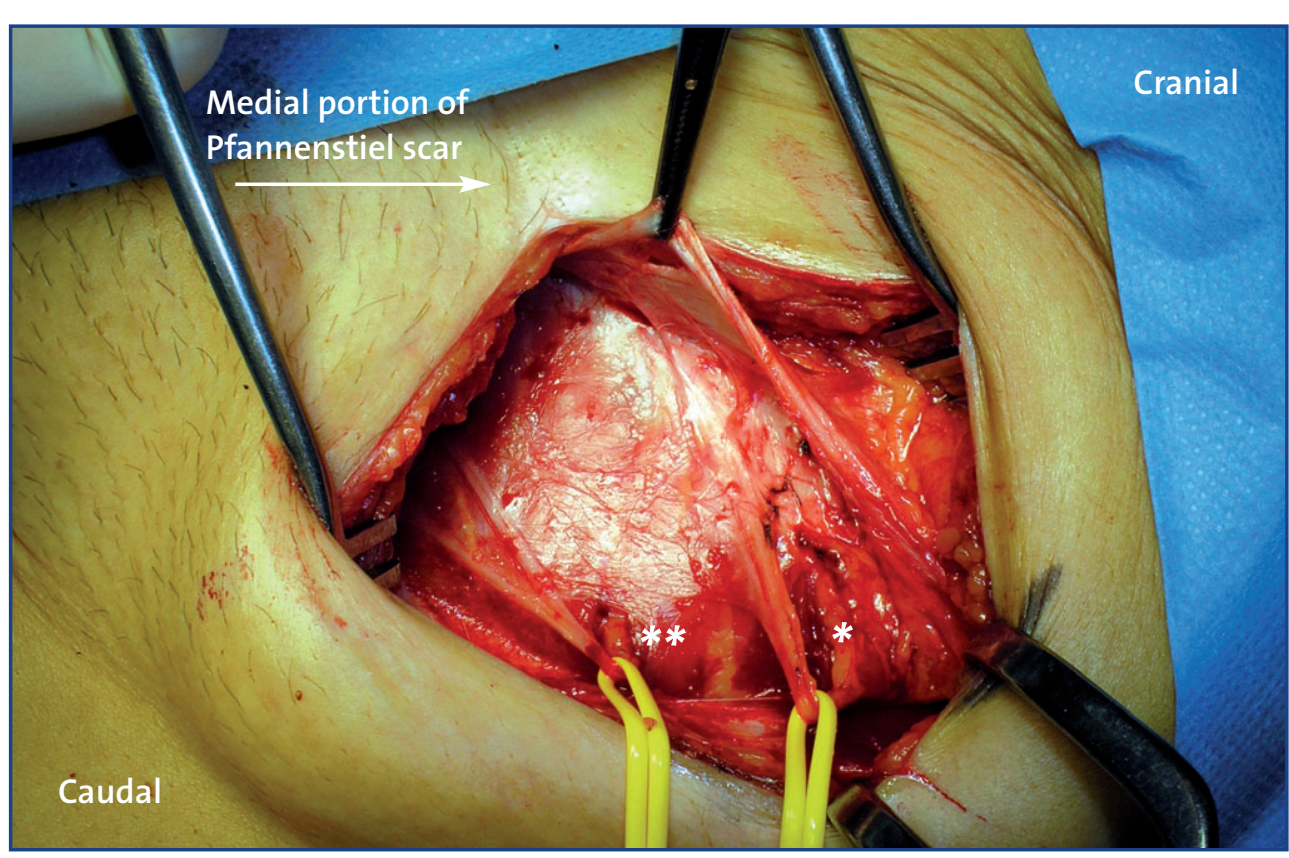

Figure 3 Neurectomy of the left iliohypogastric* and ilioinguinal nerve ${ }^{* *}$
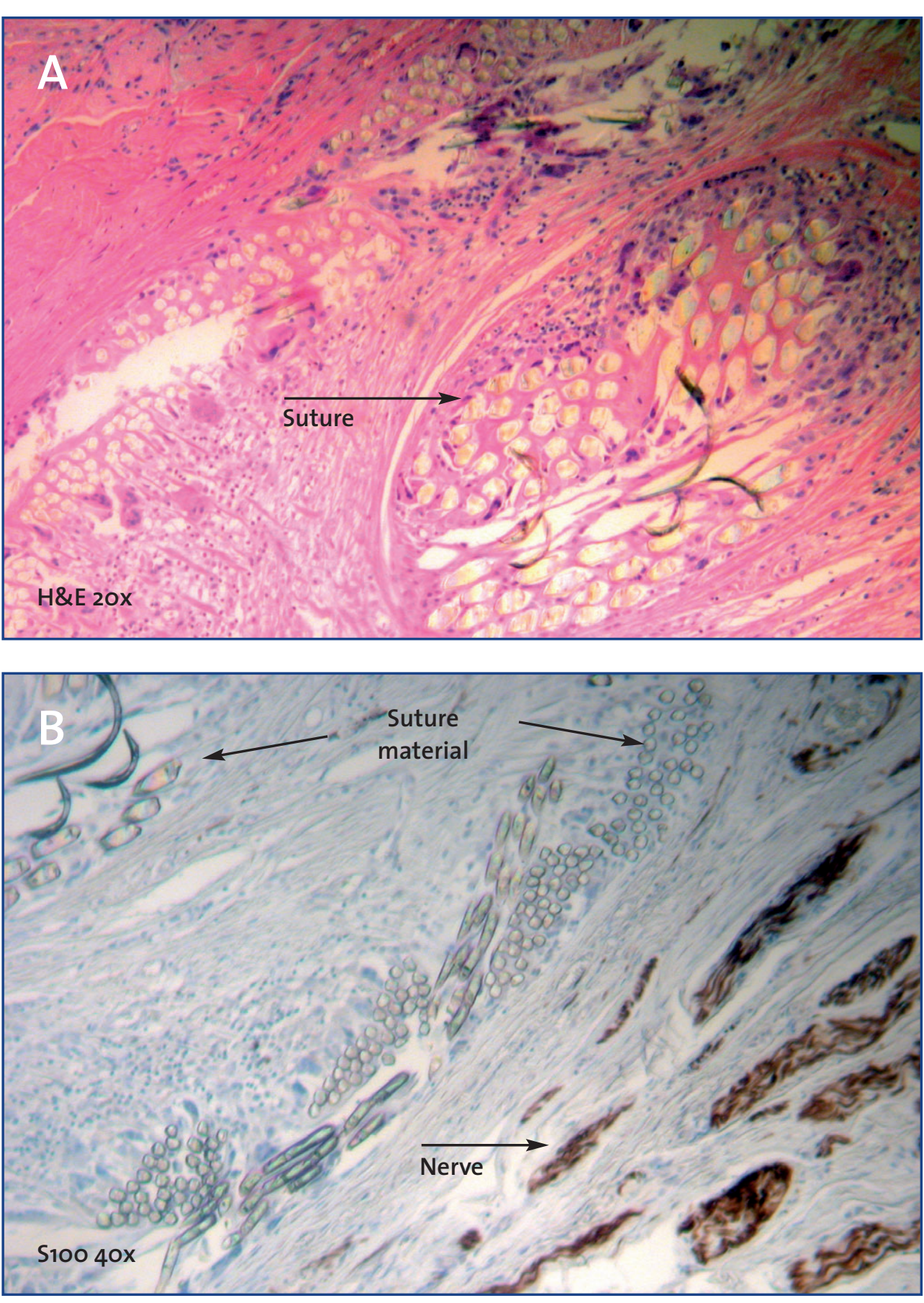

Figure 4 Microscopic examination of removed tissue revealing suture material and nerve tissue.

Figure 4 Microscopic examination of removed tissue revealing suture material and nerve tissue.
(A) H\&E staining 20x magnification, (B) S10o staining $40 x$ magnification. This case concerned a woman with a $32-y e a r$ lasting previously unrecognised pain syndrome, caused by inappropriate (non-resorbable) suture placement at the lateral border of a Pfannenstiel incision. 
Possible negative determinants for satisfaction with neurectomy results were presence of co-morbidities (endometriosis, lumbosacral radicular syndrome) and previous invasive pain treatment (e.g. sympathectomy, lumbar facet denervation, table 2). Table 3 demonstrates that intercourse-induced pain was commonly reported prior to surgery (58\%). Invasive treatment reduced these pain symptoms in $75 \%$ of the women. Histo-

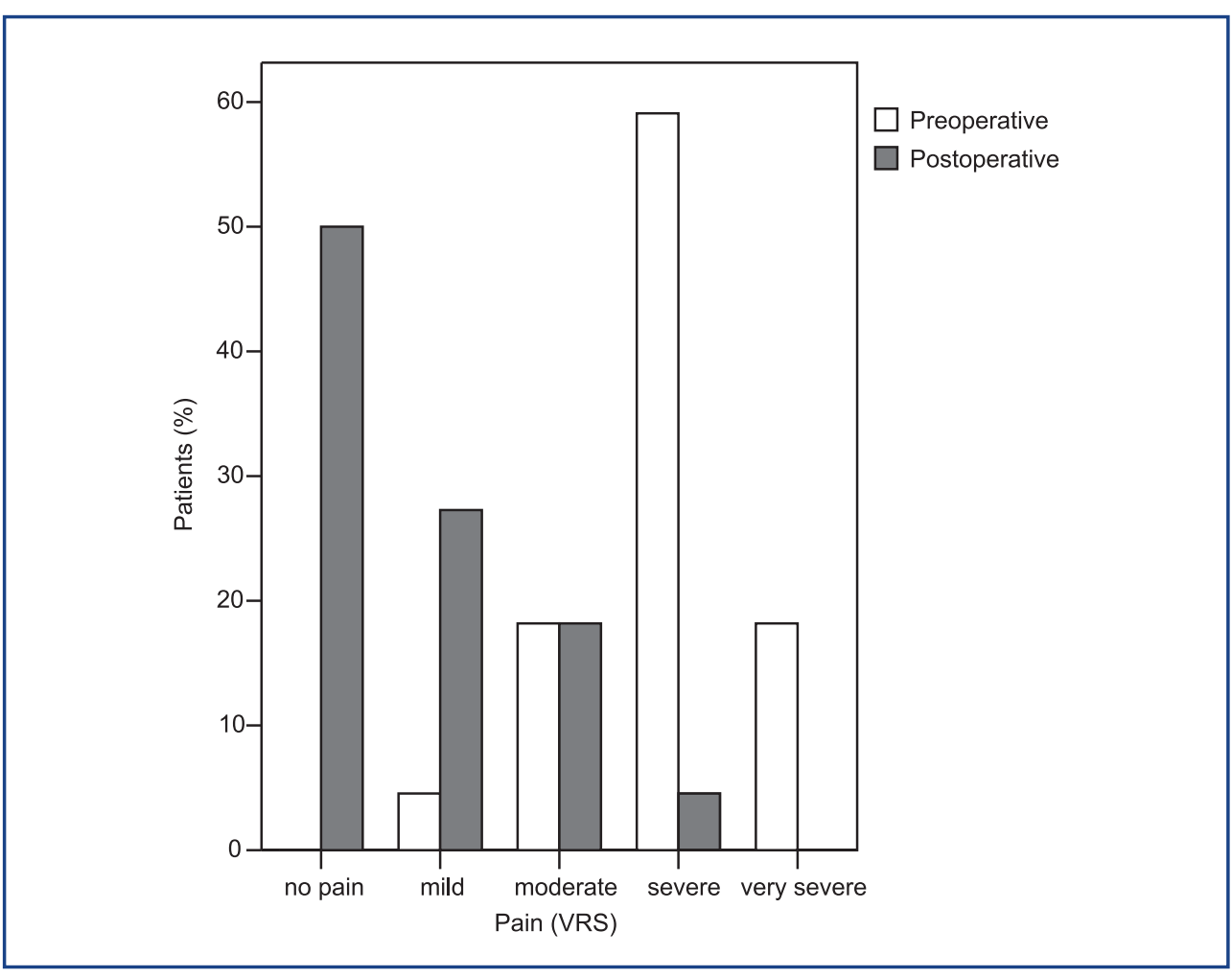

Figure 5 Pain intensity before and after neurectomy for Pfannenstiel-associated nerve entrapment ( $n=22)$.

$\begin{array}{ll} & n(\%) \\ \text { - Excellent - I am pain free } & 11(50) \\ \text { - Good - I am almost pain free } & 5(23) \\ \text { - Moderate - Although there is some pain reduction, } & 3 \\ \text { I am still frequently bothered by pain complaints } & 1(4) \\ \text { - Poor - The operation had no effect and the pain is } & \\ \text { virtually the same } & 2(9) \\ \text { - Worse - The operation has worsened my pain } & \end{array}$

Table 1 Patient satisfaction with neurectomy $y^{4}(n=22)$. pathology revealed the following findings: perineural fibrosis $(n=2)$, degenerative nerve tissue $(n=3)$, neuroma $(n=2)$, normal nerve tissue $(n=8)$, and fibrosis without nerve tissue $(n=1)$. In 6 patients no pathological examination was obtained. These findings did not seem to correlate with pain outcome. Currently, a quarter of the patients reported the occasional use of pain medication.

\begin{tabular}{|c|c|c|c|}
\hline & $\begin{array}{l}\text { High satisfaction ( } \mathrm{n}=16) \\
\text { (Good/ excellent) } \\
\mathrm{n}(\%)\end{array}$ & \multicolumn{2}{|c|}{$\begin{array}{l}\text { Low Satisfaction }(\mathrm{n}=6) \\
\text { (Moderate/ poor/ worse) } \\
\mathrm{n}(\%)\end{array}$} \\
\hline \multicolumn{4}{|c|}{ Duration of pain complaints } \\
\hline$\geq 5$ years & $4(25)$ & $3(50)$ & $p=0.262^{*}$ \\
\hline$<5$ years & $12(75)$ & $3(50)$ & \\
\hline \multicolumn{4}{|c|}{ Co-morbidities** } \\
\hline No & $15(94)$ & $1(17)$ & $p<0.001$ \\
\hline Yes & $1(6)$ & $5(83)$ & \\
\hline \multicolumn{4}{|c|}{ Previous received treatment ${ }^{* * *}$} \\
\hline No & $11(69)$ & $1(17)$ & $p=0.029$ \\
\hline Yes & $5(31)$ & $5(83)$ & \\
\hline
\end{tabular}

Table 2 Factors possibly related to satisfaction with neurectomy ( $n=22$.

"Chi-square test, ${ }^{* *}$ Co-morbidities = endometriosis, lumbosacral radicular syndrome, ${ }^{* * *}$ Previous treatment $=$ sympathectomy " adhesiolysis, Lichtenstein procedure, laparoscopic femoral hernioplasty (or a combination of several).

\begin{tabular}{|c|c|}
\hline & $n(\%)$ \\
\hline \multicolumn{2}{|l|}{ Before the intervention, I experienced pain: } \\
\hline During intercourse & $9(33)$ \\
\hline During and after intercourse & $4(15)$ \\
\hline After an orgasm & $3(11)$ \\
\hline No preoperative pain during sex/ Not appropriate & $11(41)$ \\
\hline \multicolumn{2}{|c|}{ The intervention had the following effect on my sex-induced pain: } \\
\hline Total pain reduction & $5(32)$ \\
\hline Certain amount of pain reduction & $7(43)$ \\
\hline Similar pain & $4(25)$ \\
\hline
\end{tabular}

Table 3 Sexual pain assessment based on questionnaire results $(n=27)$. 


\section{DISCUSSION}

In the present study a neurectomy of the ilioinguinal and/ or iliohypogastric nerve(s) provided good to excellent results in nearly three quarters of all women suffering from Pfannenstiel-induced neuralgic pain. Apart from a few case reports ${ }^{16-21}$, literature is scarce. One study described a large number of neurectomies including 36 that were Pfannenstiel-induced with similar favourable results ${ }^{22}$. In another recent study all seven reported patients were pain free following a neurectomy ${ }^{23}$. Neurectomy of the genita branch of the genitofemoral nerve is unnecessary. There is increasing evidence that a selective neurectomy constitutes a safe and effective treatment for postoperative Pfannenstiel-related neuralgia in most patients.

Using the presented algorithm, total pain relief occurred in five cases after administering a local nerve block omitting the need for neurectomy ${ }^{12}$. The anaesthetic agent probably pushes the pain threshold back to its normal level. This finding further stresses the conditional need for using diagnostic nerve blocks as they appear to have therapeutic value as well.

Inguinal neuralgia caused pain during sexual activities in over half of the women, possibly due to compressed nerve tissue during muscle contraction. A neurectomy or therapeutic nerve block provided intercourse-related pain relief in a substantial portion of the patients. Remarkably, to the author's knowledge, this entity has never been reported in medical literature. Since these forms of inconvenience greatly affect quality of life, proper attention should be given to these issues. Moreover, inguinal neuralgia should be included into the differential diagnosis of dyspareunia as well.

Results of the present study indicate that surgery was ineffective in a quarter of the patients. Various factors possibly contributing to unsuccessful neurectomy must be considered. First of all, before proceeding to surgery, pain reduction (albeit temporary) after a peripheral nerve block is a 'sine qua non'. A recent study suggested a treatment algorithm using pain history and physical examination as main parameters for surgery, omitting diagnostic nerve blocks ${ }^{23}$. In our experience, some patients do not react on nerve blocks, as their central nervous system may be sensitized. These patients suffer from 'central neuropathic pain', and this separate population will not respond to peripheral nerve surgery, leaving only drug therapy (antidepressants, anti-epileptics, gabapentin) as therapeutic measures. Secondly, a neurectomy should probably include all pain conducting nerve structures as also promoted for pain syndromes following groin hernia surgery ${ }^{24}$. Thirdly, pain may recur after an initially successful neurectomy or present elsewhere on the abdominal wall. Possible explanations involve neuroma formation at the nerve stump, or revelation of a previously suppressed non-neuropathic pain cause (e.g. periostitis pubis). Moreover, as non-responders differ from responders in number of associated co-morbidities and earlier invasive pain treatments, these aspects may act as denominators for surgical failure. Taking these considerations into account, a positive nerve block followed by a thorough neurectomy in patients with few risk factors will likely lead to satisfying surgical results.

Which preventive measures can be taken by the surgeon performing the Pfannenstiel incision? A solid knowledge of neuroanatomy, meticulous tissue dissection, avoidance of extreme lateral incision ${ }^{2}$, and prevention of suturing beyond the rectus margin will help to avoid nerve entrapment. In case of immediate severe postoperative pain, surgical exploration of the painful area may be performed without delay as nerve entrapment by suture material must be excluded. Since nerve entrapment may also occur over time due to fibrosis, knowledge on clinical presentation and treatment of this debilitating pain syndrome is warranted.

In conclusion, peripheral nerve blocking provides long-term pain reduction in some individuals. An iliohypogastric or ilioinguinal nerve neurectomy is a safe and effective procedure in most remaining patients.

\section{REFERENCES}

1 Kisielinski K, Conze J, Murken AH, et al. The Pfannenstiel or so called "bikini cut": Still effective more than 100 years after first description. Hernia 2004; 8: 177-181

2 Luijendijk RW, Jeekel J, Storm RK, et al. The low transverse Pfannenstiel incision and the prevalence of incisional hernia and nerve entrapment. Ann Surg 1997; 225:365-369

3 Tisdale BE, Kapoor A, Hussain A, et al. Intact specimen extraction in laparoscopic nephrectomy procedures: Pfannenstiel versus expanded port site incisions. Urology 2007; 69: 241-244

4 Kessler H, Hohenberger W. Laparoscopic total colectomy for slow-transit constipation. Dis Colon Rectum 2005; 48: 860-86

5 Loos MJA, Scheltinga MRM, Mulders LGM, Roumen RMH. The 'Pfannenstiel' approach as a source of chronic pain. Obstet Gynecol 2008; 111: 839-846

6 Hannah ME, Whyte H, Hannah WJ, et al. Maternal outcomes at 2 years after planned cesarean section versus planned vaginal birth for breech presentation at term: the international randomized term breach trial. Am J Obstet Gynecol 2004; 191: 917-927

7 Nikolajsen L, Sørensen HC, Jensen TS, et al. Chronic pain following Caesarean section. Acto Anaesthesiologica Scandinavica 2004; 48: 111-116

8 Huikeshoven FJ, Dukel L. De bikini-snede, mooi maar niet altijd zonder pijnlijke gevolgen. Ned Tijdschr Geneesk 1998; 142: 1481-1483

9 Mandelkow $\mathrm{H}$, Loeweneck $\mathrm{H}$. The iliohypogastric and ilioinguinal nerves. Distribution in the abdominal wall, danger areas in surgical incisions in the inguinal and pubic regions and reflected visceral pain in their dermatomes. Surg Radiol Anat. 1988; 10: 145-149

10 Rab M, Ebmer J, Dellon L. Anatomic variability of the ilioinguinal and genitofemoral nerve: implications for the treatment of groin pain. Plast Reconstr Surg 2001; 108: 1618-1623

11 Blanco R.G, Parithivell V.S, Shah A.K, Abdominal Wall Endometriomas. Am J Surg 2003; 185:596-598 
12 Loos MJA, Roumen RMH, Scheltinga MRM. Classifying postherniorrhaphy pain syndromes following elective inguinal hernia repair. World I Surg 2007; 31: 1760-1765; discussion 1766-1767

13 Loos MJA, Roumen RMH, Scheltinga MRM. Chronic sequelae of common elective groin hernia repair. Hernia 2007; 11: 169-173

14 Hahn L. Clinical findings and results of operative treatment in ilioinguinal nerve entrapment syndrome. Br J Obstet Gynaecol 1989; 96: 1080-1083

15 Loos MJA, Houterman S, Scheltinga MRM, Roumen RMH. Evaluating postherniorrhaphy groin pain: Visual Analogue or Verbal Rating Scale? Hernia 2008; 12: 147-152

16 Whiteside JL, Barber MD. Ilioinguinal/iliohypogastric neurectomy for management of intractable right lower quadrant pain after cesarean section: a case report.J Reprod Med. 2005; 50: 857-859

17 Melville K, Schultz EA, Dougherty JM. Ilioinguinal-iliohypogastric nerve entrapment. Ann Emerg Med 1990; 19: 925-929

18 Tosun $K$, Schäfer $G$, Leonhartsberger $N$, et al. Treatment of severe bilateral nerve pain after Pfannenstiel incision. Urology 2006; 67: 623-656

19 Sippo WC, Burghardt A, Gomez AC. Nerve entrapment after Pfannenstiel incision. Am J Obstet Gynecol 1987; 157:420-421

20 Sippo WC, Gomez AC. Nerve-entrapment syndromes from lower abdominal surgery. J Fam Pract $1987 ; 25: 585-587$

21 Piura B. Nerve entrapment after Pfannenstiel incision (comment and reply). Am J Obstet Gynecol 1989; 161:499-500

22 Madura JA, Madura II JA, Copper CM, et al. Inguinal neurectomy for inguinal nerve entrapment: an experience with 100 patients. Am J Surg 2005; 189:283-287

23 Ducic l, Moxley M, Al-Attar A. Algorithm for treatment of postoperative incisional groin pain after cesarean delivery or hysterectomy. Obstet Gynecol 2006; 108: 27-31.

24 Amid PK. Causes, prevention, and surgical treatment of postherniorrhaphy neuropathic inguinodynia: Triple neurectomy with proximal end implantation. Hernia 2004; 8:343-349 


\section{CHAPTER 9}

Occupational disability due to chronic postherniorrhaphy neuralgia: a plea for tailored neurectomy

Loos MJA, Lemmers ChHC, Heineman E, Scheltinga MRM, Roumen RMH

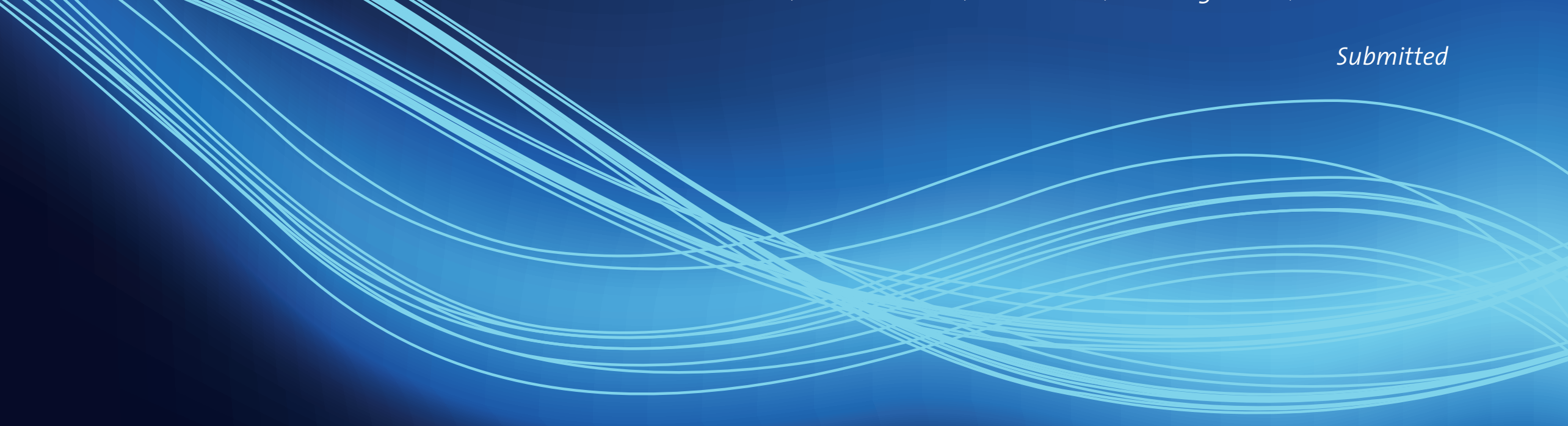




\section{Background}

Routine inguinal hernia repair results in severe persisting pain with occupational disability in $1-2 \%$ of the patients. Resumption of work after pain treatment can be regarded as an important outcome measure. Aim of this study was to evaluate the effect of surgical and non-surgical treatment on resolving occupational disability due to postherniorrhaphy inguinal neuralgia.

\section{Study design}

First, relevant studies on operative and non-operative treatment for postherniorrhaphy inguinal neuralgia were reviewed with respect to effect on occupational disability. Second, a recently published registry of patients with postherniorrhaphy neuralgia treated by operative neurectomy was analyzed for occupational disability. Patients were contacted by telephone and given a set of predetermined questions concerning pre- and postoperative disability. Finally, a cost-benefit analysis for occupational disability and neurectomy was made.

\section{Results}

Only 4 out of 23 studies on neurectomy for inguinal neuralgia reported on occupational disability as a secondary outcome measure. Some 56 to $100 \%$ of the patients could resume their occupational obligations after pain treatment. Studies on non-surgical pain treatment and occupational disability were unavailable. Forty-eight patients previously treated by neurectomy were analyzed for occupational disability. Severe pain disabled 13 patients and a neurectomy resulted in total recovery in 7 of them $(7 / 13,54 \%)$. Finally, an estimating cost-benefit analysis showed that effective pain treatment such as a tailored neurectomy can save a minimum of $€ 1.8$ million of workers' compensational costs in The Netherlands yearly.

\section{Conclusions}

Tailored neurectomy is an effective treatment for occupational disability due to postherniorrhaphy inguinal neuralgia in some patients. A successful neurectomy greatly reduces workers' compensational costs and may have substantial financial consequences worldwide. 


\section{INTRODUCTION}

In the Netherlands, approximately 28.000 individuals of 18 years or older are yearly diagnosed with an inguinal hernia whereas some 22.000 patients receive operative correction (http://www.primant.nl). Severe postherniorrhaphy pain may develop in up to $2 \%(n=440)$ of this population ${ }^{1-3}$. Knowledge of the pathophysiology of chronic postherniorrhaphy pain is increasing. The pain is frequently neuropathic due to entrapment or neuroma formation of the inguinal nerves (Iliohypogastric, llioinguinal, genital branch of the genitofemoral nerve) ${ }^{4}$. Other patients suffer from nociceptive pain including periostal inflammation due to sutures, compressed and displaced prosthetic material or fibrosis causing mechanical discomfort ${ }^{4}$.

There are non-operative or operative treatment options. It has been estimated that some $1 \%$ of all patients after open herniorrhaphy require a multidisciplinary non-operative treatment regimen for chronic pain in a specialized pain clinic 5 . Such treatment modalities include peripheral nerve blocks ${ }^{6,7}$, prescription of neuropathic agents (e.g. amitriptylin or gabapentin), Transcutaneous Electric Nerve Stimulation (TENS), physiotherapy, acupuncture, peripheral neurostimulation using implantable devices ${ }^{8}$ or Pulsed Radio Frequency (PRF). In contrast to the many non-surgical pain strategies ${ }^{6-11}$, there is a paucity of data on treatment results. However, the body of data on surgery for severe postherniorrhaphy pain is quickly expanding. Several studies on operative treatment modalities such as neurectomy, cryoanalgesic ablation or removal of mesh or tackers demonstrate long-term pain reduction in $60-80 \%$ of the patients ${ }^{12-19}$. At groin exploration inguinal nerves may be found 'entrapped' by suture material or encased in fibrosis 4 . Moreover, a traumatic neuroma may also be identified. Traumatized nerves are removed as proximally and distally as possible while proximal nerve ends are buried in healthy muscular tissue ${ }^{18}$. Bulky mesh material may require resection as well. The number of nerves requiring resection remains under debate. Some authors advocate a triple neurectomy removing all three inguinal nerves at once whereas others favour a selective neurectomy of the affected nerve ('tailored neurectomy') ${ }^{18}$.

Most studies use long-term pain resolution as primary treatment outcome measure. However, work resumption is considered important for the patient's well-being as well as from an economical point of view. As young males are particularly prone to chronic pain development, the socio-financial consequences of severe postherniorrhaphy pain are thought considerable as most of these young patients will file for workers' compensation for a substantial number of years if not for the rest of their working lifes,20. Moreover, these relatively young disabled patients are thought to demonstrate increased health care consumption thus adding to the society's loss of financial resources ${ }^{21}$

The present study aimed at reviewing the present body of literature on surgical treatment (neurectomy) and non-surgical treatment on overcoming occupational disability due to postherniorrhaphy inguinal neuralgia. Moreover, the results of recently published study on tailored neurectomy were reviewed with respect to occupational disability. A cost-benefit analysis for occupational disability and neurectomy was performed.

\section{METHODS}

\section{Review of the literature}

Databases including Medline, Embase, and Pubmed were searched for relevant studies on treatment options for chronic postherniorrhaphy inguinal pain and the effect on occupational disability. A search using the term Pain was combined with the following entries: Inguinal, Hernia, Neuralgia, Neurectomy, Treatment, Workers' compensation, Occupational disability, Nerve blocks, PRF, and TENS. There was no limitation in publication date and only English language articles were extracted. A study was excluded if references to occupational disability or workers' compensation were absent. Reference lists of selected articles were cross-checked for pertinent literature. The following data were used for analysis: operative or non-operative treatment, number of included patients, type of study design, treatment, length of follow-up, and effect on occupational disability.

\section{Tailored neurectomy}

Our group of investigators recently published on the long-term 'tailored neurectomy' outcome for inguinal neuralgia after hernioplasty ${ }^{18}$. As our experience with treating these patients grew, we started to appreciate the potential detrimental impact of this chronic pain state on occupational capabilities and consequently the possible curative effect of a neurectomy. Therefore, this population was again analyzed aimed at studying the effect of the surgical neurectomy on occupational disability. All patients were contacted by telephone and received a set of questions regarding working status prior to the initial hernia repair, (if applicable) type of work (light or heavy physical work), onse of postherniorrhaphy pain and occupational disability and its degree (partial/ total), result of neurectomy on occupational disability and whether the previous work could be resumed (table 1).

1 What was your occupational status before the inguinal hernia repair?

2 Did your occupational status alter due to pain complaints after the inguinal herniorrhaphy?

3 Did you become occupationally disabled?

4 What is the degree of your occupational disability? Partial/ complete?

5 Did you resume your work after operative treatment for the postherniorrhaphy pain syndromes?

Table 1 Questions regarding occupational disability. 


\section{Cost-benefit analysis}

The National Institute of Workers Benefit Compensation (The Netherlands: UWV) was asked to make an approximation of the cost-benefit analysis. Firstly, the average yearly costs for a person on workers' compensation was calculated. Second, the yearly number of patients with severe postherniorrhaphy neuralgia applying for a workers benefit compensation was estimated based on published data. From these numbers the total compensational costs in the Netherlands were calculated. The health care costs for neurectomy were approximated. Finally an estimating cost-benefit analysis for neurectomy and workers benefit costs was tabulated.

\section{RESULTS}

\section{Review of the literature}

We analyzed the effects of operative and non-operative treatment for chronic postherniorrhaphy inguinal neuralgia. In total, 23 articles on operative neurectomy were identified $^{12-19,22-35}$. However, the effects on occupational disability after operative treatment was mentioned in just 4 studies $13,15,16,28$. The follow-up period ranged from 1 week to 60

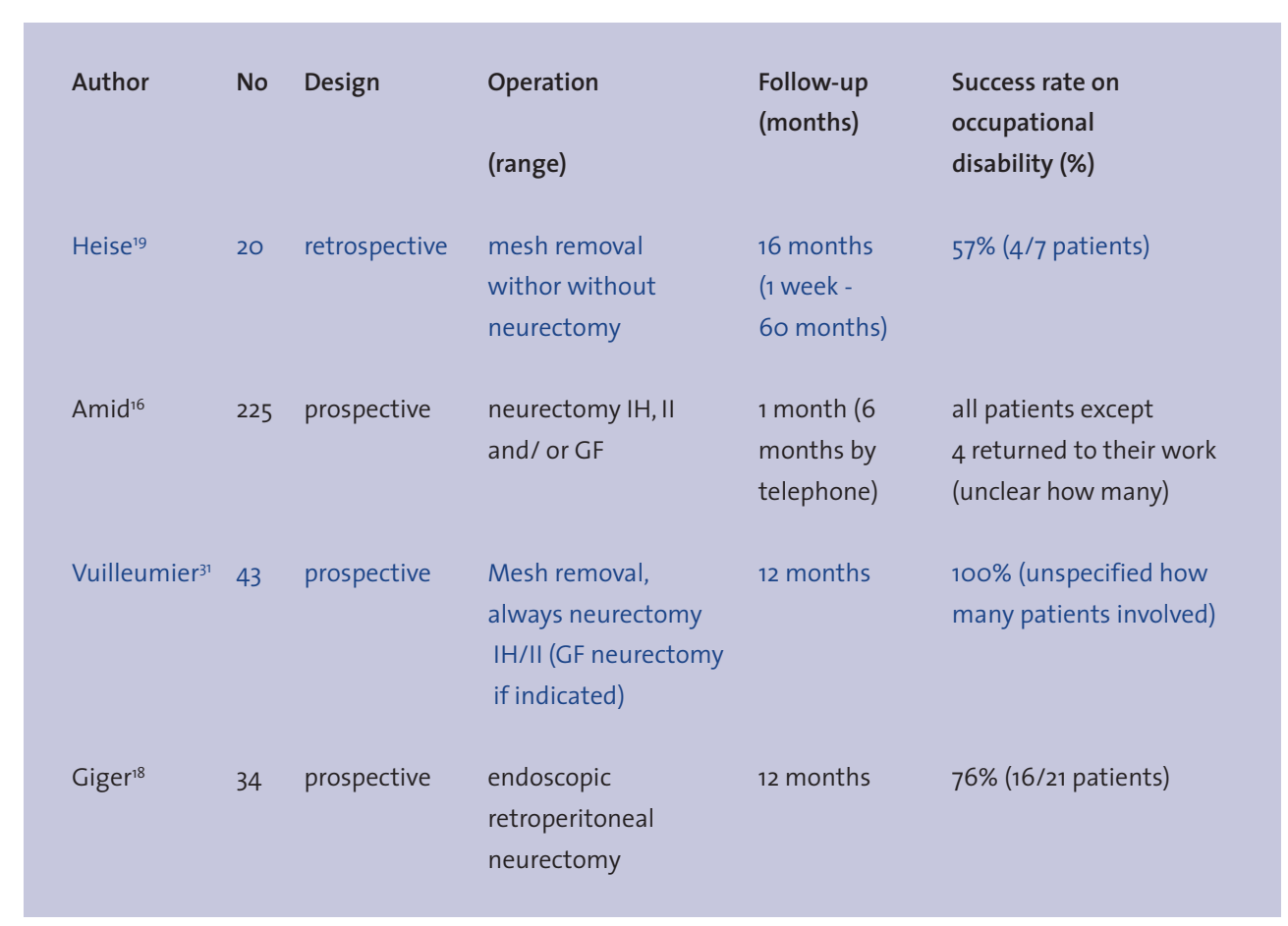

Table 2 Previous studies on surgical management of postherniorrhaphy groin pain syndromes and effect on

occupational disability. months. There was only one retrospective study ${ }^{13}$. Amid et al. described by far the largest series of 225 patients ${ }^{15}$. Type of treatment varied among studies. Giger et al. performed a neurectomy using an endoscopic retroperitoneal technique instead of an open anterior approach ${ }^{15}$. The number of resected nerves also differed among these studies. Vuilleumier et al. routinely performed a radical neurectomy of the iliohypogastric and ilioinguinal nerve ${ }^{28}$. Additional specifics are listed in table 2 . Of all patients that were deemed unfit to properly work due to severe inguinal pain, 56 to $100 \%$ could resume their occupational obligations after neurectomy.

A small number of articles regarding non-surgical treatment options including peripheral nerve block, analgesics, TENS or PRF due to chronic postherniorrhaphy inguinal pain were identified ${ }^{6-11}$. The effect on occupational disability was usually ignored except in one case study describing a full regain of work after treatment with an implantable neurostimulator ${ }^{8}$. We found one surgical study suggesting that nerve blocks for inguinal neuralgia were more effective compared to neurectomy ${ }^{25}$. Twenty-two out of 24 patients with postherniorrhaphy neuralgia were successfully treated with repetitive nerve blocks with Bupivacain and Methylprednisolon. However, no follow-up period nor effect on occupational disability were mentioned.

\section{Tailored neurectomy}

54 patients received a tailored neurectomy as recently reported ${ }^{18}$. Of this population, 48 patients could be contacted by telephone (response rate $89 \%$ ). There were 36 males and 11 females, and their mean age was $52 \pm 6$ yrs (range 26 to 73 ).

Figure 1 demonstrates a flow chart with respect to occupational disability. 20 patients were excluded from further analysis because of the depicted reasons. Of the remaining 28 patients, fifteen could continue their work uninterrupted despite their chronic pain and the neurectomy did not alter their capacity to continue work activities. In contrast, 13 patients were forced to discontinue their prior work due to the incapacitating chronic pain syndrome. Most of these disabled patients $(9 / 13,70 \%)$ judged their work as physically heavy. Some were totally disabled $(n=6)$ whereas others could only work part-time $(n=7)$. After a successful neurectomy, 7 patients $(54 \%)$ had fully resumed their old working habits without disability whereas 6 patients were still occupationally restricted. In a previously published questionnaire study, these 7 working patients had scored their postoperative results as 'satisfactorily'. Results for the persistent disabled patients were generally poor.

\section{Cost-benefit analysis}

In the Netherlands, a person on workers' compensation will cost the society approximately $€_{34.000}$ per year during the first 2 years. This number is composed of an average salary of $€ 32.000$ added with $€ 2000$ extra costs for replacement of personnel, loss of production etc (table 3). These benefits are paid by the employer. After this initial 2-year 
period, a $25 \%$ reduction on their income is applied, leaving $€ 25.000$ ( $75 \%$ of $€ 34000$ ). The state will take over from this time period and compensate the beneficiary. Over a 10-year period the average total costs will approximate $€ 29.000$ per year.

Yearly, $2 \%$ of the postherniorrhaphy hernia repairs will result in severe pain. In the Netherlands, some 440 inguinal hernia repair patients ( $2 \%$ of 22.000 inguinal hernia repairs) will eventually develop a chronic pain syndrome. Most of these patients wil suffer from neuropathic pain that is treatable by a neurectomy. The questionnaire that

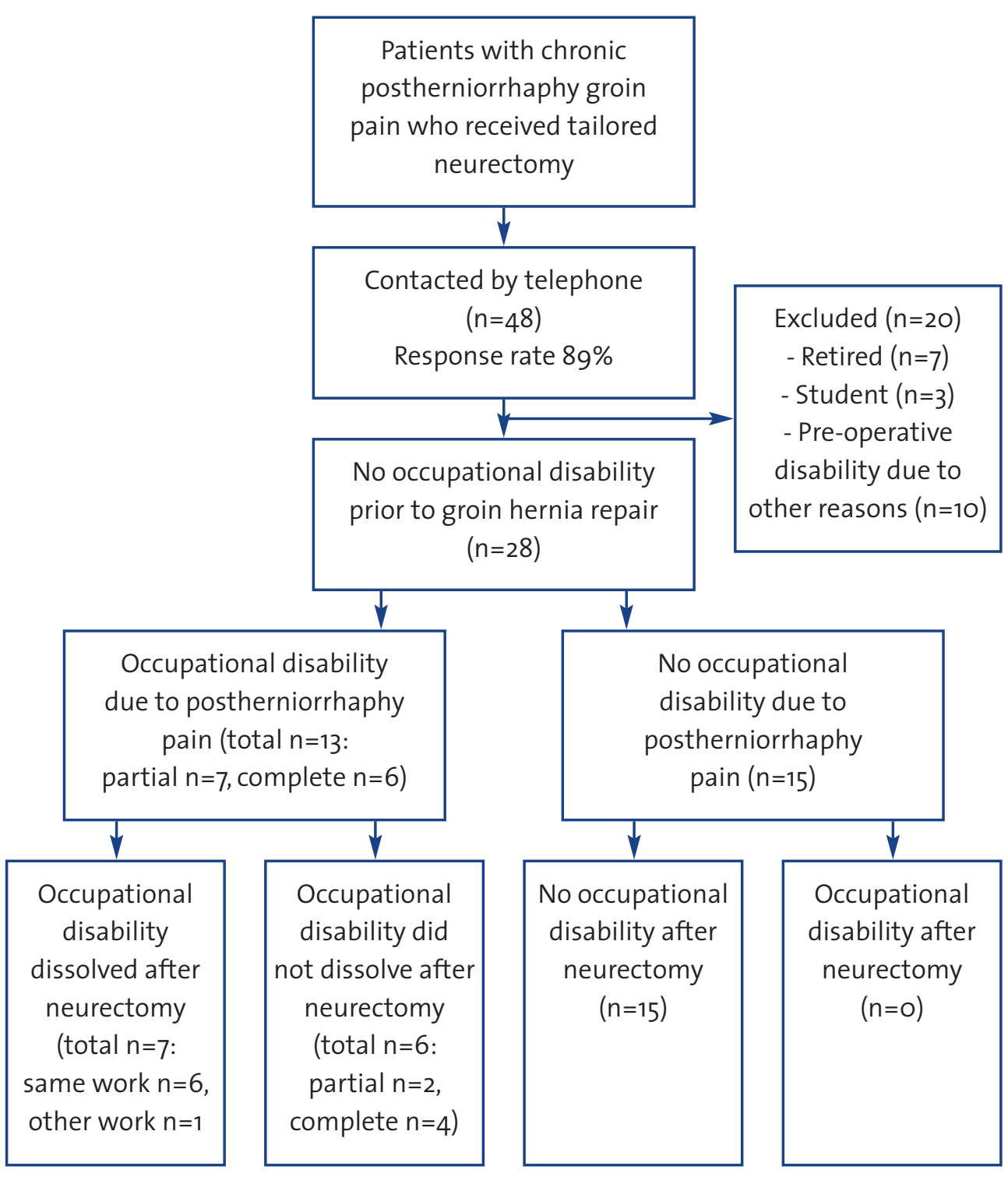

Figure 1 Flow chart of occupational disability in patients receiving neurectomy for chronic postherniorrhaphy groin pain. was used to study our neurectomy patients showed that half of the population was excluded from further analysis because of studentship, retirement, pre-operative occupational disability, or unemployment. If these percentages were used in the entire Dutch population, some 220 patients with severe pain are unable to return to their work yearly. Our results show that about half of these patients $(n=110)$ have become occupationally disabled after their inguinal hernia repair $(220 / 2=110)$. The total yearly costs for workers' compensation in The Netherlands will thus amount to $110 \times € 29.000=€ 3.2$ million. Without treatment these costs will accumulate every year. In contrast, the costs for operative neurectomy are only $€ 1300$ per person. As previously mentioned, a neurectomy can reduce occupational disability with more than $50 \%$. Thus $€ 1.6$ million (50\% of $€ 3.2$ million) can be saved in The Netherlands per year if all patients on workers' compensation due to severe postherniorrhaphy pain were treated with a neurectomy.

\section{DISCUSSION}

Pain-induced occupational disability after routine inguinal hernia repair should be considered disastrous. This complication probably affects half of the patients with severe postherniorrhaphy groin pain (some $1 \%$ of all operated patients) ${ }^{1-3}$. Adequate treatment of these pain syndromes is vital for the patient's physical and mental health status. Considering only a few studies report on the effect of neurectomy on occupationa disability $13,15,16,28$, some 56 to $100 \%$ of the neurectomized patients were again able to rejoin the working process. Moreover, there is no report on patients becoming more disabled after a neurectomy. However, it should be realized that the data were often incomplete and inconsistent. It is obvious that the current body of literature on the

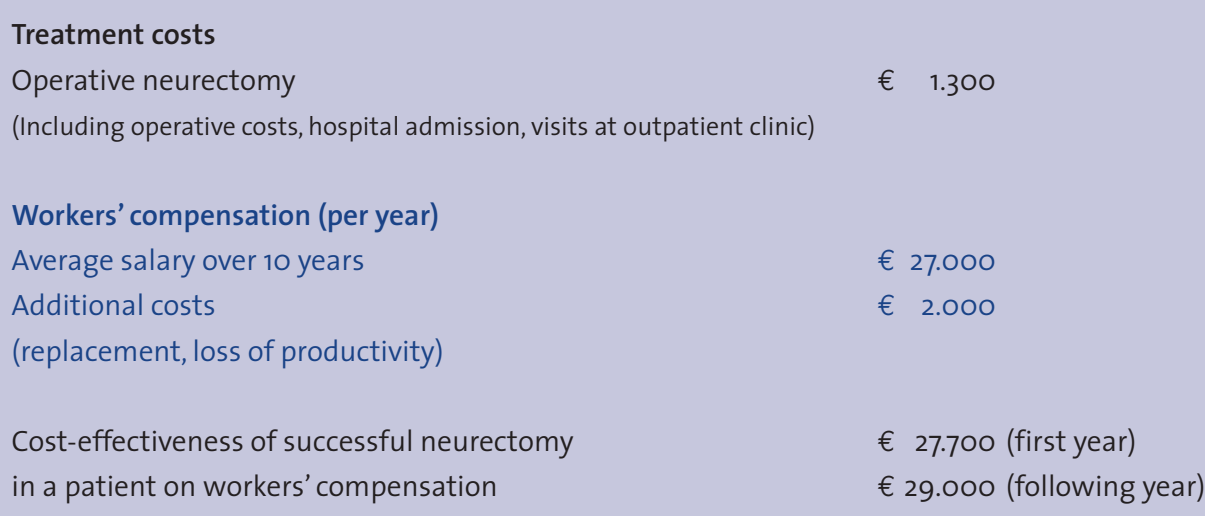


effect of neurectomy on occupational disability is annoyingly insufficient. Non-surgical treatment results with reference to return to work in chronic postherniorrhaphy pain patients are virtually nonexistent. In general, these effects on occupational disability are not mentioned at all. In a recent retrospective study by Bright et al. the majority of patients attending a pain clinic were discharged pain-free after a 1-year period 35 . It is obvious that due to a lack of major studies on non-surgical treatment regimes the effect on chronic pain resolution and occupational disability also remains unclear.

The present study demonstrates that, based on a recently published registry of neurectomy patients ${ }^{18}$, over $50 \%$ of the patients went back to work. Moreover a lot of patients were occupationally disabled even before their inguinal hernia repair due to other reasons. So, on the one hand there is a definite pain reductive effect of our treatment, but on the other it does not always result in alleviation of the occupational disability in each patient. Moreover, some patients continued to work despite severe pain complaints. Our success rate may seem somewhat lower compared to earlier mentioned success rates, but is probably a more realistic one. An overestimation in previous studies due to absence of in- and exclusion criteria as well as inaccurate measurement of disability or incomplete follow-up may possibly explain this discrepancy. In contrast, a 50\% success rate is much higher when compared to percentages observed in other causes of occupational disability (e.g. chronic musculoskeletal problems). In the Netherlands, only $10 \%$ of the occupationally disabled patients will eventually get back to work, often by means of an intensively subsidized reintegration project ${ }^{36}$. Despite the lack of large and uniformly conducted studies, operative neurectomy appears to provide a substantial reduction in occupational disability in most patients suffering from severe postoperative inguinal pain Occupational disability due to inguinal neuralgia is associated with major workers compensational costs. A tailored neurectomy can save over $€ 1.6$ million per year in the Netherlands alone. As most patients are disabled for many years, these costs are cumulative. Since chronic postherniorrhaphy neuralgia is encountered all over the world, an enormous cost reduction can be accomplished globally with adequate treatment. Another aspect of occupational disability is the increased medical consumption for other health issues, which generates high costs as well ${ }^{21}$

The present study has certain limitations. A drawback includes the small number of studied patients. Moreover, a totally reliable cost-benefit analysis is impossible due to absence of previous studies on this subject. In future studies occupational disability should be taken into account as a standard outcome measure for treatment regimes. We also strongly feel that most patients are currently inadequately treated for severe inguinal pain complaints. A 'tailored neurectomy' is obvious beneficial for most patients although some issues remain unsolved including timely referral patterns to pain clinics as well as the effects of non-surgical treatment on occupational disability. Theoretically, it may be possible that some patients are treated with adequate pain reduction within one year of non-surgical treatment.
In conclusion, neurectomy is an effective treatment modality for the resolution of occupational disability due to postherniorrhaphy inguinal neuralgia. Results on nonsurgical treatment options are unavailable. Neurectomy probably greatly reduces workers' compensational costs. Worldwide an enormous cost-reduction can be accomplished with adequate treatment.

\section{REFERENCES}

1 Bay-Nielsen M, Perkins FM, Kehlet H. Pain and functional impairment 1 year after inguinal hernior-rhaphy: a nationwide questionnaire study. Ann Surg 2001; 233: 1-7

2 Loos MJ, Roumen RM, Scheltinga MR. Chronic sequelae of common elective groin hernia repair. Hernia 2007; 11: 169-173

3 Nienhuijs S, Staal E, Strobbe L, Rosman C, Groenewoud H, Bleichrodt R. Chronic pain after mesh repair of inguinal hernia: a systematic review. Am I Surg 2007; 194: 394-400

4 Loos MJ, Roumen RM, Scheltinga MR. Classifying post-herniorrhaphy pain syndromes following elective inguinal hernia repair. World I Surg 2007; 31: 1760-1765

5 Hindmarsh AC, Cheong E, Lewis MP et al. Attendance at a pain clinic with severe chronic pain after open and laparoscopic inguinal hernia repairs. BrJ Surg 2003; 90: 1152-1154

6 Hameroff SR, Carlson GL, Brown BR. Ilioinguinal pain syndrome. Pain 1981; 10:253-257

7 Maaliki H, Naja Z, Zeidan A. Repeated ilioinguinal block using a catheter technique for pain relief in inguinal neuralgia. Pain Pract 2008; 8: 144-146

8 Rauchwerger JJ, Giordano J, Rozen D, Kent JL, Greenspan J, Closson CW. On the therapeutic viability of peripheral nerve stimulation for ilioinguinal neuralgia: putative mechanisms and possible utility. Pain Pract 2008; 8: 138-143

9 Cohen SP, Foster A. Pulsed radiofrequency as a treatment for groin pain and orchialgia. Urology 2003; 61: 645

10 Rho RH, Lamer TJ, Fulmer JT. Treatment of genitofemoral neuralgia after laparoscopic inguinal herniorrhaphy with fluoroscopically guided tack injection. Pain Med 2001; 2: 230-233

11 Rozen D, Parvez U. Pulsed radiofrequency of lumbar nerve roots for treatment of chronic inguinal herniorraphy pain. Pain Physician 2006; 9: 153-156

12 Aasvang $E K$, Kehlet $H$. The effect of mesh removal and selective neurectomy on persistent postherniotomy pain. Ann Surg 2009; 249:327-334

13 Amid PK. Causes, prevention, and surgical treatment of postherniorrhaphy neuropathic inguinodynia: triple neurectomy with proximal end implantation. Hernia 2004; 8:343-349

14 Bower S, Moore BB, Weiss SM. Neuralgia after inguinal hernia repair. Am Surg 1996; 62: 664-667

15 Giger U, Wente MN, Buchler MW, Krähenbühl S, Lerut J, Krähenbühl L. Endoscopic retroperitoneal neurectomy for chronic pain after groin surgery. Br J Surg 2009; 96: 1076-1081

16 Heise CP, Starling JR. Mesh inguinodynia: a new clinical syndrome after inguinal herniorrhaphy? J Am Coll Surg 1998; 187: 514-518 
17 Madura JA, Madura JA 2nd, Copper CM, Worth RM. Inguinal neurectomy for inguinal nerve entrapment: an experience with 100 patients. Am J Surg 2005; 189: 283-287

18 Loos MJ, Scheltinga MR, Roumen RM. Tailored neurectomy for treatment of postherniorrhaphy inguinal neuralgia. Surgery 2010; 147: 275-281

19 Zacest AC, Magill ST, Anderson VC, Burchiel KJ. Long-term outcome following ilioinguinal neurectomy for chronic pain. J Neurosurg 2010; 112: 784-789

20 Fränneby U, Sandblom G, Nordin P, Nyren O, Gunnarson U. Risk factors for long-term pain after hernia surgery. Ann Surg 2006; 244: 212-219

21 Steenbeek R, ljbema JF. De relatie tussen medische consumptie en verzuim bij personeel van een groot ziekenhuis. Tijdschr voor gezondheidswetenschappen 2008; 85:337-344

22 Amid PK, HiattJR. New understanding of the causes and surgical treatment of postherniorrhaphy inguinodynia and orchalgia. J Am Coll Surg 2007; 205: 381-385

23 Ducic I, West J, Maxted W. Management of chronic postoperative groin pain. Ann Plast Surg 2008; 60: 294-298

24 Miller JP, Acar F, Kaimaktchiev VB, Burchiel KJ. Pathology of ilioinguinal neuropathy produced by mesh entrapment: case report and literature, e review. Hernia 2008; 12: 213-216

25 Palumbo P, Minicucci A, Nasti AG, Simonelli I, Vietri F, Angelici AM. Treatment for persistent chronic neuralgia after inguinal hernioplasty. Hernia 2007; 11: 527-531

26 Seid AS, Amos E. Entrapment neuropathy in laparoscopic herniorrhaphy. Surg Endosc 1994; 8: 1050-1053

27 Starling JR, Harms BA. Diagnosis and treatment of genitofemoral and ilioinguinal neuralgia. World J Surg 1989; 13: 586-591

28 Vuilleumier H, Hubner M, Demartines N. Neuropathy after herniorrhaphy: indication for surgical treatment and outcome. World J Surg 2009; 33: 841-845

29 Nahabedian MY, Dellon AL. Outcome of the operative management of nerve injuries in the ilioinguinal region. J Am Coll Surg 1997; 184:265-268

30 Deysine M, Deysine GR, Reed WP, Jr. Groin pain in the absence of hernia: a new syndrome. Hernia 2002; 6: 64-67

31 Harms BA, DeHaas DR, Jr., Starling JR. Diagnosis and management of genitofemoral neuralgia. Arch Surg 1984; 119:339-341

32 Kim DH, Murovic JA, Tiel RL, Kline DG. Surgical management of 33 ilioinguinal and iliohypogastric neuralgias at Louisiana State University Health Sciences Center. Neurosurgery 2005; 56: 1013-1020

33 Krahenbuhl L, Striffeler H, Baer HU, Buchler MW. Retroperitoneal endoscopic neurectomy for nerve entrapment after hernia repair. Br J Surg 1997; 84: 216-219

34 Lee CH, Dellon AL. Surgical management of groin pain of neural origin. J Am Coll Surg 2000; 191: 137-142

35 Bright E, Reddy VM, Wallace D, Garcea G, Dennison AR. The incidence and success of treatment for severe chronic groin pain after open, transabdominal preperitoneal, and totally extraperitoneal hernia repair. World J Surg 2010; 34: 692-696
36 Velden van der N. Rapport arbeidsparticipatie en Reïntegratie van chronisch zieken en gehandicapten. Iresearch 2007 


\section{CHAPTER 10}

Summarizing discussion, conclusions and future perspectives 


\section{SUMMARIZING DISCUSSION}

\section{Prevalence and risk factors of chronic pain after routine inguinal surgery}

'Routine' operations such as inguinal herniorrhaphy and Pfannenstiel incisions for cesarean deliveries may inflict patients with unacceptable high rates of severe chronic pain $^{1,2}$. To investigate the chronic pain morbidity caused by inguinal hernioplasty in a large patient cohort, a questionnaire concerning frequency and intensity of pain, numbness and functional impairment was composed (chapter 2). 1766 questionnaires were returned (response $81.6 \%$ ) and after a median follow-up period of three years $40.2 \%$ of patients reported some degree of pain. Thirty-three patients (1.9\%) experienced severe pain. One fifth of the patients felt functionally impaired in their work or leisure activities. Chronic pain and functional impairment are apparently very common long-term complications after inguinal herniorrhaphy. Apart from our study, several assessments of chronic postherniorrhaphy pain have been performed by others in recent years. According to a recently published review some $11 \%$ of patients suffer from chronic pain after a mesh-based repair 3 . This discrepancy with our study (40.2\%) is probably due to the fact that many patients with only minor discomfort are included in our 'pain group' as well.

Almost one-fourth of the patients with pain reported numbness as a risk factor. Other variables associated with the development of pain were age and recurrent hernia repair One can classify risk factors as patient- or surgery-related factors. Patient-related issues are age, occurrence of any postoperative complication, and high levels of pre- and direct postoperative pain 4 . High pain levels appear to predispose for chronicity of pain symptoms ${ }^{5}$. A genetic susceptibility for pain may be the underlying mechanism ${ }^{6}$. Furthermore, psychosocial characteristics may also act as patient-related risk factors. Normal pain perception partly relies on adequate coping behaviour?. On the other hand, research has also identified surgery-related factors such as nerve handling (preservation versus prophylactic neurectomy). However, prophylactic neurectomy of the ilioinguinal nerve does not always seem to prevent chronic pain ${ }^{7-9}$. Possibly all other remaining inguinal nerves need to be neurectomized prophylactically as well. Second, surgical technique may also play a role in the onset of pain. Numerous studies have compared open with laparoscopic mesh repair with respect to chronic pain. Results are inconclusive. According to a meta-analysis published in 2002, persistent pain was less common after laparoscopic hernia repair ${ }^{10}$. In contrast, results of a large randomized controlled tria published in 2004 did not show any difference in pain scores after two years, and open hernia repair was advocated". Third, the prosthetic material itself may be crucial. In general, light-weight polypropylene meshes improved some aspects of chronic pain ${ }^{12-14}$. All of these issues have led to the question whether surgery should always be the primary treatment in men with asymptomatic or mild symptomatic inguinal hernias. A recent randomized controlled trial showed that 'watchful waiting' is a perfectly acceptable option ${ }^{15}$. Due to the low incidence of incarceration, delayed or even aborted surgical repair is considered safe. In the Netherlands however, most inguinal hernias still receive operative treatment. It is clear that patients scheduled for routine inguinal hernia repair should be counselled preoperatively on the risk of chronic post-operative pain.

Since inguinal nerve damage plays an important part in inguinal pain development, a side-step to another frequently performed type of inguinal surgery, the Pfannenstie incision, was made. Chronic pain after a Pfannenstiel incision was incidentally reported with emphasis on severe neuralgia ${ }^{16}$. However, larger studies aimed at studying chronic pain after a Pfannenstiel incision as a main objective have not been performed. Therefore we initiated a questionnaire study assessing prevalence, risk factors and aetiology of 'post-Pfannenstiel pain syndromes' (Chapter 3). All women $(n=866)$ in our hospital with a Pfannenstiel incision for cesarean delivery or abdominal hysterectomy during a two year time period received a questionnaire evaluating pain located in the Pfannenstiel region. A high $80 \%$ response rate was achieved. After a 2 year follow-up, one third experienced some form of chronic pain at the incision site. Moderate or severe pain was reported by $7 \%$ and $8.9 \%$ was impaired in daily activities. Nerve entrapment was present in over half of the examined patients with moderate to severe pain. This study demonstrated that chronic pain is common following a routine Pfannenstiel incision. Nerve entrapment was found to be a frequent cause of moderate to severe pain.

Very few comparable studies on Pfannenstiel operations have been published. One study assessing chronic pain following a cesarean delivery identified a 12.3\% lower abdominal pain prevalence after one year ${ }^{17}$. Another study reported a chronic pain prevalence of $23 \%$ in the Pfannenstiel incision area after 5 years ${ }^{2}$. These results supplemented by the present study illustrate the high prevalence of chronic pain after a Pfannenstiel incision.

The present study identified several risk factors. Numbness, recurrent Pfannenstiel surgery and emergency cesarean delivery were significant predictors for chronic pain. The onset of numbness is likely related to nerve injury resulting in neuropathic pain. As with inguinal hernia repair, recurrent Pfannenstiel surgery will increase the risk of nerve damage, but will also initiate more tissue fibrosis possibly causing nociceptive pain. An additional risk factor was emergency cesarean delivery, probably due to hasty dissection and nerve traumatisation. As with postherniorrhaphy inguinal pain, nerve injury significantly contributes to moderate or severe post-Pfannenstiel pain development. Both inguinal hernia repair and Pfannenstiel incisions are frequently related to chronic pain. Since these pain symptoms cannot always be prevented, awareness among physicians should be increased. This often debilitating pain symptomatology requires quick diagnostic and therapeutic intervention. 
2. Diagnostic approach of postherniorrhaphy inguinal pain

Several tools for pain measurement in chronic postherniorrhaphy syndromes are currently used. Multi-dimensional pain tools including the McGill Pain questionnaire and Wisconsin Brief Pain questionnaire measure sensory, affective and evaluative aspects of pain ${ }^{18,19}$. Visual Analogue Scale (VAS) and a Verbal Rating Scale (VRS) are two frequently used unidimensional scales assessing sensory aspects (e.g. pain intensity). Choosing a pain measurement tool and its interpretation can greatly affect outcome results. In chapter 4 two pain tools, the Visual Analogue Scale (VAS) and 4-point Verbal Rating Scale (VRS), are analyzed for scale failure, sensitivity and interpretability. A questionnaire identified pain intensity level in a cohort of patients that previously underwent inguinal herniorrhaphy. Current pain intensity was graded on a 4 point-VRS-scale (no pain, mild, moderate or severe pain) and on a $100 \mathrm{~mm}$-VAS-scale (o=no pain, $100=$ unbearable). 'Scale failure' (one or both tests not completed correctly) was determined, and cut-off points for the VAS test were calculated by creating the optimal Kappa coefficient between both tools. The response rate was $78.2 \%$. Scale failure was observed five times more frequently in VAS tests compared to VRS. Advanced age was a significant risk factor for scale failure. The four categories of VRS corresponded with mean VAS scores of 1, 20, 42 and $78 \mathrm{~mm}$, respectively. VAS categories associated with the highest Kappa coefficient $(k=0.78)$ were: $0-8=$ no pain, 9-32 = mild, 33-71= moderate, $>71=$ severe pain. VAS scores grouped per VRS category showed considerable overlap. However, age and sex did not significantly influence cut-off points. These results clearly indicate that the VRS should be favoured over the VAS in postherniorrhaphy pain assessment. Although an unidimensional pain tool is easy and highly accessible, multidimensional measurement tools may provide more reliable information. Recently, a validated inguinal pain questionnaire (IPO) was published ${ }^{21}$. A seven step fixed-point rating scale was used to assess pain with steps linked to pain behaviour. Current and worst pain during the previous week is measured. A second part of the questionnaire focuses on interference with daily activities. Such a novel multidimensional pain questionnaire may be preferable over unidimensional pain scales, but comparisons are currently unavailable.

\section{A novel classification of chronic postherniorrhaphy pain}

In the late eighties, neuropathic pain was highlighted as a phenomenon by Lichtenstein providing a description of the inguinal neuro-anatomy as well as a clinical differentiation between genitofemoral and ilioinguinal neuralgia ${ }^{21}$. Eight years later, Cunningham published an alternative classification on chronic pain after inguinal hernia repair ${ }^{22}$. Three different pain syndromes based on clinical investigation of ten patients were proposed: nociceptive, neuropathic and visceral. According to his judgement, most patients suffer from nociceptive pain due to suture damage of the periosteum and the inguinal ligament. In contrast, only ten percent $(n=1)$ suffered from neuropathic pain caused by nerve damage. Visceral pain defined as pain during ejaculation was seen in another ten percent $(n=1)$. In 2004, a classification was introduced that differentiated between neuropathic (nerve compression or neuroma formation), non-neuropathic (periosteal reaction, scar tissue, mechanical pressure of folded mesh) or a mixed form ${ }^{23}$. In Chapter 5 a novel classification of chronic postherniorrhaphy pain syndromes is proposed based on an extensive survey in more than two thousand patients. All patients with an elective inguinal hernia repair performed over a 5 year period received a questionnaire evaluating chronic inguinal pain as described in chapter $2(n=2164)$. Patients with moderate to severe pain complaints (VAS $\geq 3$ ) were invited for an interview and an outpatient department physical examination. Moderate to severe pain was present in 211 patients (11.9 per cent). Three separate groups of diagnoses were identified based on a follow-up study in 148 patients. Group I: neuropathic pain $(n=72,47 \%)$ indicating inguinal nerve damage, Group II: non-neuropathic pain $(n=40,27 \%)$ due to various diagnoses including periostitis $(n=18)$ and recurrent hernia $(n=13)$, and Group III: a tender spermatic cord and/or a tight feeling in the lower abdomen (termed 'funiculodynia', $n=43,28 \%$ ). Chronic pain following elective hernia repair is diverse in etiology but a classification may contribute to the development of tailored treatment regimens. Our classification may share similarities with Amid's ${ }^{23}$. However, we identified a large separate group of patients presenting with diffuse funicular pain without neuropathic pain symptoms. It is our hypothesis that compression by scar tissue, venous congestion or chronic inflammation as a reaction to mesh placement may act as possible underlying causes in this subpopulation. A recent case report describes an ilioinguinal nerve mesh entrapment with neurophysiological changes that suggests an inflammatory cause for this chronic pain syndrome ${ }^{24}$. Future research may aim at identifying the central role of funicular structures in inguinal pain syndromes.

\section{Surgical management of chronic inguinal pain syndromes}

Conservative treatment including nerve blocks, analgesics or transcutaneous electric nerve stimulation (TENS) is often unsuccessful. Selective neurectomy may be efficient but long-term results are scarce. We assessed the long-term efficacy of surgical neurectomy for chronic postherniorrhaphy groin neuralgia (chapter 6). A population of postherniorrhaphy groin pain patients treated by neurectomy received a questionnaire evaluating current pain intensity, overall treatment results, and effects on sexual intercourse-related pain symptomatology. Risk factors for failure and a learning curve were investigated. Fifty-four patients underwent a neurectomy over a 5-year time period, and forty-nine patients responded to the questionnaire (response rate $91 \%$ ). After a median follow-up period of 1.5 years, about half of the patients (52\%) claimed to be painfree or almost pain free, a quarter (24\%) experienced some pain reduction but still experienced pain at a regular basis, whereas the remaining quarter (24\%) did not benefit from the neurectomy at all. Sexual intercourse-related pain responded favourably to neurectomy in two-thirds of the involved patients. 
Results of our study are in concert with previous reports. In general, approximately three quarters of the patients will benefit from a neurectomy. Unfortunately, one fourth continues to suffer from severe pain. If one studies the literature, reasons for treatment failure are unclear. Several factors may be important. First of all, appropriate patient selection is crucial. Patients with peripheral nerve injury may develop sensitization of the central nervous system over time. As a rule these patients are refractory to surgica peripheral nerve interventions but should be treated with pain medication. Second, an adequate surgical technique is of great importance. The affected nerve needs to be identified in a scarred operative field and resected as far proximal and distal as possible burying the nerve ends in healthy muscular tissue. To prevent neuroma formation in unaffected neurectomized nerve ends, we believe that only the affected nerve(s) should be removed, 'the tailored approach'. A learning curve is present and failures significantly depended on previously received pain treatment.

A surgical neurectomy provides good long-term pain relief for postherniorrhaphy groin neuralgia in the majority of patients. Hernia surgeons should take their responsibility for this iatrogenic complication and incorporate selective neurectomy in their surgical armamentarium. Future research should focus on identifying additional factors associated with unfavourable surgical outcome.

As high level evidence based treatment regimes for iatrogenic inguinal pain syndromes are currently lacking, patients usually receive a random combination of pain medication, local nerve blocks or an occasional surgical neurectomy. A randomized controlled tria ('GroinPain Trial') was constructed to identify the optimal treatment modality in this population. In chapter 7 aim and rationale of this trial are presented. Adult patients with chronic postherniorrhaphy inguinal pain ( $>3$ months) caused by inguinal nerve entrapment with a temporary but significant pain reduction after a lidocain nerve block are eligible for randomization. They either receive repetitive nerve blocks with lidocain corticosteroids and hyaluronic acid, or a 'tailored' surgical neurectomy. Patient enrollment started in February 2006 and is expected to end in June 2011. Initial results will be available towards the end of 2011. This trial is the first randomized controlled effort comparing two invasive treatment modalities for peripheral inguinal nerve entrapment. As awareness and knowledge on chronic neuropathic pain after inguinal herniorrhaphy in the near future is expected to increase, findings of this trial will aid in optimizing care for this patient population.

Pfannenstiel incisions are also incidentally associated with chronic lower abdomina pain due to nerve entrapment $(2-4 \%)^{2}$. Treatment options include peripheral nerve blocks or a neurectomy of neighbouring nerves. Knowledge on adequate (surgical) management is limited. In chapter 8 we assessed long-term pain relief after local nerve blocks or neurectomy in patients suffering from chronic pain due to Pfannenstiel-induced nerve entrapment. Patients treated for iliohypogastric and/ or ilioinguinal neuralgia following a Pfannenstiel incision received a questionnaire assessing current pain intensity (by 5-point Verbal Rating Scale), complications and overall satisfaction. Twenty-seven women with Pfannenstiel-related neuralgia were identified over a seven-year period. A single diagnostic nerve block provided long-term pain relief in 5 patients. This phenomenon may be explained by resetting the pain threshold to normal levels. A similar effect is occasionally observed in postherniorrhaphy groin neuralgia. Satisfaction in the remaining women undergoing neurectomy $(n=22)$ was good to excellent in $73 \%$, moderate in $14 \%$, and poor in $13 \%$. Smaller series show similar success rates ${ }^{25,26}$. Interestingly, successful treatment improved sexual intercourse-related pain in most females, a phenomenon that has never been described before in literature. Co-morbidities (endometriosis, lumbosacral radicular syndrome) and earlier pain treatment were identified as risk factors for surgical failure. Some cases of treatment failure may also be explained from the concept of genetic susceptibility for chronic pain syndrome development as described in postherniorrhaphy groin pain as well 7 . This study demonstrates that peripheral nerve blocking provides long-term pain reduction in some individuals with post-Pfannenstiel neuralgia. An iliohypogastric or ilioinguinal nerve neurectomy is a safe and effective procedure in most remaining patients. Gynaecologists must be prepared to offer a surgical consultation to this group of patients.

\section{Occupational disability after inguinal hernia repair}

Resumption of daily leisure activities and occupational obligations is considered an important outcome measure after hernia repair. However, the exact percentage of pain patients confronted with occupational disability is unknown. In chapter 9 the effect of operative and non-operative treatment on resolving occupational disability due to postherniorrhaphy inguinal neuralgia is evaluated.

All relevant studies on treatment for postherniorrhaphy inguinal neuralgia were reviewed with respect to effect on occupational disability. A recently published registry of patients with postherniorrhaphy neuralgia treated by neurectomy was analyzed for occupational disability. Patients were contacted by telephone and given a set of predetermined questions concerning pre- and postoperative disability. Finally, a cost-benefit analysis was made.

Only 4 out of 23 studies on neurectomy for inguinal neuralgia reported on occupational disability as an outcome measure. These few studies demonstrated that some 56 to $100 \%$ of the patients could resume their occupational obligations after pain treatment. Studies on non-operative pain treatment and occupational disability appeared unavailable. Forty-eight patients previously treated by neurectomy were analyzed for occupational disability. Severe pain disabled 13 patients and a neurectomy resulted in total recovery in $7(7 / 13,54 \%)$. An estimating cost-benefit analysis showed that effective pain treatment such as a tailored neurectomy can save a minimum of $€ 1.8$ million of workers' com- 
pensational costs in The Netherlands yearly.

It should be appreciated that occupational disability affects about $1 \%$ of all operated inguinal hernia patients. Interestingly, occupational disability after hernia repair and appropriate management schemes have received very little attention. Yet, with respect to work resumption, a neurectomy seems to be effective in over $50 \%$ of the patients. Therefore, millions of euros for worker's compensational and additional costs (replacement, loss of productivity, medical costs) may be saved if an effective treatment modality such as a neurectomy is provided. When these figures are extrapolated globally, huge sums of money can be saved.

The present study indicates that tailored neurectomy is an effective treatment for occupational disability due to postherniorrhaphy inguinal neuralgia in over half of the patients. A successful neurectomy greatly reduces workers' compensational costs and may have substantial financial consequences worldwide.

\section{CONCLUSIONS}

1. Chronic pain and functional impairment are common long-term complications after inguinal hernia repair and Pfannenstiel incisions.

2. The VRS should be favoured over the VAS in future postherniorrhaphy pain assessment. 3. Moderate to severe chronic pain after inguinal hernia repair can be classified into neuropathic pain (50\%), non-neuropathic pain (25\%), and 'funiculodynia' (25\%). Nerve entrapment is a frequent cause of chronic pain after a Pfannenstiel incision.

4. Neurectomy provides substantial long-term pain relief in the majority of patients (50-75\%) suffering from inguinal neuralgia after inguinal hernia repair or Pfannenstiel incisions.

5. Neurectomy is an (cost-)effective treatment modality for resolution of occupational disability due to postherniorrhaphy inguinal neuralgia.

\section{FUTURE PERSPECTIVES}

The introduction of mesh techniques has reduced inguinal hernia recurrence rates spectacularly. However, some issues related to chronic pain are largely unknown. The body of evidence suggests that type of mesh or placement technique are not crucial for the development of pain. Therefore, which direction should future pain studies take? As some patients apparently are at risk for chronic pain development, it would be helpful to identify their characteristics preoperatively ${ }^{27}$. Some have found that genetic susceptibility indeed is a risk factor for chronic pain development ${ }^{6}$. At present a few genotypes have been identified that may predispose for chronic pain states. Other 'pain genes' will likely be recognized in the near future, and this tendency could serve as a basis for preoperative identification of 'pain individuals'. As a consequence, surgery may be postponed in these individuals.

Lately, numerous psychosomatic risk factors for chronification of pain have been identified. Among the most important determinants are long duration of the operation, high levels of acute postoperative pain, preoperative fear of surgery and optimism ${ }^{28}$. Prospective pre-operative identification with subsequent postoperative modulation of the most influential risk factors, may be worthwhile in preventing pain chronification. Future research may also focus on the identification of altered peripheral nerve signalling. The effects of inguinal neurectomy on various aspects of nerve signalling pathways may give clues as to why this treatment is effective in some but not all individuals. Microglia in the dorsal horn are found to play a critical role in neuropathic pain ${ }^{29}$. Nerve injury reduces microglial neuronal inhibition which may lead to a pathologically altered signalling pathway. Secondly, proinflammatory cytokines (IL-6) and sphingolipids have been found responsible for mechanical hypersensitivity ${ }^{30}$. Thirdly, neurotrophic factors including nerve growth factor (NGF) act as peripheral pain mediators as well ${ }^{31}$. In future studies these and other substances may be chemically or histologically studied in neurectomized nerve tissue. It may be hypothesized that different responses in these signalling pathways are related to clinical outcome.

Various other clinical aspects of chronic pain mechanisms deserve further exploration. Some studies have assessed static quantative sensory testing (OST, measuring pain thresholds, magnitude levels and tolerance) in the prediction of direct postoperative pain or chronic postoperative pain ${ }^{32}$. Research suggests that certain QST patterns can be linked to somatosensory phenotypes which may mirror certain pain mechanisms. These characteristics may eventually result in a mechanism-based treatment, or may even allow for a separation between successful patients and failures. However, the discriminative value of these tests as a means of chronic pain prediction is still under debate. The role of inter-individual differences in dynamic pain tests such as diffuse noxious inhibitory controls (DNIC) may even be more promising33. DNIC describes the phenomenon of one noxious stimulus inhibiting the pain produced by a second. For instance, subjects may receive thermal and cold stimuli in a certain order after which perceived DNIC is measured using questionnaires. A reduced DNIC may be related to hypersensitivity for clinical pain and possibly also to its chronification ${ }^{32}$. These test panels may therefore aid in selecting patients at risk for chronification of pain. If other risk factors for pain are involved as well, one may decide against operation such as inguinal hernia repair or a gynaecological procedure using a Pfannenstiel incision.

Is there any room for future improvement in the imaging department? Neuro-imaging studies may provide objective data on plasticity, sensitisation and certain amplification processes ${ }^{34}$. Moreover, functional MRI may identify the locations of neural sensitisation and other amplification processes, and may relate these findings to pain experience 
and possible treatment effect. Ideally, these modalities aid in selecting individuals with central sensitisation, a condition that probably forms a contraindication for intended peripheral nerve surgery.

Procedure-related factors also deserve discussion. From an empirical point of view, a meticulous operative technique with proper nerve identification and preservation is a crucial first step in pain prevention. However, is there still any merit in studying alternative mesh materials with respect to chronic pain? Recently, a self-fixing mesh (Parietene Progrip ${ }^{\circledR}$, Sofradim Production, Trévoux, France-Group Covidien) became available that adheres to the operative field using vicryl micro-hooks omitting the need for suture fixation ${ }^{35}$. This technique prevents suture-induced nerve entrapment whereas its semiresorbable construction may reduce chronic nociceptive pain such as periostitis pubis. A randomized controlled trial using this mesh is has been performed by our group of investigators (PARADE trial, NTR 1212) and the results will be expected shortly. Biological meshes composed of a porcine or human extracellular matrix stripped of its cellular components are being studied by other hernia surgeons. The effect on chronic pain is still unclear but improved biocompatibility may result in diminished nociceptive pain. When pain tends to chronify, its appearance and cause should be recognized by treating surgeons. Improved awareness requires education of both patients and doctors. Recognition of post-Pfannenstiel pain syndromes is currently lacking and deserves attention of gynaecologists. An internet site can provide useful information (e.g. www.liespijn.nl, which will be online soon).

An important under-acknowledged aspect of inguinal pain syndromes is sexual intercourse-related or ejaculatory pain. These debilitating syndromes affect both sexes and may occur after inguinal hernia repair and Pfannenstiel incisions. The beneficial effect of neurectomy and mesh removal on intercourse-related pain is incidentally recorded and merits future investigation.

Management protocols for chronic inguinal pain are unavailable in most general hospitals. Therefore, a diagnostic algorithm may be helpful and is provided in this thesis (see appendix for examples). Guidelines allow for a sensible approach and create uniformity in data management. Management must be supported by psychological assessments as chronic pain is frequently associated with catastrophic thinking and depressive thoughts. A downward spiral may subsequently aggravate pain sensation.

Knowledge on therapeutic options is still limited. Operative neurectomy is being performed on a small scale with average success rates reaching $60-70 \%$ at most. As a consequence, a significant group of patients is left with persisting pain. The underlying mechanisms of treatment failure require full investigation. Non-operative treatment options such as pulsed radio frequency and pharmacological treatment (e.g. Pregabaline/ Lyrica ${ }^{\circledR}$ ) must be explored in controlled studies. Ideally, complex pain patients should be discussed in a multidisciplinary team consisting of surgeons, anaesthesiologists, neurologists and psychologists/ psychiatrists. The complexity of these pain

\section{REFERENCES}

1 Bay-Nielsen M, Perkins FM, Kehlet H. Pain and functional impairment 1 year after inguinal herniorrhaphy: a nationwide questionnaire study. Ann Surg 2001; 233: 1-7

2 Luijendijk RW, Jeekel J, Storm RK, Schutte PJ, Hop WC, Drogendijk AC, Huikeshoven FJ. The low transverse Pfannenstiel incision and the prevalence of incisional hernia and nerve entrapment. Ann Surg 1997; 225:365-369

3 Nienhuijs S, Staal E, Strobbe L et al. Chronic pain after mesh repair of inguinal hernia: a systematic review. Am J Surg 2007; 194: 394-400

4 Franneby U, Sandblom G, Nordin P, Nyrén O, Gunnarsson U. Risk factors for long-term pain after hernia surgery. Ann Surg 2006; 244: 212-219

5 Courtney CA, Duffy K, Serpell MG, O'Dwyer PJ. Outcome of patients with severe chronic pain following repair of groin hernia. Br J Surg 2002; 89: 1310-1314

6 Kehlet H, Jensen TS, Woolf CJ. Persistent postsurgical pain: risk factors and prevention. Lancet 2006; 367: 1618-1625

7 Kehlet H. Chronic pain after groin hernia repair. Br I Surg 2008; 95: 135-136

8 Alfieri S, Di MD, Doglietto GB. Prophylactic ilioinguinal neurectomy in open inguinal hernia repair. Ann Surg 2007; 245: 663

9 Picchio M, Palimento D, Attanasio U. Randomized controlled trial of preservation or elective division of ilioinguinal nerve in open inguinal hernia repair with polypropylene mesh. Arch Surg 2004; 139: 755-758

10 EU Hernia Trialists Collaboration. Repair of groin hernia with synthetic mesh: meta-analysis of randomized controlled trials. Ann Surg 2002; 235: 322-332

11 Neumayer L, Giobbie-Hurder A, Jonasson O, Fitzgibbons R Jr, Dunlop D, Gibbs J, Reda D, Henderson W, Veterans Affairs Cooperative Studies Program 456 Investigators. Open mesh versus laparoscopic mesh repair of inguinal hernia. N Engl J Med 2004; 350: 1819-1827

12 Bringman S, Wollert S, Osterberg J, Smedberg S, Granlund H, Felländer G, Heikkinen T. One year results of a randomised controlled multi-centre study comparing Prolene and Vypro II-mesh in Lichtenstein hernioplasty. Hernia 2005; 9: 223-227

13 Bringman S, Wollert S, Österberg J, Smedberg S, Granlund H, Heikkinen TJ. Three-year results of a randomised clinical trial of lightweight or standard polypropylene mesh in Lichtenstein repair of primary inguinal hernia. Br J Surg 2006; 93:1056-1059

14 O'Dwyer PJ, Kingsnorth AN, Molloy RG, Small PK, Lammers B, Horeyseck G. Randomized clinical trial assessing impact of a lightweight or heavyweight mesh on chronic pain after inguinal hernia repair. BrJ Surg 2005; 92: 166-170 
15 Fitzgibbons RJ Jr, Giobbie-Hurder A, Gibbs JO, Dunlop DD, Reda DJ, McCarthy M Jr, Neumayer LA, Barkun JS, Hoehn JL, Murphy JT, Sarosi GA Jr, Syme WC, Thompson JS Wang J, Jonasson O. Watchful waiting vs. repair of inguinal hernia in minimally symptomatic men, a randomized controlled trial. JAMA 2006; 295: 285- 292

16 Sippo WC, Burghardt A, Gomez AC. Nerve entrapment after Pfannenstiel incision. Am J Obstet Gynecol 1987; 157: 420-421

17 Kisielinski K, Conze J, Murken AH, Lenzen NN, Klinge U, Schumpelick V. The Pfannenstiel or so called "bikini cut": still effective more than 100 years after first description. Hernia 2004; 8: 177-181

18 Daut RL, Cleeland CS, Flanery RC. Development of the Wisconsin Brief Pain Questionnaire to assess pain in cancer and other diseases. Pain 1983; 17: 197-210

19 Melzack R. The McGill Pain Questionnaire: major properties and scoring methods. Pain 1975; 1: $277-299$

20 Franneby U, Gunnarsson U, Andersson M, Heuman R, Nordin P, Nyrén O, Sandblom G. Validation of an Inguinal Pain Questionnaire for assessment of chronic pain after groin hernia repair. BrJ Surg 2008; 95: 488-493

21 Lichtenstein IL, Shulman AG, Amid PK, Montllor MM. Cause and prevention of postherniorrhaphy neuralgia: a proposed protocol for treatment. Am I Surg 1988; 155: 786-790

22 Cunningham J, Temple WJ, Mitchell P, Nixon JA, Preshaw RM, Hagen NA. Cooperative hernia study: pain in the postrepair patient. Ann Surg 1996; 224: 598-602

23 Amid PK. Causes, prevention, and surgical treatment of postherniorrhaphy neuropathic inguinodynia: triple neurectomy with proximal end implantation. Hernia 2004; 8: 343-349

24 Miller JP, Acar F, Kaimaktchiev VB, Gultekin SH, Burchiel KJ. Pathology of ilioinguinal neuropathy produced by mesh entrapment: case report and literature review. Hernia 2008; 12: 213-216

25 Madura JA, Madura JA 2nd, Copper CM, Worth RM. Inguinal neurectomy for inguinal nerve entrapment: an experience with 100 patients. Am J Surg 2005; 189: 283-287

26 Ducic I, Moxley M, Al-Attar A. Algorithm for treatment of postoperative incisional groin pain after cesarean delivery or hysterectomy. Obstet Gynecol 2006; 108:27-31

27 Granot M. Can we predict persistent postoperative pain by testing preoperative experimental pain? Curr Opin Anaesthesiol 2009; 22: 425-430

28 Peters ML, Sommer M, de Rijke JM, Kessels F, Heineman E, Patijn J, Marcus MA, Vlaeyen JW, van Kleef M. Somatic and psychologic predictors of long-term unfavorable outcome after surgical intervention. Ann Surg. 2007;245:487-94

29 Beggs S, Salter MW Microglia-neuronal signalling in neuropathic pain hypersensitivity 2.o. Curr Opin Neurobiol. 2010 Aug;20(4):474-80.

30 Andratsch M, Mair N, Constantin CE, Scherbakov N, Benetti C, Quarta S, Vogl C, Sailer CA, Uceyler N, Brockhaus J, Martini R, Sommer C, Zeilhofer HU, Müller W, Kuner R, Davis JB, Rose-John S, Kress M. J Neurosci. A key role for gp1zo expressed on peripheral sensory nerves in pathological pain. 2009 Oct 28;29(43):13473-83.

31 Pezet S, McMahon SB. Annu Rev Neurosci. Neurotrophins: mediators and modulators of pain. 2006;29:507-38. Review.
32 Edwards RR. Individual differences in endogenous pain modulation as a riskfactorfor chronic pain. Neurology 2005; 9: 437-434

33 Edwards RR, Ness TJ, Weigent DA, Fillingim RB. Individual differences in diffuse noxious inhibitory controls (DNIC): association with clinical variables. Pain. 2003; 106: 427-437

34 Lee MC, Zambreau L, Menon DK, Tracey I. Identifying brain activity specifically related to the maintenance and perceptual consequence of central sensitization in humans. J Neurosci. 2008, 28: 11642-11649

35 Chastan P. Tension-free open hernia repair using an innovative self-gripping semi-resorbable mesh. Hernia. 2009; 13: 137-142 


\section{CHAPTER 11}

Nederlandse samenvatting 


\section{Prevalentie en risicofactoren}

Chronische pijn vormt tegenwoordig de belangrijkste complicatie na liesbreukchirurgie. Ook de Pfannenstiel-incisie kan leiden tot chronische pijnklachten. Om de mate van chronische pijnmorbiditeit na diverse vormen van liesbreukchirurgie te analyseren, werd in hoofdstuk 2 aan alle liesbreukpatiënten, geopereerd tussen januari 2000 tot en met augustus 2005 in het Máxima Medisch Centrum, gevraagd pijnfrequentie en intensiteit, aanwezigheid van zwelling, gevoelsstoornissen en functionele beperkingen te noteren. 1766 vragenlijsten werden teruggestuurd (81,6\%). Na een mediane followup duur van drie jaar rapporteerde $40,2 \%$ van de patiënten enige vorm van pijn (1,9\% ernstige pijn). Eénvijfde van de patiënten voelde zich in enige mate functioneel beperkt in zijn dagelijkse bezigheden. Chronische pijn en functionele beperkingen komen derhalve frequent voor na liesbreukchirurgie. Ook ander studies melden een hoge pijnprevalentie (11\%). De discrepantie met de huidige studie (40.2\%) is waarschijnlijk te wijten aan het feit dat onze 'pijngroep' alle patiënten omvat, dus ook die met slechts milde symptomen

Risicofactoren voor pijn kunnen patiënt- of procedureafhankelijk zijn. Patiëntfactoren omvatten onder andere leeftijd, hoge pre- en direct postoperatieve pijnintensiteit en psychosociale problematiek. Inguinale sensibiliteitsstoornissen (zenuwschade) en recidief liesbreukherstel zijn procedure-afhankelijk. De rol van peroperatieve neurectomie ter preventie van chronische pijn is onduidelijk. Daarnaast zou de operatietechniek (open of laparoscopisch) een rol kunnen spelen. Grote studies tonen echter geen verschil in pijn op de lange termijn. Ten slotte zou het mesh materiaal een factor kunnen zijn. Lichtgewicht mesh lijkt namelijk met iets minder chronische pijnklachten gepaard te gaan. Echter, de ultieme vorm van preventie zou nog wel eens conservatieve liesbreukbehandeling kunnen zijn. Uit gerandomiseerd onderzoek blijkt dat 'watchful waiting' een acceptabele behandeling van de weinig lastgevende of asymptomatische liesbreuk is gezien het lage incarceratiepercentage. Deze studie laat onomstotelijk zien dat patiënten pre-operatief over het risico van chronische pijn geïnformeerd dienen te worden.

Een Pfannenstiel-incisie kan ook met chronische liespijnklachten gepaard gaan. In Hoofdstuk 3 worden prevalentie, risicofactoren en etiologie van 'post-Pfannenstiel pijnsyndromen' in een groot patiëntencohort onderzocht. Alle vrouwen $(n=866)$ in het Máxima Medisch Centrum (Veldhoven) met een Pfannenstiel-incisie voor een sectio caesarea of abdominale uterusextirpatie tussen januari 2003 en december 2004 ontvingen een vragenlijst waarin pijn nabij of in het Pfannenstiel-litteken geëvalueerd werd. Het responspercentage was hoog (80\%). Eénderde van de patiënten gaf na gemiddeld twee jaar pijn ter plaatse van het Pfannenstiel-litteken aan. Matig tot ernstige pijn, resulterend in beperkte dagelijkse activiteiten, werd gerapporteerd door $7 \%$. Zenuwbeklemming was aanwezig bij meer dan $50 \%$ van de onderzochte patiënten met matig tot ernstige pijn (17/32). Chronische neuropathie komt derhalve frequent voor na een Pfannenstiel-incisie. Slechts enkele vergelijkbare studies zijn beschikbaar. Pijnprevalentie variërend van 12.3 tot $23 \%$ wordt gemeld. Een aantal risicofactoren worden uit het huidige onderzoek duidelijk: verminderd gevoel bij aanraking, meerdere Pfannenstiel-incisies en spoed sectio caesarea. Het opnieuw gebruiken van een Pfannenstielincisie gaat gepaard met een hogere kans op zenuwletsel en meer postoperatieve fibrosering. Gehaaste weefseldissectie met mogelijk meer zenuwschade kan in het geval van een spoed sectio caesarea ook met meer chronische pijn gepaard gaan.

Liesbreuk- en Pfannenstielchirurgie gerelateerde pijn gaan frequent gepaard met chronische pijn. Er dient dan ook meer aandacht voor preventie en behandeling van beide pijnsyndromen te komen.

\section{Pijnmeting na liesbreukchirurgie}

Chronische pijn kan aan de hand van diverse pijnscores gedocumenteerd worden. De McGill Pain questionnaire en Wisconsin Brief Pain questionnaire zijn multidimensioneel. Ze meten namelijk sensibele, affectieve en evaluatieve aspecten van pijn. Daarentegen kan met de Visual Analogue Scale (VAS) of Verbal Rating Scale (VRS) slechts één dimensie gemeten worden (bijv. pijnintensiteit). Het gebruik van het juiste meetinstrument is van groot belang voor een valide onderzoeksresultaat. Hoofdstuk 4 beschrijft met welke pijnscore, VAS of VRS, chronische pijn na liesbreukchirurgie het meest betrouwbaar gemeten kan worden. De resultaten van een eerdere studie (zie hoofdstuk 1) werden gebruikt om beide pijnschalen met elkaar te vergelijken. 'Scale failure' (onjuist invullen van pijnschaal) was met name aanwezig bij de VAS. Hoge leef tijd bleek een risicofactor voor 'scale failure' ( $p<0.001)$. De vier categorieën van de VRS correspondeerden met een gemiddelde VAS score van respectievelijk 1, 20, 42 and 78 $\mathrm{mm}$. De volgende VAS categorieën kwamen met de hoogste kappa-coëfficiënt $(\mathrm{k}=0.78)$ overeen: $0-8$ = geen pijn, 9-32 = mild, 33-71 = matig, >71 = ernstige pijn. Er ontstond een aanzienlijke overlap indien VAS scores per VRS categorie gegroepeerd werden. Factoren als leeftijd en geslacht hadden geen invloed op de afkapwaarden. Uiteindelijk blijkt de VRS score gemakkelijker in gebruik en beter interpreteerbare resultaten op te leveren. Indien de VAS toch gebruikt wordt, dienen de alhier beschreven afkapwaarden gebruikt te worden. Echter, met multidimensionele pijnscores kan waarschijnlijk een completer beeld verkregen worden. Er is recent een specifieke postoperatieve liespijnscore ('Inguinal Pain Questionnaire') gepubliceerd. Zowel de pijnintensiteit als de beperking in dagelijkse functioneren worden hierbij geëvalueerd. Een dergelijke pijnscore verdient waarschijnlijk de voorkeur boven de VRS

\section{Een nieuwe postherniotomie pijnclassificatie}

Eind jaren tachtig beschreef Lichtenstein enkele klinische aspecten van neuropathische pijn op basis van $\mathrm{n}$. genitofemoralis/ ilioinguinalis schade. Acht jaar later publiceerde Cunningham een alternatieve classificatie. Op basis van klinisch onderzoek bij tien 
patiënten beschreef hij drie verschillende pijnsyndromen: nociceptief $(n=8)$, neuropathisch $(n=1)$ en visceraal $(n=1)$. Onder viscerale pijn werd pijn gedurende ejaculatie verstaan. In 2004 werd er een derde classificatie geïntroduceerd, die onderscheid maakt in neuropathisch, non-neuropathisch of een mengvorm. In hoofdstuk 5 introduceren wij een nieuwe classificatie op basis van een cohort van 2000 liesbreukpatiënten. Naar aanleiding van een enquêtestudie (hoofdstuk 2 ) werden alle patiënten met matig tot ernstige pijn (VAS $\geq 3$ ) uitgenodigd voor poliklinisch onderzoek $(n=148)$. Drie separate groepen konden worden onderscheiden; Groep I: neuropathische pijn $(n=72)$ primair op basis van zenuwschade, Groep II: niet-neuropathische pijn $(n=40)$ onder andere door periostitis $(n=18)$ en recidief hernia inguinalis $(n=13)$, en Groep III: een gevoelige funiculus spermaticus/'funiculodynie' $(n=43)$. Hoewel er diverse postoperatieve liespijnsyndromen mogelijk zijn, blijkt met anamnese en lichamelijk onderzoek het merendeel ondergebracht te kunnen in deze drie hoofdgroepen. Afgezonderd van de funiculodyniegroep vertoont onze classificatie enige overeenkomsten met die van Amid uit 2004 Funiculodynie wordt mogelijk veroorzaakt door veneuze congestie of chronische inflammatie. Een recent gepubliceerd case report bevestigt dat dergelijke inflammatie chronische postoperatieve pijn kan induceren.

\section{Chirurgische behandeling van chronische inguinale pijnsyndromen}

Chronische pijnsyndromen zijn vaak refractair voor conservatieve pijnbehandeling (bijv. zenuwblokkades, analgetica of transcutane elektrische zenuw stimulatie, TENS). Een selectieve neurectomie lijkt daarentegen veelbelovend. Gegevens omtrent langdurige follow-up ontbreken echter nog. In de huidige studie wordt de effectiviteit van selectieve neurectomie op de lange termijn geëvalueerd (hoofdstuk 6). Een database van neurectomieën in verband met neuropathische postherniotomie-liespijn werd geanalyseerd. Gedurende de afgelopen 5 jaar ondergingen 54 patiënten in ons ziekenhuis een selectieve neurectomie. Een enquête over diverse pijnaspecten werd door 49 patiënten geretourneerd (respons percentage 91\%). De tevredenheid met behandelresultaat was goed to uitstekend bij $52 \%$ van de patiënten, matig bij $24 \%$ en slecht bij $24 \%$ (mediane followup duur 1,5 jaar). Succesvolle neurectomie resulteerde bij tweederde van de patiënten tot afname van sex-gerelateerde pijnklachten. Er bleek een evidente leercurve ten aanzien van een succesvol behandelresultaat. Persisteren van pijn was tevens gerelateerd aan eerder ontvangen pijntherapie. De huidige resultaten komen overeen met eerdere studies. Over het algemeen bewerkstelligt een neurectomie bij driekwart van de patiënten een langdurige pijnreductie. Helaas persisteren pijnklachten bij de overige vijfentwintig procent. Redenen hiervoor zijn onbekend. Diverse factoren kunnen van belang zijn. Ten eerste is een adequate patiëntenselectie cruciaal. Zenuwschade kan immers al centrale sensitisatie hebben geïnduceerd, waarna een neurectomie zelden effect sorteert. Ten tweede moeten de juiste zenuwstructuren geïdentificeerd worden, gevolgd door een correcte neurectomie zo ver mogelijk naar lateraal met begraven van de zenuw- stomp in spierweefsel. Om de kans op neuroomvorming na neurectomie te minimaliseren, zijn wij van mening dat alleen de zichtbaar beschadigde of beklemde zenuw verwijderd moet worden ('tailored approach') en dus overige macroscopisch gave zenuwen in situ kunnen blijven. Dit in tegenstelling tot anderen die een standaard verwijdering van takken van alle 3 lieszenuwen propageren. Op de lange termijn biedt een selectieve neurectomie derhalve adequate pijnreductie in de meerderheid van de patiënten met ernstige neuropathische pijn na liesbreukchirurgie. Als veroorzaker van zenuwletsel dienen chirurgen hun verantwoordelijkheid te nemen en een selectieve neurectomie in hun chirurgisch arsenaal te includeren.

De huidige behandelingsmogelijkheden zijn allerminst evidence-based. Meestal wordt teruggegrepen op de eigen ervaring met als gevolg dat er tot op heden geen gefun deerd stappenschema onderzocht is. Om de optimale behandelingsstrategie te identificeren bij chronische neuralgie na liesbreukchirurgie werd er een gerandomiseerde studie ('GroinPain Trial') opgezet. In hoofdstuk 7 worden het doel en de achtergrond van deze trial beschreven. Alle volwassen patiënten met chronische neuralgie na standaard liesbreukchirurgie (>3 maanden) die reageerden met een significante pijnreductie na een zenuwblokkade met lidocaine voldoen aan de inclusiecriteria. Er wordt gerandomiseerd tussen (herhaaldelijke) zenuwblokkades met een combinatie van lidocaine, corticosteroïden and hyaluronzuur of een 'tailored' neurectomie. Inclusie is gestart in februari 2006 en sluit eind 2011/ begin 2012. Dit zal dan het eerste gerandomiseerde onderzoek naar de behandeling van chronische pijn na liesbreukchirurgie zijn en hopelijk een eerste stap naar een evidence-based behandelingsschema.

Zoals eerder gemeld, gaat een Pfannenstiel-incisie soms gepaard met chronische liespijnklachten. Hier ligt dan ook vaak een neuralgie van de n. iliohypogastricus en/of ilioinguinalis (2-4\%) aan ten grondslag. Perifere zenuwblokkades of een neurectomie behoren tot de behandelingsmogelijkheden. In hoofdstuk 8 werden de lange-termijn resultaten na één van deze interventies onderzocht. Alle patiënten die behandeld zijn voor een neuralgie door hun Pfannenstiel-incisie ontvingen een vragenlijst met betrekking tot huidige pijnintensiteit (VRS), complicaties en tevredenheid. In de afgelopen acht jaar (2000-2007) werden 27 vrouwen behandeld. Een éénmalige zenuwblokkade met lidocaine resulteerde bij 5 patiënten tot persisterende pijnreductie. Tevredenheid na neurectomie bij de overige patiënten $(n=22)$ was goed tot uitstekend bij $73 \%$ van de patiënten, redelijk bij $14 \%$ en slecht bij $13 \%$ (mediane follow-up duur 2 jaar). Succesvolle behandeling resulteerde meestal ook in afname van eventueel eerder aanwezige sex-gerelateerde klachten. Aanwezigheid van comorbiditeit (endometriose of lumbaal radiculair syndroom) en eerder ontvangen pijnbehandeling bleken significante risicofactoren voor het persisteren van pijnklachten na de neurectomie. Verras senderwijs had een enkel diagnostisch bedoelde perifere zenuwblokkade bij sommige 
patiënten dus een blijvend therapeutisch effect. Mogelijk dat dit fenomeen berust op het doorbreken van de pijncyclus met normalisatie van de pijndrempel. Een neurectomie van de $n$. iliohypogastricus of ilioinguinalis is een veilige en effectieve behandeling bij deze patiënten. Gynaecologen dienen deze patiënten dan ook te verwijzen voor een chirurgisch consult.

\section{Arbeidsongeschiktheid na liesbreukchirurgie}

Hervatting van dagelijkse werkzaamheden kan beschouwd worden als een belangrijke uitkomstmaat voor (liesbreuk)chirurgie. Echter, chronische pijn leidt tot arbeidsongeschiktheid bij een onbekend aantal patiënten na standaard liesbreukchirurgie. In hoofdstuk 9 wordt het effect van zowel chirurgische als niet-chirurgische behandeling op pijn geïnduceerde arbeidsongeschiktheid onderzocht. De huidige literatuur werd nagekeken met nadruk op het effect van verschillende pijnbehandelingsmodaliteiten op arbeidsongeschiktheid. Vervolgens werd een recent onderzocht cohort neurectomiepatiënten (zie hoofdstuk 6) telefonisch gevraagd naar (eventuele) veranderingen in arbeidsongeschiktheid. Ook werd een kosten-batenanalyse voor de Nederlandse situatie opgesteld.

In slechts 4 van de 23 studies over neurectomie voor neuropatische pijn na liesbreukchirurgie werd arbeidsongeschiktheid als uitkomstmaat vermeld. 56 tot $100 \%$ van de patiënten konden hun werk na de uitgevoerde neurectomie weer hervatten. Studies over niet-chirurgische pijnbehandeling en arbeidsongeschiktheid waren niet beschikbaar. In ons eigen bestand werden 48 neurectomiepatiënten geanalyseerd met betrekking tot arbeidongeschiktheid, waarvan 13 patiënten door ernstige pijn hun werkzaamheden niet meer konden verrichten en dus arbeidsongeschikt waren bevonden. Neurectomie resulteerde bij 7 van hen tot herstel en volledige arbeidsgeschiktheid (7/13, 54\%). Een kosten-batenanalyse liet zien dat effectieve pijnbehandeling zoals neurectomie tot een minimale kostenreductie van $€ 1.8$ miljoen per jaar in Nederland kan leiden. Een chirurgische neurectomie is derhalve effectief om arbeidsongeschiktheid door chronische neuralgie na eerdere liesbreukchirurgie te reduceren. Tevens kan hierdoor een forse kostenreductie voor de maatschappij gerealiseerd worden. 


\section{CHAPTER 12}

List of publications 
Loos MJA, Roumen RMH, Scheltinga MRM. Chronic sequelae of common elective groin hernia repair. Hernia 2007; 11:169-173

Loos MJA, Roumen RMH, Scheltinga MRM. Classifying postherniorrhaphy pain syndromes following elective groin hernia repair. World J Surg 2007; 31: 1760-1765

Paffen MLE, Loos MJA, Zwiers W, Roumen RMH. Een inguinale vesicale herniatie. Ned Tijdschr Urol, november 2007; 7: 182-185

Loos MJA, Houterman S, Scheltinga MRM, Roumen RMH. Evaluating postherniorrhaphy groin pain: Visual Analogue or Verbal Rating Scale? Hernia 2008; 12:147-151

Loos MJA, Roumen RMH, Scheltinga MRM. Chronische pijn na eerdere liesbreukchirurgie. Ned Tijdschr Heelk 2008; 5: 196-199

Loos MJA, Mulders LGM, Scheltinga MRM, Roumen RMH. The Pfannenstiel approach as a source of chronic pain. Obstet Gynecol 2008; 111: 839-46.

Loos MJA, Scheltinga MRM, Roumen RMH. Surgical management of inguinal neuralgia following a low transverse Pfannenstiel incision. Ann Surg 2008: 248: 880-885

Loos MJA, Scheltinga MRM, Roumen RMH. De Pfannenstiel-incisie als oorzaak van chronische pijn in de onderbuik. Ned Tijdschr Obstet Gyn 2008; 121: 259-263

Loos MJA, Roumen RMH. Een man met chronische postoperatieve liespijn. Ned Tijdschr Geneesk 2009; 153: 572

Loos MJA, Roumen RMH. Peripheral schwannoma. snapshots in surgery. Br J Surg 2008; 95:1184

Loos MJA, Scheltinga MRM, Roumen RMH. Comments on the article by Ducic et al. entitled "Management of chronic postoperative groin pain. Ann Plast Surg 2008; 61: 659

Loos MJA, Scheltinga MRM, Roumen RMH. Tailored neurectomy for treatment of postherniorrhaphy inguinal neuralgia. Surgery 2010; 147:275-281

Loos MJA, Houterman S, Scheltinga MRM, Roumen RMH. Randomized controlled tria of neurectomy versus injection with lidocain, corticosteroids and hyaluronic acid for postherniorrhaphy inguinal neuralgia. Hernia 2010; 14:593-597
Loos MJA, Lemmers Ch.C, Heineman E, Scheltinga MRM, Roumen RMH. Occupational disability due to chronic postherniorrhaphy neuralgia: a plea for tailored neurectomy. Submitted- 


\section{CHAPTER 13}

Dankwoord 
In de loop van de tijd zijn er toch aardig wat mensen bij de verschillende aspecten van mijn onderzoek betrokken geraakt. Al deze mensen wil ik graag bedanken met enkelen in het bijzonder.

Er zijn eigenlijk twee personen die mij op een inspirerende manier begeleid hebben tijdens dit onderzoekstraject: dr. M.R.M. Scheltinga en dr. R.M.H. Roumen.

Om van te start te gaan met dr. M.R.M. Scheltinga. Beste Marc, via jou ben ik eigenlijk in de chirurgie en de 'liespijnbusiness' gerold. Wat begon als een wetenschapsstage werd al snel een totale 'liespijngekte' met alle gevolgen van dien. Mede door jouw enthousiasme, hulp en kenmerkende rode pen kwam dit proefschrift snel tot stand. Dank voor de geweldige begeleiding en de genoten opleiding heelkunde tot nu toe!

Dr. R.M.H. Roumen, beste Rudi, net als Marc ben jij vanaf het begin af aan de drijvende kracht geweest achter dit proefschrift. Jouw kritische probleemanalyse en toewijding voor dit lastige onderwerp zijn uniek en een voorbeeld voor menigeen. Ik heb enorm genoten van onze 'liespijnpoli's', peroperatieve ontdekkingen en uiteraard Deense biertjes in Kopenhagen. Vooral dankzij jou heb ik mijn wens om chirurg te worden vrij snel concreet zien worden en hoop ik in de toekomst nog met je samen te kunnen werken.

Beste prof. dr. E. Heineman. Dank voor het feit dat u mijn promotor wilt zijn.

Beste dr. Saskia Houterman, dank voor je ondersteuning op het gebied van de statistiek co-auteurschap en wetenschappelijke begeleiding.

Dr. L.G.M. Mulders, Beste Leon, dank voor je hulp en enthousiasme voor het onderzoek naar pijn bij het Pfannenstiel litteken.

Dank aan dr. Ch.H.C Lemmers voor de informatie en begeleiding ten aanzien van arbeidsongeschiktheid en chronische pijn.

Hooggeleerde leden van de leescommissie, prof. dr. M. van Kleef, prof. dr. R. van der Hulst, prof. dr. R.P. Bleichrodt, prof. dr. M. Miserez en prof. dr. J.G. Nijhuis, hartelijk dank voor het beoordelen van het manuscript.

Graag wil ik alle chirurgen van de maatschap heelkunde in het Máxima Medisch Centrum bedanken voor het genoten opleiding tot nu toe. Ik heb het erg naar mijn zin gehad. Na vijf skiweekenden heb ik jullie ook erg goed leren kennen...
Dank aan Riekie, Marian en Mieke (en alle andere secretaresses) voor het opvangen van de telefoontjes van het enquêteerde 'patiënten', verdragen van de rommel cq. onderzoeksstatussen op jullie secretariaat en de goede roddels.

Alle polikliniekmedewerkers van de heelkunde in het MMC bedankt voor de mogelijkheid van het zien van liespijnpatiënten.

Daarnaast wil ik al mijn collega's van het MMC bedanken voor de collegialiteit, leuke werksfeer en soms leerzame momenten..

Dank aan de DHS en verschillende sponsoren voor het financieel mogelijk maken van dit proefschrift.

Beste Paranimfen, Rik de Jongh en Denis Susa. Dank voor jullie hulp! Het MMC heeft ons bij elkaar gebracht en enkele onvergetelijke momenten opgeleverd. Gelukkig hebben we de foto's nog...

Vrienden, dank voor de ontspanning naast werk en promotie-onderzoek.

Lieve familie, dank voor jullie steun en liefde.

En tot slot wil ik mijn lieve vriendinnetje Joyce bedanken. Heb zin in onze tijd in Utrech en daarna! 


\section{CHAPTER 14}

Curriculum Vitae 


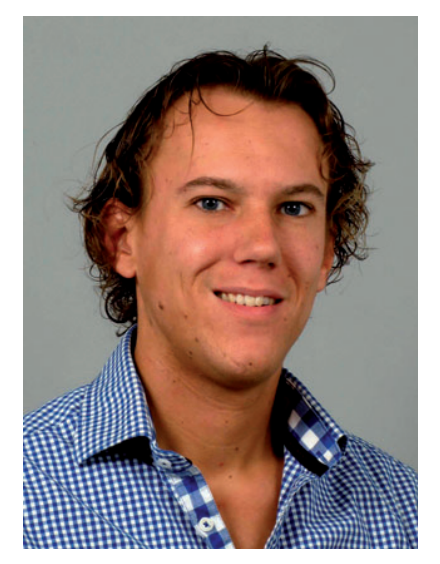

Maarten J.A. Loos werd geboren op 27 december 1981 in Roosendaal (Noord-Brabant). In 2000 haalde hij zijn Gymnasium Bèta diploma (cum laude) aan het Norbertus College in Roosendaal. In hetzelfde jaar werd gestart met de studie geneeskunde aan de Universiteit van Maastricht en behaalde hij zijn doctoraalexamen in 2004. Reeds aanwezige interesse in de Heelkunde werd na het desbetreffende co-schap in het Máxima Medisch Centrum te Veldhoven versterkt. Zodoende begon hij tijdens zijn coschappen onder leiding van dr. R.M.H. Roumen en dr. M.R.M. Scheltinga met onderzoek naar 'chronische pijn na liesbreukchirurgie'. Andere vormen van 'lieschirurgie' zoals de Pfannenstiel-incisie werden hier snel bij betrokken. In juli 2006 behaalde hij zijn artsexamen, waarna hij aan de slag ging als AGNIO Heelkunde/ Intensive Care in het Máxima Medisch Centrum. Ondertussen ging het onderzoek gestaag door wat uiteindelijk geresulteerd heeft in dit proefschrift. Sinds 1 januari 2008 is hij via opleidingsregio Nijmegen in opleiding tot algemeen chirurg in het Máxima Medisch Centrum (Veldhoven/ Eindhoven), opleider dr. R.M.H. Roumen/ dr. W.F. Prakken. 


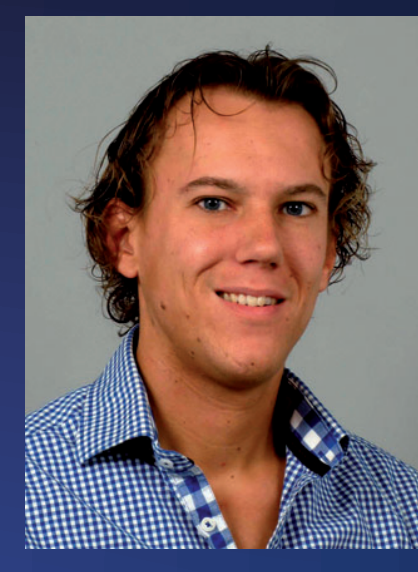

Maarten J.A. Loos werd geboren op 27 december 1981 n Roosendaal (Noord-Brabant). In 2000 haalde hij zijn Gymnasium Bèta diploma (cum laude) aan het Norbertus College in Roosendaal. In hetzelfde jaar werd gestart met de studie geneeskunde aan de Universiteit van Maastricht en behaalde hij zijn doctoraalexamen in 2004 Reeds aanwezige interesse in de Heelkunde werd na het desbetreffende co-schap in het Máxima Medisch Centrum te Veldhoven versterkt. Zodoende begon hij tijdens zijn coschappen onder leiding van dr. R.M.H. Roumen en dr. M.R.M. Scheltinga met onderzoek naar 'chronische pijn na liesbreukchirurgie'. Andere vormen van 'lieschirurgie zoals de Pfannenstiel-incisie werden hier snel bij betrokken. In juli 2006 behaalde hij zijn artsexamen, waarna hij aan de slag ging als AGNIO Heelkunde/ Intensive Care in het Máxima Medisch Centrum. Ondertussen ging het onderzoek gestaag door wat uiteindelijk geresulteerd heeft in dit proefschrift. Sinds 1 januari 2008 is hij via opleidingsregio Nijmegen in opleiding tot algemeen chirurg in het Máxima Medisch Centrum (Veldhoven/ Eindhoven), opleider dr. R.M.H. Roumen/ dr. W.F. Prakken.

Indien u vanwege dit supplement graag de rest van het proefschrift zou willen inzien, ben ik uiteraard bereid $u$ een exemplaar toe te sturen. $U$ kunt mij contacteren vi loosmaarten@hotmail.com. Het volledige proefschrift zal ook online beschikbaar zijn op www.liespijn.nl.

\section{Surgical management of chronic inguinal pain syndromes}

Maarten Loos 


\section{INTRODUCTION}

This supplement is part of the thesis of Maarten Loos on 'the surgical management of chronic inguinal pain syndromes' (University of Maastricht, september 29th 2011).

'Routine' operations such as inguinal herniorrhaphy and Pfannenstiel incisions for caesarean deliveries may inflict patients with chronic pain that is likely related to the interference with nerve structures located in the lower abdominal and inguinal area ${ }^{1,2}$. Knowledge on the diagnostic and therapeutic options is limited. The aim of this thesis was to study the management of chronic pain syndromes after inguinal hernia repair and Pfannenstiel incisions in general patient populations.

\section{Prevalence and risk factors}

An initial questionnaire study investigated the incidence of chronic pain among more than 2000 inguinal hernia repair patients 3 . Over $40 \%$ of the patients reported some degree of pain (moderate pain $9 \%$, severe $2 \%$ ). One fifth felt functionally impaired in their work or leisure activities and almost one-fourth of the pain patients reported inguinal numbness. Other pain associated variables were age and recurrent hernia

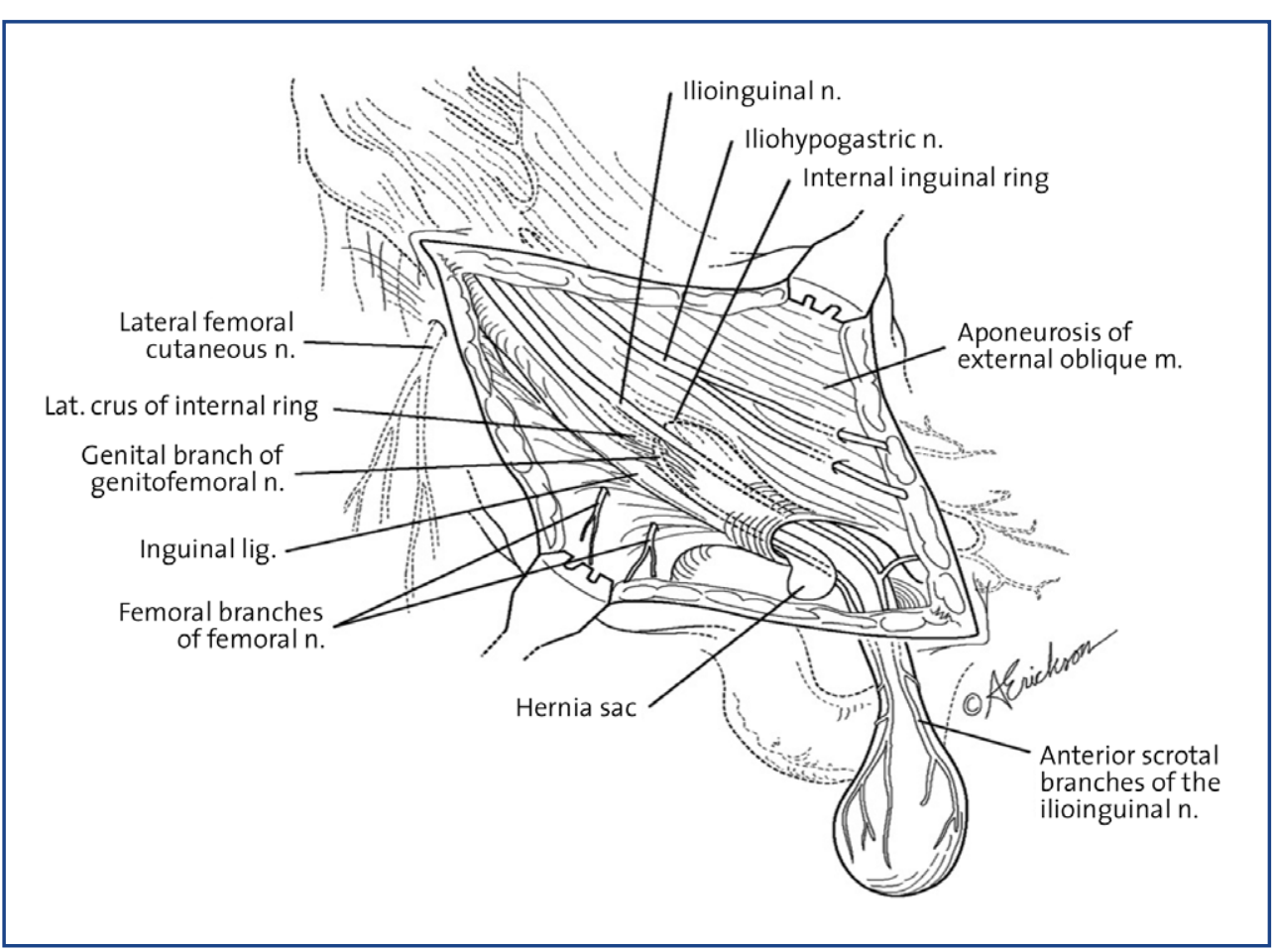

Inguinal neuro-anatomy" 
repair. This first study clearly indicated that patients scheduled for routine inguinal hernia repair should be counselled preoperatively on the risk of chronic post-operative pain

A second study described a modified questionnaire interviewing a MMC cohort of women $(n=866)$ with a history of Pfannenstiel incision for caesarean delivery or abdominal hysterectomy ${ }^{4}$. After a 2 year follow-up, one third experienced some form of chronic pain at the incision site. Moderate or severe pain was reported by $7 \%$, and $9 \%$ of the women was impaired in daily activities. Nerve entrapment was present in over half of the examined patients reporting moderate to severe pain. This study demonstrated that chronic pain due to nerve entrapment is common following a routine Pfannenstiel incision.

\section{Diagnostic approach}

Various pain tools are available in pain research. A third study compared two commonly used tests (Visual Analogue Scale (VAS, 1-10omm) and 4-point Verbal Rating Scale (VRS) for scale failure, sensitivity and interpretability. ${ }^{5}$. A questionnaire identified the pain intensity level in a cohort of patients that previously underwent inguinal herniorrhaphy. Scale failure (one or both tests not completed correctly) was observed five times more frequently in VAS tests compared to VRS. Advanced age was a significant risk factor for scale failure. VAS categories which concurred the most with VRS scores were: 0-8 mm = no pain, 9-32 $\mathrm{mm}=$ mild, $33-71 \mathrm{~mm}=$ moderate, $>71 \mathrm{~mm}=$ severe pain. VAS scores grouped per VRS category showed considerable overlap. The VRS was superior in sensitivity and interpretability. It was concluded that the VRS should be favoured over the VAS in postherniorrhaphy pain assessment.

\section{A novel classification}

A universally accepted classification for postherniorrhaphy pain is lacking. A fourth study studied 148 patients with moderate to severe postherniorrhaphy pain complaints using an interview and a physical examination ${ }^{6}$. Three separate groups of diagnoses were identified. Group I was suffering from neuropathic pain (50\%) indicating inguinal nerve damage. Group II harboured non-neuropathic pain (25\%) due to various diagnoses such as periostitis and recurrent hernia. Group III was characterized by a tender spermatic cord and/or a tight feeling in the lower abdomen ('funiculodynia', 25\%). Chronic pain following elective hernia repair apparently is diverse in etiology, but our classification may contribute to the development of tailored treatment regimens.

\section{Surgical management}

Our treatment approach of neuropathic pain after inguinal hernia repair and Pfannenstiel incisions offers nerve blocks and operative neurectomy. First, treatment results of
54 postherniorrhaphy neuropathic pain patients who underwent a neurectomy (dissection and removal of affected nerve) in our hospital were analyzed?. About half claimed to be pain-free or almost pain-free, a quarter experienced some pain reduc tion but still experienced pain at a regular basis, whereas the remaining quarter did not benefit from the neurectomy. Sexual intercourse-related pain and dysejaculation disorders responded favourably to neurectomy in two-thirds of the involved patients. This retrospective cohort study demonstrated that a surgical neurectomy provides reasonably good long-term pain relief for postherniorrhaphy groin neuralgia in the majority of patients.

A randomized controlled trial ('GroinPain Trial') was constructed to identify the optimal treatment modality in patients with postherniorrhaphy pain ${ }^{8}$. Adult patients with chronic postherniorrhaphy inguinal pain (> 3 months) caused by inguinal nerve entrapment with a temporary, but significant pain reduction after a lidocain nerve block are eligible for randomization. They either receive repetitive local nerve blocks with lidocain, corticosteroids and hyaluronic acid, or a 'tailored' surgical neurectomy. Patient enrollment started in February 2006 and is expected to end in June 2011. Results of this prospective randomized controlled trial are expected shortly.

Patients treated for neuropathic pain after a Pfannenstiel incision were retrospectively investigated 9 . Twenty-seven women had either received a neurectomy and/ or only local nerve blocks. A single diagnostic nerve block provided long-term pain relief in five patients. Satisfaction in the remaining 22 women undergoing neurectomy was good to excellent in $73 \%$, moderate in $14 \%$, and poor in $13 \%$. Successful treatment improved sexual intercourse-related pain in most females. Co-morbidities (endometriosis, lumbosacral radicular syndrome) and earlier pain treatment were identified as risk factors for surgical failure. This study demonstrated that peripheral nerve blocking provides long-term pain reduction in some individuals with post-Pfannenstiel neuralgia. An iliohypogastric or ilioinguinal nerve neurectomy is a safe and effective procedure in most remaining patients.

\section{Occupational disability}

Routine inguinal hernia repair results in occupational disability in $1-2 \%$ of the patients ${ }^{10}$. However, only 4 of 23 studies on neurectomy for inguinal neuralgia reported on occupational disability as a secondary outcome measure. In our patient registry ${ }^{7}$ some 56 to $100 \%$ of the patients could resume their occupational obligations after pain treatment. Moreover, effective pain treatment, such as our 'tailored neurectomy' is calculated to save a minimum of $€ 1.8$ million of workers' compensational costs in The Netherlands yearly. Tailored neurectomy apparently is an effective treatment for occupational disability due to postherniorrhaphy inguinal neuralgia in patients. A successful neurectomy greatly reduces workers' compensational costs and may have substantial financial consequences worldwide. 
1 Bay-Nielsen M, Perkins FM, Kehlet H. Pain and functional impairment 1 year after inguinal herniorrhaphy: a nationwide questionnaire study. Ann Surg 2001; 233: 1-7

2 Luijendijk RW, Jeekel J, Storm RK, Schutte PJ, Hop WC, Drogendijk AC, Huikeshoven FJ. The low transverse Pfannenstiel incision and the prevalence of incisional hernia and nerve entrapment. Ann Surg 1997; 225: 365-369

3 Loos MJA, Roumen RMH, Scheltinga MRM. Chronic sequelae of common elective groin hernia repair. Hernia 2007; 11:169-173

4 Loos MJA, Mulders LGM, Scheltinga MRM, Roumen RMH. The Pfannenstiel approach as a source of chronic pain. Obstet Gynecol 2008; 111: 839-46.

5 Loos MJA, Houterman S, Scheltinga MRM, Roumen RMH. Evaluating postherniorrhaphy groin pain: Visual Analogue or Verbal Rating Scale? Hernia 2008; 12: 147-151

6 Loos MJA, Roumen RMH, Scheltinga MRM. Classifying postherniorrhaphy pain syndromes following elective groin hernia repair. World I Surg 2007 Jun; 31: 1760-1765

7 Loos MJA, Scheltinga MRM, Roumen RMH. Tailored neurectomy for treatment of postherniorrhaphy inguinal neuralgia. Surgery 2010; 147:275-281

8 Loos MJA, Houterman S, Scheltinga MRM, Roumen RMH. Randomized controlled trial of neurectomy versus injection with lidocain, corticosteroids and hyaluronic acid for postherniorrhaphy inguinal neuralgia. Hernia 2010; 14: 593-597

9 Loos MJA, Scheltinga MRM, Roumen RMH. Surgical management of inguinal neuralgia following a low transverse Pfannenstiel incision. Ann Surg 2008: 248: 880-885

10 Loos MJA, Lemmers Ch.C, Heineman E, Scheltinga MRM, Roumen RMH. Occupational disability due to chronic postherniorrhaphy neuralgia: a plea for tailored neurectomy. Submitted

11 Ferzli $G$ et al. Postherniorrhaphy groin pain and how to avoid it. Surg Clin N Am. 2008; 88: 203216
A 42-year old man developed neuropathic pain symptoms (hypoesthesia, hyperalgesia and allodynia) in the groin region after a Lichtenstein hernioplasty resulting in occupational disability. After a two years doctor's delay, a surgical exploration was performed revealing a neuroma $(\rightarrow)$ of the ilioinguinal nerve that was entrapped at the lateral corner of the mesh. After a neurectomy and excision of the neuroma of the affected nerve, total pain relief was obtained. He was able to perform his original work again.

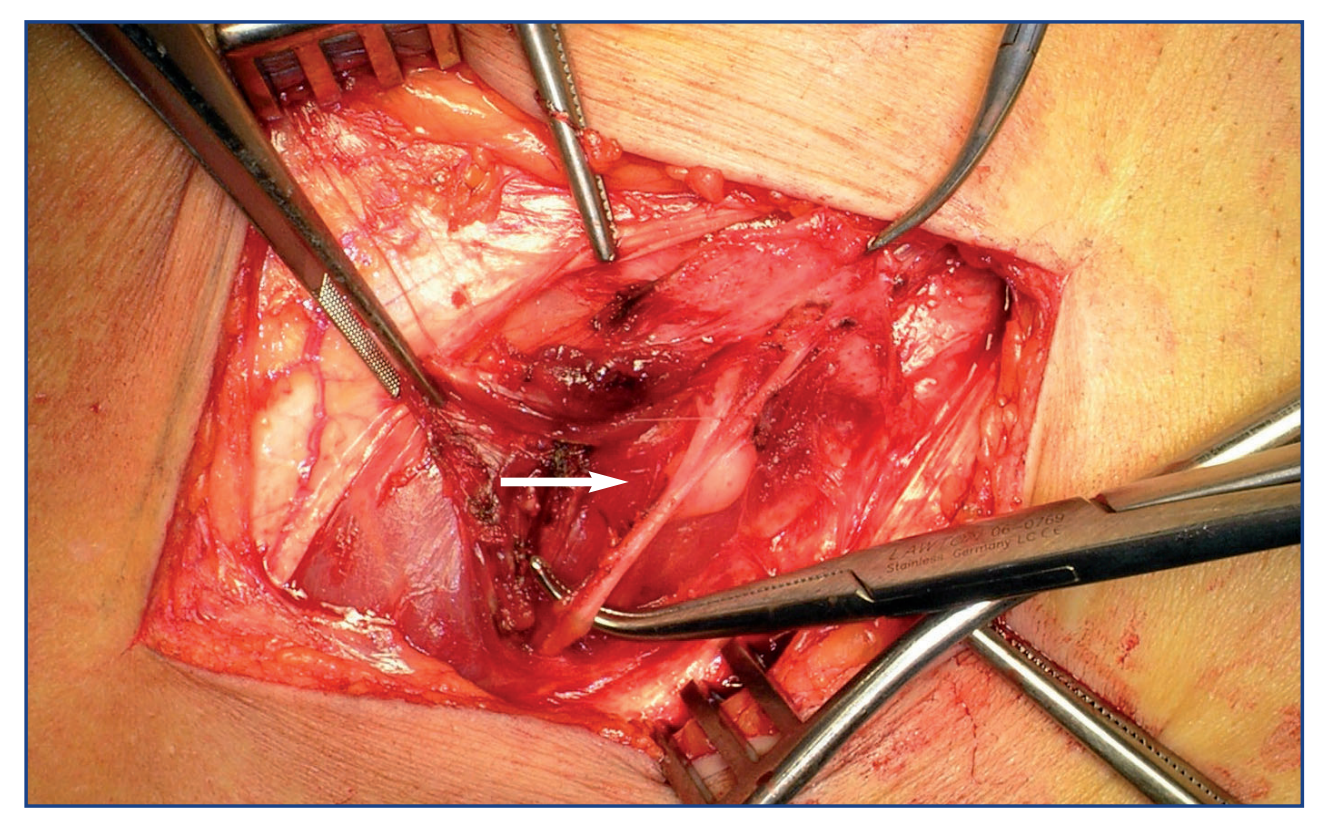


A 44-year old woman presented with persisting stabbing pain in the right groin after multiple inguinal operations. Inguinal exploration revealed an entrapment by suture material $(\rightarrow)$ around the ilioinguinal nerve. Neurectomy relieved her pain substantially.
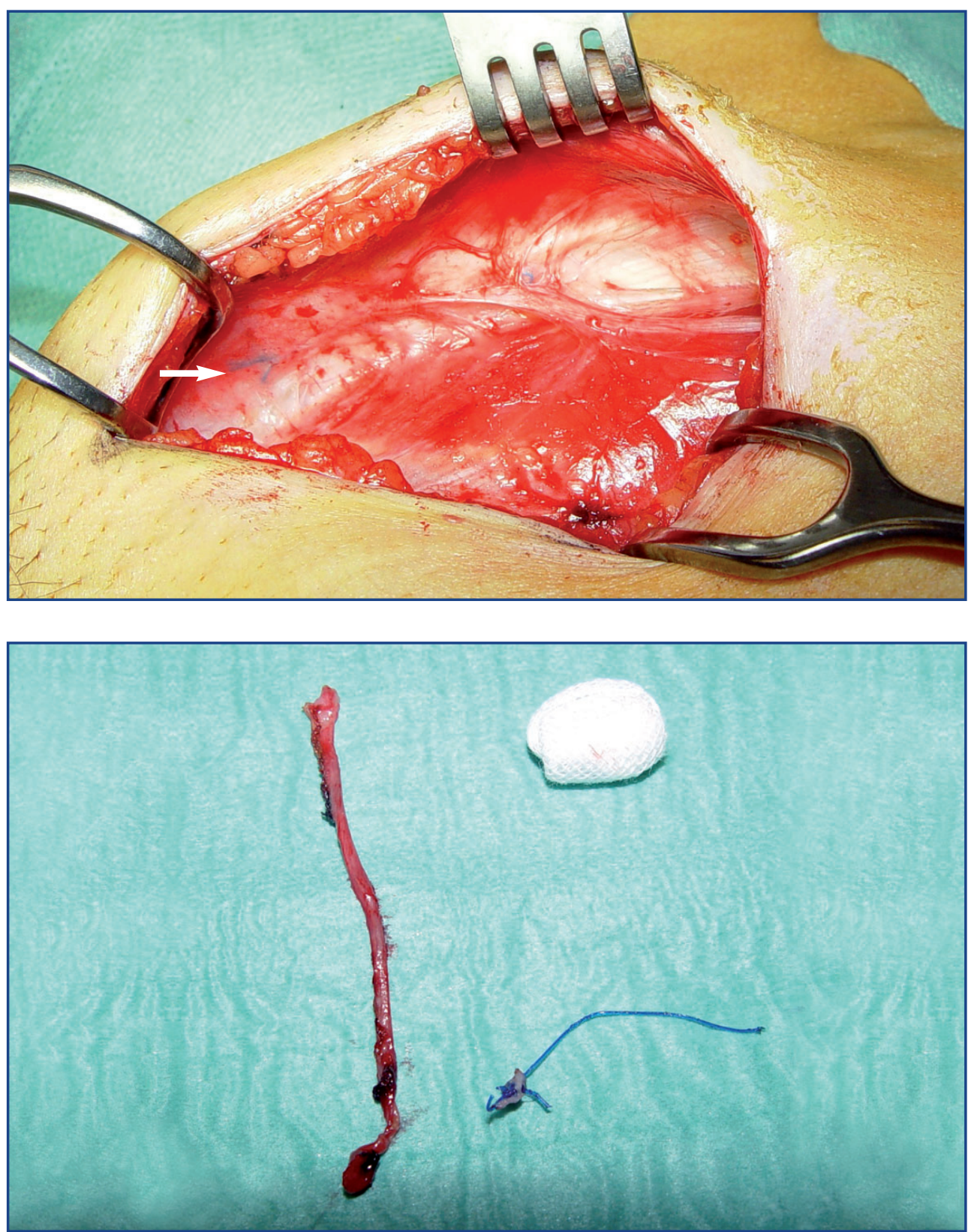

A 50-year old patient reported persistent pain for at least 3 years that had started mmediately after a hernioplasty including mesh. This picture illustrates an entrapped nerve by an unfortunate placement of suture material $(\rightarrow)$.

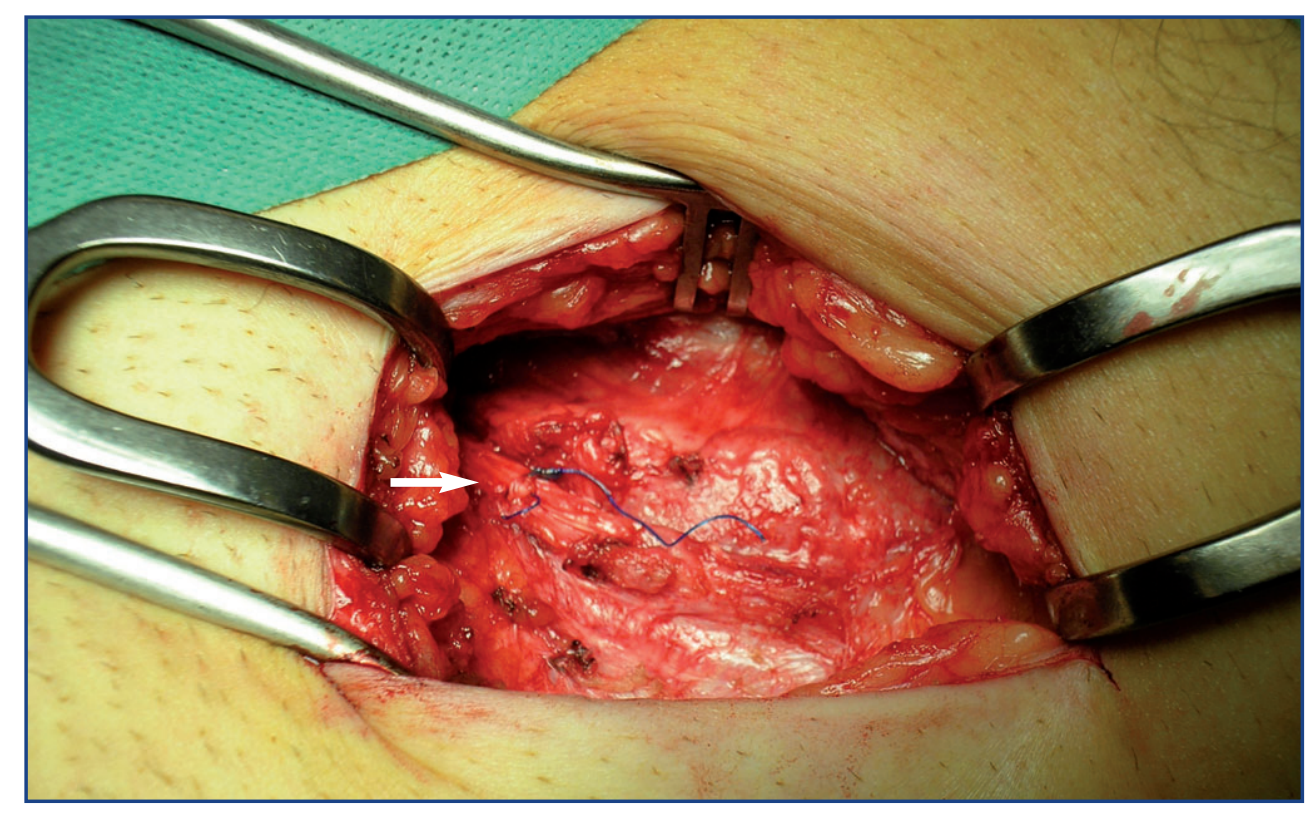


One and a half year after a Lichtenstein repair a 54-year old man presented with intermittent but progressive stabbing pain in the right groin. The first year after the hernia repair he had been without complaints. He also reported pain after ejaculation that negatively influenced his sexual activities. At inguinal exploration both the iliohypogastric $\rightarrow$ and genitofemoral nerves were trapped in the mesh. Neurectomy of both nerves provided considerate long-term pain relief. The dysejaculation complaints completely resolved.

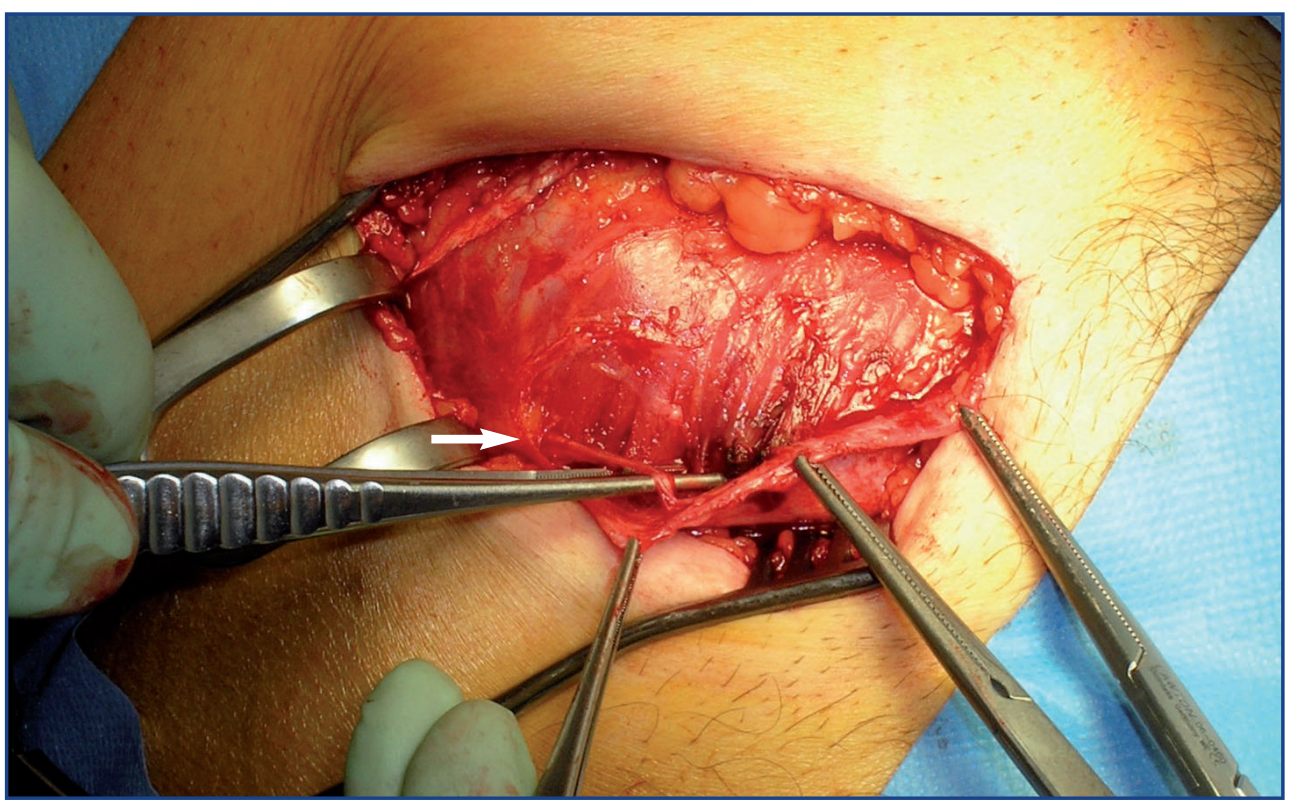

A 57-year old man presented with right inguinal pain after numerous hernia repairs He had become occupationally disabled due to the severity of the pain. Exploration revealed a neuroma of the ilioinguinal nerve $(\rightarrow)$ which was confirmed by histopathology After neurectomy the pain intensity decreased to an acceptable level and he could resume his previous work.
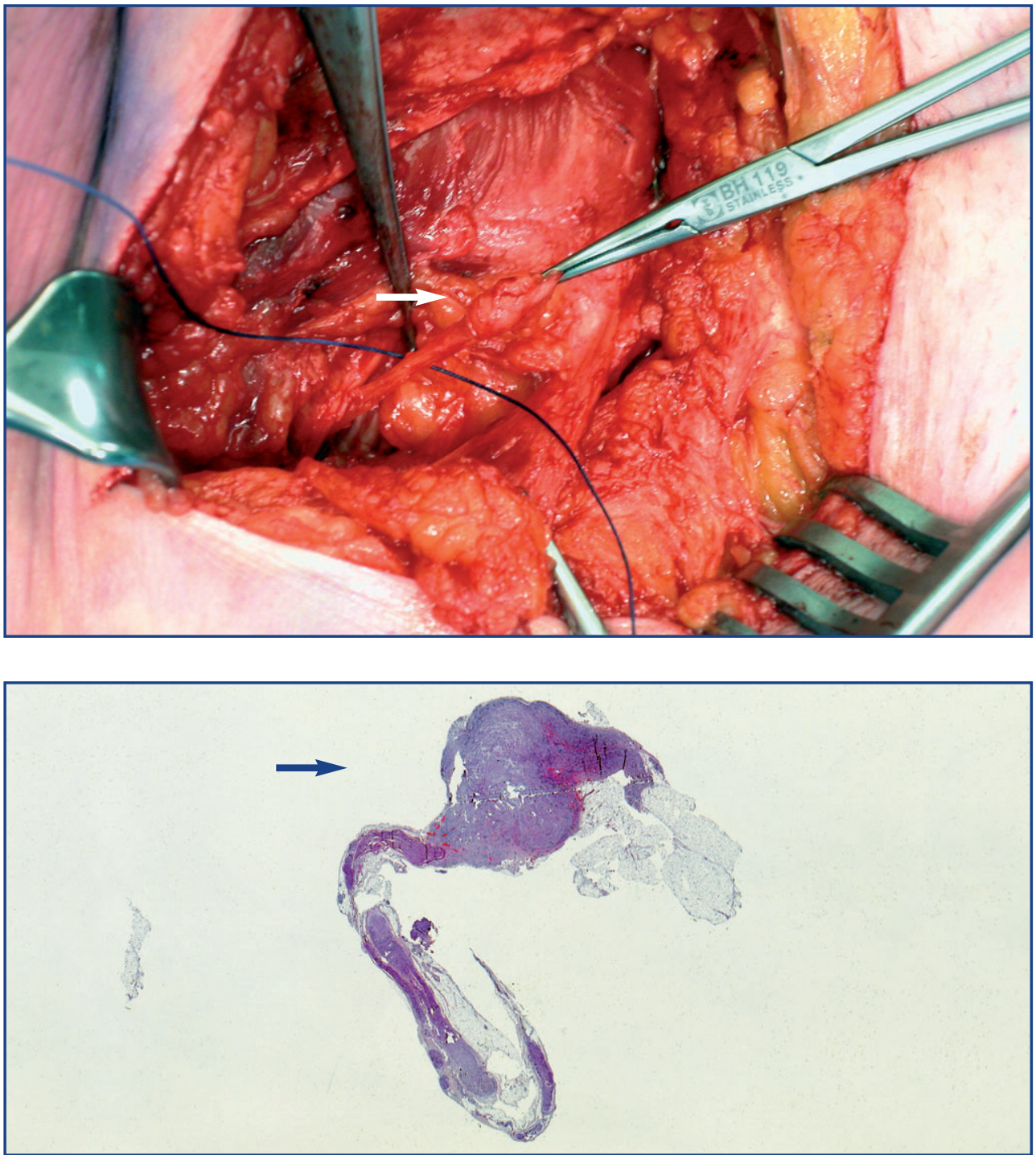
We saw a 32-year old man with severe left chronic inguinal pain which was position depen dent. There were no specific sensory disturbances. Therefore, we concluded that the pain was most probably nociceptive of origin. His hernia had previously been repaired using the so called mesh plug technique. After plug removal $\rightarrow$ pain intensity decreased significantly. About one year later, he developed new inguinal pain symptoms due to a recurrent hernia. A laparoscopic hernia repair (TEP procedure) resulted in moderate pain relief.

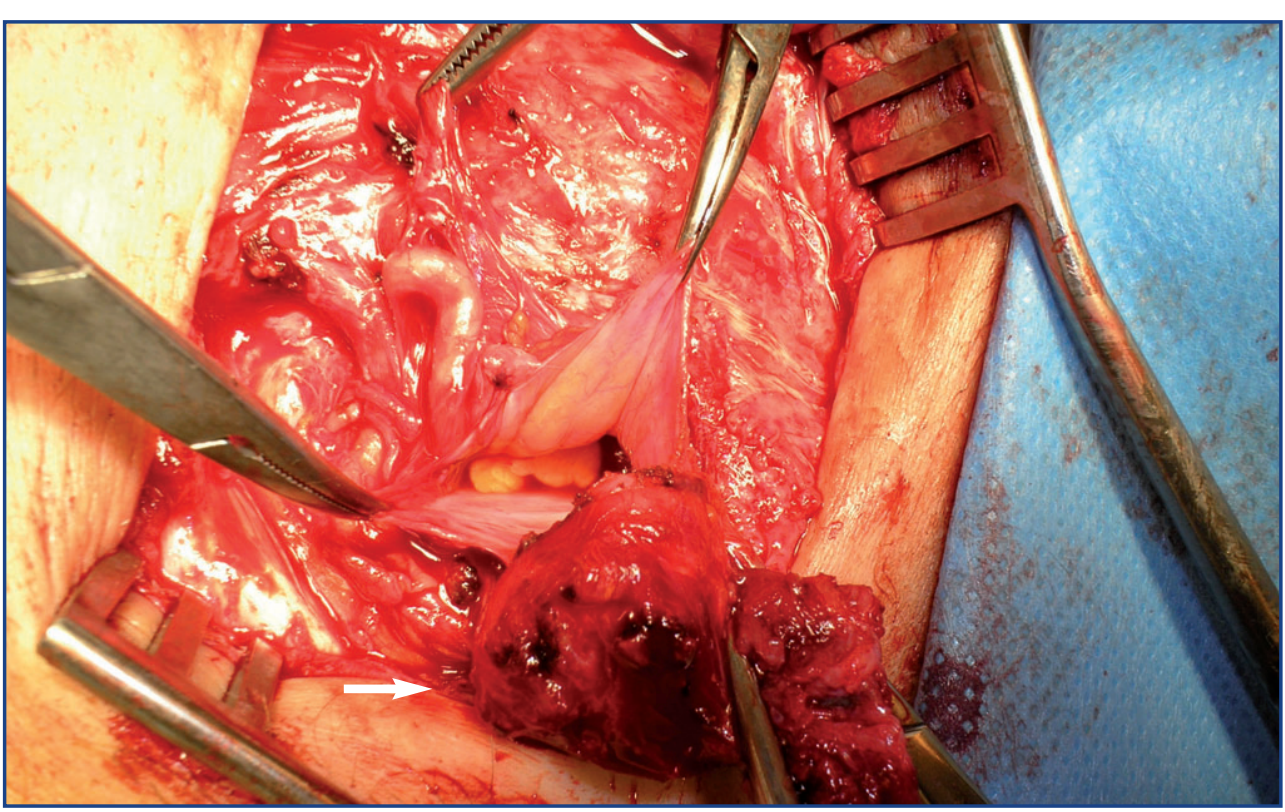

A 50-year old female patient presented with neuropathic pain after a laparoscopic herniorrhaphy (TAPP) resulting in major impairment of her daily activities. At groin exploration the preperitoneal space was opened by dividing the internal oblique and transverse abdominal muscles. The genitofemoral nerve appeared to be encapsulated by the wrinkled mesh (meshoma $\rightarrow$ ). Neurectomy of this nerve with partial mesh excision decreased her pain substantially.

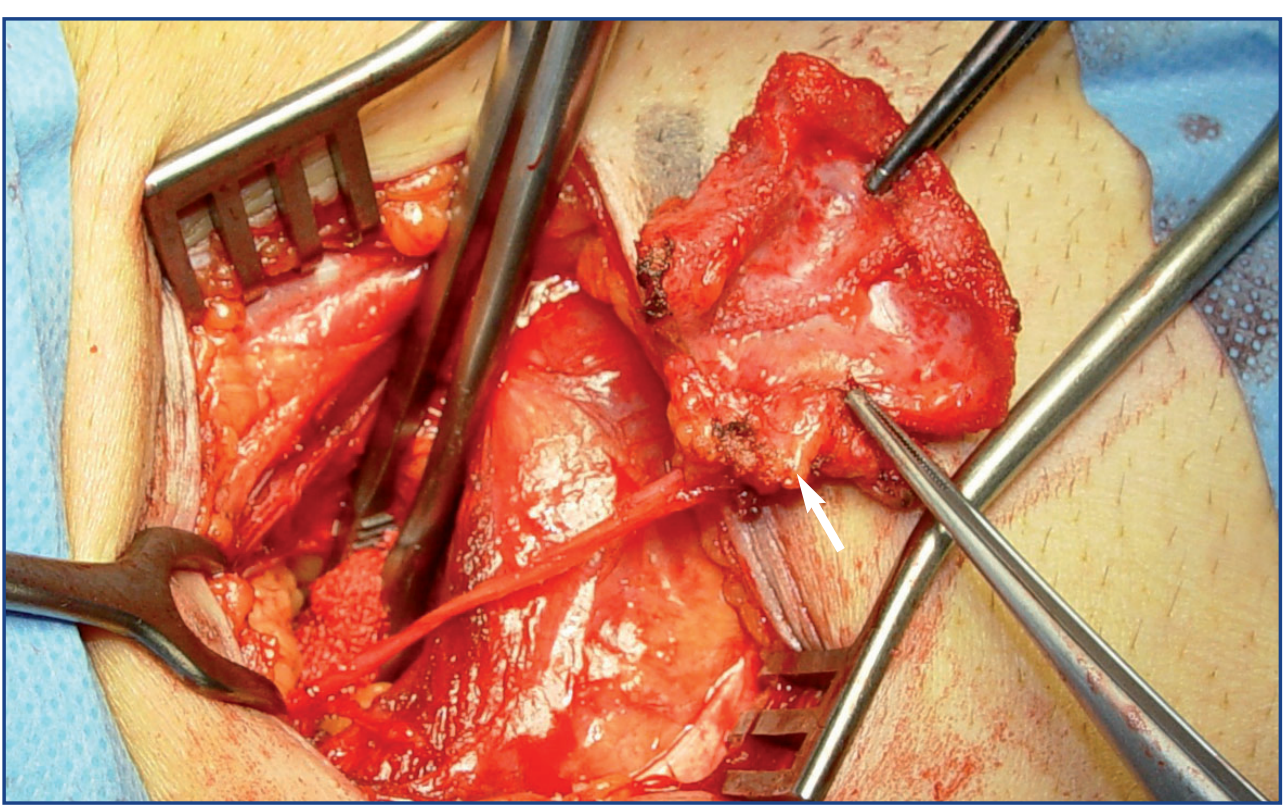


This 28-year old woman presented with inguinal pain after laparoscopic femoral hernia repair. At physical examination she had a trigger point at the lateral border of the pubic bone, suggesting periostitis pubis. She also reported a position dependent pain in the inguinal and femoral region with some numbness of the skin. Local injections did not result in pain relief. We explored the inguinal region and discovered several tackers $(\rightarrow)$ that had penetrated the pubic bone at exactly the pain trigger point. These were re moved. No neurectomy was performed. Her pubic pain was resolved, but she still had disabling groin discomfort.

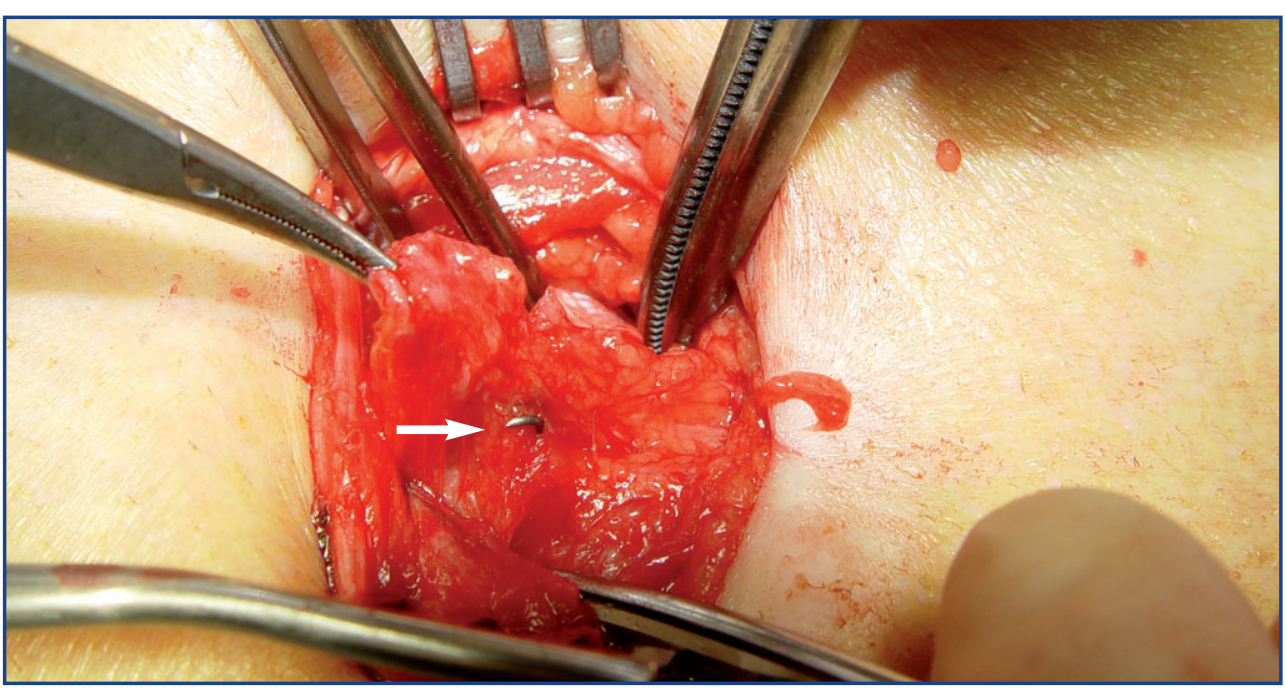

A 44-year old woman developed neuropathic pain after a caesarean delivery 4 years previously. Her Visual Analogue Scale (VAS) was 8/10. At physical examination she had hypoesthesia and hyperalgia in the groin. Palpation of the lateral border of right Pfannenstiel area triggered her pain, which irradiated to the pubic and inner thigh region During exploration, a penetrating branch of the ilioinguinal nerve was discovered which was entrapped in fibrosis and subsequently neurectomized. She became nearly painfree, with a VAS of $2 / 10$
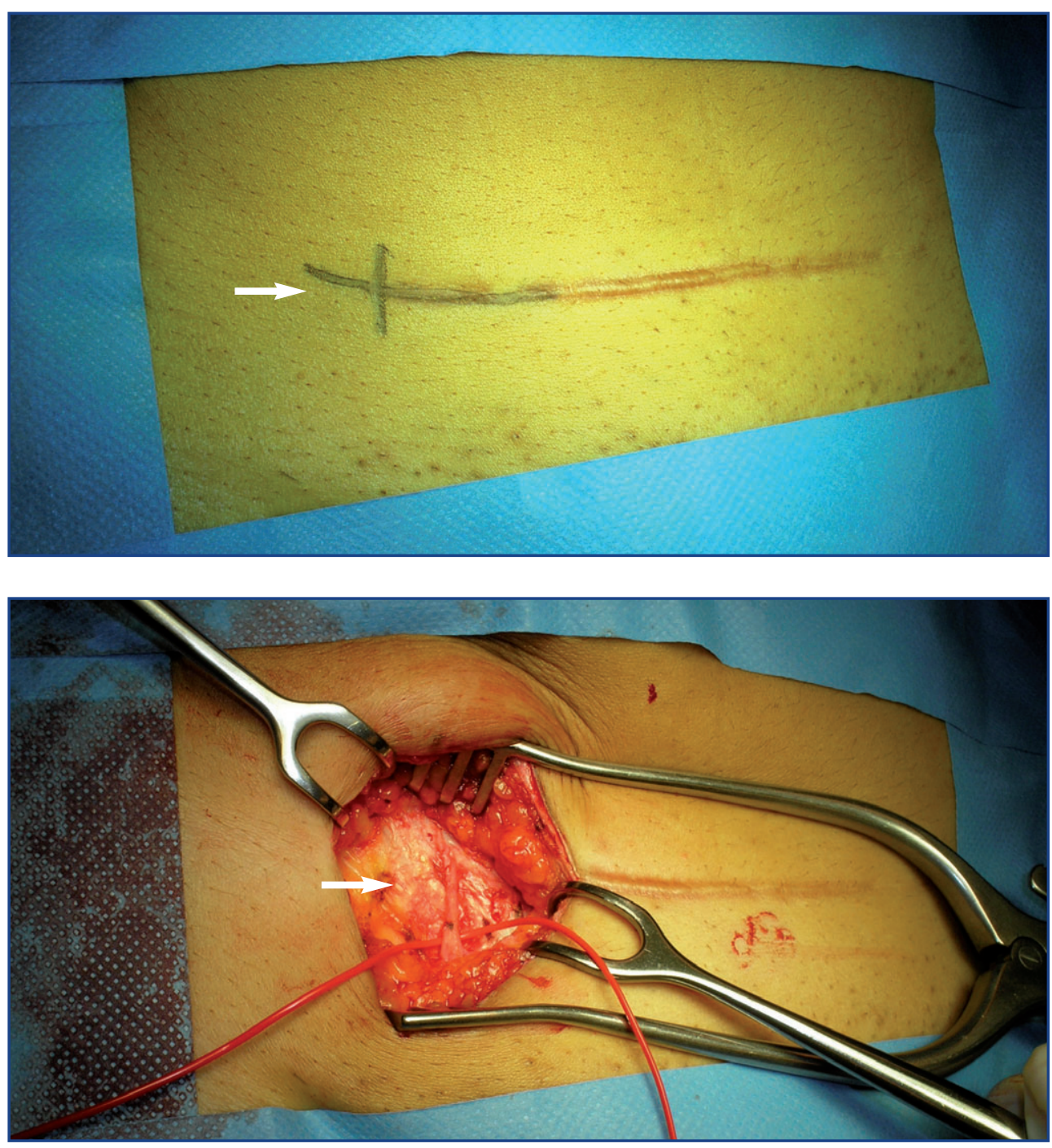


\section{CASE 10}

During the last couple of years a 67-year old woman had frequently been admitted for chronic abdominal pain located in the left lower quadrant. Although she never had shown any infectious signs (fever, elevated C-reactive protein or leucocytosis), she was still diagnosed with diverticulitis. However, a detailed pain history clarified that her pain had started after her caesarean section in 1969 at the age of 28 . Since then, no one had been able to elucidate the origin of her pain. She stopped visiting doctors and tried to cope with this discomfort during her active life as a housewife. At our physical examination a Pfannenstiel scar was noticed and therefore a nerve entrapment was suspected. Local infiltration with lidocain shortly relieved her pain. Surgical exploration revealed a huge neuroma of $1,5 \mathrm{~cm}$ and the ilioinguinal nerve was strangled by a still visible non absorbable suture. The neuroma and nerve were resected and her pain disappeared. The impact on her daily life was dramatic.
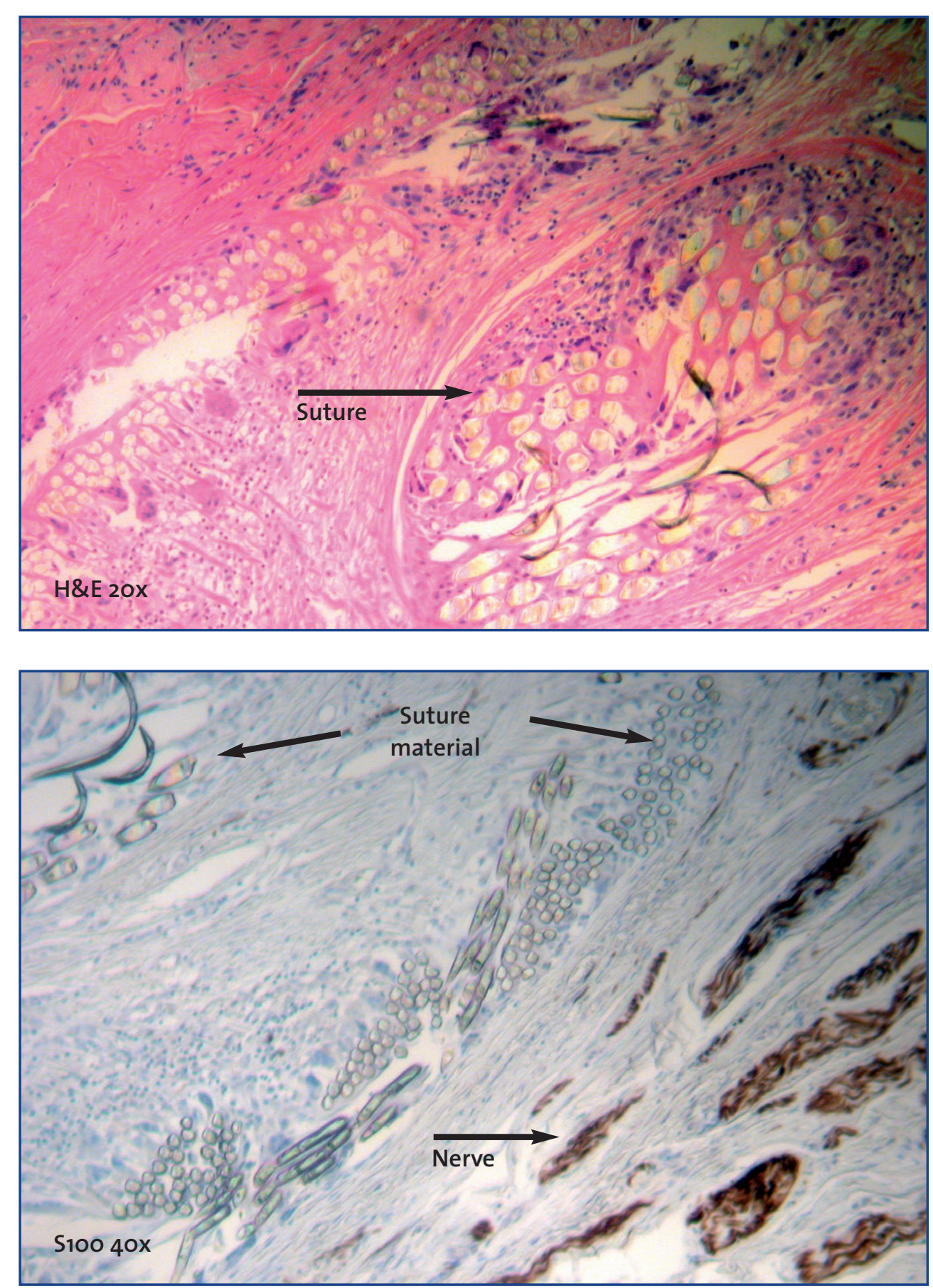
This case concerned a 43-year old woman with a more than 15 year lasting previously unrecognised pain syndrome, caused by postoperative fibrosis at the lateral border of a Pfannenstiel incision. During that period the pain had negatively influenced her sex-life. She was advised to consult a psychiatrist for her pain syndrome. Physical examination however was typical for nerve entrapment and the ilioinguinal and iliohypogastric nerve were both resected as distal and proximal as possible. Afterwards she was pain free, with a dramatic improvement of her quality of life including joyful sexual activity.



This case concerns a 37-year old woman who was successfully treated in our institute for a post-Pfannenstiel pain syndrome on the left side. She had received a neurectomy of the iliohypogastric nerve. Unfortunately, her pain complaints recurred after some 6 months and after a temporary successful local block a re-exploration was performed. We came across a stump-neuroma of the iliohypogastric nerve $(\rightarrow)$ at the level of the internal oblique muscle. It was resected as far laterally as possible. Evaluation at 3 months after this second neurectomy showed that she was very satisfied with the result.
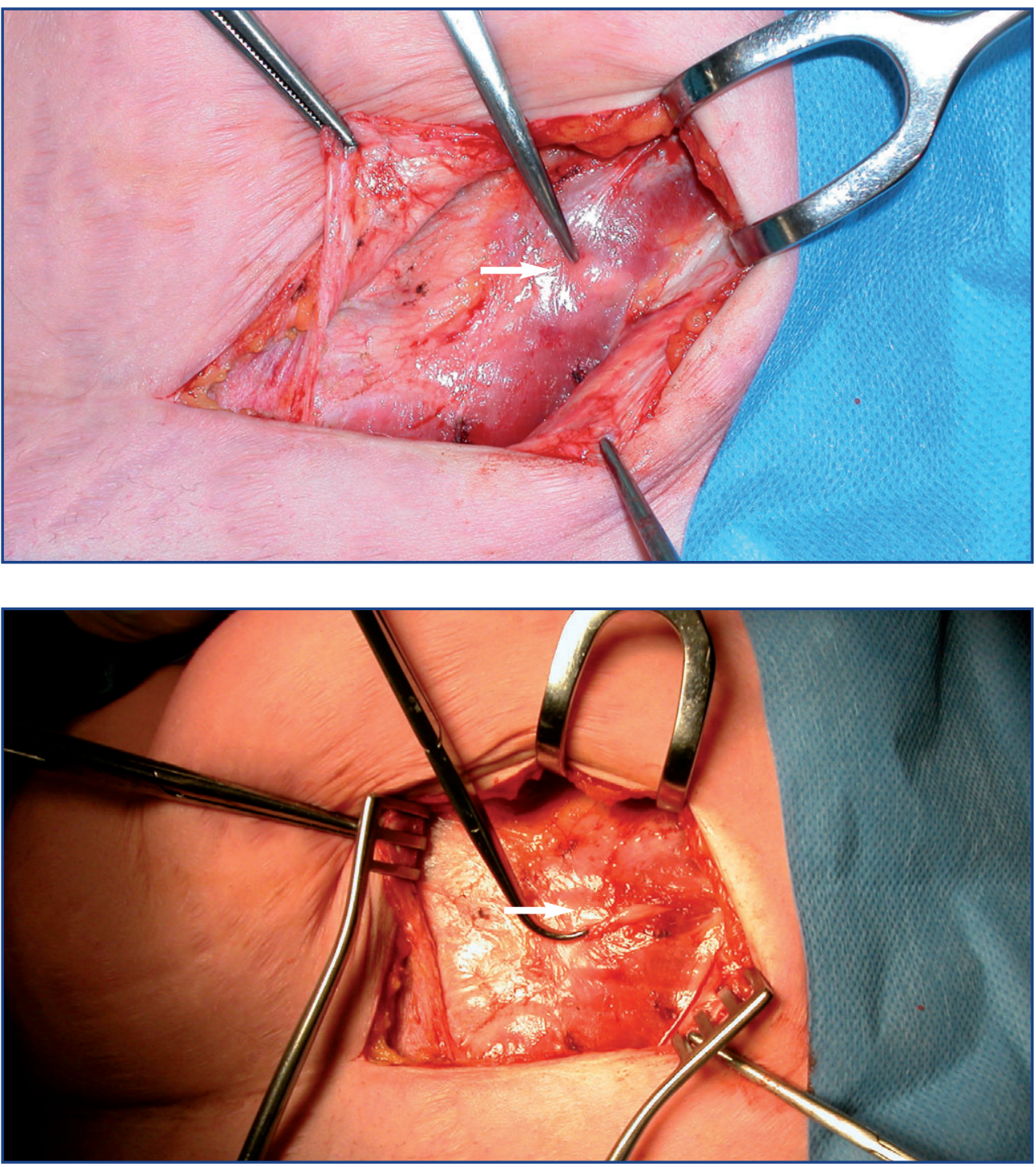


\section{TREATMENT ALGORITHM}

I Diagnostic and therapeutic pathway for postherniorrhaphy inguinal pain



TREATMENT ALGORITHM

II Diagnostic and therapeutic pathway for chronic post-Pfannenstiel pain

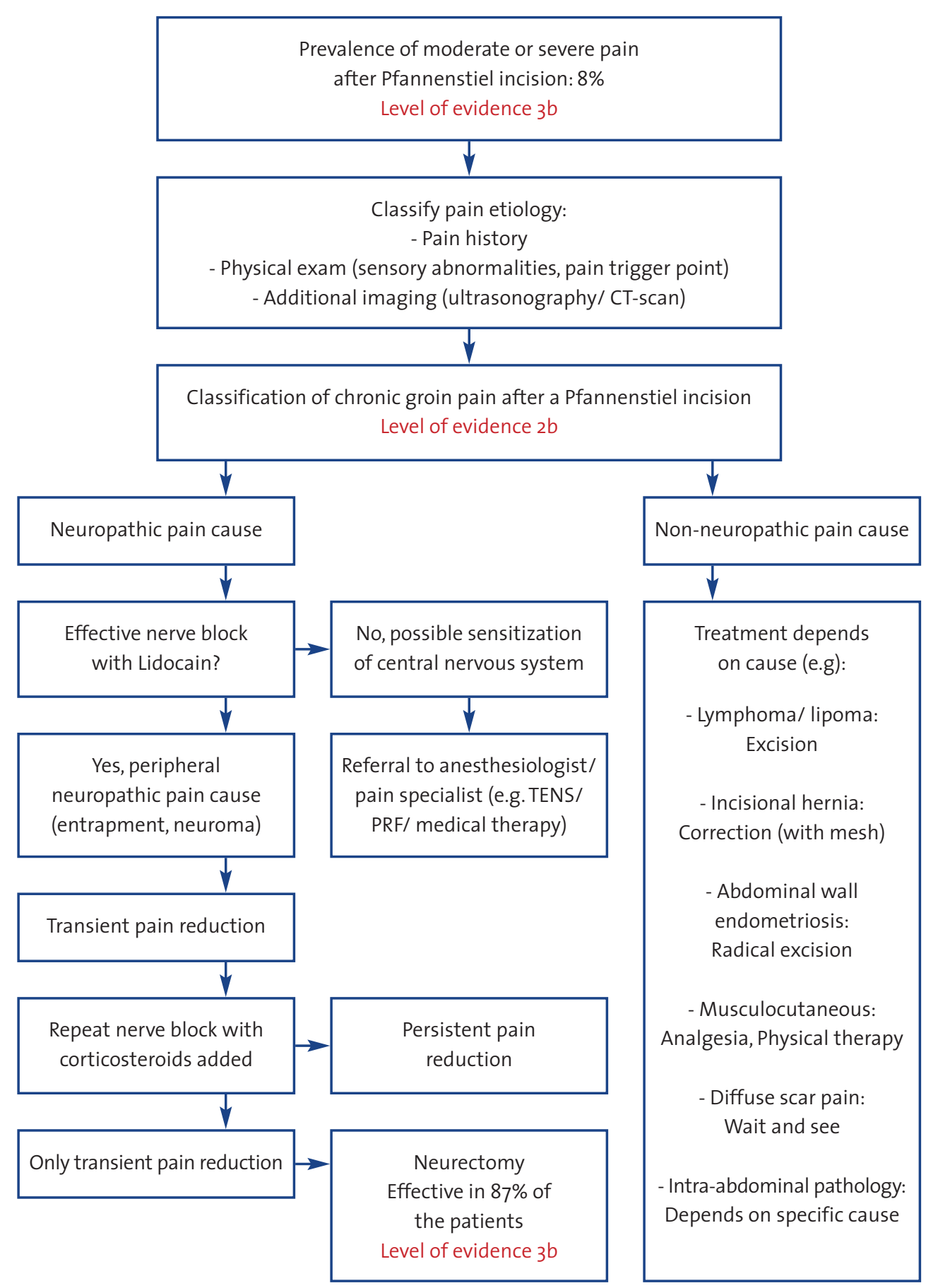




\section{DIFFERENTIAL DIAGNOSIS OF CHRONIC GROIN PAIN*}

\section{Surgery}

- Primary hernia

- Inguinal

- Femoral

- Obturator

- Recurrent hernia

- Posthernia

Initial open repair:

o Neuropathic (nerve

entrapment/ neuroma

- lliohypogastric

- Ilioinguinal

- Genitofemoral

Lateral Femoral Cutaneous

o Non-neuropathic

- Rolled-up mesh

- Tack

Periostitis pubis

Initial laparoscopic repair

o Neuropathic (nerve entrapment/

neuroma, often genital branch)

o Non-neuropathic

- Abdominal Cutaneous Nerve

Entrapment Syndrome

\section{Gynecology}

- Pfannenstiel incision

o Neuropathic

- lliohypogastric

- Ilioinguinal

- Cervical cancer

- Endometriosis

$$
\begin{aligned}
& \text { - Round ligament } \\
& \text { - Pfannenstiel incision } \\
& \text { - Intra-abdominal }
\end{aligned}
$$

- Tubal/ ovarian disorders

- Uterus myomatosis

\section{Orthopedics}

Acetabular labral tears

- Avascular necrosis

- Chondritis dissecans

- Legge-Calve Perthes disease

- Osteoarthritis

- Pelvic stress fractures

- Slipped femoral capsule epiphysis

- Snapping hip syndrome (ant/ lat)

- Synovitis

- lliopectineal bursitis

- Spondylolisthesis

- Spondylolysis

\section{Sports medicine}

- Rectus strain

- Adductor tendinitis

- lliopsoas tendinitis

- Symphysiolysis/ symphysitis

- 'Sportsman hernia' (tear in inguinal ring)

\section{Urology}

- Postvasectomy pain syndrome

(entrapment genital branch)

- Vas granuloma/ fibrosis

- Cystitis

- Epididymitis

- Urinary tract infection

- Prostatitis

- Nephrolithiasis

- Torsion of testis

Gastroenterology

- Appendicitis

- Adhesions

- Diverticulitis

\section{DIFFERENTIAL DIAGNOSIS OF CHRONIC GROIN PAIN *}

- Inflammatory retroperitoneal

phlegmon (pancreatitis)

- Meckel diverticulitis

- Granulomatous colitis

Vascular

- Hematoma

- Varices (during pregnancy!)

- Pelvic congestion syndrome

- Postvein stripping

- Pseudoaneurysm

- lliac/ femoral artery aneurysm/ stenosis

- Thrombosis

- Vascular graft

- Abdominal aortic aneurysm (with compression of genitofemoral nerve)

\section{Oncology}

Retroperitoneal neoplasm

- Osseous metastases pelvis/ hip joint

*Modified from: Ferzli G et al. Postherniorrhaphy groin pain and how to avoid it.

Surg Clin N Am 2008; 88: 203-216 and Roumen RMH, Scheltinga MRM. Liespijn en geen liesbreuk, maar wat dan wel? Ned Tijdschr Geneesk 2004; 148: 2421-2426. 


\section{Inguinal Pain Assessment Form}

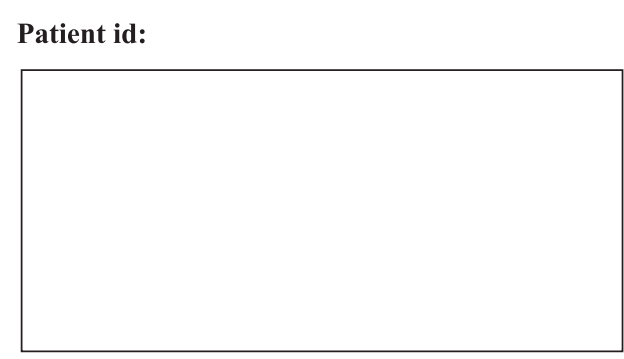

Date:.............................

Doctor:............................

\section{Pain history:}

…

1. Symptomatic groin: $\square$ right $\square$ left $\square$ both

Since:..........months/years

2. Onset of pain symptoms: $\square$ immediately $\quad \square$...............months postoperatively

Difference with preoperative situation: $\square$ better $\square$ same $\quad \square$ worse

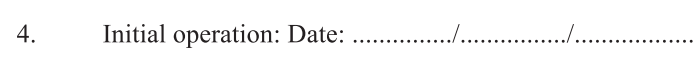

$\square$ Inguinal hernia repair: $\square$ Lichtenstein $\quad \square$ Shouldice $\square$ Hernia sac resection

$\square$ Plug \& patch $\quad \square$ TEP $\quad \square$ TAPP $\square$ Other:.........

$\square$ Pfannenstiel $\quad \square$ Vasectomy $\square$ Appendectomy $\square$ Laparoscopy

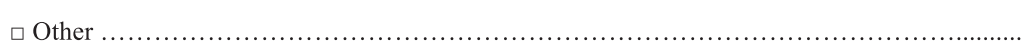

5. Frequency: $\square$ rare $(<1 \mathrm{x} /$ week $) \quad \square$ occasional( $(1-7 \mathrm{x} /$ week $) \quad \square$ regular (once daily) $\square$ always ........... $\mathrm{x} /$ month

6. Localisation: $\square$ inguinal area $\quad \square$ upper leg ( $\square$ medial $\square$ lateral $)$

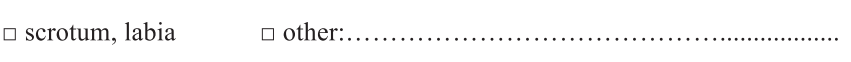

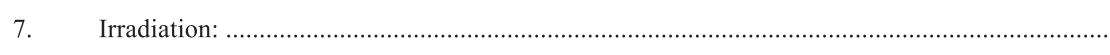

8. Pain character: $\square$ burning $\square$ prickling $\square$ nagging

$\square$ stabbing $\square$ gnauwing $\square$ pulling

$\square$ sharp $\square$ pounding $\square$ other:

$\square$ electric $\square$ pinching
9. Pain-inducing activities:

\begin{tabular}{|c|c|c|c|c|}
\hline$\square$ none & $\square$ standing $>$ half hour & $\square$ sitting & $\square$ lifting & $\square$ standing up \\
\hline $\mathrm{Ari}$ & $\square$ defecating & $\square$ sleeping & $\square$ playing sports & $\square$ walking \\
\hline ittir & $\square$ lying down & & & \\
\hline
\end{tabular}

10. Sexual pain complaints: $\square$ ejaculatory pain ( $\square$ during $\square$ afterwards) $\quad \square$ erectile pain $\square$ orgasmic pain

11. Course over time (after initial operation): $\square$ decreasing $\square$ constant

$\square$ intermittent $\square$ progressive

12. Other chronic pain syndromes present: $\square$ no $\quad \square$ yes

Please specify:.........

Specific questions:

\begin{tabular}{|c|c|c|c|}
\hline 13. & Inguinal bulge: & $\square$ yes & $\square$ no \\
\hline 14. & Pain at flexion, exo-, endorotation of the hip: & $\square$ yes & $\square$ no \\
\hline 15. & Hip joint pain: & $\square$ yes & $\square$ no \\
\hline 16. & Pain related to the menstrual cycle: & $\square$ yes & $\square$ no \\
\hline
\end{tabular}

Relevant medical history:
Year
Diagnosis
Operation

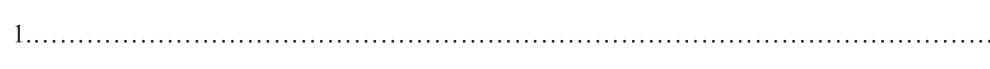

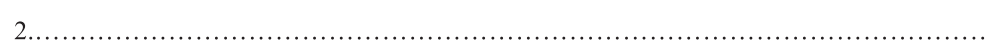

Risk factors:



Effect of pain on work status: $\square$ none $\quad \square$ changed jobs after last operation due to pain

$\square$ stopped working due to pain

$\square$ works part-time due to pain

Loos MJA. Dissertation 'Surgical management of chronic inguinal pain syndromes', sept 2011 


\section{Physical examination (indicate left/ right):}

Inspection:

- Bulges ( $\square$ inguinal $\square$ femoral)

- Scars (draw)

- Inguinal varicose veins:

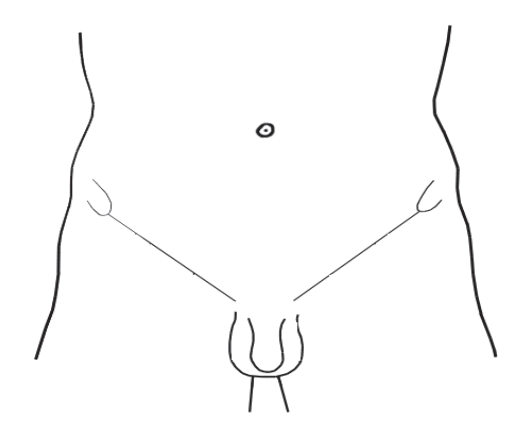

Sensation: (draw)

- Test with monofilament wire
$\square$ anesthesia
$\square$ hypoesthesia
$\square$ hyperalgesia
$\square$ allodynia

Palpation:

- Inguinal bulge

$\square$ yes $\square$ no

- Femoral bulge

$\square$ yes $\square \mathrm{n}$

- Painful lymph nodes

$\square$ no

- Pain pressing pubic tubercle

$\square$ no

- Pain pressing adductor tendons

$\square$ yes

$\square$ no

- Trigger point

$\square$ yes $\square$ no

Radiation to:

Specific tests:

- Laseque's test:

$\square$ positive

$\square$ negative

$\square$ positive

$\square$ negative

- Adductor test:

$\square$ positive

$\square$ negative

- Pain at flexion/ endo-exorotation hip*: $\square$ positive

$\square$ negative

$\left({ }^{*}=\right.$ suggestive for iliopectineal bursitis $)$

\section{Pain level before nerve block}

No pain

\section{VRS $\square$ No Pain $\square$ Moderate pain \\ $\square$ Very mild pain $\square$ Severe pain}

$\square$ Mild pain $\square$ Very severe pain

\section{After nerve Block (5-10}

minutes:

$V A S$

No pain

$V R S \square$ No Pain

$\square$ Moderate pain

$\square$ Very mild pain $\square$ Severe pain

$\square$ Mild pain $\square$ Very severe pain

\section{Additional diagnostics:}

\begin{tabular}{|c|c|c|}
\hline$\square \mathrm{X}$-ray -pelvis/hip & $\square$ Ultrasonography & $\square$ Herniography \\
\hline$\square$ CT-scan & $\square \mathrm{MRI}$ & $\square$ Bone scan \\
\hline
\end{tabular}

Differential diagnosis:

Treatment:

$\square$ None $\quad \square$ Additional nerve blocks:

$\square$ Mesh removal $\quad \square$ Recurrent inguinal hernia repair

$\square$ Neurectomy ( $\square$ Iliohypogastric $\square$ Ilioinguinal $\square$ Genitofemoral nerve)

Other:

Loos MJA. Dissertation 'Surgical management of chronic inguinal pain syndromes', sept 2011 